FRANCIS MASSASHI KAKUDA

\title{
Desenvolvimento e a utilização de um equipamento de grandes dimensões na análise do comportamento mecânico de uma seção de pavimento sob carregamento cíclico
}

Tese apresentada à Escola de Engenharia de São Carlos, da Universidade de São Paulo, como parte dos requisitos para obtenção do título de Doutor em Ciências, Programa de Pós-Graduação em Engenharia de Transportes.

Área de Concentração: Infraestrutura de Transportes.

Orientador: Prof. Tit. Dr. Alexandre Benetti Parreira

Co-orientador: Prof. Tit. Dr. Benedito de Souza Bueno 

Dedico esta Tese à Eliane, esposa dedicada, amorosa e compreensiva, cuja ajuda foi de fundamental importância para a conclusão deste trabalho. 



\section{AGRADECIMENTO}

Em especial, ao orientador Prof. Dr. Alexandre Benetti Parreira pela dedicação, paciência, ensinamento, excelente orientação e amizade. Agradeço também, pela oportunidade oferecida e confiança depositada neste trabalho.

Ao Prof. Glauco Túlio Pessa Fabbri pela grande contribuição nesta pesquisa principalmente na parte experimental, sendo essencial para o desenvolvimento do equipamento.

Ao co-orientador Prof. Benedito de Souza Bueno pela contribuição e sugestões apresentadas durante a pesquisa.

A todos os professores, funcionários e alunos do Departamento de Transportes da EESC, pela colaboração e amizade.

Aos funcionários: Gigante, João, Paulo, Toco, Vicente e Clever pela amizade e participação no desenvolvimento do equipamento.

Aos ajudantes: Noé, Reginaldo e Emilio que foram de grande ajuda na compactação e preparação dos materiais. 
Às secretárias Eloisa e Beth pela eficiência administrativa.

Aos amigos de pós-graduação Wallace, Alex, Paulo, David, Walter, Wesley, Idaliria, Madalena, Jesner, Sergio, Vivian, Luiz, André, Bruno, Matheus, Marcão, Pablo, entre outros pela amizade durante esse período.

À Coordenadoria de Aperfeiçoamento de Pessoal de Nível Superior, CAPES pela concessão da bolsa de estudo.

À Fundação de Amparo à Pesquisa do Estado de São Paulo, FAPESP pela concessão de auxílio pesquisa em nome do professor Parreira para o desenvolvimento e aquisição do equipamento.

À empresa HUESKER Ltda. pelo fornecimento das geogrelhas utilizadas nos ensaios e pelo auxílio bolsa.

Aos irmãos Márcio e Luciene pela amizade e companheirismo até hoje compartilhados.

Aos meus amados pais Francisco e Tereza pelos constantes incentivos e apoios em todo trajeto para chegar até este momento. 
No meio de qualquer dificuldade encontra-se a oportunidade. Albert Einstein 



\section{RESUMO}

KAKUDA, F. M. Desenvolvimento e a utilização de um equipamento de grandes dimensões na análise do comportamento mecânico de uma seção de pavimento sob carregamento cíclico. 290p. Tese (Doutorado) - Escola de Engenharia de São Carlos, Universidade de São Paulo, São Paulo, 2010.

A presente pesquisa tem por objetivo desenvolver, montar e testar um equipamento de grandes dimensões (largura de $1,5 \times 1,5 \mathrm{~m}$ e altura de 1,2m) para o ensaio em laboratório de estruturas de pavimentos com materiais, espessuras de camadas e condições de carregamento similares às de campo. Ainda nesta pesquisa analisouse o emprego de geossintético como reforço da camada de base de novos pavimentos sobre o efeito da variação da umidade do subleito. O carregamento cíclico é gerado a partir de um cilindro pneumático. A instrumentação é constituída de LVDTs, células de carga e de tensão total que permitem o monitoramento das cargas aplicadas, das tensões no interior das camadas, e deformações elásticas e permanentes na superfície do pavimento. O carregamento cíclico, com frequência de $1 \mathrm{~Hz}$, foi aplicado sobre placas rígidas com diâmetros de $300 \mathrm{~mm}$ e $216 \mathrm{~mm}$ e magnitudes de $40 \mathrm{kN}$ e $20 \mathrm{kN}$, respectivamente. A partir das bacias de deflexões obtidas, foi possível, por meio de retro-análise, a determinação dos módulos de resiliência dos materiais e a partir das curvas de recalque obter uma equação da deformação plástica em função do número de ciclos de carga. O equipamento apresentou bom funcionamento, atendeu às expectativas e os transdutores forneceram medidas com a precisão exigida. E a utilização de geogrelha como reforço de camada de base mostrou eficaz tanto na redução das deformações permanentes como elásticas.

Palavra chave: Equipamento de grande escala, Pavimento flexível, geossintéticos, reforço de base e geogrelha 

KAKUDA, F. M., Development and the use of large-scale equipment in the analysis fo the mechanical behavior of a paviment section under cyclicloading, 290p. Tese (Doutorado) - Escola de Engenharia de São Carlos, Universidade de São Paulo, São Paulo, 2010.

This research aims at develop, assembly and test of application of large-scale equipment (width of $1.5 \times 1.5 \mathrm{~m}$ and height of $1.2 \mathrm{~m}$ ) for the testing in pavement structures laboratory, with materials, thicknesses of layers and loading conditions similar to the field ones. The research still studied the application of geosynthetics as base layer reinforcement to news pavements by effect of variation in subgrade layer moisture. The loading is cyclic and generated from a pneumatic actuator. The instrumentation is constituted of LVDTs, load-cells and soil pressure transducers that permit monitoring the applied loads and the stress distribution in the interior of the layers, as well as plastic and elastic deformations. The cyclic-loading (frequency of 1 $\mathrm{Hz}$ ) was applied on a 30-mm-diameter and a 26-mm-diameter rigid plate with force of $40 \mathrm{kN}$ and $20 \mathrm{kN}$, respectively. From the deflection basin obtained, it is possible, by means of back calculation, the determination of the resilient modulus of the materials and from the deformation basin obtained the equation of permanent deformation in function of the cycle number. The equipment showed a good operation, attended to the expectations and the transducers supplied measures with the precision required.

Keywords: Equipment of large-scale pavement flexile, geosynthetic, reinforcement and geogrid. 



\section{LISTA DE FIGURAS}

Figura 2.1 - Tensões em um pavimento (MEDINA, 2005). .38

Figura 2.2 - Tipos de deformação permanente (adaptado de CARVALHO ,1997) ....46

Figura 2.3 - Hipótese de Origem do "Rutting" (adaptado de SIMPSON, 1995) .48

Figura 2.4 - Ensaio de placa (ALBERNAZ, 1997) 60

Figura 2.5 - Esquema do sistema de referência na viga e no caminhão (DNER-ME 039/1996)

Figura 2.6 - Deflectômetro de impacto (DNIT, 2006) ........................................64

Figura 2.7 - Principio de funcionamento do FWD (HAAS et al., 1994) .....................64

Figura 2.8 - Modelo elástico de Hogg (NÓBREGA, 2003) ...................................74

Figura 2.9 - Linhas de iguais deflexões verticais no sistema pavimento-subleito (NÓBREGA, 2003) .

Figura 2.10 - Sistema de multicamadas linearmente elásticas (BURMISTER, 1945)80

Figura 2.11 - Distribuição de tensões (BURMISTER, 1945) .81

Figura 2.12 - Equipamento da Universidade do Alaska: a) vista em planta; b) vista em corte (COLLIN, kINNEY and Fu, 1996)

Figura 2.13 - Vista em planta e corte do teste (KINNEY, ABBOTT AND SCHULER, 1998)

Figura 2.14 - Diagrama esquemático de equipamento de ensaio (PERKINS, 1999) 92

Figura 2.15 - Equipamento de ensaio (DEMERCHANT, 2002) 94

Figura 2.16 - Diagrama esquemático de caixa de teste e configuração do carregamento (LENG and GARB, 2002) .95

Figura: 2.17 - Vista em corte do LSME (KIM, 2005) .96 
Figura 2.18 - Teste de pavimento em laboratório (TINGLE and JERSEY, 2005) ..... 98

Figura 2.19 - Valores de TBR em função da espessura da base para deslocamento de $25 \mathrm{~mm}$ (COLLIN, 1996). 109

Figura 2.20 - TBR, geogrelha A, pressão de pneu 551kPa (KINNEY, ABBOUT and SCHULER, 1998) 109

Figura 2.21 - Módulo do subleito vs u/B, para 1 e 2 geogrelhas (DEMERCHANT, 2002). 111

Figura 2.22 - Deslocamento versus numero de carregamento para diferentes geogrelhas (WEBSTER, 1993) 113

Figura 2.23 - Superfície de deslocamento para base de espessura 152 mm (LENG and GARB,2002) 114

Figura 2.24 - Distribuição da tensão vertical para 8000 ciclos; a) $152 \mathrm{~mm}$ de base e b) $254 \mathrm{~mm}$ de base (LENG and GARB,2002)... 116

Figura 2.25 - Espessura da camada de agregado para um pavimento sem revestimento, recalque de $50 \mathrm{~mm}, 1000$ passadas de veículos (TINGLE AND JERSEY, 2007).

Figura 2.26 - Espessura da camada de agregado para um pavimento reforçado com geossintéticos, recalque de $50 \mathrm{~mm}, 1000$ passadas de veículos (TINGLE AND JERSEY, 2007).

Figura 2.27 - Método para espessura do agregado em função do subleito de Giroud and Noiray, (TINGLE AND JERSEY, 2007) ................................................... 119

Figura 2.28 - Espessura da base vs retroanálise do módulo (KINNEY, 1998) ....... 122

Figura 2.29 - Espessura da base vs retroanálise dos módulos variando a geogrelha (KINNEY, 1998) 122

Figura 2.30 - Distribuição das tensões no fator tan $\alpha$ para sistema de duas camadas (LENG AND GARB, 2006) 125

Figura 2.31 - Distribuição das tensões na camada de aterro (Milligan et al. 1989) 130

Figura 2.32 - Taxa de capacidade de carga mobilizada (LENG AND GARB, 2006)134

Figura 3.1 - Mapa do Estado de São Paulo com indicação aproximada das regiões de coleta dos Solos 1 e 2 141

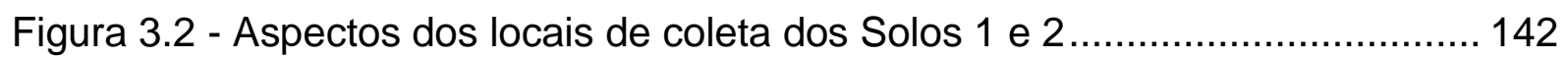

Figura 3.3 - Curvas granulométricas dos Solos 1 e 2 
Figura 3.4 - Curva de compactação do solo 1 (Subleito) …..................................144

Figura 3.5 - Curva de compactação do solo 2 (Solo-Brita)...................................144

Figura 3.6 - Gráfico de classificação MCT (Nogami \& Villibor, 1995) com a indicação do posicionamento dos Solos 1 e 2 e suas respectivas imagens eletrônicas. ........145

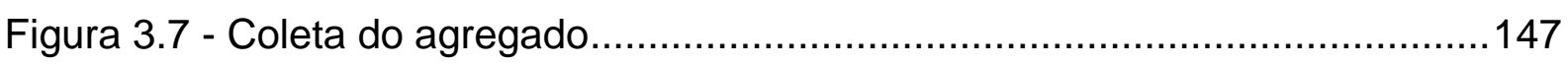

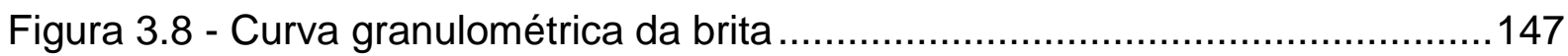

Figura 3.9 - Curva granulométrica da mistura solo-brita, do solo 2 e da brita .........149

Figura 3.10 - Geogrelha Fornit J600 (30/30) ...............................................151

Figura 3.11 - Curvas para a mistura solo-brita: a) CBR e b) Compactação .............153

Figura 3.12 - Equipamento usado nos ensaios triaxiais cíclicos ...........................157

Figura 3.13 - Simulação de uma seção de pavimento segundo saída gráfica do Programa Plaxis, vínculos e carregamento: a) Malha não-deformada e b) Malhadeformada pelo carregamento ...................................................................162

Figura 3.14 - Programa Plaxis e Elsym-5 - Bacias de recalque para caixas com dimensões variadas ...................................................................................163

Figura 3.15 - Perspectiva e dimensões da caixa de ensaios …………………...165

Figura 3.16 - Sala de ensaios e localização da laje de concreto para fixação da caixa 167

Figura 3.17 - Construção da laje de apoio: a) Concretagem e b) Fixação dos fusos 167

Figura 3.18 - Caixa de ensaios: a) Uma das laterais; b) Base e c) Caixa montada 168 Figura 3.19 - Fixação da viga de reação: a) Fixação por fusos e b) Fixação por

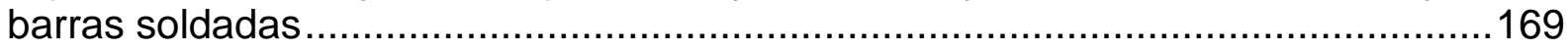

Figura 3.20 - Sistema de umedecimento do subleito ….....................................170

Figura 3.21 - Camada drenante com destaque para a brita e o recobrimento com o geotêxtil

Figura 3.22 - Dispositivo de indicação da carga da água (piezômetro) 172

Figura 3.23 - Ar comprimido: a) Compressor e b) Filtro purgador e filtro coalescente

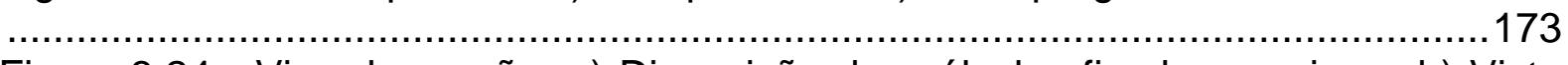
Figura 3.24 - Viga de reação: a) Disposição das válvulas fixadas na viga e b) Vista da retirada do sistema pneumático 174 
Figura 3.25 - Placas metálicas: a) Diâmetro de 21,6cm; b) Diâmetro de $30 \mathrm{~cm} \mathrm{e} \mathrm{c)}$ Perfil da placa.

Figura 3.26 - Cilindros pneumáticos: a) Diâmetro de $175 \mathrm{~mm}$ e b) Diâmetro de $300 \mathrm{~mm}$ 176

Figura 3.27 - Posicionamento dos LVDTs: a) Vista em corte e b) Vista em planta. 178

Figura 3.28 - Extensômetro digital para calibração de LVDTs 179

Figura 3.29 - Fixação da régua no cilindro pneumático 180

Figura 3.30 - LVDTs: a) Fixação da régua na lateral da caixa e b) Posicionamento dos LVDTs 181

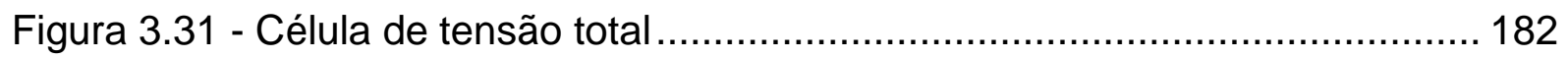

Figura 3.32 - Célula de carga instalada no pistão do cilindro pneumático 183

Figura 3.33 - Sistema de controle e aquisição de dados: a) Montagem das caixas de interface; b) Fontes e condicionadores de sinais e c) Computador e monitores..... 185

Figura 3.34 - Ilustração da saída gráfica do programa - monitor 1 ....................... 186

Figura 3.35 - Ilustração da saída gráfica do programa - monitor 2 …................... 187

Figura 3.36 - Procedimento de compactação das camadas: a) Colocação do material; b) Distribuição uniforme; c) Compactação manual das laterais; d) Compactação mecânica; e) Controle da espessura da camada e f) Controle da umidade 189

Figura 3.37 - Instalação das células de tensão total: a) No subleito e b) Na base .190

Figura 3.38 - Superfície do pavimento após a imprimação 190

Figura 4.1- Bacia de deflexão obtida em diferentes estágios 194

Figura 4.2 - Deflexão máxima em função do número de ciclos de carga 196

Figura 4.3- Saída gráfica do programa utilizado para retroanálise 197

Figura 4.4 - Curva de deflexão para diferentes espessuras de camada de base ... 200

Figura 4.5- Deflexão para espessuras de camada de base de $15 \mathrm{~cm}$ com placa de carregamento de 21,6 e $30 \mathrm{~cm}$ 202

Figura 4.6 - Deflexão para espessuras de camada de base de $25 \mathrm{~cm}$ com placa de carregamento de 21,6 e $30 \mathrm{~cm}$ 202 
Figura 4.7 - Bacia de deflexão obtida em diferentes ciclos de carga sem a utilização da geogrelha

Figura 4.8 - Deflexão máxima em função do número de ciclos de carga sem a utilização da geogrelha 205

Figura 4.9 - Recalque em função do número de ciclos de carga sem a utilização de geogrelha e curvas correspondentes às equações 4.1 e 4.2 209

Figura 4.10 - Modelo de Wekmeister et al. (2001) apud Guimarães (2009). 213

Figura 4.11 - Enquadramento no Modelo de Wekmeister et al. (2001) do ensaio sem geogrelha

Figura 4.12 - Variação do teor de umidade com a profundidade do subleito após o umedecimento.

Figura 4.13 - Bacia de deflexão obtida em diferentes ciclos de carga, sem a utilização da geogrelha na condição após umedecimento do subleito 216

Figura 4.14 - Deflexão máxima em função do número de ciclos de carga sem a utilização da geogrelha na condição antes e após o umedecimento do subleito ....217

Figura 4.15 - Bacia de deflexão, sem a utilização da geogrelha na condição antes e após o umedecimento do subleito 218

Figura 4.16 - Recalque em função do número de ciclos de carga, sem a utilização da geogrelhas na condição antes e após o umedecimento do subleito e os modelos correspondentes às equações 4.3 e 4.4 219

Figura 4.17 - Bacia de deflexão obtida em diferentes ciclos de carga com a utilização da geogrelha posicionada na interface subleito-base 222

Figura 4.18 - Deflexão máxima em função do número de ciclos de carga com a geogrelha posicionada na interface subleito-base .223

Figura 4.19 - Recalque em função do número de ciclos de carga com a geogrelha posicionada na interface subleito-base e os modelos correspondentes as equações 4.5 e 4.6 226

Figura 4.20 - Enquadramento no Modelo de Wekmeister et al. (2001) do ensaio com geogrelha na interface subleito-base 228

Figura 4.21- Variação do teor de umidade com a profundidade do subleito após o umedecimento, ensaio com geogrelha na interface 229 Figura 4.22 - Bacia de deflexão obtida em diferentes ciclos de carga com a utilização da geogrelha posicionada na interface, situação após o umedecimento do subleito 
Figura 4.23 - Deflexão máxima em função do número de ciclos de carga, com a utilização da geogrelha na interface na condição antes e após o umedecimento do subleito

Figura 4.24 - Bacia de deflexão com a utilização da geogrelha na interface na condição antes e após o umedecimento do subleito 232

Figura 4.25 - Recalque em função do número de ciclos de carga, com a utilização da geogrelha posicionada na interface na condição antes e após o umedecimento do subleito e os modelos correspondentes as equações 4.7 e 4.8 233

Figura 4.26 - Bacia de deflexão obtida em diferentes ciclos de carga com a utilização da geogrelha posicionada no horizonte médio da camada de base 236

Figura 4.27 - Deflexão máxima em função do número de ciclos de carga com a geogrelha posicionada no horizonte médio da camada de base 236

Figura 4.28 - Recalque em função do número de ciclos de carga com a geogrelha posicionada no horizonte médio da camada de base e os modelos correspondentes as equações 4.9 e 4.10 . 238

Figura 4.29 - Enquadramento no Modelo de Wekmeister et al. (2001) do ensaio com geogrelha na interface subleito-base 239

Figura 4.30 - Variação do teor de umidade com a profundidade do subleito após 0 umedecimento, ensaio com geogrelha na interface 241

Figura 4.31 - Bacia de deflexão obtida em diferentes ciclos de carga, com a utilização da geogrelha posicionada no horizonte médio da camada de base, situação após o umedecimento do subleito 242

Figura 4.32 - Deflexão máxima em função do número de ciclos de carga, com utilização de geogrelha no horizonte médio da base na situação antes e após o umedecimento do subleito 242

Figura 4.33 - Bacia de deflexão em função do número de ciclos de carga com utilização da geogrelha no horizonte médio da camada de base na situação antes e após o umedecimento do subleito 243

Figura 4.34 - Recalque em função do número de ciclos de carga, com geogrelha posicionada no horizonte médio da camada de base, na situação antes e após 0 umedecimento do subleito 245

Figura 4.35 - Deflexão máxima em função do número de ciclos de carga dos ensaios sem geogrelha e com geogrelha posicionada na interface e no horizonte médio da base, subleito na umidade ótima 248

Figura 4.36 - Bacias de deflexão após 400.000 ciclos de carga para estruturas sem e com reforço e subleito na umidade ótima 248 
Figura 4.37 - Recalque em função do número de ciclos de carga após 400.000 ciclos de carga para estruturas sem e com reforço e subleito na umidade ótima

Figura 4.38 - Deflexão máxima em função do número de ciclos de carga dos ensaios sem geogrelha e com geogrelha posicionada na interface e no horizonte médio da base, subleito após inundação 253

Figura 4.39 - Bacia de deflexão após 100.000 ciclos de carga para estruturas sem e com reforço e subleito após inundação 254

Figura 4.40 - Recalque em função do número de ciclos de carga após 100.000 ciclos de carga para estruturas sem e com reforço e subleito após umedecimento 256

Figura 4.41 - Estrutura do pavimento hipotético, variação das tensões e módulo de resiliência em função da profundidade, obtidos a partir do ensaio triaxial cíclico, com o auxilio do programa Fepave 258

Figura 4.42 - Estrutura do pavimento hipotético, variação das tensões e módulo de resiliência em função da profundidade, obtidos a partir do ensaio triaxial cíclico, com o auxilio do programa Elsym5 259 



\section{LISTA DE TABELAS}

Tabela 2.1 - Sumário dos parâmetros utilizadas em 27 modelos da literatura adaptado de El-Badawy and Witczad (2007) .49

Tabela 2.2 - Localização dos pontos de leitura de deflexão (DNER, 1994) 61

Tabela 2.3 - Detalhes dos aparelhos e materiais utilizados em pesquisas de reforço de estradas não pavimentadas, utilizando geossintéticos (TINGLE and JERSEY, 2005) .99

Tabela 2.4 - Levantamento bibliográfico de equipamentos de ensaio (PERKINS and ISMEIK, 1997) 100

Tabela 2.5 - Características da estrutura de pavimento e do geossintético utilizados nas pesaquisas (PERKINS AND ISMEIK, 1997). 101

Tabela 2.6 - Propriedades dos geossintéticos utilizados nas pesquisas (PERKINS

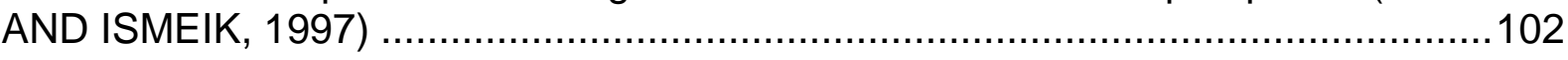

Tabela 3.1 - Características e propriedades dos Solos 1 e 2 143

Tabela 3.2 - Resultados dos ensaios da Metodologia MCT e a classificação dos solos

Tabela 3.3 - Propriedades mecânicas da geogrelha Fornit J600 (30/30) (Dados fornecidos pelo fabricante) 150

Tabela 3.4 - Características e propriedades mecânicas da geogrelha (Modificado do U.S. Army Corps of Engineers, 2003)

Tabela 3.5 - Resultados dos ensaios de compactação e CBR para os materiais geotécnicos utilizados na pesquisa na umidade ótima de compactação

Tabela 3.6 - Sequência de tensões de ensaio para base/sub-base segundo a AASHTO-T 307-99

Tabela 3.7- Sequência de tensões de ensaio para subleito segundo AASHTO T30799 
Tabela 3.8 - Modelos avaliados para representação do $M_{R}$ em função do estado de tensão

Tabela 3.9 - Valores das constantes dos modelos avaliados para o solo utilizado 158

Tabela 3.10 - Valores das constantes dos modelos avaliados para a mistura solobrita.

Tabela 3.11 - Programa Plaxis - Módulo de elasticidade e coeficiente de Poisson dos materiais e espessura das camadas que compõem o pavimento

Tabela 3.12 - Configuração dos ensaios da primeira etapa.................................. 191

Tabela 3.13 - Configuração dos ensaios da segunda etapa 192

Tabela 4.1- Módulos de resiliência obtidos a partir do ensaio triaxial cíclico e a partir da retroanálise da bacia de deflexão

Tabela 4.2 - Propriedades mecânicas das geogrelhas utilizadas como reforço de base nesta pesquisa e na literatura 224

Tabela 4.3 - Módulos de resiliência obtidos a partir do ensaio triaxial cíclico e a partir da retroanálise das bacias de deflexões para condição de subleito compactado na umidade ótima de compactação 260

Tabela 4.4 - Módulos de resiliência obtidos a partir da retroanálise das bacias de deflexões dos ensaios com e sem reforço, para condição de subleito compactado na umidade ótima 261

Tabela 4.5 - Módulos de resiliência obtidos a partir da retroanálise das bacias de deflexões para condição de subleito após o umedecimento 262

Tabela 4.6 - Tensão desvio na fibra inferior da capa e o número de aplicações de carga para se atingir a fadiga da capa asfáltica, para os ensaios sem e com utilização da geogrelha 264

Tabela 4.7 - Tensões verticais no topo do subleito obtidas com a célula de tensão total no topo do subleito 265 


\section{SUMÁRIO}

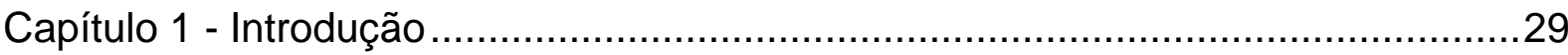

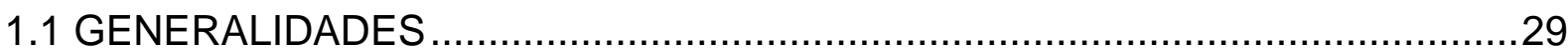

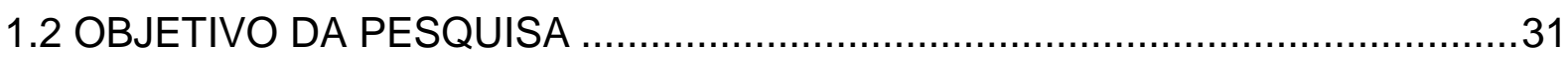

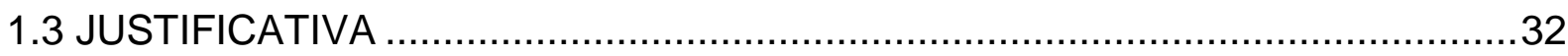

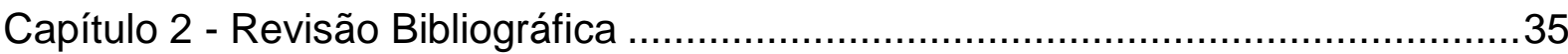

2.1 INTRODUÇÃO

2.2 MECANISMOS DE RUPTURA DE PAVIMENTOS FLEXÍVEIS .........................36

2.2.1 Deformações elásticas - Ruptura por fadiga ……….....................................36

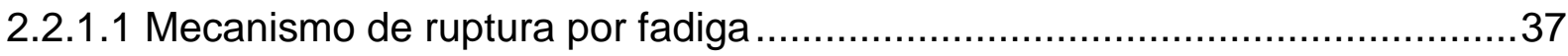

2.2.1.2 Vida de fadiga de uma mistura asfáltica..................................................38

2.2.1.3 Trincas em pavimentos asfálticos …………….................................... 40

2.2.2 Deformações permanentes - Afundamento "trilha de roda" ............................43

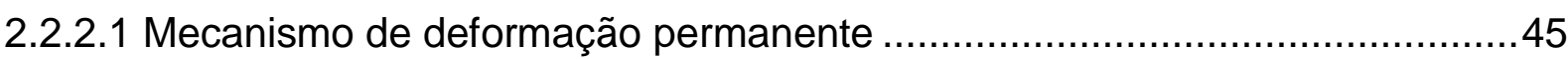

2.2.2.2 Contribuição do subleito e das camadas da estrutura de pavimento nas deformações permanentes.................................................................................47

2.2.2.3 Modelos de predição de deformações permanentes....................................48

2.3 AVALIAÇÃO ESTRUTURAL DO PAVIMENTO .............................................54

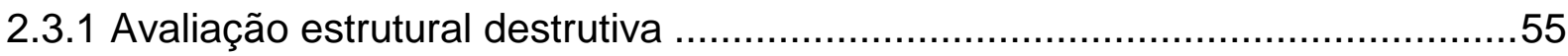

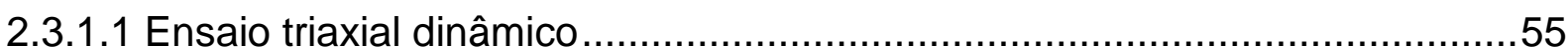


2.3.2 Avaliação Estrutural não Destrutiva ........................................................ 57

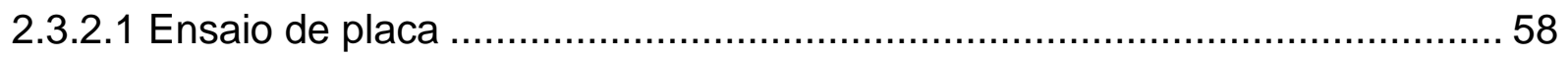

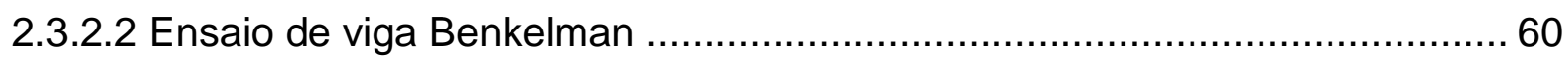

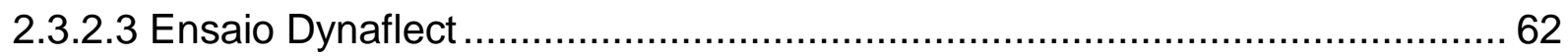

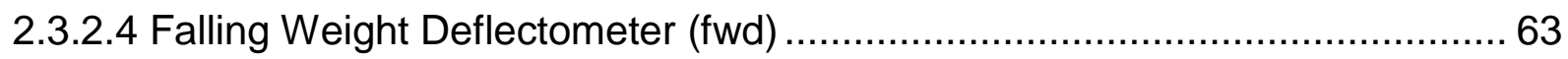

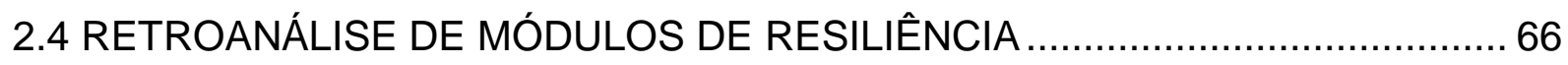

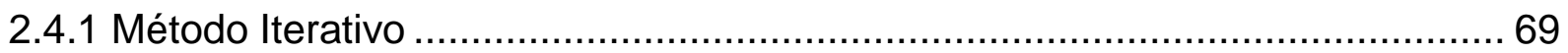

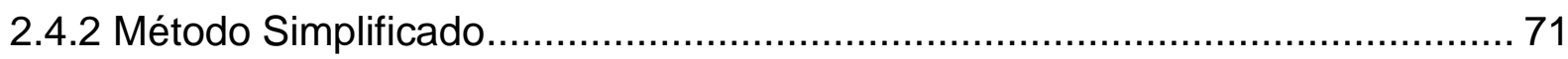

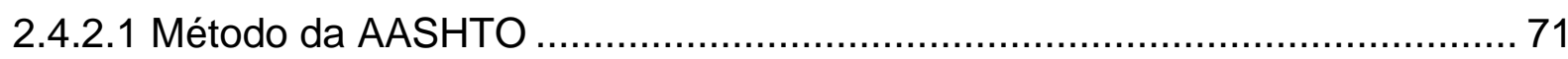

2.4.2.2 Método de Fabrício et al. (1988 e 1994) ………..................................... 74

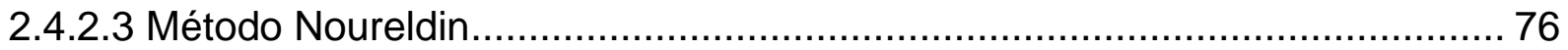

2.5 DISTRIBUIÇÃO DE TENSÕES E DESLOCAMENTOS EM PAVIMENTOS ....... 79

2.6 INSTRUMENTAÇÃO EM PAVIMENTOS FLEXÍVEIS ...................................... 82

2.7 ANÁLISE DE TENSÕES PELO MÉTODO DOS ELEMENTOS FINITOS........... 85

2.8 UTILIZAÇÃO DE GEOSSINTÉTICO EM PAVIMENTO FLEXÍVEL ..................... 86

2.8.1 Principais geossintéticos utilizados em pavimentação..................................... 86

2.8.2 Geossintéticos em reforço de base de pavimentos flexíveis ......................... 87

2.8.2.1 Equipamentos de ensaios em laboratório................................................ 89

2.8.2.2 Trechos experimentais para análise da utilização de geossintéticos em estruturas de pavimentos................................................................................... 103

2.8.2.3 Efeito a serem considerados na utilização de geossintéticos no reforço de base de estrutura de pavimento …….............................................................. 107

2.8.2.3.1 Efeito da espessura da camada granular a ser reforçada e posicionamento

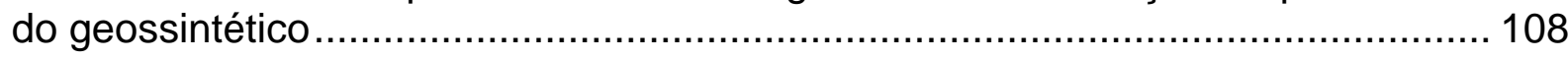

2.8.2.3.2 Efeito do tipo e características mecânicas do geossintético .................... 111

2.8.2.3.3 Efeito do geossintético na distribuição de tensão no topo do subleito ..... 115

2.8.2.3.4 Efeito da capacidade de suporte do subleito ....................................... 116 
2.8.2.3.5 Efeito da forma de aplicação do carregamento nos ensaios 119

2.8.2.3.6 Efeito do geossintético no módulo de resiliente da camada de base .......121

2.8.2.4 Dimensionamento de pavimento considerando o uso de geossintético ......125

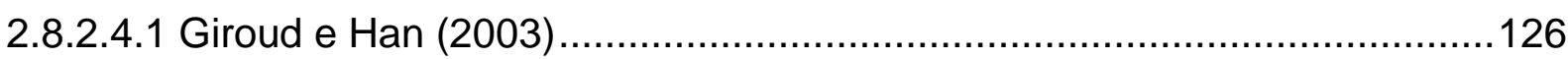

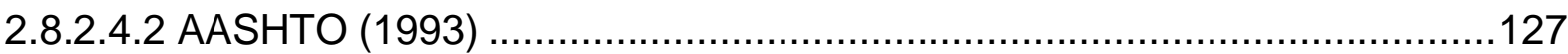

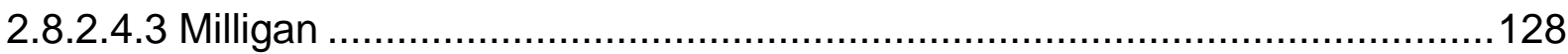

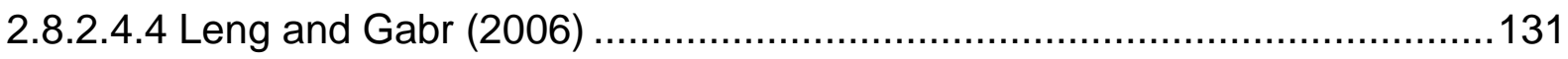

2.8.2.4.5 Perkins and Cuelho (2007) ..........................................................135

Capítulo 3 - Materiais e Métodos..................................................................139

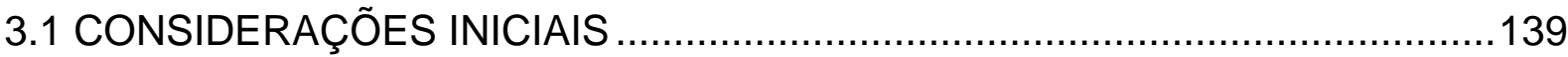

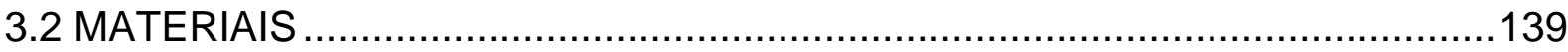

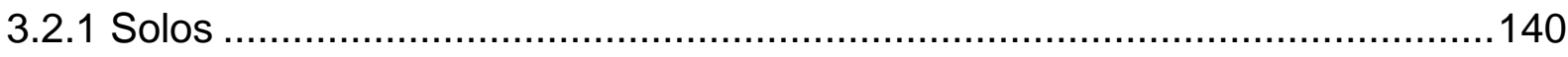

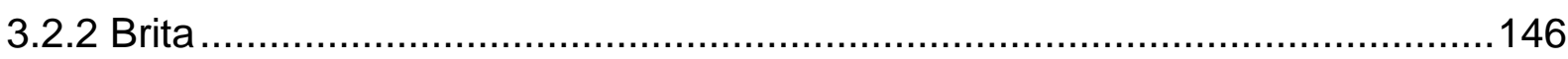

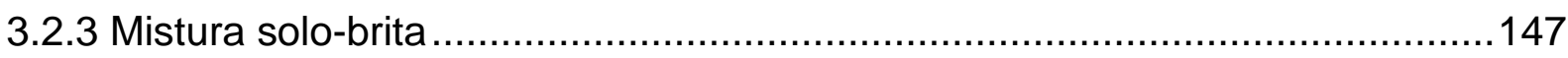

3.2.4 Elemento de reforço da base ...............................................................149

3.3 ENSAIOS LABORATORIAIS CONVENCIONAIS .......................................152

3.3.1 Índice de Suporte California (CBR) ……...............................................152

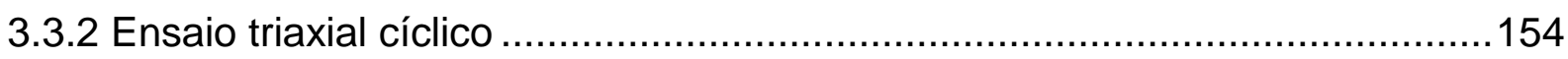

3.4. ENSAIO DE CARREGAMENTO CÍCLICO EM EQUIPAMENTO DE GRANDES

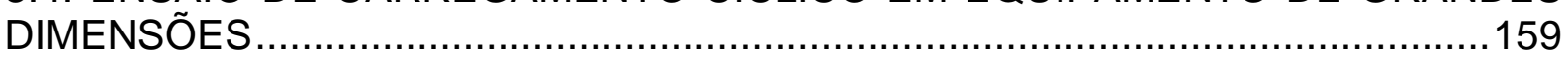

3.4.1 Análise da espessura do subleito e das dimensões da caixa de ensaio ........160

3.4.2. Montagem e calibração do equipamento e testes .......................................165

3.4.2.1 Adaptação da sala de ensaio e montagem da caixa metálica......................166

3.4.2.2 Sistema de umedecimento da camada de subleito ...................................169

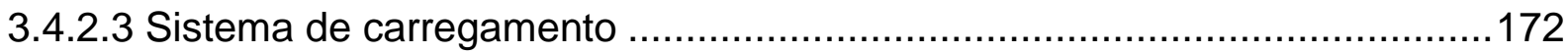

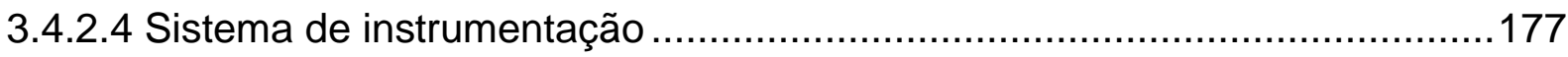


3.4.2.5 Sistema de aquisição de dados e programação 183

3.4.2.6 Compactação das seções ensaiadas 187

3.5. PROGRAMA DOS ENSAIOS REALIZADOS NO EQUIPAMENTO ................. 191

Capítulo 4 - Apresentação e Análise dos Resultados ........................................... 193

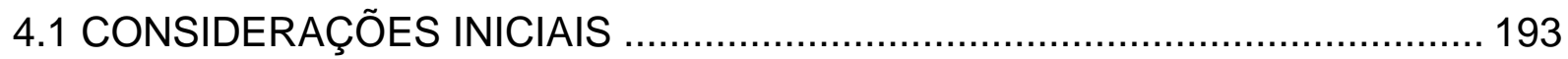

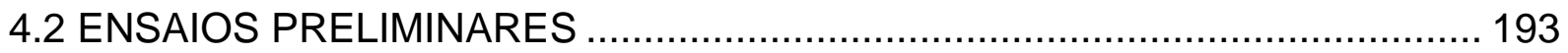

4.3 RESULTADOS DOS ENSAIOS DA ETAPA DEFINITIVA.............................. 203

4.3.1 Ensaio sem a utilização de geogrelha ...................................................... 204

4.3.1.1 Análise das deformações elásticas na superfície sem a utilização de geogrelha e subleito na umidade ótima de compactação.

4.3.1.2 Análise das deformações permanentes na superfície sem a utilização de geogrelha e subleito na umidade ótima de compactação. 208

4.3.1.3 Análise das deformações elásticas na superfície sem a utilização de geogrelha após o umedecimento do subleito 215

4.3.1.4 Análise das deformações permanentes na superfície sem a utilização de geogrelha após o umedecimento do subleito 219

4.3.2 Ensaio com a utilização de geogrelha na interface subleito-base 221

4.3.2.1 Análise das deformações elásticas na superfície com a utilização da geogrelha posicionada na interface subleito-base e subleito na umidade ótima de compactação 222

4.3.2.2 Análise das deformações permanentes na superfície com a utilização da geogrelha posicionada na interface subleito-base e subleito na umidade ótima de compactação 225

4.3.2.3 Análise das deformações elásticas na superfície com a utilização da geogrelha posicionada na interface subleito-base após o umedecimento do subleito 228

4.3.2.4 Análise das deformações permanentes na superfície, com a utilização da geogrelha posicionada na interface subleito-base após o umedecimento do subleito 232

4.3.3 Ensaio com a utilização de geogrelha no horizonte médio da base 235 
4.3.3.1 Análise das deformações elásticas na superfície com a utilização da geogrelha posicionada no horizonte médio da base e subleito na umidade ótima de compactação.

4.3.3.2 Análise das deformações permanentes na superfície com a utilização da geogrelha posicionada no horizonte médio da base e subleito na umidade ótima de compactação

4.3.3.3 Análise das deformações elásticas na superfície com a utilização da geogrelha posicionada no horizonte médio da base na condição após o umedecimento do subleito após o umedecimento do subleito 240

4.3.3.4 Análise das deformações permanentes na superfície, com a utilização da geogrelha posicionada no horizonte médio da base após o umedecimento do subleito. .244

4.4 ANÁLISE COMPARATIVA DOS ENSAIOS APRESENTADOS NA ETAPA DEFINITIVA.

4.4.1 Análise comparativa das deformações elásticas para o subleito na umidade ótima

4.4.2 Análise comparativa das deformações permanentes para o subleito na umidade ótima.

4.4.3 Análise comparativa das deformações elásticas para o subleito umedecido .253 4.4.4 Análise das deformações permanentes após o umedecimento do subleito ...255 4.5 ANÁLISES COMPLEMENTARES

4.5.1 Análise dos módulos de resiliência obtidos a partir da retroanálise das bacias de deflexão.

4.5.2 Análise do efeito do uso do reforço na fadiga de uma capa asfáltica 263

4.5.3 Análise das células de tensão total 264

Capítulo 5 Conclusões 267

5.1 CONCLUSÕES 267

5.2 RECOMENDAÇÕES PARA TRABALHOS FUTUROS 269 REFERÊNCIAS BIBLIOGRÁFICAS .271 



\section{Capítulo 1 - Introdução}

\subsection{GENERALIDADES}

As rodovias pavimentadas brasileiras, em quase sua totalidade, são constituídas de pavimentos flexíveis. Os esforços provocados pelas cargas atuantes nestes pavimentos induzem o desenvolvimento de deformações elásticas ou resilientes, e deformações permanentes. As deformações elásticas repetidas geradas pelo tráfego são responsáveis pela ruptura por fadiga do material asfáltico, que provoca o surgimento e a evolução das trincas observadas nos revestimentos. As deformações permanentes acumuladas são responsáveis pelo afundamento de trilhas de rodas na superfície de rolamento.

A infra-estrutura do transporte rodoviário nacional encontra-se envelhecida e o seu estado é extremamente precário em muitas regiões do país. Sabe-se que a escassez de recursos financeiros é fator preponderante no planejamento dos investimentos públicos. Assim, os grandes volumes de recursos exigidos na área da infra-estrutura de transportes demandam que técnicas inovadoras de construção sejam incorporadas à prática da engenharia rodoviária de maneira a reduzir custos e 
aumentar a durabilidade de nossas estradas, garantido o retorno do capital investido.

Outra situação que tem contribuído para a deterioração dos pavimentos é o emprego de bases granulares diretamente sobre subleitos de baixa capacidade de suporte ou insuficientemente compactados. O resultado desta associação é a redução da espessura útil da camada de base decorrente da cravação de material granular no subleito aliada à dificuldade de alcançar-se o grau de compactação exigido na região de contato com substrato de fundação, que ocasiona significativa perda de rigidez nos horizontes inferiores da camada granular.

Uma das tecnologias disponíveis para controlar ou reduzir a manifestação de patologias resultantes da situação destacada anteriormente é a utilização de geossintéticos, em especial as geogrelhas, por apresentarem uma maior rigidez, como elemento de reforço da camada de base. O efeito dos geossintéticos contribui para a redução das espessuras exigidas para as camadas granulares ou para o aumento da vida de serviço do pavimento.

A melhoria do desempenho do pavimento com a inserção de geossintéticos foi comprovada tanto em experimentos de laboratório como em experimentos em campo (KLEIN et al., 2003; HASS et al., 1988; MIURA et al., 1990, etc.). Os resultados obtidos indicam que os pavimentos reforçados apresentam vida ou período de projeto maior em comparação a seções similares não-reforçadas. No caso de reforço com geossintético da camada de base granular, os experimentos mostram uma redução de $20 \%$ a $50 \%$ na espessura deste elemento quando os geossintéticos são utilizados. Novos estudos devem ser desenvolvidos para que se avance no conhecimento do comportamento de estruturas de pavimentos reforçados 
com geossintéticos e seja possível estabelecerem-se rotinas de projeto, que considerem o seu efeito estrutural e novos procedimentos construtivos, contemplando-se os materiais, clima e tráfego das rodovias brasileiras.

Para esclarecimento destes mecanismos e possibilitar a quantificação destes benefícios é de grande importância a avaliação das deformações permanentes e elásticas em estruturas de pavimento em verdadeira grandeza. Assim mostra-se necessário o desenvolvimento de um equipamento de laboratório de grandes dimensões que possibilite a análise de estruturas de pavimentos com materiais, espessuras de camadas e condições de carregamento similares às de campo.

\subsection{OBJETIVO DA PESQUISA}

O objetivo da pesquisa é desenvolver, construir e testar um modelo físico em laboratório que permita a avaliação e a análise do comportamento mecânico de seções de pavimentos com dimensões similares às reais submetidas a carregamentos cíclicos. Para testar o modelo físico desenvolvido, será estudado o efeito da incorporação de uma geogrelha como elemento de reforço de uma base de solo-brita apoiada a uma camada de subleito a partir da análise das bacias de deflexão e das deformações permanentes observadas 


\subsection{JUSTIFICATIVA}

No Brasil, o sistema rodoviário ocupa a primeira posição como meio de locomoção, tanto de passageiros, que corresponde a $90 \%$ dos deslocamentos no país, quanto de carga, com mais de $60 \%$ do total (Confederação Nacional de Transporte, 2002). A malha rodoviária, em sua grande maioria, é constituída de pavimentos flexíveis.

Pesquisas realizadas em 2004 pelo Ministério do Transporte demonstraram que $40,80 \%$ das rodovias federais são conceituadas como ruins; $30,90 \%$ regular e apenas $28,3 \%$ são boas. Quanto à idade dos pavimentos, $80 \%$ da malha rodoviária apresentam mais de 10 anos; $15 \%$ de cinco a dez anos, e 5\%, idades inferiores a cinco anos.

Na décima edição da pesquisa rodoviária CNT realizada em 2005, foram avaliados $81.944 \mathrm{~km}$ de rodovias em todo território nacional. O estado geral de conservação foi determinado quanto à qualidade do pavimento, a sinalização e a geometria das vias. Os resultados da pesquisa mostraram que apenas $17 \%$ da extensão das vias pesquisadas alcançaram conceito bom, e apenas $11 \%$ alcançaram o conceito ótimo. E $72 \%$ das rodovias analisadas encontram-se em situações consideradas ruins ou péssimas, fato que compromete significativamente a segurança dos usuários, a competitividade dos mais variados setores produtivos e o desenvolvimento econômico do país. Dentre os defeitos encontrados nos pavimentos analisados constataram-se desgastes, ondulações, buracos, trincas e remendos, e em alguns casos, a completa deterioração do pavimento. 
Os dados confirmam que não aconteceram mudanças significativas no quadro geral das rodovias brasileiras nos últimos anos e que grande parte da malha rodoviária apresenta-se em estado de deterioração avançada, exigindo a reabilitação da camada de rolamento, e em alguns casos, até mesmo a reconstrução de toda a estrutura do pavimento. Por outro lado, os recursos financeiros disponíveis para investimentos no setor são muito limitados em razão da escassez das verbas públicas.

Diante desta situação gravíssima, é necessário o aporte de investimentos públicos e privados na área da infraestrutura rodoviária, promovendo-se a manutenção, recuperação e modernização da malha existente e a sua ampliação, de maneira a garantir o crescimento e a competitividade do país.

Neste sentido, é de grande importância o desenvolvimento de equipamento de ensaios que possibilite a obtenção de parâmetros que auxiliem na concepção de projetos mais lucrativos e duradouros. Neste sentido, esse estudo busca apresentar um equipamento em verdadeira grandeza que possibilite a obtenção de parâmetros confiáveis para auxiliar no dimensionamento de pavimentos. 


\section{Capítulo 2 - Revisão Bibliográfica}

\subsection{INTRODUÇÃO}

Neste capítulo é apresentada uma visão geral dos principais mecanismos de ruptura de pavimentos flexíveis, um breve detalhamento dos ensaios não destrutíveis para avaliação estrutural de pavimentos flexíveis, métodos de retroanálise dos módulos de resiliência das camadas por meio das bacias deflectométricas, distribuição das tensões, deslocamentos e instrumentação utilizados nos ensaios. Ainda neste capítulo apresenta-se uma descrição dos geossintéticos utilizados em pavimentação, enfatizando-se a sua utilização em reforço de base de pavimentos flexíveis e na restauração de pavimentos deteriorados.

Por fim, são apresentados os principais fatores que influenciam o comportamento da estrutura de pavimento reforçado com geossintético e um levantamento bibliográfico dos equipamentos de laboratório utilizados nesses estudos. 


\subsection{MECANISMOS DE RUPTURA DE PAVIMENTOS FLEXÍVEIS}

Os principais mecanismos de ruptura de pavimentos asfálticos são a ruptura por fadiga seguido da deformação permanente ou "trilha de roda".

\subsubsection{Deformações elásticas - Ruptura por fadiga}

O estudo do fenômeno da fadiga em revestimentos asfálticos de pavimentos flexíveis iniciou-se a partir da metade do século XX. Na década de 50 , Hveem correlacionou as deflexões sob várias cargas por eixo com o comportamento dos pavimentos, salientando o fato de o fendilhamento ser resultado da fadiga dos materiais, fenômeno este que dependia da amplitude das deflexões e do tempo de aplicação de carga (MEDINA, 1997).

Pinto (1991) descreveu o fenômeno da fadiga como um processo de deterioração estrutural que sofre um material, quando submetido a um estado de tensões e de deformações repetidas, resultando em trincas ou fratura completa, após um número suficiente de repetições do carregamento, ou seja, é a perda de resistência que o material sofre, quando solicitado repetidamente por uma carga. 


\subsubsection{Mecanismo de ruptura por fadiga}

As trincas na camada de revestimento são geradas predominantemente a partir das elevadas deflexões reversíveis a que são submetidos os pavimentos flexíveis, não necessariamente acompanhadas de significativas deformações permanentes.

O trincamento por fadiga inicia-se quase sempre, nas fibras inferiores da camada do revestimento asfáltico, propagando-se por toda a espessura até o surgimento das trincas na superfície.

A Figura 2.1 ilustra a distribuição das tensões que são geradas na estrutura de pavimento flexível, quando solicitado por uma carga vertical de compressão na superfície. Observa-se que nas fibras inferiores da camada asfáltica surgem tensões de tração e de compressão, devido ao carregamento e descarregamento repetido.

No entanto, as trincas podem iniciar-se pelo topo da camada do revestimento asfáltico, neste caso, o início do trincamento dar-se-á devido ao surgimento de tensões críticas na fibra superior da camada, agravadas pelo enrijecimento ocasionado pelo envelhecimento, dependendo também da espessura da camada. 


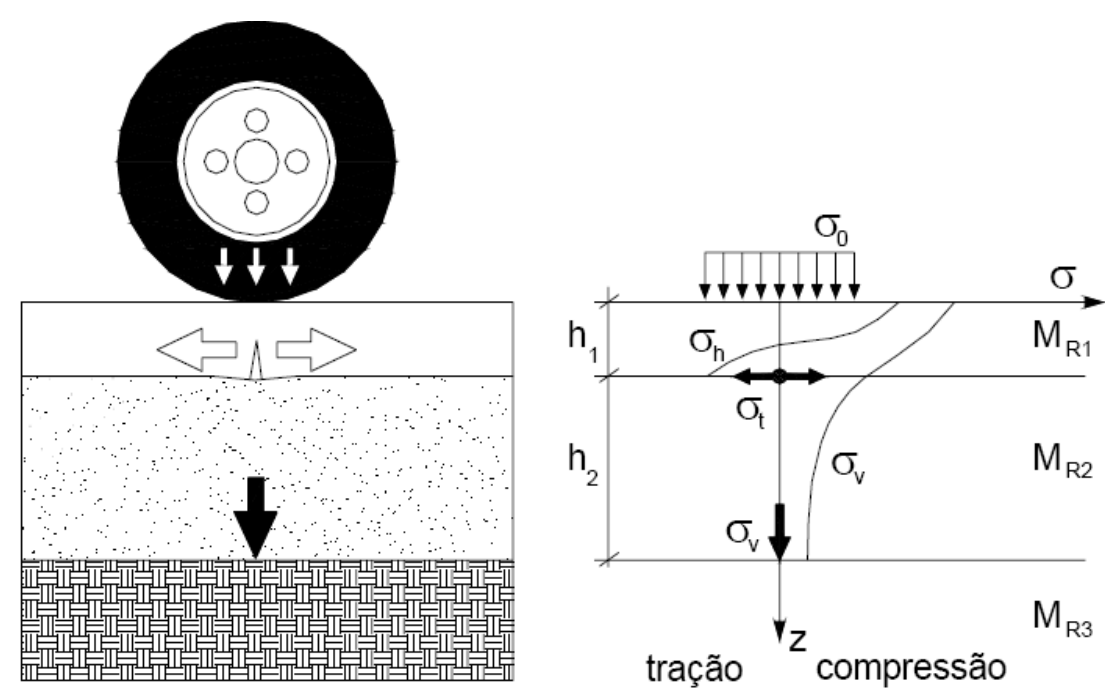

Figura 2.1 - Tensões em um pavimento (MEDINA e MOTTA, 2005)

Deformações excessivas do subleito e das camadas inferiores ao revestimento asfáltico também aumentam a probabilidade da ocorrência de fadiga. Desta forma, variação da umidade do subleito, pode acelerar o processo de fadiga do revestimento, uma vez que resulta em elevadas deformações nas camadas subjacentes.

A ruptura por fadiga da camada de revestimento está associada à estrutura do pavimento como um todo, ou seja, aos módulos elásticos e às espessuras de cada camada constituinte da estrutura de pavimento.

\subsubsection{Vida de fadiga de uma mistura asfáltica}

A vida de fadiga de um material asfáltico pode ser dita como o número de aplicações de carga necessário para que a mistura atinja ruptura sob dado estado de tensões. É afetada principalmente pelo fator de carga, em que se destaca a 
magnitude, a frequência e a forma de carregamento. Ainda, pelo tipo, forma, granulometria e textura do agregado, teor de asfalto, índice de vazios da mistura, módulo de resiliência e fatores ambientais, principalmente temperatura e umidade.

A temperatura de serviço do pavimento consiste em um fator com grande influência na flexibilidade da camada asfáltica, uma vez que o asfalto é um material termossensível. Temperaturas elevadas aumentam a flexibilidade e temperaturas mais baixas tornam a camada asfáltica mais rígida e com maior tendência a se tornar quebradiça. Com a diminuição da temperatura, as tensões de tração que se desenvolvem na base do revestimento asfáltico aumentam.

O aumento na temperatura pode atuar de dois modos na vida de fadiga de misturas asfálticas: diminuindo o módulo de resiliência e diminuindo a resistência à tração do material e assim as misturas asfálticas se tornam mais sensíveis às aplicações da carga, o que contribui para a redução da vida de fadiga da camada. Os modelos básicos de previsão do número de repetições de carga para atingir o trincamento por fadiga estão relacionados às tensões de tração ou às deformações de tração, aplicadas nos pontos críticos.

A estimativa de vida de fadiga pode ser realizada através de pistas de simulação de tráfego ou de ensaios de laboratório, em placas, vigotas ou corpos de provas cilíndricos.

Motta (1991) considera que o módulo de resiliência é importante na avaliação da vida de fadiga de uma mistura asfáltica, mas não é só ele que comanda esta vida de fadiga. Módulos de resiliência bem próximos resultam em equações de fadiga 
bem distintas, quando alguma outra característica é diferente na mistura, como, por exemplo, a granulometria, o agregado, a origem do ligante asfáltico, etc.

A partir da curva de fadiga de uma mistura asfáltica e prevendo-se o nível de tensão e deformação a que uma dada estrutura estaria sujeita no campo, pode-se estimar, de maneira aproximada, quantas passagens do eixo padrão o pavimento resistirá e, portanto, qual será sua vida útil em termos de fadiga do revestimento.

\subsubsection{Trincas em pavimentos asfálticos}

As trincas nos revestimentos asfálticos surgem na forma de micro-fissuras que, com o passar do tempo e aumento do número de ciclos de carga e descarga ou ciclos térmico, a que o pavimento é submetido, crescem e se ligam, formando uma trinca (VILCHEZ, 1996).

Segundo Colombier (1989), o aparecimento das trincas em pavimentos asfálticos é decorrente dos seguintes fatores:

- Fadiga: ruptura da camada pela passagem de cargas repetidas após um determinado número de ciclos;

- Retração: em locais com temperaturas muito baixas, combinadas com a utilização de camadas estabilizadas com ligantes hidráulicos (cimento, cal, etc.) surge a retração das camadas do pavimento, favorecendo a formação de trincas; 
- Movimentação do Subleito: movimento vertical diferencial entre os bordos das trincas, provocados pelo aumento de umidade, recalques, retração hidráulica e expansão; e

- Defeitos Construtivos: gerados por uma composição inadequada das camadas do pavimento, má execução de juntas longitudinais e deslocamento das camadas.

Durante o ciclo de deformação, face ao carregamento do tráfego, as trincas sofrem concentrações de tensões repentinas e acabam aliviando as tensões no pavimento. A formação de zonas plásticas é espalhada ao redor da trinca durante o carregamento brusco da propagação das trincas. Durante o descarregamento elástico, as trincas são solicitadas com tensões residuais, que também contribuem para o seu desenvolvimento, porém de forma mais lenta.

As trincas isoladas podem apresentar as seguintes configurações:

- Transversais (se aproximadamente perpendiculares ao eixo estrada); e

- Longitudinais (se aproximadamente paralelas ao eixo estrada), sendo curtas quando a extensão for inferior a 1,0 m ou longas, caso contrário.

Existem ainda as trincas ditas interligadas, que são divididas em duas categorias:

- Trinca em bloco, com lados bem definidos aparentando blocos; e

- Trinca "couro de jacaré", conjunto de trincas interligadas sem direções preferenciais, assemelhando-se ao aspecto de couro de jacaré, essas trincas podem apresentar, ou não, erosão acentuada nas bordas. 
Atualmente, os modelos básicos de previsão do número de repetições de carga, para se atingir o trincamento por fadiga, baseiam-se na deformação de tração e no módulo de deformação. Existem vários modelos para determinação do número de repetições de carga que, leva à ruptura por fadiga na porção inferior da camada do revestimento, por exemplo:

- Modelos de fadiga foram desenvolvidos pelo Instituto de Asfalto dos EUA (MS 1 e MS 11), pela Shell Oil e pelo Superpave (A-357), citados em Franco (2000);

- Modelos de fadiga desenvolvidos por Pinto (1991), para misturas asfálticas brasileiras, utilizando $\left(\Delta \sigma\right.$ ou $\left.\varepsilon_{t}\right)$ e módulo de resiliência da camada asfáltica, e

- Rodrigues (1991) - modelo obtido através da relação entre a vida de fadiga e a densidade de energia de deformação (energia de deformação por unidade de volume).

Os modelos de fadiga necessitam ser calibrados de forma a corrigir os valores determinados em laboratório, que são obtidos em condições específicas, tais como: carregamento e frequência de carregamentos constantes, temperatura fixa, forma e tipo de compactação, etc., diferentes das condições esperadas no campo.

A forma mais usual é a aplicação de um fator campo/ laboratório dado pela equação 2.1.

$$
N_{c}=f \cdot N_{l a b}
$$

Em que: $\quad N_{c}$ : número de repetição de carga para atingir o trincamento por fadiga no campo; 
$N_{\text {lab: }}$ número de repetição de carga para atingir o trincamento por fadiga no laboratório, e

f: fator campo/ laboratório.

Segundo Pinto e Motta (1995), o fator campo-laboratório é bastante variável na literatura nacional e internacional. Para um número de aplicação de carga $\mathrm{N}$ de campo calculado, segundo os fatores de equivalência de carga do método de dimensionamento do DNER e para uma área trincada de $40 \%$, o fator campo/ laboratório pode variar de $10^{3}$ a $5 \times 10^{4}$.

\subsubsection{Deformações permanentes - Afundamento "trilha de roda"}

A deformação total de um pavimento flexível ocorre devido à ação cíclica do tráfego de veículos pesados, sendo dividida em duas parcelas: deformação resiliente ou reversível e plástica ou permanente. É fato, que o defeito mais frequente nos pavimentos flexíveis, no Brasil, é o trincamento da camada superior de concreto asfáltico, que se desenvolve a partir da flexão alternada da camada de revestimento apoiada em camadas granulares, geralmente bastante deformáveis elasticamente.

Porém, observam-se também deformações permanentes irreversíveis nas trilhas de rodas dos veículos comerciais em estradas, corredores de ônibus urbanos, pátios de veículos pesados e outros. 
A deformação permanente ou plástica é a deformação que ocorre no material, tendo em vista a ação de uma carga, e que não é recuperável quando cessa o carregamento.

Em projetos de pavimentos flexíveis, seu efeito é caracterizado pelos afundamentos ao longo da trilha de roda nas rodovias e pelas irregularidades na superfície dos pavimentos, que por consequência diminuem os níveis de segurança e aumentam o desconforto dos usuários.

O afundamento de trilha de roda é um defeito do pavimento flexível associado ao acúmulo de deformação vertical permanente, desenvolvido em cada camada constituinte do pavimento (MOTTA 1991; GUIMARÃES, 2001). O valor admissível do afundamento de trilha de roda para auto-estradas é de $10 \mathrm{~mm}$, e para estradas de menor volume de tráfego poderia chegar a $16 \mathrm{~mm}$, mas ao atingir $20 \mathrm{~mm}$ recomenda-se o reparo imediato (MEDINA 2005).

Modelos de previsão da deformação permanente dos materiais de pavimentação têm sido desenvolvidos a partir de dados obtidos em laboratório, principalmente através de ensaios triaxiais de cargas repetidas. Nestes ensaios são utilizados corpos de prova preparados para as condições de temperatura, estado de tensões, umidade e densidade próximas ao encontrado em campo.

O modelo matemático simplificado, mais comumente citado na literatura para representar a deformação permanente é o modelo proposto por Monismith et al. (1975), apresentado na equação 2.2.

$$
\varepsilon_{p}=A \cdot N^{B}
$$

Em que: $\quad \varepsilon p$ : deformação plástica; 
$A$ e B: parâmetros experimentais; $\mathrm{e}$

$N$ : número de repetições de carga.

O modelo simplificado representa bem o comportamento à deformação permanente para variação do número de aplicações de carga, das condições específicas de carregamento e da preparação de cada material, se considerados os solos granulares e argilosos. Entretanto, não prevê mudanças no comportamento em função de variações climáticas ou variações de parâmetros das camadas, tais como: umidade, densidade e estado de tensões, uma vez que ele relaciona apenas o número de aplicação de carga à deformação permanente (FRANCO, 2000).

\subsubsection{Mecanismo de deformação permanente}

A deformação permanente manifesta-se a partir da combinação de dois mecanismos distintos, sendo eles: a densificação ou variação do volume e a deformação cisalhante repetida ou fluxo plástico sem variação de volume.

A Figura 2.2 ilustra os dois tipos de mecanismo de deformação permanente, que podem ocorrer num pavimento flexível em serviço. 


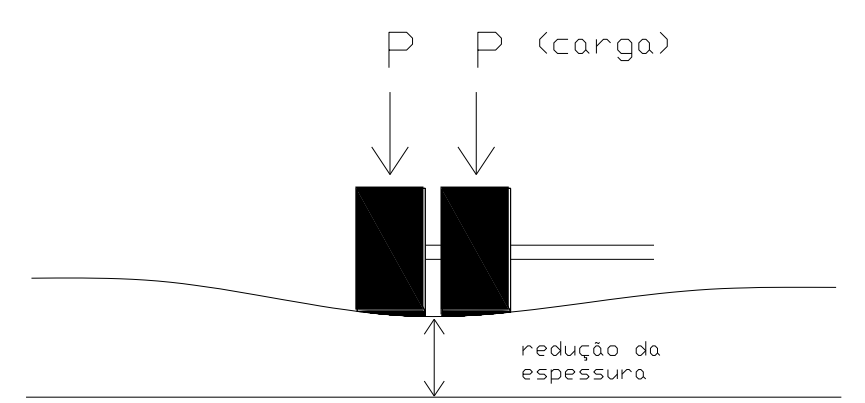

a) deformação permanente devido à consolidação

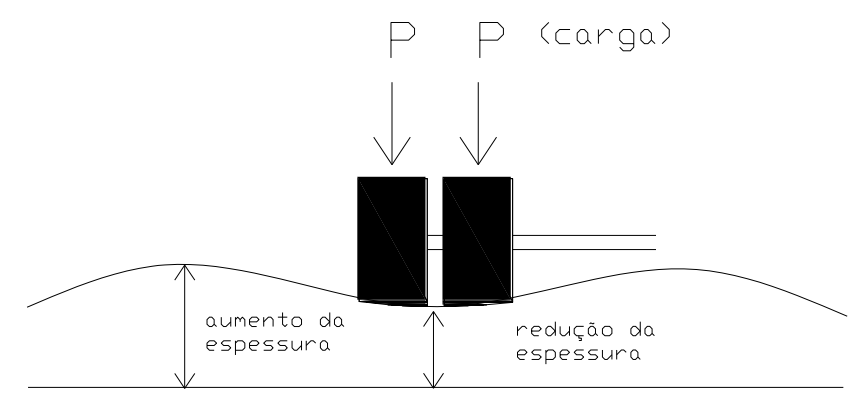

b) deformação permanente devido à tensões cisalhantes repetidas

Figura 2.2 - Tipos de deformação permanente (adaptado de CARVALHO ,1997)

Geralmente, a fase crítica em que surgem as deformações permanentes excessivas é durante a etapa inicial de compactação das camadas constituintes do pavimento. Nesta fase, os materiais geotécnicos sofrem grandes deformações permanentes e na medida em que esta operação vai sendo efetivada, elas vão reduzindo-se gradativamente. Ao se atingir o grau de compactação especificado em projeto, as deformações permanentes reduzem-se muito. Com a abertura do tráfego os materiais sofrem ainda o efeito de acomodação no decorrer do tempo, em função dos fatores ambientais e do tráfego repetido.

No caso de solicitação de tráfego inferior à utilizada durante a fase de compactação, as deformações permanentes que irão surgir sob efeito da densificação e das tensões cisalhantes, não chegam a causar sérios problemas, desde que se mantenha o grau de saturação do subleito e das camadas que compõem a estrutura do pavimento. Ainda assim, pequenas deformações 
permanentes poderão ocorrer e com o passar do tempo tendem a acumular-se, formando um afundamento na superfície do pavimento na região de trilha de roda.

O acúmulo de deformações permanentes nas trilhas de roda é um defeito comum em pavimentos flexíveis e normalmente utilizado por órgãos reguladores e agências, como indicador da necessidade de reabilitação. Estudos vêm sendo realizados para se investigar as possíveis causas do surgimento e do desenvolvimento da trilha de roda. Para tanto, inicialmente, há a necessidade de identificar a camada que mais contribui na deformação permanente medida na superfície de rolamento.

\subsubsection{Contribuição do subleito e das camadas da estrutura de pavimento nas deformações permanentes}

Medina (1997) cita resultados da pista experimental da AASHO (1958-1960), na qual foi possível determinar a porcentagem de contribuição do subleito e das camadas do pavimento para o afundamento da trilha de roda. Constatou-se que a camada de revestimento foi responsável por $32 \%$; a base de brita graduada por $4 \%$; a sub-base granular por $45 \%$ e o subleito argiloso por $19 \%$ do afundamento total desenvolvido na trilha de roda. Detectou-se que $20 \%$ da deformação permanente do revestimento de concreto asfáltico provieram da densificação causada pelo tráfego. Nas regiões tropicais, pode-se atribuir ao revestimento asfáltico, quando não dosado adequadamente, a maior parte das deformações permanentes. 
Simpson, Daleiden e Hadley (1995) propuseram uma abordagem fundamentada na forma do perfil transversal do pavimento, para se investigar a origem da trilha de roda, que surgem na superfície de rolamento. A Figura 2.3 ilustra os quatro perfis, relacionadas ao surgimento da trilha de roda, devido ao subleito, a base, a superfície de rolamento e ao aumento do volume do solo face às condições climáticas de desgelo.

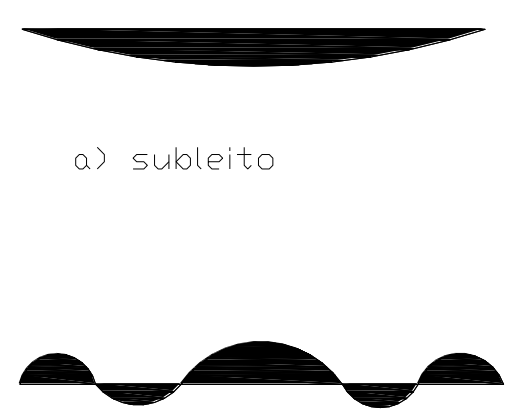

c) superficie

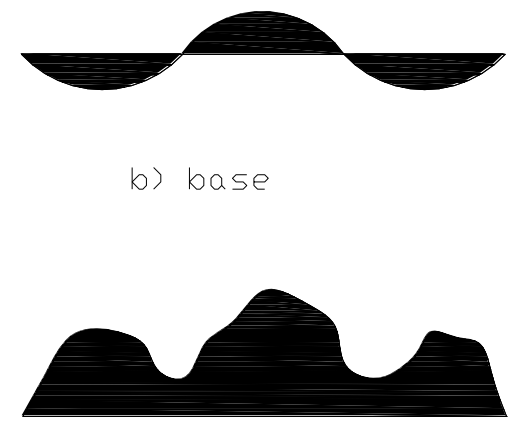

d) heave

Figura 2.3 - Hipótese de Origem do "Rutting" (adaptado de SIMPSON ET AL., 1995)

\subsubsection{Modelos de predição de deformações permanentes}

O estudo da deformação permanente em pavimento flexível vem sendo realizado desde a década de 70, na qual se destacam Barksdale (1972) e Monismith et al. (1975).

No decorrer dos anos, pesquisadores propuseram diferentes métodos para previsão das deformações permanentes de várias camadas constituintes de uma estrutura de pavimento. A somatória destas deformações permanentes resulta no afundamento de trilha de roda. 
A maioria dos modelos apresentados na literatura foi baseada nos resultados de ensaios triaxiais de carga repetida em condição drenada ou não drenada, sob uma tensão de confinamento ou não. Alguns autores utilizaram tensão confinante cíclica ao invés de uma tensão confinante constante. A aplicação da carga varia entre 10.000 a 100.000 ciclos, com duração de 0,1 a 0,5 segundos e com frequência entre 20 a 300 ciclos por minutos.

Os corpos de provas utilizados nos ensaios triaxiais apresentam formato cilíndrico com dimensões respeitando uma relação de 2 entre altura e diâmetro. Para materiais coesivos, os pesquisadores adotaram corpos de prova de dimensão desde 2,2" diâmetro por 4,4" de altura até 4" x 8". E para materiais não coesivos, dimensões de 5,9" x 11,8" à 11,8" x 23,6". A Tabela 2.1 apresenta um sumário do parâmetros utilizados nos modelos para predição das deformações permanentes, baseados em 27 modelos encontrados na literatura apresentado por El-Badawy and Witczad (2007).

Tabela 2.1 - Sumário dos parâmetros utilizadas em 27 modelos de deformação permanente da literatura adaptado de El-Badawy and Witczak (2007)

\begin{tabular}{lc}
\hline \multicolumn{1}{c}{ Descrição } & \% encontrado na literatura \\
\hline Log-log & 79 \\
Semi-log & 21 \\
Deformações permanentes & 79 \\
Razão entre deformações plástica e resilientes & 21 \\
N<=10000 repetições & 37 \\
N>10000 repetições & 63 \\
Relação tensão deformação & 68 \\
Teor de umidade & 7 \\
Modulo resiliente & 18 \\
Materiais granulares & 61 \\
Materiais coesivos & 57 \\
\hline
\end{tabular}


A seguir serão apresentadas, de forma resumida, algumas formulações para previsão das deformações permanentes em camadas de pavimentos.

Barksdale (1972 apud MOTTA,1991) propôs a equação 2.3 para a predição da deformação permanente total da estrutura de um pavimento, que é dada pela somatória das deformações de camada constituinte de uma estrutura de pavimento.

$$
\delta_{\text {total }}^{P}=\sum_{i=1}^{n} \varepsilon_{P}^{i} \cdot h_{i}
$$

Em que: $\quad \delta_{\text {total: }}$ profundidade total do afundamento;

$\varepsilon_{p}$ : deformação específica plástica média da i-ésima camada;

$h_{i}$ : espessura da i-ésima camada; e

n: número total de camadas.

Lentz and Baladi (1981) apresentam o modelo constitutivo para estimar as deformações permanentes em solos arenosos, a expressão pode ser utilizada para predizer as deformações acumuladas para várias aplicações de carregamento e sob diferentes níveis de tensões. Resultados de ensaios triaxiais estáticos e cíclicos foram utilizados para calibração do modelo constitutivo, apresentando a equação 2.4 para a previsão das deformações permanentes.

$$
\varepsilon_{p}=a+b \cdot \ln N
$$

Em que: $\quad \varepsilon_{p}$ : deformações permanentes;

$N$ : número de aplicação de carga repetida; e $a$ e b: constantes de regressão. 
Lentz \& Baladi (1981) propuseram um modelo, cuja definição dos parâmetros é realizada através de ensaio de material sob as condições de campo. O modelo é apresentado para solos granulares, para base ou sub-base de pavimento, dado pela equação 2.5 .

$$
\varepsilon_{p}=\varepsilon_{0.95} \cdot \sigma_{\text {drupt }} \cdot \ln \left(1-\frac{\sigma_{d}}{\sigma_{\text {drupt }}}\right)^{-0.15}+\left[\frac{n \cdot \sigma_{d} / \sigma_{\text {drupt }}}{1-m \cdot \sigma_{d} / \sigma_{\text {drupt }}}\right] \cdot \ln (N)
$$

Em que: $\quad n:\left(0,0809+0,0038 \cdot \sigma_{3}\right) \cdot 10^{-4}$;

$m: 0,856+0,05 \cdot \ln \left(\sigma_{3}\right)$;

$\sigma_{3}:$ tensão confinante, em psi;

$\sigma_{d}$ : tensão desvio, em psi;

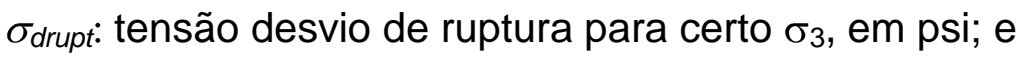

$\varepsilon_{0,95:}$ deformação axial medida no ensaio triaxial estático, a 95\% da tensão de ruptura para certo $\sigma_{3}$, psi.

Khedr (1985) obteve um modelo, a partir de resultados de observações de ensaios realizados em uma brita graduada calcária, com tensão confinante pulsante simultaneamente com a tensão desvio, conforme equação 2.6.

$$
\frac{\varepsilon_{p}}{N}=A \cdot \mathbb{N}_{-m}^{>m}
$$

Em que: $\quad$ A e m: parâmetros experimentais;

$\varepsilon_{p}$ : deformação específica permanente; e

N: número de aplicações de carga. 
O parâmetro $m$ teve pequena variação para as amostras estudadas por Khedr, enquanto o parâmetro $A$ mostrou-se mais sensível ao estado de tensões e ao módulo resiliente.

O parâmetro $A$ pode ser correlacionado a diversas variáveis, tais como, apresentado pelas equações 2.7 e 2.8 .

$$
\begin{gathered}
A=C_{1} \cdot \sigma_{d}^{C_{2}} \cdot \sigma_{3}^{C_{3}} \\
A=S_{1} \cdot\left(\frac{\tau_{O C T}}{\sigma_{O C T}}\right)^{S_{2}} \cdot M_{R}^{S_{3}}
\end{gathered}
$$

Em que: Ci e Si: constantes experimentais;

$\sigma_{d}$ : tensão desvio;

$\sigma_{3}:$ tensão confinante;

$\sigma_{o c t}$ tensão octaédrica;

$\tau_{o c t}$ tensão cisalhante octaédrica; e

$M_{R}$ : módulo resiliênte.

Ullditz (1993) propõe a equação 2.9 para o cálculo da deformação permanente, sendo proporcional ao número de carregamento repetido e da tensão principal maior, considera-se ainda o efeito da tensão confinante.

$$
\varepsilon_{p}=A \cdot N^{\alpha}\left[\frac{\sigma_{Z}}{\sigma}\right]^{\beta}
$$

Em que: $\quad \varepsilon_{p}$ : tensão efetiva vertical;

$\sigma:$ pressão atmosférica; e

A, $\beta$ e $\alpha$ : constantes de calibração. 
Puppala et al. (1999) apresenta o modelo da equação 2.10.

$$
\log \varepsilon_{p}=\log A \cdot \alpha \log N+\beta \log \left[\frac{\sigma_{o c t}}{\sigma_{\text {atm }}}\right]
$$

Concluem que a natureza e magnitude das deformações de solos argilosos parecem depender da sequência das tensões aplicadas nos testes. As constantes da equação proposta dependem do teor de umidade, do peso específico aparente e do tipo do solo. A constante $\log A$ indica a magnitude das deformações permanentes e variou entre 3,1 e 7,9. Valores de $\beta$ negativos são obtidos para os solos arenosos e valores positivos para os solos argilosos. Valores negativos indicam que as deformações permanentes da areia diminuem com o aumento da tensão confinante e desviatória. O estudo mostrou que o subleito de silte argiloso também pode contribuir, significativamente, para a formação da trilha de roda.

El-Badawy e Witczak (2007) concluíram que, a razão da tensão pela deformação e o grau de saturação têm forte influência nas deformações permanente e resiliente dos solos analisados. O grau de saturação apresentou significativa influência na força de cisalhamento e deformação axial total e os coeficientes de regressão são influenciados por: relação tensão-deformação, grau de saturação, índice de plasticidade e porcentagem de finos.

Os modelos propostos foram desenvolvidos, em sua grande maioria, em países de clima temperados que apresentam solos com características diferentes dos encontrados no Brasil.

Cabe ressaltar que a grande maioria dos pavimentos brasileiros foi dimensionada pelo método do CBR. Tal método tende a super 
dimensionar o pavimento, no que se refere ao afundamento de trilha de roda, uma vez que, as propriedades mecânicas do subleito são avaliadas por uma resistência à penetração, que não simula a condição real na qual o solo é solicitado em campo. Ainda, a imersão do corpo de prova em água durante quatro dias não é compatível com as condições climáticas dos países situados nas zonas climática tropical e subtropical.

\subsection{AVALIAÇÃO ESTRUTURAL DO PAVIMENTO}

A avaliação estrutural de um pavimento implica em avaliar sua capacidade de resistir aos esforços solicitados pela passagem das cargas de tráfego. O principal objetivo de se obter modelos de desempenho de um pavimento, a partir da avaliação, é o de poder prever a condição futura do pavimento, a partir da condição analisada.

Nas últimas décadas, a avaliação estrutural de pavimentos tem tido atenção especial dos engenheiros rodoviários, pois a correta determinação da condição estrutural é de fundamental importância para a aplicação de métodos mecanísticosempíricos de projeto de pavimentos novos ou de reforços.

A avaliação estrutural pode ser realizada de duas formas distintas:

- Destrutiva: abrem-se poços de sondagens para coleta de amostras do material constituinte das camadas, para posterior análise em laboratório; 
- Não Destrutiva: realizam-se ensaios in situ, sem coleta de material, através de medidas de deflexão e deformação.

\subsubsection{Avaliação estrutural destrutiva}

A avaliação estrutural destrutiva incide na análise das propriedades mecânicas dos materiais constituintes do pavimento, sendo essas propriedades obtidas por ensaios realizados em campo e laboratório. Consistem na abertura de poços de sondagem para a identificação da natureza e da espessura das camadas do pavimento, bem como, a coleta de amostras dos materiais para futuros ensaios laboratoriais.

Dentre os ensaios laboratoriais pode-se citar o CBR, os limites de consistência, propriedades físicas (granulometria, densidade, umidade e outros), módulo de resiliência, resistência à tração ou a compressão, fadiga e deformação permanente. Os ensaios mais utilizados em campo são o de frasco de areia e umidade.

\subsubsection{Ensaio triaxial dinâmico}

O ensaio triaxial dinâmico possibilita a determinação dos módulos de resiliência e, consequentemente, o dimensionamento de pavimentos novos e restaurados. Dentre os principais modelos pode-se citar: 
- Modelo em função da tensão desvio representado pela equação 2.11.

$$
M_{R}=K_{1} \cdot \sigma_{d}^{k_{2}}
$$

Em que: $\quad$ MR: módulo de resiliência;

$\sigma d$ : tensão desvio; e

k1 e k2: parâmetros de regressão.

A representação da variação do módulo de resiliência com a tensão desvio apresenta melhor desempenho quando utilizados em solos coesivos.

- Modelo em função da tensão confinante, representado pela equação 2.12.

$$
M_{R}=K_{1} \cdot \sigma_{3}^{k_{3}}
$$

Em que: $\quad$ MR: módulo de resiliência;

$\sigma_{3}:$ tensão confinante; e

$k_{1} e k_{3}:$ parâmetros de regressão.

Este modelo descreve a relação entre o módulo de resiliência e a tensão confinante, sendo mais utilizado para solos granulares.

- Modelo Composto, representado pela equação 2.13.

$$
M_{R}=K_{1} \cdot \sigma_{d}^{k_{2}} \cdot \sigma_{3}^{k_{3}}
$$

Em que: $\quad$ MR: módulo de resiliência;

$\sigma_{3}:$ tensão confinante;

$\sigma d$ : tensão desvio; e

$k_{1}, K_{2}$ e $k_{3}:$ parâmetros de regressão. 
- Modelo Universal da AASHTO representado pela equação 2.14 .

$$
M_{R}=K_{1} \cdot p_{a} \cdot\left(\frac{\theta}{p_{a}}\right)^{K_{2}} \cdot\left(\frac{\tau_{o c t}}{p_{a}}+1\right)^{K_{3}}
$$

Em que: $\quad k_{1}, k_{2}$ e $k_{3}:$ constantes de regressão;

Pa: pressão atmosférica (usada para normalizar as unidades do MR);

$\theta$ : primeiro invariante de tensão;

$\sigma_{1}$ : tensão principal maior;

$\sigma_{2}$ : tensão principal intermediária $=\sigma_{3}$ para ensaios de MR em corpos de prova cilíndricos;

$\sigma_{3}:$ tensão principal menor $=$ pressão de confinamento; e $\tau_{\text {oct: }}$ tensão cisalhante octaédrica;

\subsubsection{Avaliação Estrutural não Destrutiva}

Usualmente, os ensaios não destrutivos em pavimentos buscam as leituras de deslocamentos recuperáveis da superfície, de maneira a caracterizar a bacia de deflexões do pavimento sob carga estática ou dinâmica.

Segundo Haas et al. (1994), os equipamentos de avaliação estrutural nãodestrutiva podem ser classificados como: equipamentos estáticos que medem a resposta do pavimento aplicando uma carga estática (ensaios de carga de placa e viga Benkelman); e equipamentos dinâmicos que medem a resposta do pavimento a uma aplicação de carga dinâmica. 
$\mathrm{Na}$ avaliação estrutural de pavimentos flexíveis pode-se citar três categorias de equipamentos de avaliação não destrutiva: os quase estáticos, os de carregamento dinâmico em regime permanente e os que medem as deflexões a partir de impulsos.

- Equipamentos quase-estáticos, que medem as deflexões do pavimento sob carregamento, através de veículo, que se desloca em baixa velocidade, a fim de não ocasionar esforços inerciais (viga de Benkelman).

- Equipamento de carregamento dinâmico em regime permanente, que aplicam uma carga estática na superfície do pavimento e o caráter dinâmico do ensaio é obtido a partir da indução de uma vibração harmônica estável (Dynaflect).

- Equipamentos que medem as deflexões a partir de carregamento por impulso. A força é aplicada pelo impacto causado por um peso em queda livre (FWD).

No Brasil, o DNER normalizou os seguintes equipamentos na avaliação estrutural de pavimentos, através de métodos não destrutivos: ensaio de placa (carga estática), a Viga Benkelman (carga quase estática), o Dynaflect (carga por vibração), e o Falling Weght deflectometer - FWD (carga por impacto), sendo os dois últimos os mais utilizados no Brasil.

\subsubsection{Ensaio de placa}

O ensaio de placa também conhecido como "prova de carga" é um ensaio limitado, pois os resultados não traduzem a realidade do carregamento que o 
pavimento sofre durante sua utilização, uma vez que, a aplicação da carga é feita em regime estático.

O parâmetro obtido deste ensaio é o coeficiente de "recalque" $k$, utilizado para o dimensionamento de pavimento rígido de concreto, definido pela equação 2.15

$$
k=\frac{p}{\delta}
$$

Em que: $\quad k$ : coeficiente de "recalque" $\left(\mathrm{kgf} / \mathrm{cm}^{2} / \mathrm{cm}\right)$;

$P$ : pressão unitária aplicada a uma placa circular rígida de $760 \mathrm{~mm}$ de diâmetro necessária para produzir um "recalque" de 1,27 cm $\left(\mathrm{kgf} / \mathrm{cm}^{2}\right)$; $\delta$ : "recalque" correspondente a 1,27 mm.

Os procedimentos para a execução das provas de cargas e determinação do coeficiente de recalque são determinados conforme a norma: DNER 35 (1992) prova de carga estática para determinação do coeficiente de recalque do subleito e sub-base em projeto e avaliação de pavimentos rígido.

O ensaio de prova de carga utiliza uma carreta com reação superior a 10 toneladas, um macaco hidráulico de 15 toneladas de capacidade provido de manômetro, uma placa circular de aço com diâmetro igual a 760 mm, três deflectômetros graduados, dispositivos de suporte dos deflectômetros, areia para regularização da superfície. Esse ensaio demanda um grande tempo de execução, resultando em uma produtividade de 4 a 6 ensaios diários.

Segundo Albernaz (1997), trata-se de um dos primeiros métodos desenvolvidos para a medição de deflexões. Neste ensaio, ao contrário dos outros 
de sua categoria, as medidas de deflexão não são tomadas sob o carregamento das rodas do veículo (HAAS et al., 1994). A Figura 2.4 apresenta detalhes do equipamento.

O ensaio de placa, em relação aos outros métodos, é considerado demorado, sendo necessário cerca de 30 minutos para ser realizado.

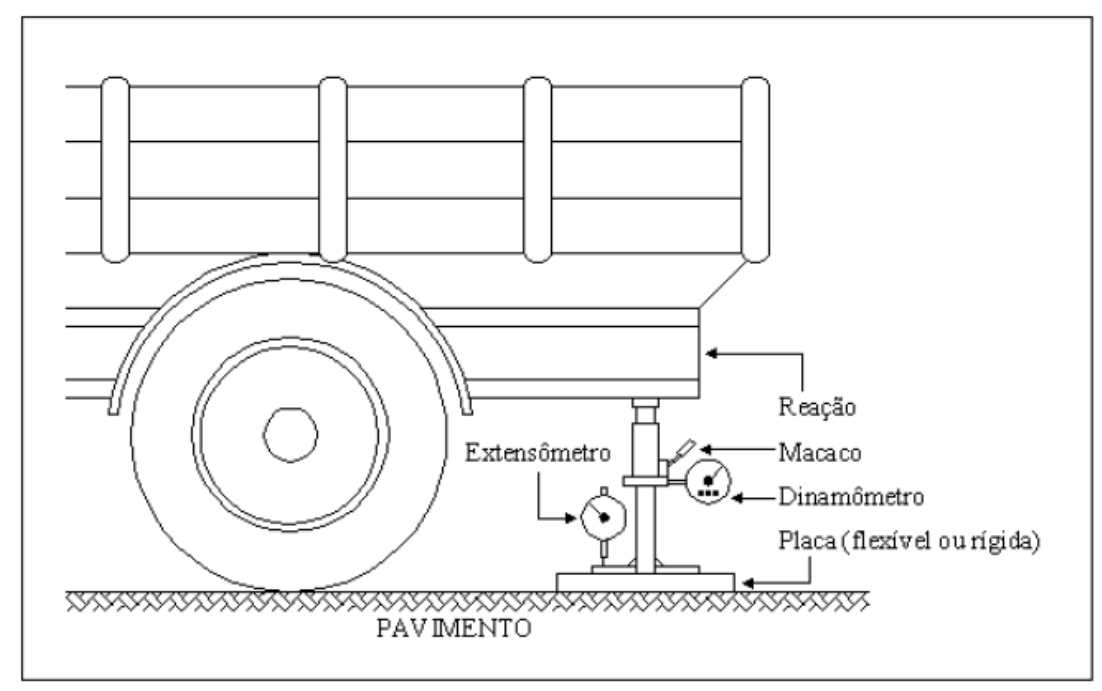

Figura 2.4 - Ensaio de placa (ALBERNAZ, 1997)

\subsubsection{Ensaio de viga Benkelman}

A Viga Benkelman foi desenvolvida, na década de 1950, na WASHO Road Test, pelo engenheiro Benkelman e seu uso, desde então, tem sido crescente e de grande importância para trabalhos, pesquisas e projetos de reforços de pavimentos em todo o mundo (HAAS et al., 1994).

As medidas obtidas do ensaio são: a Deflexão Máxima $\left(D_{0}\right)$ e o Raio de curvatura $\left(R_{C}\right)$. Como estes dados são insuficientes para o cálculo dos módulos de resiliência das camadas, devem ser coletadas amostras de alguns, ou de todos, os 
materiais das camadas constituintes do pavimento, para a determinação de seus respectivos módulos em laboratório. Considera-se a viga um deflectômetro quaseestático, pois as cargas aplicadas movem-se a baixas velocidades (da ordem de 3 $\mathrm{km} / \mathrm{h})$.

A Figura 2.5 mostra, de maneira esquemática, o sistema de referência da viga e do caminhão (DNER-ME 039/1996). Para a determinação da bacia de deformação por intermédio da viga Benkelman, as estações devem ser convenientemente marcadas e estar localizadas nas trilhas de rodas, de maneira que as rodas traseiras do veículo mantenham-se a uma distância fixada da borda do revestimento, de acordo com a Tabela 2.2.

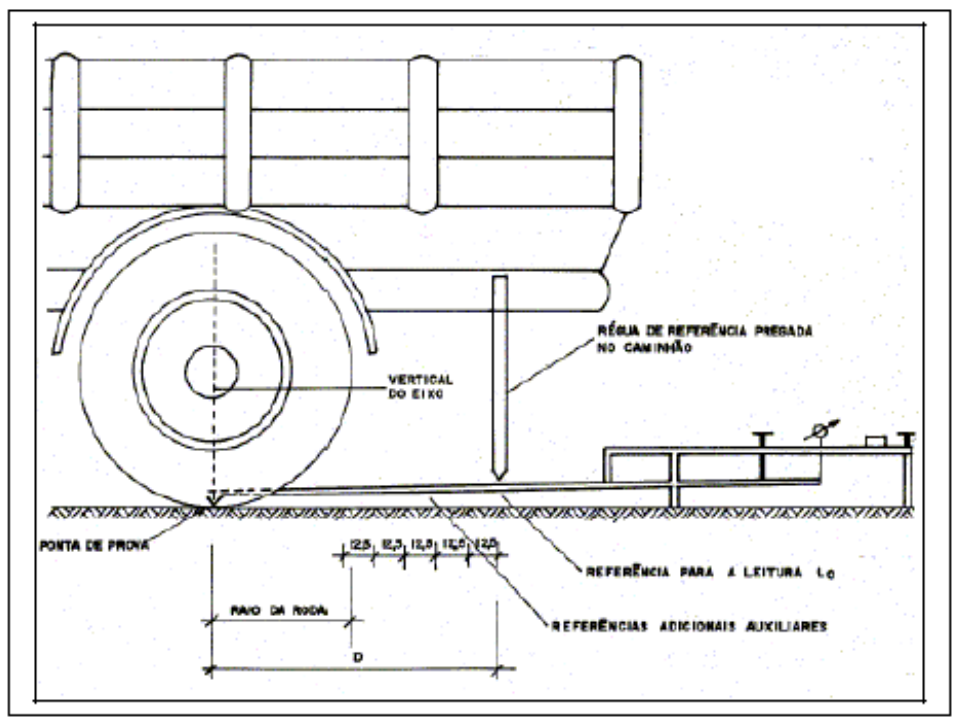

Figura 2.5 - Esquema do sistema de referência na viga e no caminhão (DNER-ME 039/1996)

Tabela 2.2 - Localização dos pontos de leitura de deflexão (DNER-ME 039/1996)

\begin{tabular}{cc}
\hline Largura da Faixa de Tráfego $(\mathrm{m})$ & Distância à Borda do Revestimento $(\mathrm{m})$ \\
\hline 2,7 & 0,45 \\
3,0 & 0,60 \\
3,3 & 0,75 \\
3,5 ou mais & 0,90 \\
\hline
\end{tabular}


As medidas são feitas posicionando-se a ponta de prova no centro de carga da roda dupla de um caminhão com carga por eixo de 8,2 t. Efetua-se, então, a leitura inicial $L_{o}$ no extensômetro. Para determinar a bacia de deflexão, afasta-se o caminhão em pequenos intervalos, de acordo com o espaçamento desejado entre medidas, e efetuam-se novas leituras $L_{i}$. Afastando-se o caminhão lentamente por, no mínimo, $10 \mathrm{~m}$ do ponto de ensaio e em tempo suficiente para que o pavimento recupere sua condição original, faz-se uma leitura final, Lf (MARQUES, 2002). A deflexão máxima da viga é definida pela equação 2.16 .

$$
d=\left(L_{i}-L_{f}\right) * F
$$

Em que: $\quad L_{i}$ : leituras intermediárias;

$L_{f:}$ leitura final; e

F: constante da viga.

\subsubsection{Ensaio Dynaflect}

Segundo Coutinho (2000), o Dynaflect é um equipamento de carregamento dinâmico em regime permanente, que opera com frequência fixa de $8 \mathrm{~Hz}$ e carga de 4,45 KN de pico a pico, distribuída entre as duas rodas carregadas do veículo. Possui um gerador de força, responsável pela produção da carga cíclica, que é produzida mediante a rotação de dois volantes desbalanceados, que giram em sentidos contrários. 
O equipamento é dotado de cinco sensores sísmicos fixados na barra do carro de reboque e distanciado de 304,8 mm. Estes sensores têm como finalidade a medição da bacia de deflexão, no momento em que a carga é aplicada.

O sistema proporciona medições rápidas e precisas das deflexões nas faixas de rolamento em cinco pontos da superfície do pavimento, se utilizando uma força cíclica de magnitude e frequência conhecidas que é aplicada no pavimento por duas rodas de aço (DNER-ME 039/94).

\subsubsection{Falling Weight Deflectometer (FWD)}

Nestes equipamentos, a maneira de caracterizar o impacto é pela duração do carregamento, definido pela extensão de tempo que o pulso de carga leva do repouso ao valor de pico da carga aplicada e retorna à posição original de repouso (MACÊDO, 1996).

Os equipamentos de carregamento por impulso, geralmente, transmitem o esforço ao pavimento através de um conjunto de pesos, que caem sobre uma placa de carga. Estes equipamentos são tipicamente conhecidos como Falling Weight Deflectometer (FWD), representada pela Figura 2.6. 


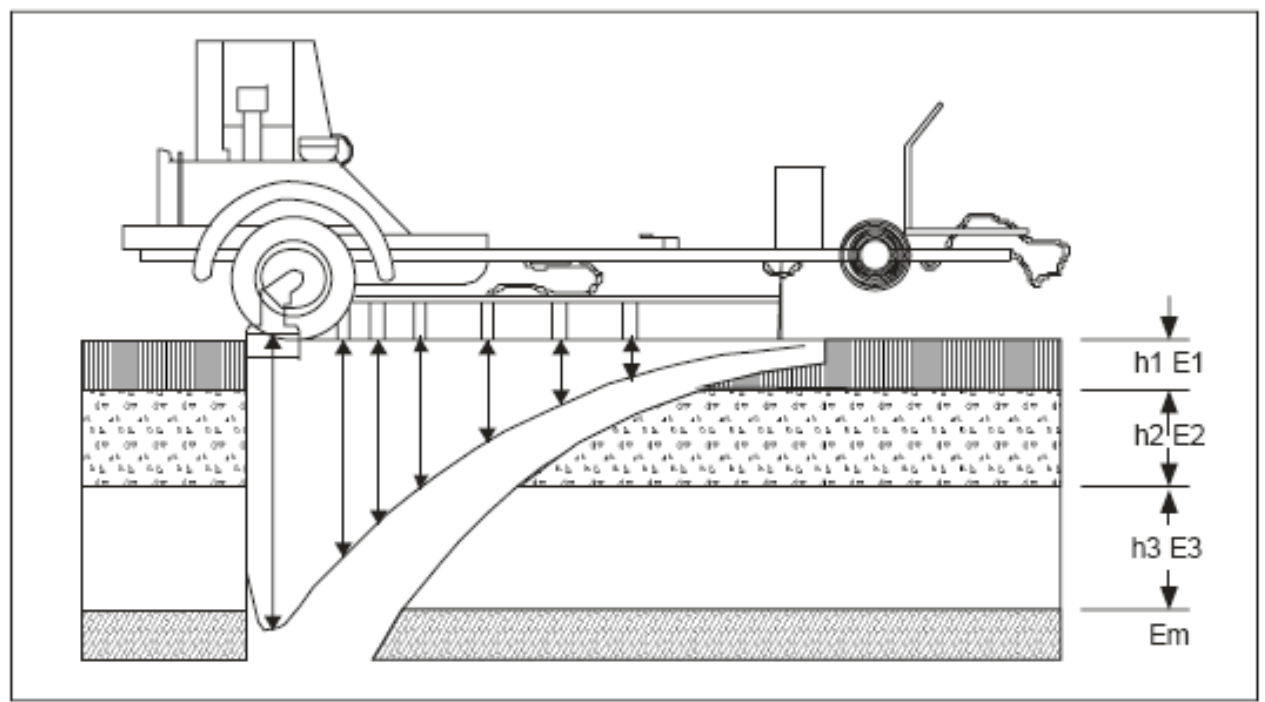

Figura 2.6 - Deflectômetro de impacto (DNIT, 2006)

O FWD mede a deflexão do pavimento, através da aplicação de carregamento gerado pelo impacto de um peso em queda livre, sobre um sistema de amortecedores de borracha, que transmitem a força aplicada a uma placa circular apoiada na superfície do pavimento, conforme apresentado na Figura 2.7.

Os deslocamentos recuperáveis, gerados na superfície do pavimento, são medidos por sensores instalados ao longo de uma barra metálica (DNER-PRO 273/96).

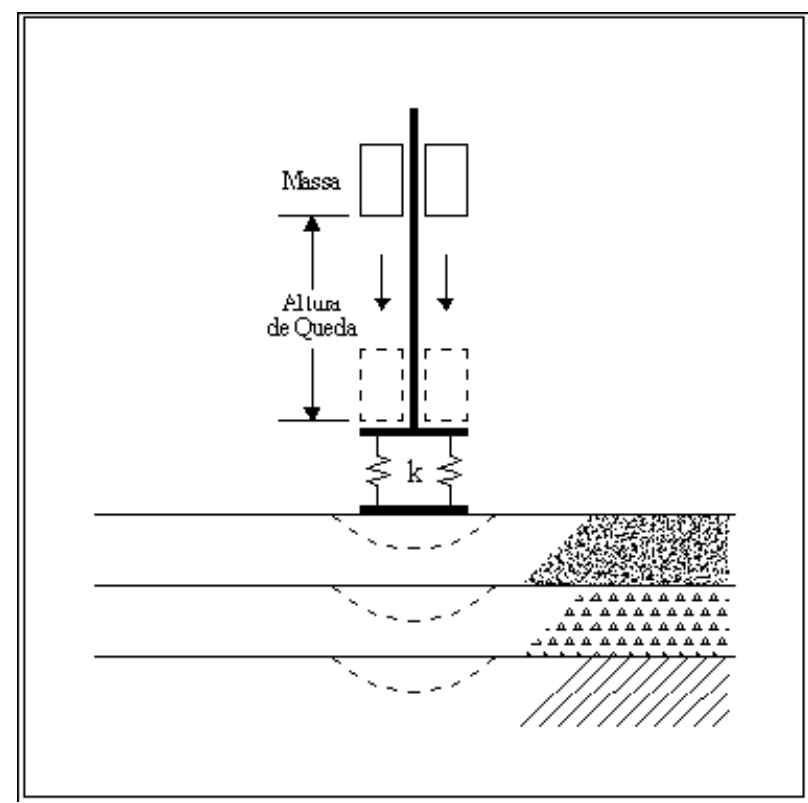

Figura 2.7 - Principio de funcionamento do FWD (HAAS et al., 1994) 
Segundo Pereira (2002) o carregamento gerado pelo FWD, na superfície pode ser variável, sendo que o de $40 \mathrm{KN}$ gera um pulso de carga de aproximadamente $0,04 \mathrm{~s}$ e é similar ao carregamento padrão do semi-eixo de $40 \mathrm{KN}$ em velocidades normais de viagem.

A força de pico imposta pelo FWD ao pavimento pode ser determinada através da equação 2.17 .

$$
F=\boldsymbol{e} \cdot \boldsymbol{m} \cdot \boldsymbol{g} \cdot h \cdot k^{-1 / 2}
$$

Em que: $\quad F$ : força de pico;

m: massa que cai;

g: aceleração da gravidade;

$h$ : altura de queda; e

$k$ : constante de mola do sistema amortecedor.

A carga é transmitida ao pavimento por meio de uma placa de $300 \mathrm{~mm}$ de diâmetro, sendo controlada por uma célula de carga. A duração do carregamento é de 25 a 30 ms que corresponde à passagem de um veículo, com velocidade de $60 \mathrm{a}$ $80 \mathrm{~km} / \mathrm{h}$.

A propagação da onda no interior da estrutura é registrada em diferentes instantes pelos sensores. As deflexões são medidas através de sete sensores: geofones, no caso do FWD da marca Dynatest e LVDTs, no caso do FWD da marca KUAB. Estes sensores estão dispostos da seguinte forma: um no centro da placa e os demais em distâncias pré-estabelecidas, ao longo de uma barra metálica (CARDOSO, 1995). 
A partir da análise das bacias de deflexão obtêm-se os módulos de resiliência dos materiais através da retroanálise, com isso, possibilitando a avaliação do comportamento mecânico da estrutura de pavimento.

\subsection{RETROANÁLISE DE MÓDULOS DE RESILIÊNCIA}

A retroanálise é o processo de determinação dos módulos de resiliência dos materiais que compõem as camadas e o subleito do pavimento em serviço através da interpretação das bacias de deflexões.

Desta forma, a retroanálise tenta resolver o problema inverso em relação ao dimensionamento de um pavimento novo, ou seja, têm-se deformações resultantes de um carregamento conhecido e deseja-se conhecer os módulos que conduziram a estas deformações elásticas, a partir de medidas de deflexões obtidas por meio de ensaios não destrutívos.

A forma de se obter os módulos de resiliência de uma estrutura existente, por processo não destrutivo, é entendida em mecânica dos pavimentos, como o procedimento analítico, para determinação dos parâmetros elásticos do pavimento e subleito nas condições "in situ", a partir da interpretação das deflexões reversíveis, medidas na superfície da estrutura do sistema analisado (FONSECA, 2002).

A norma ASTM D5858 (1996) define a retroanálise como a técnica usada para determinar o módulo elástico equivalente das camadas de um pavimento, correspondentes a uma carga aplicada e a deflexões medidas. 
Esta análise pode ser feita por várias técnicas, tais como: métodos simplificados, interativos, bancos de dados, solução fechada, quando considera apenas duas camadas e por meio de equações simultâneas. Cada método tem sua particularidade, apresentando tanto vantagens como desvantagem, dependendo dos parâmetros considerados.

Segundo Albernaz (1996), as principais vantagens e desvantagens da utilização dessa ferramenta são:

- Minimiza a necessidade de coletas de amostras nas pistas;

- Os módulos são estimados para as condições reais em campo;

- Rapidez na caracterização elástica do pavimento.

Porém, pode-se também destacar algumas falhas apresentadas pela retroanálise:

- É possível a obtenção de diferentes módulos para uma mesma bacia de deflexões, variando os valores iniciais e os limites dos módulos (multiplicidade de soluções);

- Os módulos retroanalisados não são exatamente os módulos reais dos materiais, mas representam um modelo equivalente do pavimento em serviço;

- A interferência de diversos fatores que ocorrem da etapa de levantamento de campo até processo de retroanálise.

Vários programas foram desenvolvidos para retroanálise de pavimento. A norma ASTM D-5858 cita os programas: MODULUS, ELMOD, ESSEM4, MODCOMP, DIPLOMAT E ISLBACK. 
A obtenção dos módulos de elasticidade das camadas do pavimento e do subleito, a partir de modelagens matemáticas, serve de subsídio para o projeto estrutural, de maneira que o sistema pavimento-subleito trabalhe em índices compatíveis de tensão e deformação, com relação à resistência característica de cada material constituinte do sistema.

Os deslocamentos calculados pelos programas de análise mecanística são utilizados para a previsão da deflexão na superfície de cada camada do pavimento e do subleito, auxiliando no controle dos serviços de pavimentação (BASÍLIO, 2002).

A retroanálise tem sido obtida mais comumente a partir de dois métodos: método iterativo e método simplificado

Os métodos iterativos buscam obter os módulos de todas as camadas do sistema existente, pavimento/subleito e através destes módulos, das espessuras das camadas e das cargas atuantes, calcular as tensões, deformações e deslocamentos em qualquer ponto do sistema analisado. Esse método utiliza de aplicativos computacionais que procuram o melhor ajuste das bacias de deflexões, através de técnicas de minimização do erro absoluto ou erro quadrático.

Os métodos simplificados estimam os módulos do sistema pavimento/subleito, a partir de aplicação de equações, tabelas, gráficos e outros procedimentos simplificados gerados a partir da Teoria da Elasticidade, aplicada aos meios homogêneos, isotrópicos e linearmente elásticos, transformando a estrutura real multicamadas em estruturas equivalentes mais simples (duas ou três camadas, incluindo o subleito) (FONSECA, 2002). 


\subsubsection{Método Iterativo}

Os métodos iterativos consistem numa comparação entre a bacia de deflexão teórica com a obtida em campo. Esta comparação é feita através de tentativas, até a obtenção de um determinado critério de convergência, com minimização das diferenças (NOBREGA, 2003).

Estes métodos possuem formulação matemática complexa e utilizam processos iterativos de convergência. Em geral apresentam boa acurácia, porém o tempo de processamento em microcomputador é relativamente grande.

Os métodos de cálculo (algoritmos) mais usados na determinação da resposta estruturais dos pavimentos baseiam-se na: teoria de multicamadas elásticas, método dos elementos finitos e a teoria das camadas finitas (PEREIRA, 2002).

Os módulos encontrados não representam os módulos reais, mas sim equivalentes, pois seus valores estão relacionados com a modelagem teórica utilizada para simular o comportamento do pavimento, visto que, em muitas ocasiões as deflexões medidas, incluem irregularidades relacionadas a fatores como a variação da espessura ao longo do trecho analisado, comportamento não linear das camadas, efeito da umidade e da temperatura, etc.

Os métodos iterativos de retroanálise podem ser classificados em três grupos (FRITZEN, 2005): 
Grupo 1: Métodos que calculam, durante o procedimento, os parâmetros elásticos de estruturas teóricas, cujas bacias de deflexão são comparadas com as bacias medidas no campo. Nestes métodos, os parâmetros das estruturas teóricas são calculados através de programas da análise mecanística, como ELSYM 5, FEPAVE2, ALIZE, entre outros. As comparações entre as bacias medidas e calculadas são feitas iterativamente, até que a semelhança entre as duas esteja dentro de um critério de aceitação estabelecido. Depois de realizado esse processo, o conjunto de módulos da estrutura teórica que gerou a bacia calculada mais próxima da bacia medida do campo é imediatamente associada ao pavimento real analisado. Obtido os módulos, pode-se calcular tensões, deformações e deslocamentos, em qualquer ponto da estrutura.

Grupo 2: Métodos que utilizam banco de dados de parâmetros elásticos de estruturas teóricas previamente calculados. Estes métodos são semelhantes aos anteriores, exceto pelo fato de que comparam as bacias medidas no campo, com bacias teóricas previamente determinadas e armazenadas em banco de dados, juntamente com os parâmetros elásticos das estruturas que lhes são correspondentes.

Grupo 3: Métodos que utilizam equações de regressão estatísticas. Esses métodos são mais raros que os citados anteriormente e utilizam fórmulas obtidas por regressão estatística, para o cálculo das deflexões teóricas em pontos, previamente, escolhidos da bacia de deformação. Estas deflexões são calculadas em função do carregamento aplicado, das espessuras e dos parâmetros elásticos das camadas. Os dados utilizados na regressão podem ser obtidos por qualquer programa de análise mecanística. Como nos métodos anteriores, a solução é atingida quando a 
diferença entre as bacias teóricas e medidas atinge, durante o processo de convergência, um valor previamente estabelecido.

\subsubsection{Método Simplificado}

De maneira geral, os métodos simplificados consistem na conversão do pavimento real em estruturas equivalentes mais simples, de duas ou três camadas, incluindo a camada de subleito. Como tratam o problema de forma simplificada, são mais rápidos do que os métodos iterativos, porém perdem em acurácia, mas ganham em tempo de processamento, podendo ser muito úteis em análises

preliminares, anteprojetos e gerência de pavimentos em nível de rede (NÓBREGA, 2003; PEREIRA, 2002).

Dentre os métodos simplificados, os mais conhecidos a nível nacional são os seguintes:

- Métodos da AASHTO (1993);

- Método de FABRícIO et al. (1988 e 1994)

- Método de NOURELDIN (1993) e ALBERNAZ (1997)

\subsubsection{Método da AASHTO}

O Guia de Projetos de Estruturas de Pavimentos da AASHTO (1993) apresenta um procedimento simplificado de retroanálise, em que o pavimento real é 
transformado em uma estrutura de duas camadas, uma sendo o conjunto das camadas do pavimento (revestimento+base+sub-base), e outra o subleito.

O módulo do conjunto das camadas do pavimento é chamado de módulo efetivo do pavimento $(E p)$. O módulo do subleito é designado por $(M R)$ (MACÊDO, 2003). A aplicação desse método exige que sejam fornecidos os dados: da bacia de deflexão (medidas das deflexões e pontos de leitura das medidas em relação ao centro de carregamento), da carga solicitante (pressão e raio da área de contato) e da espessura total do pavimento acima do subleito.

O módulo de resiliência do subleito $(M R)$ é obtido através da equação 2.18.

$$
M R=\frac{0,24 * P}{d_{i} * r_{i}}
$$

Em que: $\quad$ MR: módulo do subleito;

P: carga aplicada sobre uma área circular;

$d_{i}$ : deflexão medida no ponto de distância ri; e

$r_{i}$ : distância radial do ponto de aplicação da carga.

O produto $\left(d_{i}^{*} r_{i}\right)$, deve ser determinado para um ponto da bacia deflectométrica bem afastado do ponto de aplicação da carga, onde só há a influência do subleito. A AASHTO recomenda que o valor de $r_{i}$ seja cerca de $70 \%$ do valor do raio do bulbo de tensões , $a_{c}$, na interface pavimento/subleito, cujo valor é dado pela equação 2.19..

O raio do bulbo de tensões é calculado com a equação 2.19 . 


$$
a_{c}=\sqrt{\left[a^{2}+\left(D * \sqrt[3]{\frac{E p}{M r}}\right)^{2}\right]}
$$

Em que: $\quad a_{c}$ : raio do bulbo de tensões;

a: raio da área circular de distribuição da carga;

D: espessura total das camadas acima do subleito (pavimento);e Ep: módulo efetivo do pavimento;

O módulo efetivo do pavimento $(E p)$ é determinado, iterativamente, pela equação 2.20, até que o valor estimado por esta expressão iguale-se ao valor da deflexão superficial máxima medida $\left(d_{0}\right)$.

$$
d_{0}=1,5^{*} p * a\left\{\frac{1}{M r * \sqrt{1+\left(\frac{D}{a} * \sqrt[3]{E p / M r}\right)^{2}}}+\frac{\left[1-\frac{1}{\sqrt{1+\left(/ a-a^{2}\right.}}\right]}{E p}\right\}
$$

Em que: $\quad p=$ pressão de contato; e $d_{0}=$ deflexões superficiais máximas medidas.

No guia da AASHTO (1993) é apresentada uma série de critérios de ajuste para o valor modular do subleito, que é influenciado por variações sazonais e pela presença de camadas rígidas no subleito (até $4.5 \mathrm{~m}$ de profundidade).

Este método recomenda que as deflexões superficiais máximas medidas $\left(d_{0}\right)$, obtidas sob diversos níveis de temperatura, sejam ajustadas para uma temperatura padrão de referência de $20^{\circ} \mathrm{C}$, com o objetivo de normalizar os valores dos módulos efetivos do pavimento (Ep) (COUTINHO, 2000). 


\subsubsection{Método de Fabrício et al. (1988 e 1994)}

Uma série de modelos poderia ser utilizada para uma retroanálise simplificada, sendo que no estudo desenvolvido por Fabrício et al. (1988) foi escolhido o Modelo de Hogg, por ser um dos mais simples. Consiste em uma placa elástica, de espessura $t$ e largura e comprimentos infinitos, assente num subleito elástico, de espessura h e, da mesma forma que a placa, de largura e comprimento infinitos. A camada de subleito está assente em um horizonte de material perfeitamente rígido, conforme ilustra a Figura 2.8.

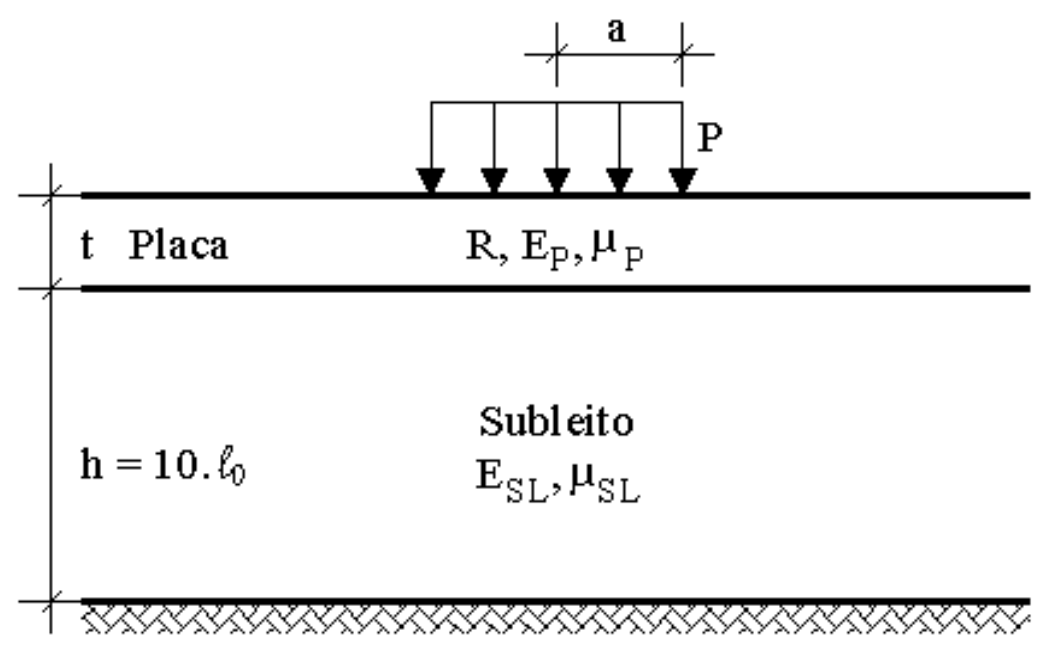

\section{Camada Rígida}

Figura 2.8 - Modelo elástico de Hogg (NÓBREGA, 2003)

Os principais parâmetros do método são: a rigidez da placa $(R)$ e 0 comprimento característico $\left(I_{0}\right)$, calculados pelas equações 2.21 e 2.22 , respectivamente.

$$
R=\frac{E p^{*} t^{3}}{12^{*}\left(-\mu_{p}{ }^{2}\right.}
$$




$$
I_{0}=\sqrt[3]{\frac{R^{*}\left(+\mu_{s l}\right)^{*} \beta-4^{*} \mu_{s l}}{E_{s l}{ }^{*} 2^{*}\left(-\mu_{s l}\right.}}
$$

Em que: $\quad R$ : rigidez da placa;

Io: comprimento da placa;

$\mu_{s}$ : coeficiente de Poisson do subleito;

Ep: módulo de deformação da placa;

$E_{s}$ : módulo de deformações do subleito; e

$t$ : espessura da placa.

A determinação dos parâmetros de interesse é feita a partir de gráfico de influência de Hogg, desenvolvido de acordo com a equação 2.23 (MEDINA e MOTTA, 2005).

$$
D_{0}=\frac{P^{*} N^{*} I_{o}}{2000^{*} \mu_{s l}}
$$

Em que: $\quad D_{o}$ : deflexão máxima $(\mathrm{cm})$;

$P$ : pressão de contato $\left(\mathrm{kgf} / \mathrm{cm}^{2}\right)$;

N: número de blocos abrangidos pela área de carregamento no gráfico;

Io: comprimento característico (na escala do gráfico); e

$\mu_{s l}$ : módulo de elasticidade do subleito $\left(\mathrm{kgf} / \mathrm{cm}^{2}\right)$.

Em Fabrício et al. (1994) esta metodologia foi aprimorada, permitindo também a determinação de parâmetros elásticos, através de levantamentos deflectométricos realizados com equipamentos do tipo FWD.

Na versão de 1994, o método apresenta dois gráficos de bacias de deflexão teórica: um foi desenvolvido para o carregamento (simplificado), característicos dos 
levantamentos com a viga Benkelman (carregamento duplo) e outro para levantamento com o FWD (carregamento simples). Tomando como base estes gráficos, pode-se estimar a espessura do pavimento equivalente, o módulo de elasticidade do subleito e a profundidade de camada rígida no subleito (COUTINHO, 2000).

\subsubsection{Método Noureldin}

Este procedimento é baseado na teoria da elasticidade aplicada a meios semi-infinitos, homogêneos, isotrópicos e linearmente elásticos. Esta teoria era, inicialmente, usada no cálculo de módulos elásticos de solos de fundação, através do ensaio de placa, sendo ,posteriormente, adaptada para a análise de pavimentos flexíveis (NÓBREGA, 2003).

Segundo Marques (2002), a premissa básica desse método é que existe um ponto na superfície do pavimento, situado a certa distância do ponto de aplicação da carga, cuja deflexão é devida, exclusivamente, ao subleito e é numericamente igual à deflexão do topo do subleito na vertical pelo centro de aplicação de carga, conforme Figura 2.9. 


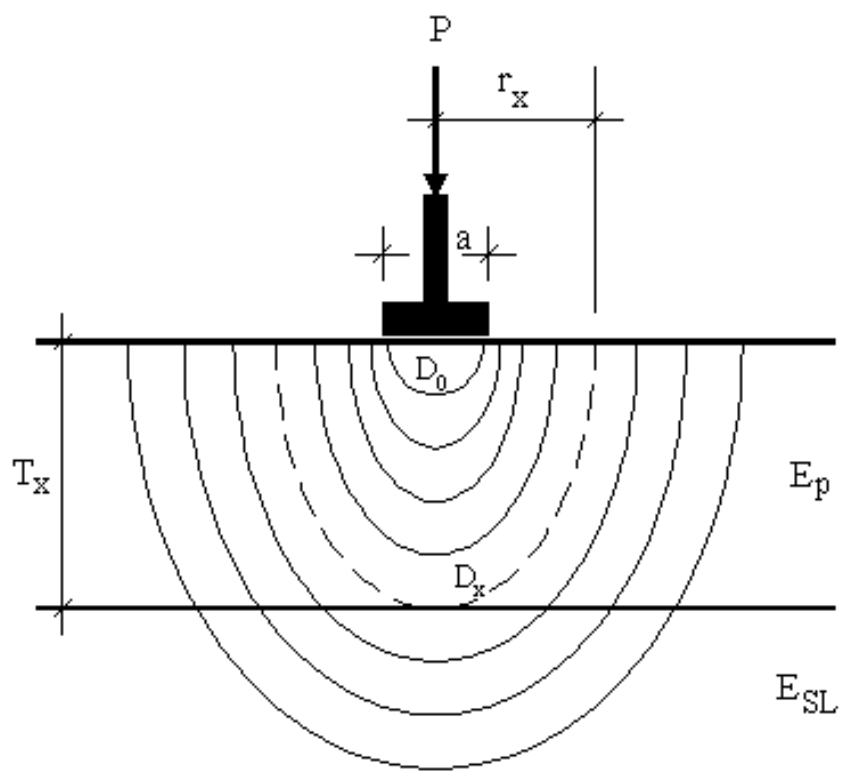

Figura 2.9 - Linhas de iguais deflexões verticais no sistema pavimento-subleito (NÓBREGA, 2003)

Segundo Macêdo (2003), este procedimento permite que a deflexão máxima seja decomposta em duas componentes, a deflexão do subleito e a do pavimento. Esta abordagem é aplicada em dois casos:

- No primeiro caso a espessura do pavimento é conhecida;

- No segundo caso a espessura do pavimento não é conhecida ou não confiável.

A deflexão superficial no centro de carregamento depende das características de toda a estrutura do pavimento, ao passo que, a deflexão no ponto situado a uma distância suficientemente grande do ponto de aplicação de carga $\left(r_{x}\right)$, dependerá somente das características do subleito (módulo resiliente).

Os valores de módulo do subleito $\left(E_{S G}\right)$, do módulo efetivo do pavimento $\left(E_{p}\right)$, da espessura efetiva $\left(T_{X}\right)$ e do número estrutural $\left(S N_{E F F}\right)$ são calculados através das equações 2.24, 2.25, 2.26 e 2.27, respectivamente (ALBERNAZ, 1997). 


$$
\begin{gathered}
E_{S G}=\frac{P \cdot\left(-\mu^{2}\right.}{\pi \cdot r_{x} \cdot D_{x}} \\
E_{p}=\frac{\frac{P}{\pi} \cdot\left(\frac{1,5}{a}-\left(\frac{1-\mu^{2}}{r_{x}}\right)\right)}{D_{0}-D_{x}} \\
T_{x}=\sqrt{\frac{2,25 \cdot r_{x}^{2}}{\left(-\mu^{2}\right.}-a^{2}} \cdot \sqrt{\frac{D_{o}-D_{x}}{D_{x} \cdot\left(\frac{1,5 \cdot r_{x}}{a \cdot\left(-\mu^{2}-1\right)}\right)}} \\
S N_{E F E}=\frac{1}{\sqrt[3]{M_{A L}}} \cdot \sqrt{\frac{2,25 \cdot r_{x}^{2}}{\left(-\mu^{2}\right.}-a^{2} \cdot \sqrt[3]{\frac{P \cdot\left(-\mu^{2}\right.}{\pi \cdot r_{x} \cdot D_{x}}}}
\end{gathered}
$$

Em que: $\quad P$ : carga aplicada $(\mathrm{kgf})$;

$\mu$ : coeficiente de poisson;

a: raio da placa $(\mathrm{cm})$;

$r_{x}$ : distância radial a partir do ponto de aplicação da carga $(\mathrm{cm})$;

$D_{o}$ : deflexão máxima $(\mathrm{cm})$;

$D_{x}$ : deflexão na distância radial $(\mathrm{cm}) ; e$

$M_{A L}$ : módulo de elasticidade do alumínio, que é o material de referência adotado pela AASHTO (1993) para o cálculo do número estrutural $\left(M_{A L}=774.070 \mathrm{kgf} / \mathrm{cm}^{2}\right)$.

O desenvolvimento de ferramentas computacionais, nas últimas décadas, propiciou que as análises de sistemas estruturais em camadas passassem a ser baseadas na teoria da elasticidade. Desta forma a retroanálise passou a ser largamente utilizada em avaliações estruturais e no dimensionamento de reforço. 


\subsection{DISTRIBUIÇÃO DE TENSÕES E DESLOCAMENTOS EM PAVIMENTOS}

Uma das primeiras soluções para estimar a distribuição das tensões, das deformações e dos deslocamentos em pavimentos flexíveis foi proposta por Boussinesq (1885). Considerou-se um semi-espaço homogêneo, isotrópico e elástico linear, permitindo calcular a tensão em qualquer ponto no interior da massa e o deslocamento na superfície provocado por uma carga. A tensão vertical a uma profundidade qualquer é dada pela equação 2.28 e a constante $(K)$ pela equação 2.29 .

$$
\begin{gathered}
\sigma_{z}=K \cdot \frac{P}{Z^{2}} \\
K=\frac{3}{2 \pi} \cdot \frac{1}{\left[1+\left(\frac{r}{Z}\right)^{2}\right]^{\frac{5}{2}}}
\end{gathered}
$$

Em que: $\quad \sigma_{z}$ : tensão vertical;

K: constante adimensional;

$P$ : carga pontual aplicada na superfície;

Z: profundidade; e

r: distância radial.

Burmister (1943) desenvolveu soluções para um sistema constituído por duas camadas, em 1945 estendeu para um sistema formado por três camadas. $\mathrm{Na}$ solução de problemas de sistema de camadas elásticas, consideraram-se algumas suposições básicas. Cada camada é homogênea, isotrópica e elástica linear com 
módulo elástico (E) e coeficiente de Poisson (v), as camadas são admitidas infinitas na direção lateral e finita em profundidade.

O subleito é considerado infinito em extensão horizontal e vertical. As camadas são perfeitamente aderentes entre si, a superfície da camada superior é livre de tensão normal e cisalhante fora da área circular uniformemente carregada. A Figura 2.10 ilustra o sistema de camadas múltiplas com carregamento circular.

O sistema de duas camadas pode ser aplicado, quando o revestimento é colocado diretamente sobre o subleito. Soluções para este problema foram obtidas por Burmister $(1943,1945,1958)$, cujos valores de tensão e deslocamento são dependentes da relação de módulos das camadas $\left(E_{1} / E_{2}\right)$, onde $E_{1}$ e $E_{2}$ são os módulos de elasticidade do revestimento e subleito, respectivamente. Para a relação $E_{1} / E_{2}=1$ obtém-se a solução de Boussinesq para o semiespaço homogêneo.
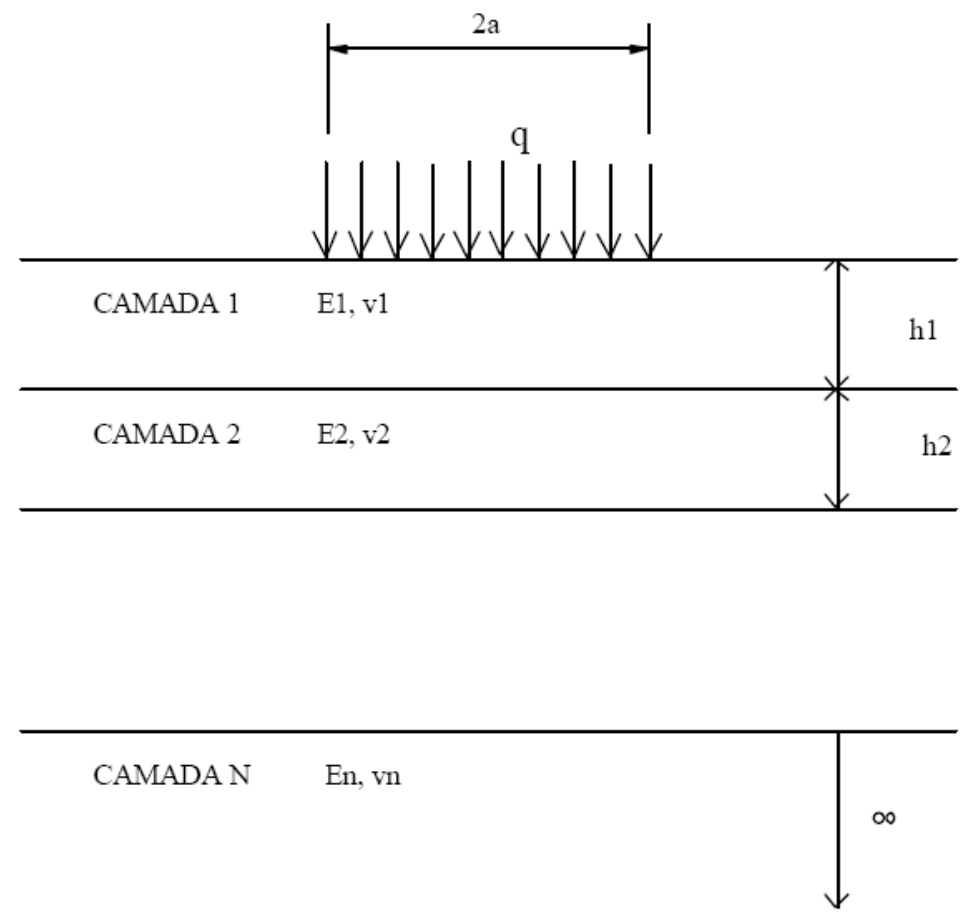

Figura 2.10 - Sistema de multicamadas linearmente elásticas 
O deslocamento vertical total máximo na superfície (recalque), em termos do fator de deflexão $F_{2}$ para $v=0.5$ (BURMISTER, 1943), pode ser calculado pelas equações 2.30 e 2.31, nos casos de placa flexível e placa rígida, respectivamente.

$$
\begin{aligned}
& \Delta=1,5 \cdot \frac{q a}{E_{2}} \cdot F_{2} \\
& \Delta=1,18 \cdot \frac{q a}{E_{2}} \cdot F_{2}
\end{aligned}
$$

Em que: $\quad$ q: carregamento uniformemente distribuído na área circular;

a: raio da placa;

$E_{2}$ : módulo de elasticidade da camada inferior;

$F_{2}$ : fator adimensional dependente da relação entre os módulos do revestimento e subleito; e

Burmister (1945) deduziu as expressões matemáticas da distribuição de tensões em sistemas elásticos constituídos por três camadas. Estas distribuições incluem a de tensão vertical nas interfaces 1 e 2 e tensões radiais em todas as camadas do sistema, conforme Figura 2.11.

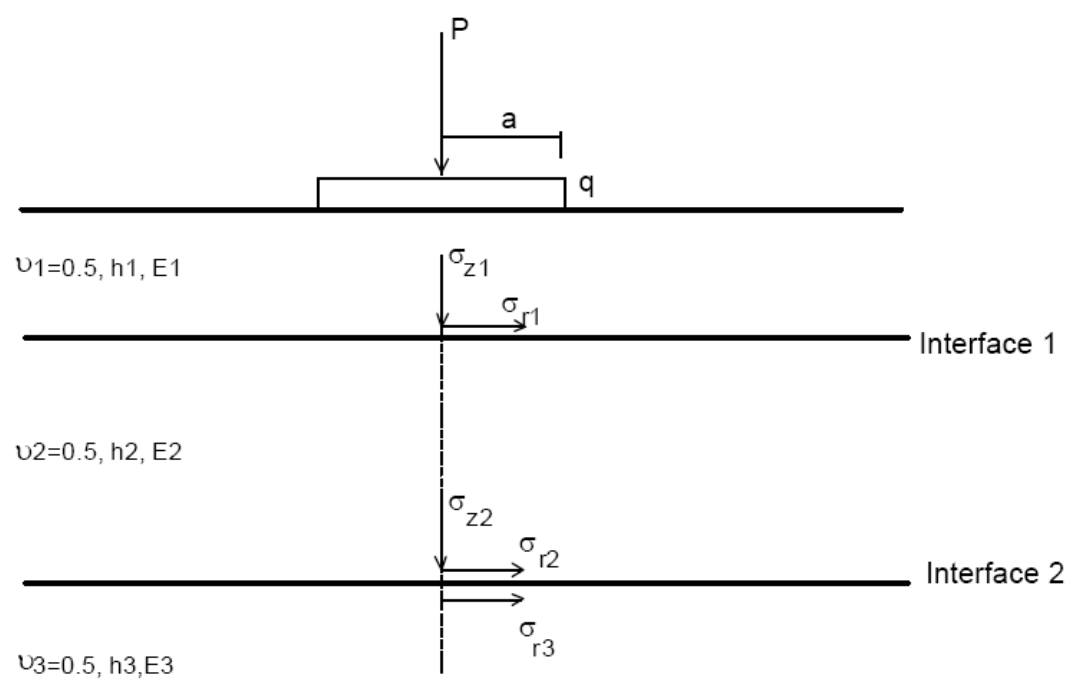

Figura 2.11 - Distribuição de tensões (BURMISTER, 1945) 


\subsection{INSTRUMENTAÇÃO EM PAVIMENTOS FLEXÍVEIS}

Atualmente, encontram-se no mercado especializado diversos instrumentos para acompanhamentos das respostas dos materiais constituintes de estrutura de pavimentos frente a ação do tráfego de veículos. As instrumentações vêem auxiliar na interpretação do desempenho de estruturas de pavimentos, permitindo a determinação de parâmetros, tais como: tensão e deformação horizontal, tensão e deformação vertical, afundamentos na superfície do pavimento, sucção e temperatura.

Os locais convencionais para instalar esses medidores são nas interfaces das camadas capa/base e base/subleito. Para a escolha dos equipamentos a serem utilizados, deve-se levar em consideração o seu desempenho, com base em determinadas características do instrumento aceitas universalmente. Estas características são utilizadas para caracterizar tais instrumentos, de um modo geral, e possibilitar a comparação entre suas performances. As características mais comuns dos equipamentos são: (WERNECK, 1996):

- Faixa: ou range (do inglês), representa todos os níveis de amplitudes do sinal de entrada, nos quais se supõe que o instrumento opere;

- Resolução: é o menor incremento do sinal de entrada que é sensível ou pode ser medido pelo instrumento;

- Sensibilidade: é a função de transferência do equipamento, isto é, a relação entre o estímulo de entrada e o sinal de saída por ele produzido;

- Linearidade: quando se mede com o instrumento um valor padrão conhecido que varia de maneira conhecida, se o instrumento for perfeito ou ocorrer um 
erro desprezível, a "curva" obtida é uma reta; no entanto, como sempre ocorre um erro, a curva obtida "foge" em alguns pontos da "curva" ideal (reta). A distância máxima observada entre uma medida feita pelo instrumento e o valor padrão dividido pela faixa e multiplicada por 100 fornece a linearidade (\%);

- Histerese: se o estímulo de entrada, que existe em um instrumento, crescer até um determinado ponto o instrumento irá acusar certo valor, mas se o estímulo começar de um ponto mais elevado e decrescer até o mesmo valor anterior, o equipamento poderá acusar um valor diferente daquele fornecido anteriormente. Pode ocorrer histerese por diversas razões, tais como: atrito mecânico dos ponteiros de um instrumento de medida, resposta de frequência, inércia molecular, etc;

- Exatidão ou erro: é a diferença absoluta entre o valor real e o valor medido pelo instrumento. Pode ser dada em porcentagem ou em partes por milhão (ppm) quando este valor for muito pequeno;

- Precisão ou repetibilidade: é a capacidade de se obter um mesmo valor em diversas medidas; pode ser dada pelo desvio padrão das medidas efetuadas de um mesmo valor ou pelo maior erro em qualquer medida;

- Estabilidade: é a capacidade de um instrumento voltar a situação de regime permanente (steady state) depois de receber um sinal transitório, como um degrau ou um pulso, por exemplo. Depende principalmente do ganho de representação e da frequência da ressonância do sistema.

Outros fatores que se devem levar em conta na escolha dos equipamentos de leitura, principalmente, em ensaio de grandes dimensões e trechos experimentais 
são a durabilidade, resistência mecânica durante a compactação das camadas, resistência à fadiga e o ponto de instalação.

Os pontos de instalação devem localizar-se próximos aos pontos críticos de tensões, sendo eles: topo do subleito e interface, revestimento/base. Nos pavimentos flexíveis, as tensões que chegam ao topo do subleito são aliviadas pelas camadas de revestimento e de base. Por outro lado, as tensões críticas de tração se localizam no limite inferior da camada de revestimento, o que no caso dos pavimentos asfálticos são os causadores das trincas por fadiga.

Silva (2009) descreve a instrumentação, realizada em 1998, da Pista Circular Experimental do IPR/DNER, com seis extensômetros e duas células de carga, para a pesquisa de whitetopping - WT. Relata, ainda, que em outubro de 2000 foram instalados onze termopares nessa pista, para monitorar a temperatura das placas de whitetopping .

Gonçalves (2002) relata a instrumentação de seis Pistas Experimentais na Universidade Federal do Rio Grande do Sul, para estudar o desempenho de misturas asfálticas convencionais e modificadas com polímeros, nas quais foram instalados medidores de tensões e deformações em toda a estrutura dos pavimentos pesquisados. As cargas de tráfego eram aplicadas pelo Simulador de Tráfego UFRGS-DAER, onde se variaram os níveis, as formas de carregamento e a pressão de inflação dos pneus. 


\subsection{ANÁLISE DE TENSÕES PELO MÉTODO DOS ELEMENTOS FINITOS}

O Método dos Elementos Finitos (MEF) é bastante difundido na Engenharia Civil como ferramenta de análise de diversos problemas, dentre os quais o estudo dos campos de deslocamentos e tensões em pavimentos flexíveis, formados por múltiplas camadas.

O procedimento básico do método consiste em dividir o meio contínuo, através de elementos finitos, formular as propriedades de cada elemento, reunir as equações dos elementos para se obter o modelo discretizado da estrutura, aplicar os carregamentos conhecidos, especificando como o modelo é vinculado, resolver o sistema de equações algébricas resultantes, para então calcular todos os deslocamentos desconhecidos, bem como os valores de tensão e deformação desejados.

Nas diversas aplicações do MEF, em estudos envolvendo o comportamento de pavimentos, em alguns casos se considera bidimensional axissimétrico, limitando-se a modelar o caso de uma roda única.

O comportamento real da estrutura do pavimento é, no entanto, de natureza tridimensional, submetido a carregamentos múltiplos e com materiais de comportamento tensão deformação não linear. A formulação tridimensional dos elementos finitos pode, então, ser utilizada para auxiliar na melhor compreensão da resposta de pavimentos reais. 


\subsection{UTILIZAÇÃO DE GEOSSINTÉTICO EM PAVIMENTO FLEXÍVEL}

A utilização de geossintéticos no reforço estrutural de pavimentos flexíveis restringe-se, basicamente, ao reforço da camada de base de pavimentos em construção e ao reforço da camada asfáltica, na restauração de pavimentos degradados. Sendo que para o reforço de base, o geossintético funcione como elemento separador e confinante, e para o reforço da camada de revestimento como elemento anti-reflexão de trincas e juntas.

\subsubsection{Principais geossintéticos utilizados em pavimentação}

\section{a) Geotêxtil}

Produto têxtil bidimensional permeável, composto por fibras cortadas, filamentos contínuos, monofilamentos, laminetes ou fios, formando estruturas tecidas, não-tecidas ou tricotadas, cujas propriedades mecânicas e hidráulicas permitem que desempenhe várias funções numa obra geotécnica (VERTEMATTI, 2004).

Para a utilização em restauração de pavimentos flexíveis, devem apresentar uma resistência à tração maior que 7 kN/m (NBR 12824), capacidade de retenção de ligante betuminoso maior que $0,9 \mathrm{l} / \mathrm{m}^{2}$ e ponto de amolecimento superior a $180^{\circ} \mathrm{C}$.

Para a utilização em base tem sido utilizado como separador ou elemento filtrante, tendo como principal função a de prevenir a interpenetração do material de 
base na camada inferior. Holtz et al. (1995) recomendam o uso de geotêxtil em subleitos de baixa capacidade de suporte, expressa por CBR<3\% (ou módulo de resiliência $<30 \mathrm{MPa}$ ).

\section{b) Geogrelha}

Produto com estrutura em forma de grelha, com função predominante de reforço, cuja abertura permite a interação do meio em que está confinado, e constituído por elementos resistentes à tração. É considerado unidirecional, quando apresenta elevada resistência à tração, apenas em uma direção, e bidirecional, quando apresenta elevada resistência a tração, nas duas direções principais (ortogonais). Em função do processo de fabricação, as geogrelhas podem ser extrudadas, soldadas ou tecidas (VERTEMATTI, 2004).

Para a utilização em restauração de pavimentos flexíveis, devem apresentar uma resistência à tração maior que $50 \mathrm{kN} / \mathrm{m}$, para deformação menor que $12 \%$ (NBR 12824), resistência à fadiga maior que 90\% de resistência retida após 100000 ciclos de carregamento, a relação entre abertura da malha e diâmetro máximo do agregado deve ficar no intervalo de 2 a 10 e o ponto de amolecimento superior a $180^{\circ} \mathrm{C}$.

\subsubsection{Geossintéticos em reforço de base de pavimentos flexíveis}

O reforço da camada de base (camada granular) com a utilização de gessintético faz com que ocorra um aumento na capacidade estrutural da camada, 
devido a quatro mecanismos, sendo eles: intertravamentos, tensão de tração, confinamento e separação

O geossintético como reforço de base de pavimento ocorre, principalmente, nos casos em que o subleito apresenta uma baixa capacidade de suporte, onde se tornam inviáveis a remoção e substituição do material.

O emprego de geossintéticos tem como principal objetivo, diminuir e distribuir de forma homogênea as tensões que chegam ao subleito, controlando ou reduzindo a um mínimo as manifestações de defeitos, como afundamento de trilha de roda e trincamento por fadiga do revestimento asfáltico. Possibilitam ainda, a redução das espessuras das camadas granulares ou aumento na vida útil do pavimento.

Um indicador que possibilita quantificar a melhora do desempenho de um pavimento em que se utilizou de um geossintético é a taxa de benefício de tráfego, TBR (traffic benefit ratio), dado pela equação 2.32 .

$$
T B R=\frac{N_{g e o}}{N}
$$

Em que: $\quad N_{\text {geo: }}$ número de repetições do eixo padrão de $82 \mathrm{kN}$, que produz um determinado afundamento em trilha de roda $\left(T_{R}\right)$ no pavimento com geossintético; e

$N$ : número de repetições do eixo padrão de $82 \mathrm{kN}$, que produz um determinado afundamento em trilha de roda $\left(T_{R}\right)$ no pavimento sem geossintético.

Os indicadores de desempenho de pavimentos reforçados com geossintéticos, em sua grande maioria, são obtidos por meio de comparação de 
estruturas com e sem a utilização de geossintéticos. Essa comparação se dá por meio de parâmetros que são obtidos de ensaio de laboratório ou campo.

Nos itens subsequentes serão apresentados a descrição dos ensaios de laboratório e campo utilizados para obtenção de parâmetros para análise dos benefícios da utilização do geossintéticos em reforço de base de pavimento. Apresentam-se dimensões dos equipamentos, forma de carregamento, frequencia da aplicação de carga e principais instrumentos de leituras utilizadas.

\subsubsection{Equipamentos de ensaios em laboratório}

Vários autores vêm desenvolvendo equipamentos em dimensões de laboratório para análise dos benefícios, provenientes da utilização de um geossintético em estruturas de pavimento.

Nota-se que os pesquisadores buscaram desenvolver equipamentos com dimensões próximas às de campo, a fim de minimizar o efeito escala (campo/laboratório), mas buscando, ao mesmo tempo a minimização dos custos, tempo de resposta e montagens dos ensaios. A seguir são apresentados em ordem cronológicas alguns dos equipamentos desenvolvidos para esses estudos.

Collin et al. (1996) utilizaram um modelo físico nas dimensões de 1,2m de profundidade, por 2,4m de largura, por 14,6m de comprimento, que foi dividida em quatro seções de $3,4 \mathrm{~m}$ de comprimento, sendo que na seção 1 utilizaram uma geogrelha B na interface do subleito (silte argiloso), na seção 2 utilizaram uma 
geogrelha A colocada também na interface, a seção 3 foi utilizado como controle e a seção 4 utilizaram duas camada de geogrelha $A$, sendo uma na interface e outra a $100 \mathrm{~mm}$ acima da primeira. Ambas as geogrelhas são de polipropileno, sendo que a geogrelha B apresenta maiores módulos secantes a 5\%. Em todas as seções a espessura da base variou de 150 a 460mm, o subleito varia de 200 a $450 \mathrm{~mm}$ e sob o subleito foi colocada uma camada de $450 \mathrm{~mm}$ de areia e agregado. Utilizaram em todas as seções uma capa de $50 \mathrm{~mm}$ de espessura de concreto asfáltico. A média do valor de CBR do subleito foi de 1,9\%. A carga foi aplicada por um pneu com 550kPa de pressão, 230mm de largura por 1,05m de diâmetro. A Figura 2.12 ilustra o corte transversal do equipamento descrito.

(a)
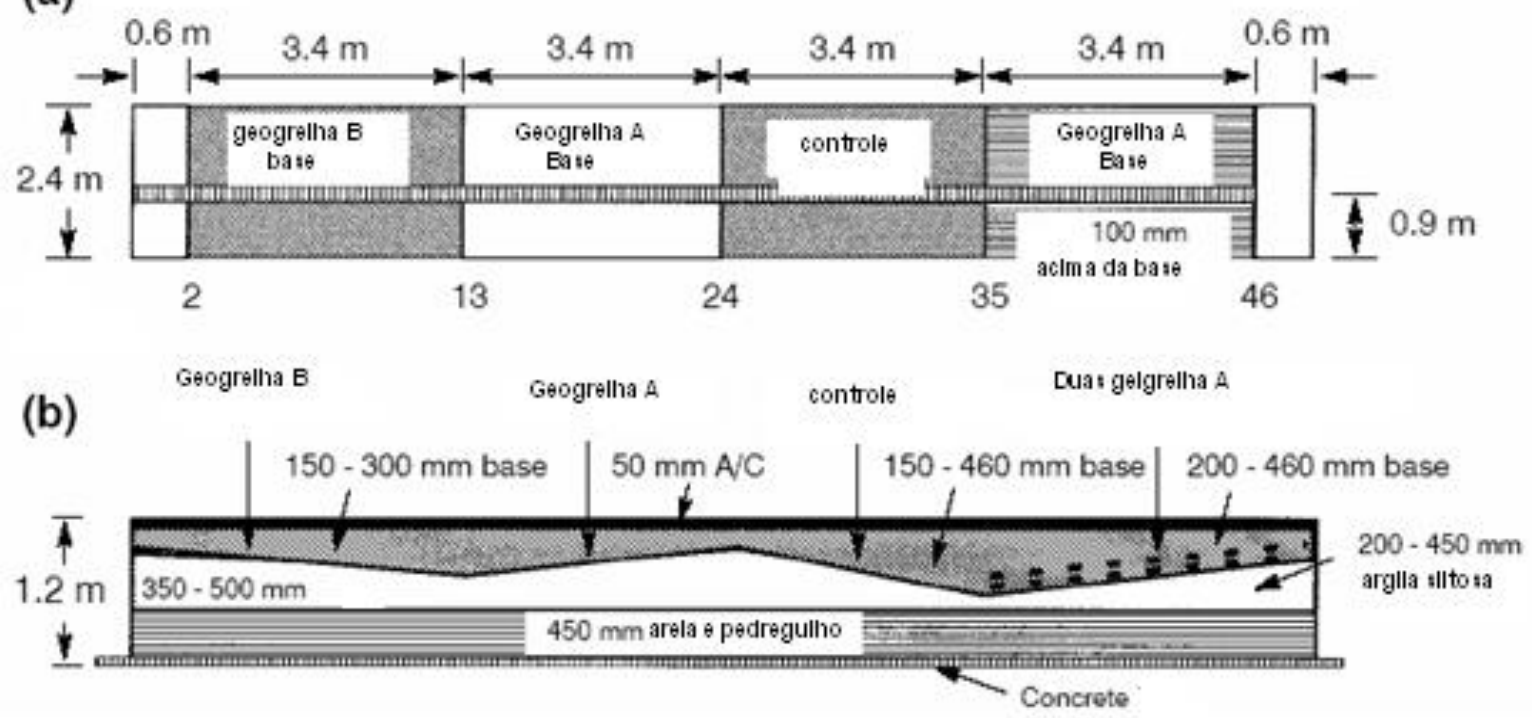

Figura 2.12 - Equipamento da Universidade do Alaska: a) vista em planta; b) vista em
corte (COLLIN et al, 1996)

Kinney, et al (1998) construíram um equipamento com uma largura de 1,2m de profundidade por $2,4 \mathrm{~m}$ de largura por $19,5 \mathrm{~m}$ de comprimento, sendo divido em três seções de $6,1 \mathrm{~m}$. Na base do equipamento foram colocados suportes de madeiras e sobre esses suportes foram dispostas chapas metálicas, seguida de uma 
camada de pedregulho e sobre ele um geotêxtil não tecido. O subleito foi constituído de uma mistura de areia siltosa e pedregulho (após saturação apresentou um CBR de $1 \%$ ). A base foi de pedra britada com espessura variando entre 203 a $365 \mathrm{~mm}$ e capa de concreto asfáltico com espessura de $61 \mathrm{~mm}$. O geotêxtil foi colocado na interface subleito/base, conforme apresentado na Figura 2.13. A velocidade do simulador de tráfego foi de $1,2 \mathrm{~m} / \mathrm{s}$, a carga de $91 \mathrm{kN}$ na ida e $18,2 \mathrm{kN}$ na volta, sendo um dos pneus com pressão de $551 \mathrm{kPa}$ e o outro com $276 \mathrm{kPa}$.

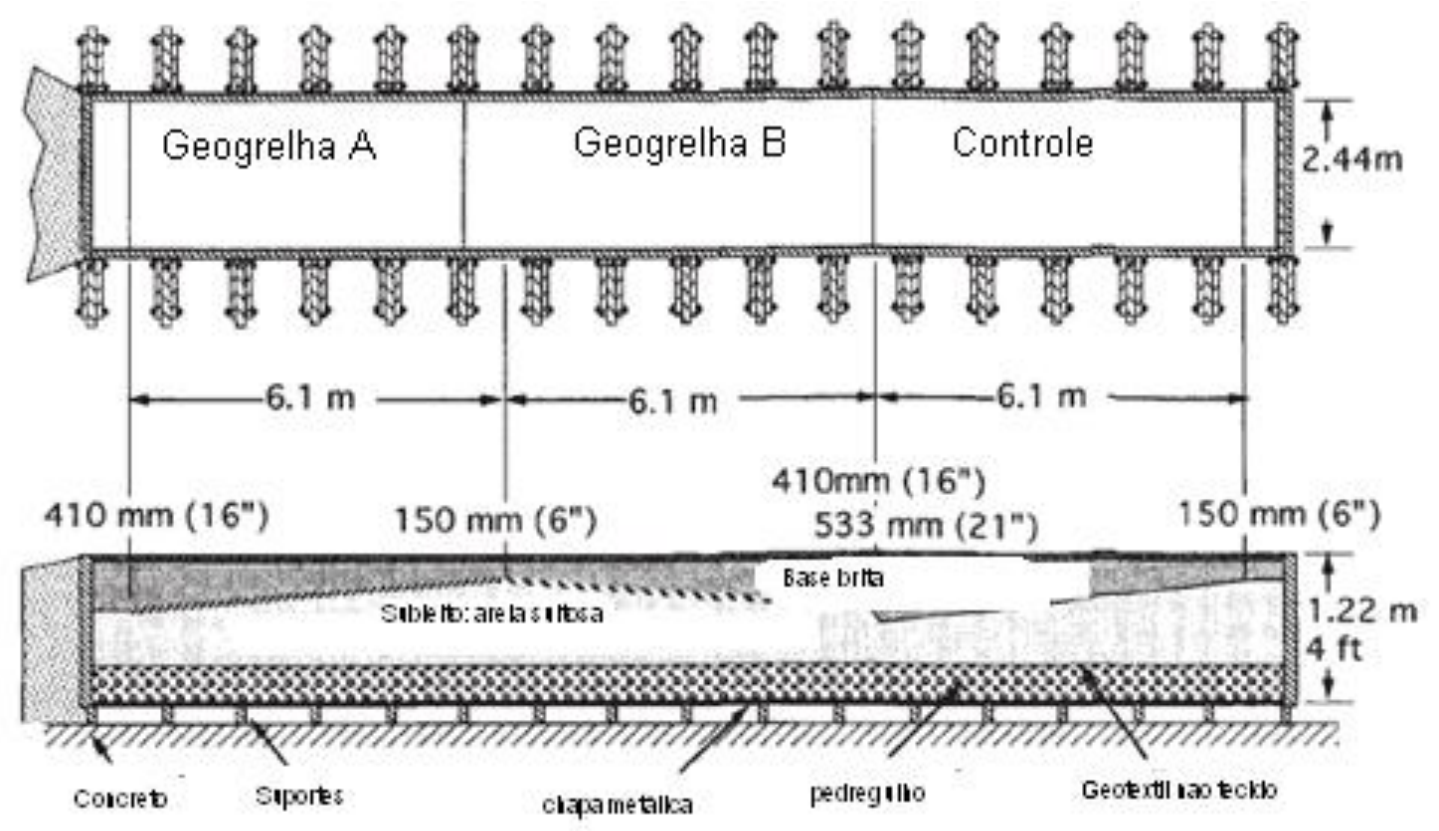

$2 \mathrm{~V}: 1 \mathrm{H}$

Figura 2.13 - Vista em planta e corte do teste (KINNEY et al, 1998)

Perkins et al. (1999) realizaram seus estudos baseados em resultados de ensaios realizados em um equipamento que consiste de uma caixa quadrada em ferro de $2 \mathrm{~m}$ de largura e 1,5m de profundidade. Utilizaram um atuador pneumático, para aplicação do carregamento cíclico sobre uma placa circular de aço de $25 \mathrm{~mm}$ de espessura e $305 \mathrm{~mm}$ de diâmetro. Uma borracha de $4 \mathrm{~mm}$ de espessura foi usada entre a placa e a superfície de concreto asfáltico. 
A frequência de carregamento foi de $0,67 \mathrm{hz}$ e a carga máxima aplicada foi de $40 \mathrm{kN}$. A seção consiste de uma superfície em concreto asfáltico com $6 \%$ de AC, uma camada de base de agregado e um subleito de argila com CBR de 1,5\% ou uma areia siltosa de CBR de 15\%. Como reforço duas geogrelhas de polietileno, biaxial de polietileno de alta densidade e um geotêxtil tecido. Utilizaram camada de base nas espessuras de 300 e $375 \mathrm{~mm}$, o subleito com espessura de $1045 \mathrm{~mm}$ e 970mm e a capa asfáltica de $75 \mathrm{~mm}$. A Figura 2.14 apresenta uma vista em corte do equipamento e os posicionamentos dos LVDTS e célula de carga.

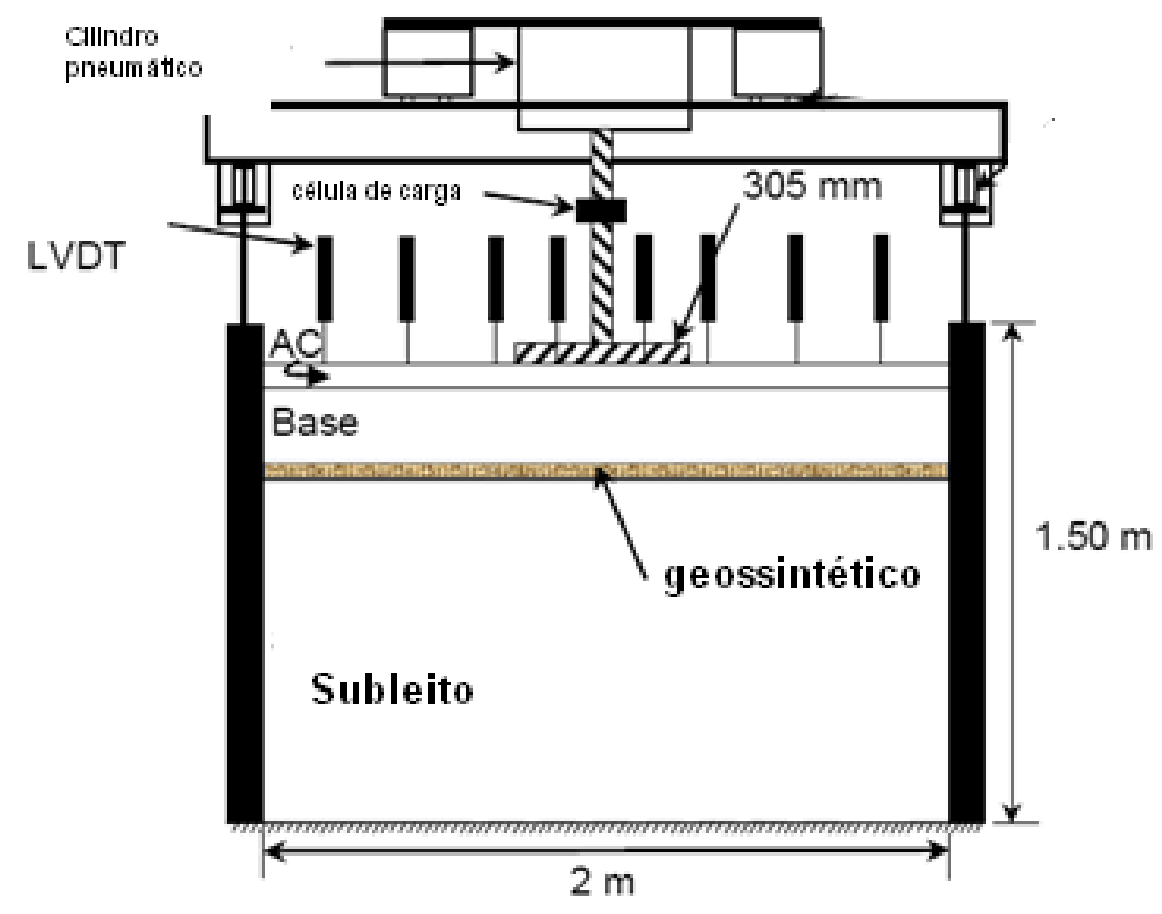

Figura 2.14 - Diagrama esquemático de equipamento de ensaio (PERKINS et al, 1999)

Hoe and Zheng (2001) avaliaram a performance de um pavimento asfáltico reforçado com geossintético, onde utilizaram ensaios sobre carregamento estático, estático com poucos ciclos de carregamento e descarregamento (218, 436 e 872 kPa) e carregamento dinâmico $(50,100,150$ e 180 kPa). Os testes estáticos foram 
controlados com uma taxa de deslocamento de $1,2 \mathrm{~mm} / \mathrm{min}$, enquanto os ensaios dinâmicos utilizaram uma frequência de $2 \mathrm{~Hz}$ aplicada por um sistema pneumático.

O modelo físico tem dimensões de $600 \mathrm{~mm}$ de comprimento, por $200 \mathrm{~mm}$ de largura e altura de $500 \mathrm{~mm}$. Utilizaram uma placa retangular de aço de $56 \mathrm{~mm}$ de largura para aplicação da carga. Nas paredes da caixa utilizaram graxa de silicone, para diminuir o atrito entre a areia e a lateral interna da caixa.

Para instrumentar os testes, usaram 5 strain gages na interface concreto asfáltico-subleito, 3 LVDTs na placa e dois espaçado de 100 e $200 \mathrm{~mm}$ do centro do carregamento. A espessura do concreto asfáltico variou de 40 a $63 \mathrm{~mm}$ e peso específico entre 20 a $21 \mathrm{kN} / \mathrm{m}^{3}$, com uma taxa de $3.5 \%$ de betume. Para o subleito, adotaram uma areia de Ottawa $D_{50}$ de $0,25 \mathrm{~mm}$ e $C_{u}$ de 1,65.

Utilizaram duas geogrelhas, uma de polipropileno de abertura 280 × $330 \mathrm{~mm}$, gramatura de $550 \mathrm{~g} / \mathrm{m}^{2}$ e resistência à tração de $46 \mathrm{kN} / \mathrm{m}$ e outra de poliéster de abertura 20,3 x 25,4 mm, gramatura de $187 \mathrm{~g} / \mathrm{m}^{2}$ e resistência a tração de $46 \mathrm{kN} / \mathrm{m}$. A geogrelha foi instalada na parte de baixo da camada de asfalto, ou seja, na interface subleito-concreto asfáltico, para resistir aos esforços de tração. O carregamento foi feito sobre condições de estado plano de tensões.

DeMerchant et al. (2002) realizaram uma análise da utilização de geogrelha para reforço de um agregado leve de argila expandida, a partir de ensaios com carregamento sobre placa rígida de $305 \mathrm{~mm}$ de diâmetro. A Figura 2.15 ilustra o equipamento de ensaio, que consistia de um cava escorada nas dimensões de 2,2 x $3,2 \mathrm{~m}$ e profundidade de 1,6 m. O carregamento foi aplicado por um atuador hidráulico fixado a uma viga de reação. 


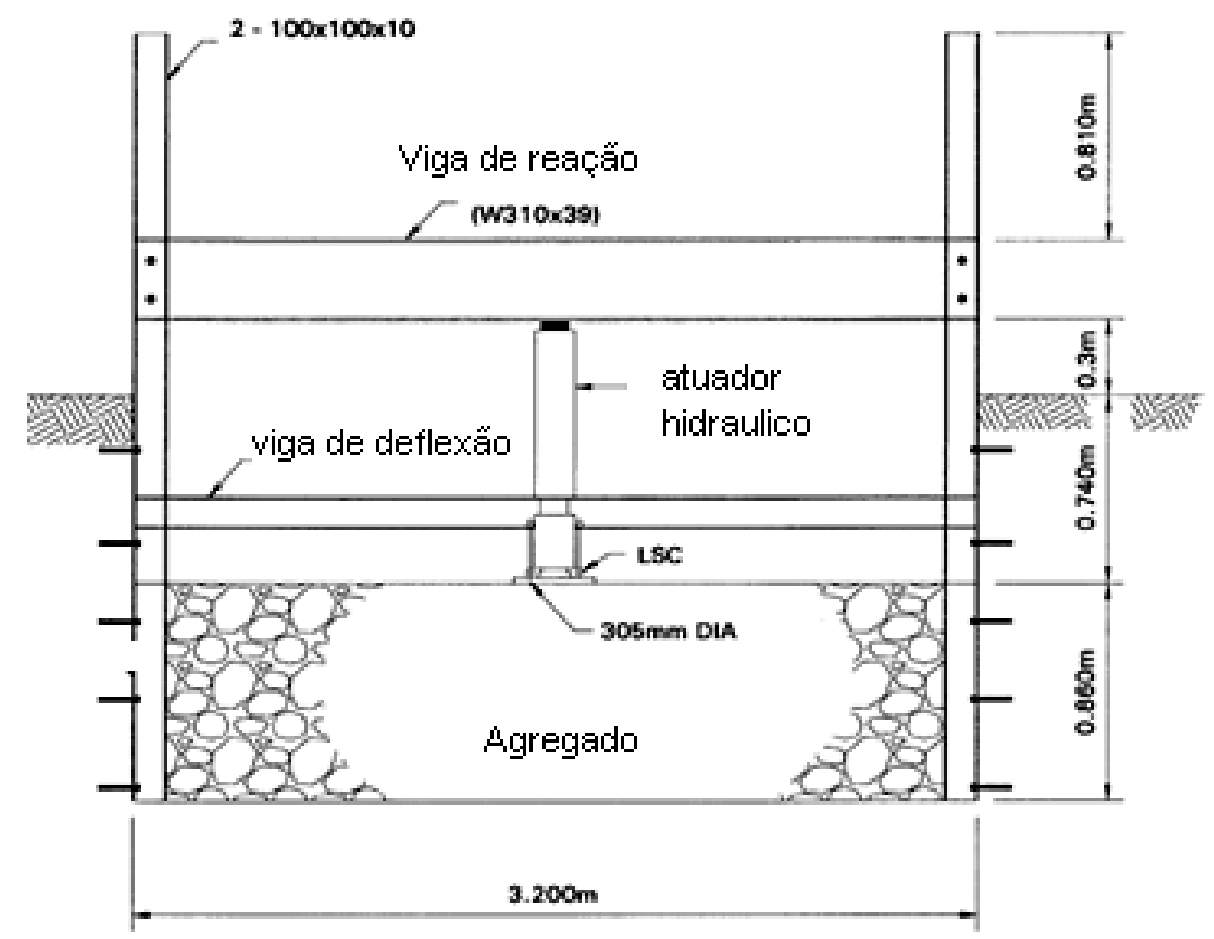

Figura 2.15 - Equipamento de ensaio (DEMERCHANT, 2002)

Jenner et al. (2002) apresentaram resultados de ensaios de laboratório em equipamento de grandes dimensões, para análise de uma estrutura de pavimento reforçado com geossintéticos, sem a colocação do revestimento asfáltico. O equipamento de ensaios era constituído de uma baia, onde eram montadas as seções de pavimentos em estudo. A baia tem as dimensões de 2,4 m de largura por $10 \mathrm{~m}$ de comprimento, que foram divididos em três partes, possibilitando 3 configurações de ensaio para cada baia. Utilizaram para esse estudo três baias, desta forma, foram analisadas 9 configurações de ensaio.

Para o subleito utilizaram argila com um CBR próximo a $2 \%$ e espessura de $500 \mathrm{~mm}$ disposto sobre o solo natural com CBR aproximado de $4 \%$. Definiram a espessura de $329 \mathrm{~mm}$ para a camada de sub-base. O carregamento foi por meio de dois pneus com carga, variando entre 23 a $100 \mathrm{kN}$ com velocidade de $20 \mathrm{kPa}$. O fator de redução de passadas para um afundamento de $40 \mathrm{~mm}$ na trilha de roda 
comparando com a seção não reforçada variou de 3 a 35\%, dependendo do material utilizado.

Leng and Garb (2002) utilizaram um equipamento nas dimensões de 1,5 m x 1,5 m x 1,35 m conforme Figura 2.16, para analisar o efeito do reforço da camada de agregado, com a utilização de uma geogrelha na interface subleito/base. O carregamento foi realizado sobre uma placa circular de $305 \mathrm{~mm}$, com o auxílio de um atuador hidráulico servo controlado. A carga cíclica aplicada foi de $40 \mathrm{kN}$, com uma frequência de 0,67 Hz. Utilizaram um subleito com CBR de entre 3 e 4\%, uma camada de base granular (GW) e duas geogrelhas biaxiais de polipropileno com as mesmas aberturas de malha e diferentes na gramatura e resistência de tração.

A instrumentação do ensaio consistia de medidores de deslocamento na superfície da camada de base e de células de tensão totais instaladas abaixo do geossintético. Analisaram o efeito da geogrelha para espessura de base de $152 \mathrm{~mm}$ e $254 \mathrm{~mm}$.

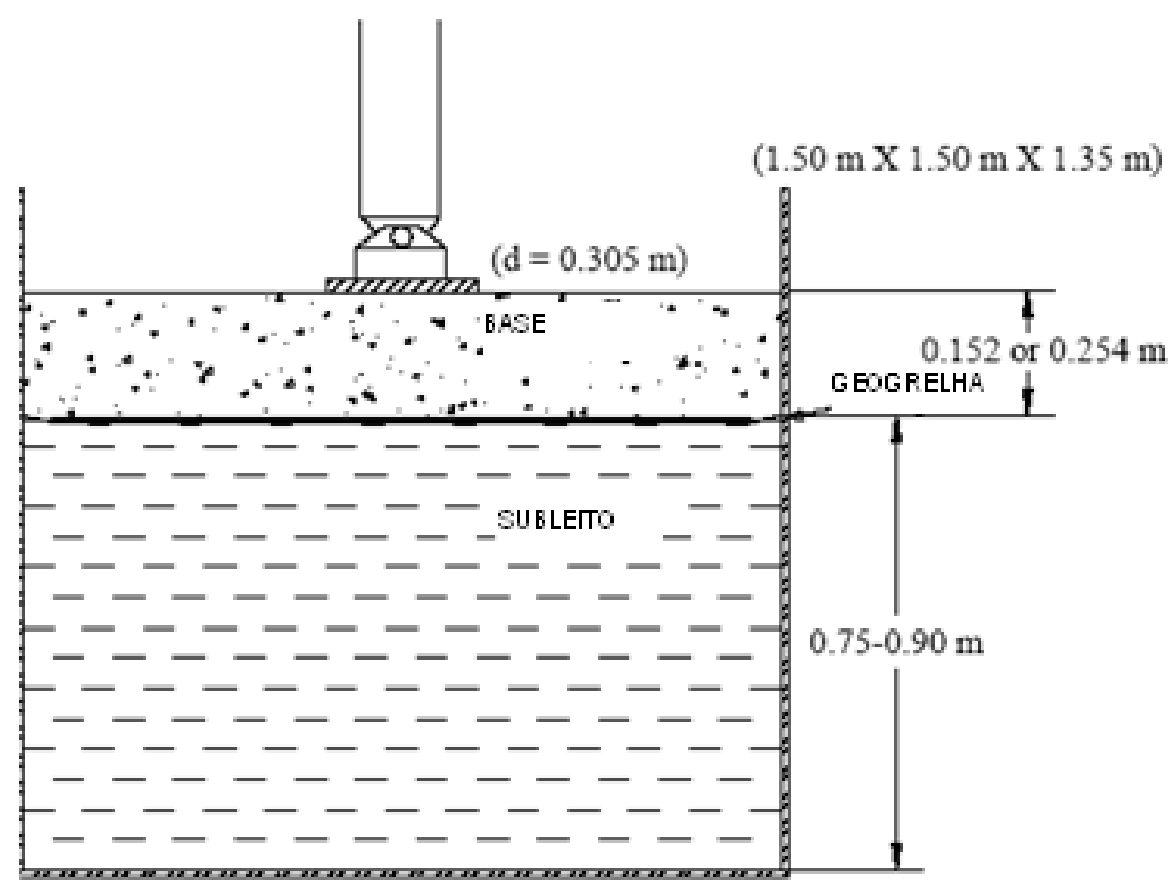

Figura 2.16 - Diagrama esquemático de caixa de teste e configuração do carregamento (LENG e GARB, 2002) 
Kim et al. (2005) apresentaram um modelo experimental de grande escala (LSME), utilizado para avaliar as deflexões durante o carregamento cíclico de protótipos de estruturas de pavimentos, que represente as condições de campo e seja prático. Os detalhes estão apresentados na Figura 2.17.

Para simular um subleito de CBR aproximado de 7\% utilizaram uma camada de $450 \mathrm{~mm}$ de espuma de poliestireno expandida. Uma placa circular rígida de diâmetro de $250 \mathrm{~mm}$ e $25 \mathrm{~mm}$ de espessura foi utilizada para aplicação de um carregamento cíclico de amplitude de $1,4 \mathrm{kN}$ e frequência de $1 \mathrm{HZ}(0,1 \mathrm{~s}$ de atuação por $0,9 \mathrm{~s}$ de descanso). Os deslocamentos foram medidos abaixo da placa e a distâncias radiais de 300, 450 e $650 \mathrm{~mm}$. Medidores de deslocamentos foram fixados no geossintéticos a 0, 130, 255 e $510 \mathrm{~mm}$ do centro de aplicação da carga, para obtenção de deformações do material.

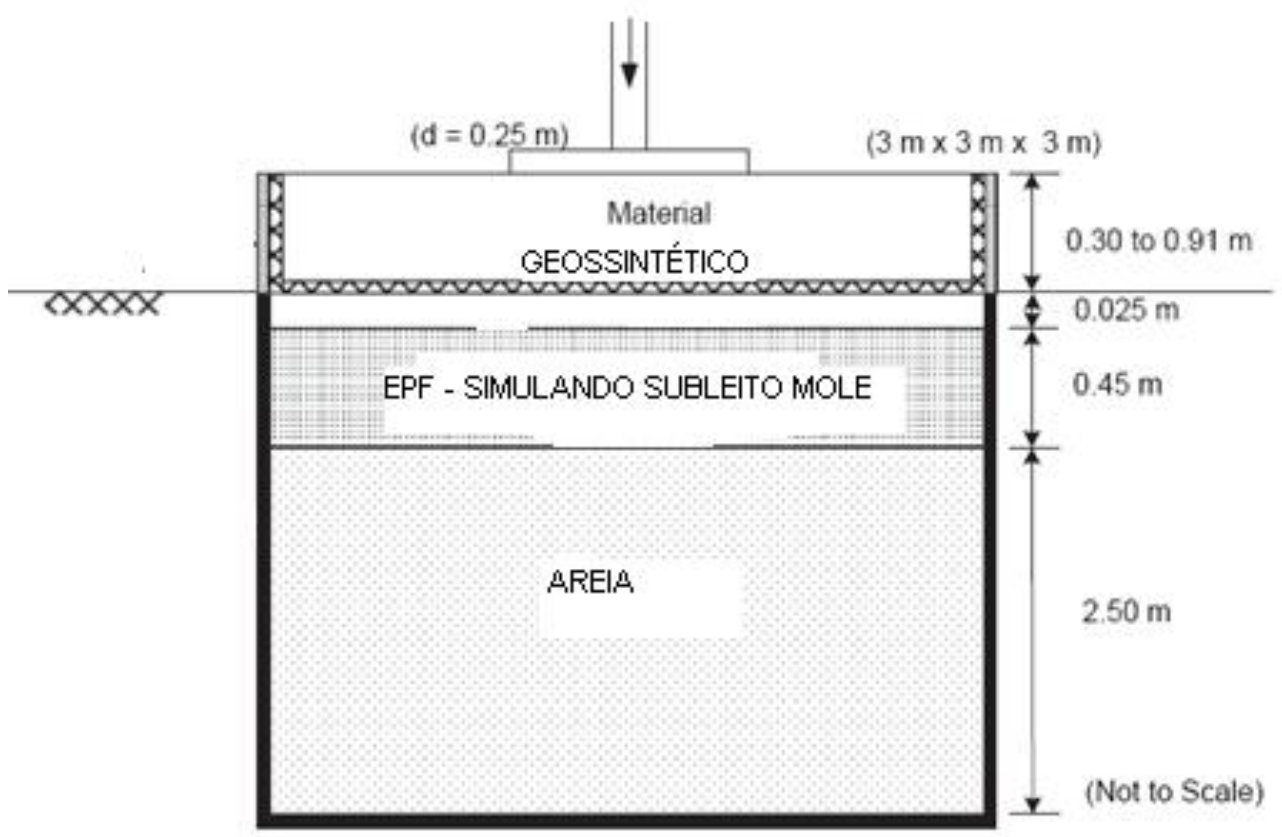

Figura: 2.17 - Vista em corte do LSME (KIM, 2005) 
Tingle \& Jersey (2005) realizaram testes de laboratório, onde investigaram a utilização de geotêxtil e geogrelha em estrutura de pavimentos sem revestimento. $O$ equipamento consiste de uma caixa de aço de espessura de $25 \mathrm{~mm}$ com dimensões de 1,83, por 1,83 m de lado e 1,37 m de profundidade. A carga cíclica de $40 \mathrm{kN}$ foi aplicada sobre uma placa de $305 \mathrm{~mm}$ de diâmetro, com espessura de uma polegada apoiada sobre um neoprene de $6 \mathrm{~mm}$ de espessura, por meio de um atuador hidráulico, a taxa de carregamento de 0,1 s de aplicação por 0,9s de descanso. As seções testadas consistiam de um subleito de argila com CBR de $1 \%$ com espessura de $810 \mathrm{~mm}$ e uma base de agregado do calcário de espessura $360 \mathrm{~mm}$, reforçada com geogrelha ou geotêxtil ou a composição dos dois na interface subleito-base.

Foram realizadas oito seções de testes, variando o tipo de reforço, sendo duas seções sem reforço, com a espessura de base $360 \mathrm{~mm}$ e $510 \mathrm{~mm}$, para serem utilizados como referência. Os testes foram instrumentados com LVDTs na superfície da camada de agregado e por célula de tensão total no interior das camadas, obtendo-se assim a superfície de deflexão, distribuição das tensões no interior das camadas e deformações permanentes na superfície. A Figura 2.18 ilustra as configurações dos ensaios e dimensões da estrutura analisada. 


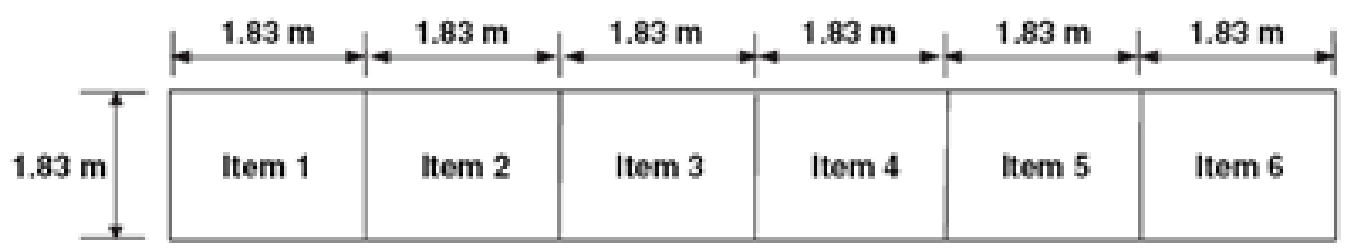

(a)

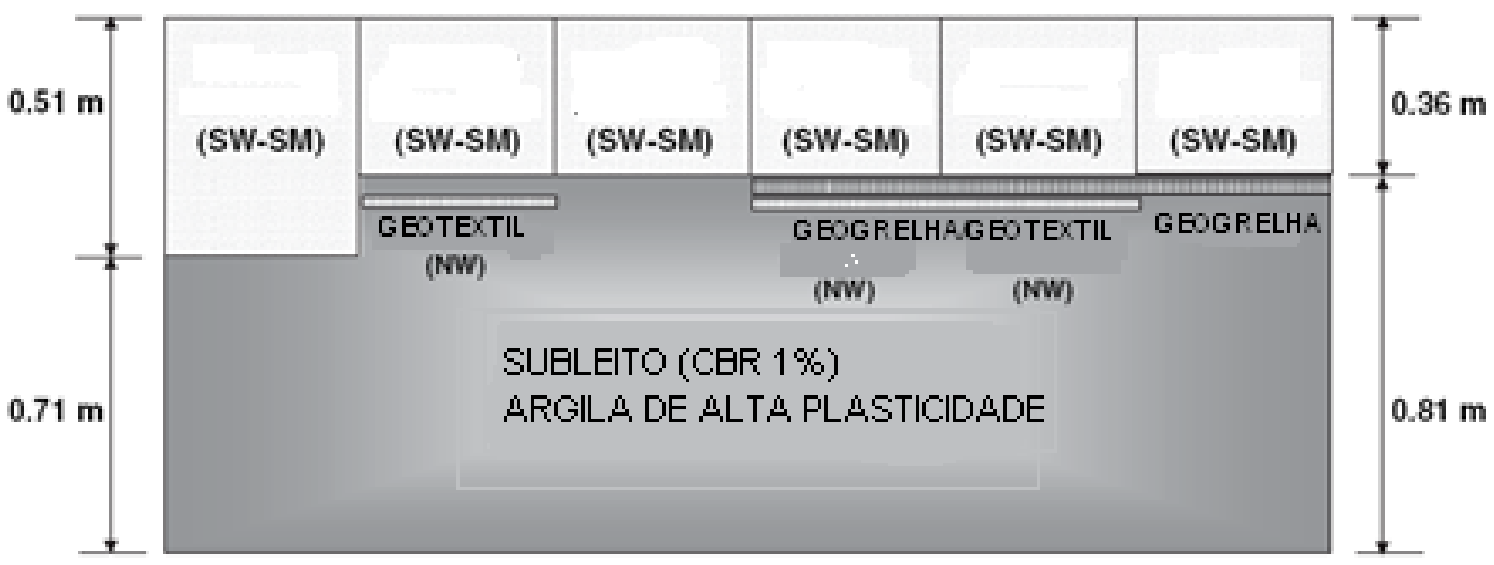

(b)

Figura 2.18 - Teste de pavimento em laboratório (TINGLE and JERSEY, 2005)

A Tabela 2.3 apresenta um levantamento bibliográfico das dimensões dos equipamentos utilizados em pesquisas em que envolveram utilização de geossintético em pavimentos sem revestimento (TINGLE and JERSEY, 2005). Apresentam os detalhes da forma de carregamento, dos materiais constituintes da camada de base e subleito, da posição da colocação do geossintético. Observa-se unanimidade quanto à utilização de um subleito de baixa capacidade de suporte. 
Tabela 2.3 - Detalhes dos aparelhos e materiais utilizados em pesquisas de reforço de estradas não pavimentadas, utilizando geossintéticos (TINGLE and JERSEY, 2005)

\begin{tabular}{|c|c|c|c|c|c|}
\hline & $\begin{array}{l}\text { Douglas, } \\
\text { R. A. } \\
(1997)\end{array}$ & $\begin{array}{l}\text { Kelly et al. } \\
(1995)\end{array}$ & $\begin{array}{l}\text { Gregory and } \\
\text { Bang (1994) }\end{array}$ & $\begin{array}{l}\text { Douglas } \\
\text { and } \\
\text { Valsangkar } \\
\text { (1992) }\end{array}$ & $\begin{array}{l}\text { Baueer and } \\
\text { Adbelhaim } \\
(1987)\end{array}$ \\
\hline \multicolumn{6}{|c|}{ Detalhes dos equipamentos utilizados nas pesquisas } \\
\hline Caixa & $\begin{array}{l}\text { Reforçado } \\
\text { acrílico } \\
1,22 \times 0,3 \\
\times 0,61 \mathrm{~m}\end{array}$ & $\begin{array}{l}\text { Caixa rígida } \\
1,2 \times 1,2 \times \\
0,8 \mathrm{~m}\end{array}$ & $\begin{array}{l}\text { Cilindro aço } \\
0,15 \mathrm{~m} \text { diam.x } \\
0,30 \mathrm{~m}\end{array}$ & $\begin{array}{l}\text { Concreto } \\
3,0 \times 4,0 \times \\
2,0 \mathrm{~m}\end{array}$ & $\begin{array}{l}\text { Concreto } \\
3,0 \times 4,0 \times \\
2,0 \mathrm{~m}\end{array}$ \\
\hline Carregamento & Sapata & $\begin{array}{l}\text { Placa } \\
\text { circular }\end{array}$ & Placa circular & $\begin{array}{l}\text { Placa } \\
\text { circular }\end{array}$ & Placa circular \\
\hline Carga $(\mathrm{kN})$ & $0,12-0,16$ & 15,0 & Variou & 4,5 & 40,0 \\
\hline Área $\left(\mathrm{cm}^{2}\right)$ & variou & 490,8 & 19,4 & 706,9 & 729,7 \\
\hline Pressão (kPa) & variou & 305,6 & Variou & 63,7 & 548,2 \\
\hline Freqüência & $0,4 \mathrm{~Hz}$ & $2,0 \mathrm{kN} / \mathrm{min}$ & Estático & $0,5 \mathrm{~Hz}$ & $3,0 \mathrm{~Hz}$ \\
\hline \multicolumn{6}{|c|}{ Propriedades dos materiais utilizados } \\
\hline Base & areia & $\begin{array}{l}\text { Areia com } \\
\text { cascalho }\end{array}$ & $\begin{array}{ll}\text { Brita } & \text { de } \\
\text { calcário } & \end{array}$ & variou & $\begin{array}{ll}\text { Brita } & \text { de } \\
\text { calcário } & \end{array}$ \\
\hline $\begin{array}{l}\text { Espessura } \\
(\mathrm{mm})\end{array}$ & $25,4-76,2$ & 200 & $0-50,8$ & 150 & $75-300$ \\
\hline $\begin{array}{l}\text { Resistência } \\
\text { relativa }\end{array}$ & baixa & alta & Alta & Baixa-alta & Alta \\
\hline Subleito & turfa & $\begin{array}{l}\text { Argila de } \\
\text { baixa } \\
\text { plasticidade }\end{array}$ & $\begin{array}{l}\text { Argila de } \\
\text { baixa e alta } \\
\text { plasticidade }\end{array}$ & turfa & $\begin{array}{l}\text { Areia mal } \\
\text { graduada }\end{array}$ \\
\hline $\begin{array}{l}\text { Espessura } \\
(\mathrm{mm})\end{array}$ & & 500 & 177,8 & 1200 & 900 \\
\hline $\begin{array}{l}\text { Resistência } \\
\text { relativa }\end{array}$ & $\begin{array}{l}\text { Muito } \\
\text { baixa }\end{array}$ & Baixa & Baixa & Muito baixa & Media \\
\hline Geossintéticos & geotêxtil & $\begin{array}{l}\text { Geogrelhas } \\
\text { ou geotêxtil }\end{array}$ & $\begin{array}{l}\text { Geogrelha } \\
\text { e/ou geotêxtil }\end{array}$ & $\begin{array}{l}\text { Geotêxtil e } \\
\text { geogrelha }\end{array}$ & Geotêxtil \\
\hline Localização & interface & interface & Interface & variou & \\
\hline
\end{tabular}


As Tabelas 2.4, 2.5 e 2.6 foram apresentadas por Perkins e Ismeik (1997), que descrevem os principais equipamentos utilizados em pesquisas que envolveram a utilização de geossintéticos, em estrutura de pavimento. A Tabela 2.4 detalha as dimensões do equipamento, tipo de carga, pressão e frequência do carregamento.

Tabela 2.4 - Levantamento bibliográfico de equipamentos de ensaio (PERKINS and ISMEIK, 1997)

\begin{tabular}{|c|c|c|c|c|}
\hline Autores & $\begin{array}{c}\text { Dimensões } \\
(\mathrm{m})\end{array}$ & Tipo de carga & $\begin{array}{c}\text { Pressão } \\
(\mathrm{kPa})\end{array}$ & $\begin{array}{l}\text { Frequência } \\
\text { ou } \\
\text { Velocidade }\end{array}$ \\
\hline (1) Al-Qadi et al. (1994) & $3,1 \times 1,8 \times 2,1$ & Disco $300 \mathrm{~mm}$ & 550 & $0,5 \mathrm{~Hz}$ \\
\hline (2) Barker (1987) & $21 \times 4,6 \times 1,1$ & $\begin{array}{c}\text { Uma roda } \\
\text { movendo em trilha }\end{array}$ & 1826 & NR \\
\hline (3) Barksdale et al. (1989) & $4,9 \times 2,4 \times 1,5$ & $\begin{array}{c}\text { Uma roda } \\
\text { movendo em trilha }\end{array}$ & $460-500$ & $1,3 \mathrm{~m} / \mathrm{s}$ \\
\hline (4) Brown et al. (1982) & $4,9 \times 2,4 \times 1,5$ & $\begin{array}{c}\text { Uma roda } \\
\text { movendo em trilha }\end{array}$ & 530 & $1,3 \mathrm{~m} / \mathrm{s}$ \\
\hline (5) Cancelli et al. (1996) & $0,9 \times 0,9 \times 0,9$ & Disco $300 \mathrm{~mm}$ & 570 & 5 ou $10 \mathrm{~Hz}$ \\
\hline (6) Collin et al. (1996) & $14,6 \times 2,4 \times 1,2$ & $\begin{array}{c}\text { Uma roda } \\
\text { movendo em trilha }\end{array}$ & 550 & $1,2 \mathrm{~m} / \mathrm{s}$ \\
\hline $\begin{array}{l}\text { (7) Halliday and Potter } \\
\text { (1984) }\end{array}$ & $20 \times 4,25 \times 1,5$ & Duas rodas & 760 & $\begin{array}{c}1,4-2,2 \\
\mathrm{~m} / \mathrm{s}\end{array}$ \\
\hline (8) Hass et al. (1988) & $4,5 \times 1,8 \times 0,9$ & Disco $300 \mathrm{~mm}$ & 550 & $8 \mathrm{~Hz}$ \\
\hline (9) Miura et al. (1990) & $1,5 \times 1,5 \times 1,0$ & Disco de $200 \mathrm{~mm}$ & 200 & $0,18 \mathrm{~Hz}$ \\
\hline $\begin{array}{l}\text { (10) Moghaddas-Nejad } \\
\text { and Small (1996) }\end{array}$ & $1,4 \times 0,5 \times 0,8$ & $\begin{array}{c}\text { Uma roda } \\
\text { movendo em trilha }\end{array}$ & 210 & $1,3 \mathrm{~m} / \mathrm{s}$ \\
\hline (11) Webster (1993) & $44 \times 3,8 \times 1$ & $\begin{array}{c}\text { Uma roda } \\
\text { movendo em trilha }\end{array}$ & 470 & \\
\hline
\end{tabular}

A Tabela 2.5 apresenta as espessuras das camadas e os materiais utilizados na estrutura de pavimento, o tipo de geossintético e o local de sua colocação em relação à camada de base. A Tabela 2.6 detalha as propriedades dos geossintéticos. 
Tabela 2.5 - Características da estrutura de pavimento e do geossintético utilizados nas pesaquisas (PERKINS AND ISMEIK, 1997)

\begin{tabular}{|c|c|c|c|c|c|c|c|}
\hline \multirow[t]{2}{*}{ Aut. } & \multicolumn{3}{|c|}{$\begin{array}{l}\text { Espessuras das camadas } \\
\qquad(\mathrm{mm})\end{array}$} & \multicolumn{2}{|c|}{ Tipo de material } & \multirow[t]{2}{*}{ geossintéticos } & \multirow[t]{2}{*}{$\begin{array}{l}\text { Posição na } \\
\text { base }\end{array}$} \\
\hline & $A C$ & Base & $\begin{array}{l}\text { Sub- } \\
\text { base }\end{array}$ & Base & $\begin{array}{l}\text { Subleito } \\
\text { (CBR) }\end{array}$ & & \\
\hline 1 & 70 & 150,200 & - & $\begin{array}{c}\text { GW-GM, } \\
\text { A-1-a }\end{array}$ & $\begin{array}{c}\text { SM-A-4 } \\
(4,2)\end{array}$ & $\begin{array}{c}\text { GG-B; GT-A; } \\
\text { GT-B }\end{array}$ & Inferior \\
\hline 2 & 75 & 150 & - & $\begin{array}{l}\mathrm{GP} \\
\mathrm{A}-1-\mathrm{a}\end{array}$ & $\begin{array}{l}\text { Areia } \\
\text { siltosa }\end{array}$ & GG-B & Meio \\
\hline 3 & 25,38 & 150,200 & - & $\begin{array}{l}\text { GP-GM, } \\
\text { A-1-a }\end{array}$ & $\begin{array}{l}C L-A 6 \\
(2,6-3,2)\end{array}$ & GG-A; GT-D & $\begin{array}{l}\text { Inferior / } \\
\text { meio }\end{array}$ \\
\hline 4 & 37,53 & 107,175 & - & $\begin{array}{l}\text { GW, } \\
\text { A-1-a }\end{array}$ & $\begin{array}{c}C L-A 6 \\
(2-8)\end{array}$ & GT-H; GT-I & $\begin{array}{l}\text { Inferior / } \\
\text { meio }\end{array}$ \\
\hline 5 & 75 & 300 & - & $\begin{array}{l}\text { GW } \\
A-1-a\end{array}$ & $\begin{array}{c}S P-A-3 \\
(1,3,8 \\
18)\end{array}$ & $\begin{array}{c}\text { GG-A, D, I, J e H } \\
\text { GT-F }\end{array}$ & $\begin{array}{l}\text { Inferior/ } \\
\text { meio }\end{array}$ \\
\hline 6 & 50 & 150,460 & - & $\begin{array}{l}\text { GW, } \\
\text { A-1-a }\end{array}$ & $\begin{array}{c}S M-A-2 \\
(1,9)\end{array}$ & GG-A; GG-B & Inferior \\
\hline 7 & 160 & 300 & - & $\begin{array}{l}\text { Agregado } \\
\text { de granito }\end{array}$ & $\begin{array}{c}\mathrm{CH}-\mathrm{A}-7- \\
6 \\
(0,7- \\
4,3)\end{array}$ & GT-E & Inferior \\
\hline 8 & $\begin{array}{l}75 \\
100\end{array}$ & $\begin{array}{c}100 \mathrm{a} \\
300\end{array}$ & - & $\begin{array}{l}\text { GW, } \\
A-1-b\end{array}$ & $\begin{array}{l}S P, A-3 \\
(8-3,5)\end{array}$ & GG-A & $\begin{array}{c}\text { Superior/ } \\
\text { inferior/ } \\
\text { meio }\end{array}$ \\
\hline 9 & 50 & 150 & $\begin{array}{l}200 \\
250\end{array}$ & NR & $\begin{array}{c}\text { Argila } \\
\text { (5 ou } 10 \\
\mathrm{kPa})\end{array}$ & $\begin{array}{c}\text { GG-A;GG-B; } \\
\text { GG-C }\end{array}$ & $\begin{array}{l}\text { Inferior/ } \\
\text { Meio }\end{array}$ \\
\hline 10 & 20 & 40 & - & $\begin{array}{l}\mathrm{SP} \\
\mathrm{A}-1-\mathrm{a}\end{array}$ & $S P-A-3$ & GG-B & $\begin{array}{l}\text { Inferior/ } \\
\text { Meio }\end{array}$ \\
\hline 11 & 50 & $\begin{array}{l}150 \mathrm{a} \\
450\end{array}$ & - & $\begin{array}{l}\text { SM-SC, } \\
\text { A-1-a }\end{array}$ & $\begin{array}{c}\mathrm{CH}-\mathrm{A}-7- \\
6 \\
(3-8)\end{array}$ & $\begin{array}{c}\text { GG-A, } B, D, E, F \\
\text { e } G\end{array}$ & $\begin{array}{l}\text { Inferior/ } \\
\text { Meio }\end{array}$ \\
\hline
\end{tabular}


Tabela 2.6 - Propriedades dos geossintéticos utilizados nas pesquisas (PERKINS AND ISMEIK, 1997)

\begin{tabular}{|c|c|c|c|c|c|}
\hline Sigla & $\begin{array}{c}\text { Tipo } \\
\text { geossintético }\end{array}$ & Polímero & $\begin{array}{c}\text { Gramatura } \\
\left(\mathrm{g} / \mathrm{m}^{2}\right)\end{array}$ & $\begin{array}{c}\text { Abertura da } \\
\text { malha } \\
(\mathrm{mm})\end{array}$ & $\begin{array}{c}5 \% \text { modulo } \\
\text { secante } \\
(\mathrm{kN} / \mathrm{m})\end{array}$ \\
\hline GG-A & geogrelha & polipropileno & 203 & $25 / 36$ & $180 / 260$ \\
\hline GG-B & geogrelha & polipropileno & 306 & 25/33 & $220 / 400$ \\
\hline GG-C & geogrelha & polipropileno & 247 & $46 / 64$ & $220 / 340$ \\
\hline GG-D & geogrelha & poliéster & 235 & $20 / 20$ & $248 / 167$ \\
\hline GG-E & geogrelha & poliéster & 270 & $30 / 33$ & $227 / 124$ \\
\hline GG-F & geogrelha & polipropileno & 230 & $32 / 40$ & $160 / 216$ \\
\hline GG-G & geogrelha & poliéster & 193 & $18 / 19$ & $218 / 161$ \\
\hline GG-H & geogrelha & polipropileno & 220 & $20 / 25$ & $160 / 240$ \\
\hline GG-I & geogrelha & polipropileno & 250 & $30 / 40$ & $180 / 260$ \\
\hline GG-J & geogrelha & polipropileno & 350 & $30 / 40$ & $200 / 370$ \\
\hline GT-A & geotêxtil & polipropileno & 120 & - & NR \\
\hline GT-B & geotêxtil & polipropileno & 190 & - & $228 / 420$ \\
\hline GT-D & geotêxtil & polipropileno & 970 & - & NR/750 \\
\hline GT-E & geotêxtil & poliéster & NR & - & NR \\
\hline GT-F & geotêxtil & polipropileno & NR & - & NR \\
\hline GT-G & geotêxtil & polipropileno & NR & - & NR \\
\hline GT-H & geotêxtil & poliéster & NR & - & NR \\
\hline GT-I & geotêxtil & $\begin{array}{l}\text { Polipropileno } \\
\text { e polietileno }\end{array}$ & NR & - & NR \\
\hline
\end{tabular}

No Brasil, Silva (2009) desenvolveu um modelo físico de grande porte para ensaios em estrutura de pavimento, entretanto não utilizou geossintéticos em seus experimentos. As dimensões são $2 \mathrm{~m}$ por $2 \mathrm{~m}$ de lados com profundidade de $1,8 \mathrm{~m}$, a aplicação da carga é dada por um cilindro pneumático que possibilita a aplicação de carga com freqüência de $1 \mathrm{~Hz}(0,1 \mathrm{~s}$ de atuação por 0,9 de descanso). Silva analisou o comportamento mecânico de pavimento sobre o efeito da variação do lençol freático. 


\subsubsection{Trechos experimentais para análise da utilização de geossintéticos em estruturas de pavimentos}

Meiarashi et al. (2002) utilizaram um geotêxtil entre a camada de base e a areia colocada como almofada dos blocos inter-travados. Para analisar o efeito do geossintético, utilizaram resultados de ensaios de campo e laboratório ("roller compacter" e "whell tracking test"). $O$ ensaio acelerado de grandes dimensões consiste de uma pista circular de raio de $200 \mathrm{~m}$ com uma faixa de largura de $5 \mathrm{~m}$. Tantos os resultados quantitativos, quanto os qualitativos mostraram que para os testes realizados em campo, em todos os trechos em que utilizaram o geotêxtil, os resultado de afundamento de trilha de roda foram satisfatórios quando comparados com trechos em que não foram utilizado o geotêxtil.

Dondi (1994 apud VERTEMATTI, 2004) verificou a partir da observação de segmento de rodovia instrumentada, que quanto mais elevada a rigidez da geogrelha, maior é a vida de fadiga. A presença da geogrelha propiciou um aumento da vida de fadiga da estrutura de 2 a 2,5 vezes, quando comparada a uma estrutura sem reforço. Concluiu, ainda, que as geogrelhas com maior módulo de rigidez conduzem a melhores desempenhos do reforço da camada granular, pois as geogrelhas flexíveis, para serem solicitadas por tração, necessitam de certa deformação para mobilizar sua resistência, para só assim, propiciarem uma redução do afundamento da superfície na "trilha de roda".

Al-Qadi e Appea (2003) em 1994 iniciaram a instrumentação de um trecho de 150 m de uma rodovia secundária, no estado americano da Virgínia, sendo esse 
trecho dividido em 9 segmentos de $15 \mathrm{~m}$ cada, onde foram utilizadas três espessuras de base, 100, 150 e 200 mm. Para cada grupo foi utilizada uma seção reforçada com geogrelha, uma com geotêxtil e uma outra para controle. Utilizaram para inspeção do pavimento o FWD, obtendo deflexões durante um período de oito anos. Nestas seções foram usadas uma capa asfáltica de $95 \mathrm{~mm}$ de espessura e um subleito de CBR de 6 a $10 \%$.

Os resultados mostraram que a seção reforçada com geossintético, com base de $100 \mathrm{~mm}$, pode aumentar a vida de serviço do pavimento em duas vezes, embora esse ganho seja diminuído para pavimentos com bases mais espessa. A seção com geotêxtil apresentou menor afundamento de trilha de roda, seguido pela seção em que se utilizou geogrelha.

Os resultados confirmaram que a melhora no desempenho do pavimento deuse pela atuação do geotêxtil como separador, evitando a migração dos materiais finos do subleito para a camada de base e a penetração dos agregados no subleito. Isto foi confirmado a partir do menor índice de danos da base (BDI), sendo esse índice diretamente relacionado com a migração dos finos para a camada de base.

Saraiva et al. (2005 a e b) avaliaram o comportamento de seis seções experimentais de $50 \mathrm{~m}$ cada, a partir de medições das deformações verticais e horizontais registradas através de sensores elétricos. O trecho experimental localizase na rodovia de ligação da cidade de Itabira-MG à cidade de Senhora do CarmoMG.

Para instrumentar o trecho, utilizaram strain-gages nas camadas de pavimento para monitoramento do comportamento da deformação em diferentes 
profundidades com a aplicação de cargas estáticas e dinâmicas. As seções testes executadas no campo incluem seis diferentes configurações. A seção 1 tem característica do projeto da obra.

As bases das seções seguintes foram executadas com mistura de $70 \%$ de Jig, $20 \%$ de argila e $10 \%$ de rejeito fino de mineração de ferro. Nas seções de 3 e 5 colocou-se como reforço da camada de base uma manta de geotêxtil e nas seções 4 e 6, utilizou-se geogrelha. Puderam observar a viabilidade da utilização de materiais alternativos, de reconhecida inserção regional que, mesmo não atendendo todos os requisitos das normas vigentes, resultam em um desempenho estrutural tão satisfatório quanto aos sistemas convencionalmente adotados.

Hufenus et al. (2006) realizaram testes de campo em escala real, onde foram utilizados geossintéticos como reforço de uma estrada não pavimentada. A seção típica do experimento é constituída de três camadas de materiais reciclados, sendo a primeira compactada estaticamente e as demais dinamicamente.

A geogrelha foi colocada na interface do subleito constituído de solo mole e a primeira camada compactada, sendo ela instrumentada com "strain gages" para leituras de deformações a curto e longo prazo. A trilha de roda foi avaliada a partir das leituras de afundamento do perfil.

Segundo os autores, os geossintéticos apresentaram um efeito relevante apenas quando utilizados sob camadas finas em subleitos de solo mole, pois sobre tais circunstâncias o subleito sofre consideráveis deformações, desta forma, passase a solicitar o reforço com tensões de tração. Quanto maior a rigidez do reforço mais eficaz torna-se o sistema reforçado. 
Os testes foram realizados em 12 trechos de $8 \mathrm{~m}$ de comprimento, onde a geogrelha foi colocada em conjunto com uma camada separadora de geotêxtil não tecido e sobre a geogrelha, foram compactadas três camadas de $200 \mathrm{~mm}$ de entulho reciclado. O subleito foi classificado como $\mathrm{CM}$, argila siltosa de média plasticidade, apresentando um teor de umidade de 38,6 \%+/- 4,7\%, com um CBR aproximado de 3 a 4\%, obtido a partir da resistência ao cisalhamento (ensaio de campo). Os trechos foram monitorados com medidas de CBR, testes dinâmicos e estáticos em placa, falling weight deflectometer (FWD), controle da compactação dinâmica e controle de perfil (trilha de roda).

Concluíram que ocorreu um aumento significativo na capacidade de carga quando utilizada uma geogrelha como reforço em camadas de base com espessuras menores que $500 \mathrm{~mm}$ sobre subleitos com CBR menor ou igual a dois. Em camada de base de 400 mm, o uso de geossintético mostrou ser eficaz quanto à formação de trilha de roda; a seção reforçada possibilitou maiores cargas axiais ou um maior período de vida útil; e é possível a redução da espessura da camada de base em 30\%, sendo entretanto, recomendada uma espessura mínima de $300 \mathrm{~mm}$.

Hoe and Huabei (2003) descrevem o estudo por elemento finitos do comportamento de um pavimento reforçado com geogrelha sob a condição de estado plano de tensões sujeito a um carregamento estático. Utilizaram o programa PLAXIS e comparam os resultados com os obtidos por Ling and Liu (2001), que realizaram ensaios em uma caixa rígida de dimensões iguais a 600 × 200 × 500 mm, sendo os ensaios conduzidos sobre condições do estado plano de tensões, com o carregamento sobre uma placa retangular rígida de $56 \mathrm{~mm}$ de largura, com taxa de aplicação de $1.2 \mathrm{~mm} / \mathrm{min}$. 
Os autores concluíram que o método dos elementos finitos foi capaz de estimar com razoável precisão tensões e deslocamentos no sistema reforçado e sem reforço. Destacam ainda que o aumento da espessura do concreto asfáltico aumenta a performance do sistema, porém, quando é atingido um limite superior, ocorre a ruptura da camada asfáltica; a rigidez da geogrelha afeta a relação carga $x$ deslocamento; o modelo linear elástico adotado para geogrelha não é o mais apropriado para representar a distribuição de tensão na geogrelha; o efeito do reforço foi mais pronunciado no subleito de menor suporte e para maiores níveis de tensão aplicada, esse efeito está relacionado com as tensões de tração mobilizado pela geogrelha.

\subsubsection{Efeito a serem considerados na utilização de geossintéticos no reforço de base de estrutura de pavimento}

A efetiva contribuição do emprego de geossintéticos no reforço de camadas de estruturas de pavimentos flexíveis foi mostrada em muitas pesquisas (PERKINS and ISMEIK, 1997; PERKINS, 1999; HOE and ZENG, 2001; PERKINS et al., 2002; AL-QADI, 2002), que em geral, analisaram a influência das seguintes variáveis no desempenho do pavimento: a espessura da camada granular a ser reforçada, a posição relativa do geossintético na camada granular, as características mecânicas dos geossintéticos, a capacidade de suporte do subleito, a rigidez do geossintéticos e a forma de aplicação do carregamento. 


\subsection{Efeito da espessura da camada granular a ser reforçada e posicionamento do geossintético}

A efetividade da geogrelha passa a ser mais visualizada para a camada de bases esbeltas, uma vez que para bases robustas, a eficiência torna-se insignificante (AL.QADI et al., 1998). Hass et al.(1988) concluíram que para bases de pavimentos de pequena espessura a geogrelha deve ser instalada na interface subleito-base e para pavimentos de bases espessas, deve ser colocada próximo ao meio da camada de base.

Moghaddas-Nejad and Small.(1996) mostraram a partir de ensaios em laboratório, que a geogrelha diminuiu as deformações permanentes, em 70 e 50\%, respectivamente, para a geogrelha colocada no meio da camada da base e na interface base-subleito.

Collin et al. (1996) concluíram o máximo valor de TBR foi encontrado para espessura de base de $250 \mathrm{~mm}$. A Figura 2.19 ilustra as curvas do TBR, em função da espessura da base para duas geogrelhas de polipropileno. Observa-se que para espessura de base acima de $250 \mathrm{~mm}$ o TBR diminui e acima de $300 \mathrm{~mm}$, praticamente, não há benefício quanto ao uso de uma geogrelha. 


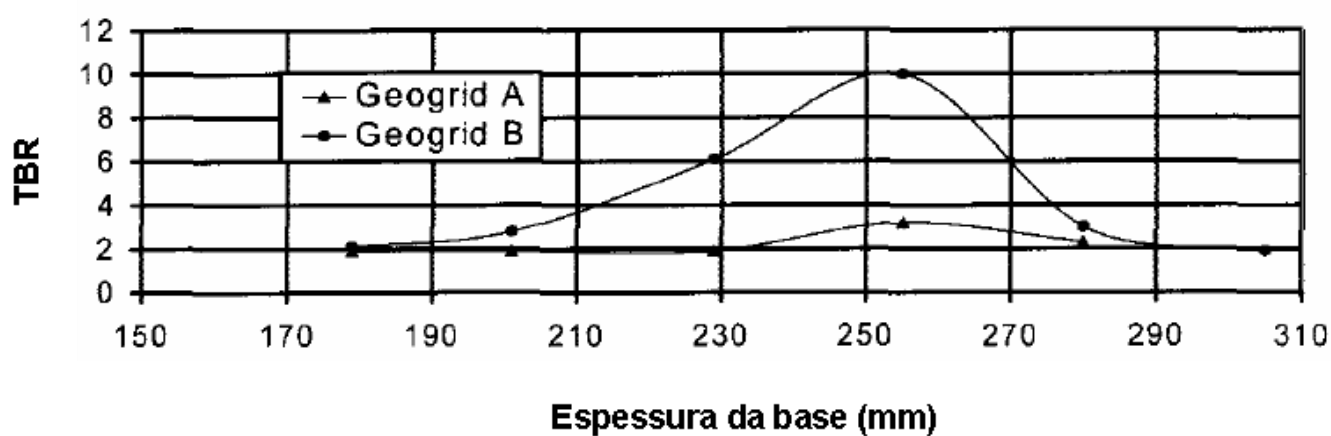

Figura 2.19 - Valores de TBR em função da espessura da base para deslocamento de 25mm (COLLIN, 1996)

Chang et al. (1998) verificaram que para profundidades de instalações de geogrelhas maiores que uma vez, o diâmetro da área carregada, o ganho do geossintético passa a ser praticamente desprezível.

Kinney, et al (1998) avaliaram valores de TBR para diferentes espessuras de base, considerando-se três deslocamentos na trilha de roda. A Figura 2.20 apresenta estas curvas obtidas de ensaios que utilizaram uma geogrelha de polipropileno de modulo $13200 \mathrm{lb} / \mathrm{ft}$. Os valores de TBR foram obtidos pela comparação em seção com e sem reforço, utilizando como parâmetro o número de ciclos necessário para alcançar determinado deslocamento.

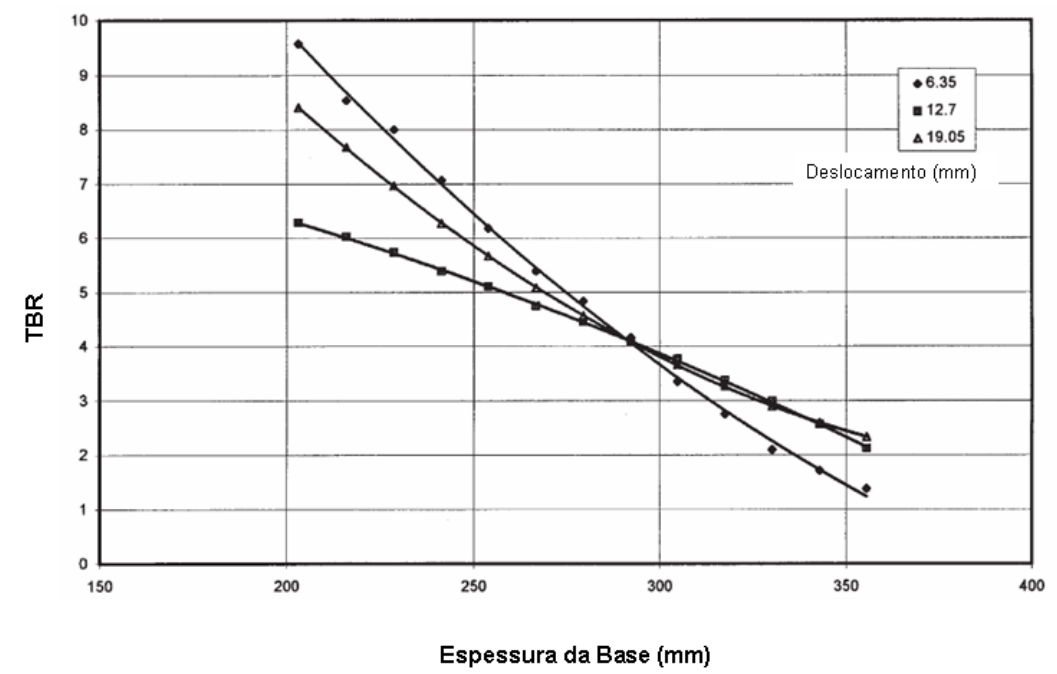

Figura 2.20 - TBR, geogrelha A, pressão de pneu 551kPa (KINNEY et al, 1998) 
Observa-se da Figura 2.20 que o uso da geogrelha proporciona ganhos nos valores representados pela TBR, para bases esbeltas e a medida que se aumenta essa espessura, o elemento de reforço deixa de ser significativo. Os autores concluem que para espessuras de base maior que aproximadamente $406 \mathrm{~mm}$ o efeito da geogrelha é mínimo.

Perkins et al. (1999) verificaram em seus ensaios em equipamento de grande escala que quando a geogrelha foi colocada a $100 \mathrm{~mm}$ acima da interface subleitobase apresentou melhor desempenho se comparado com a geogrelha colocada na interface (base de $300 \mathrm{~mm}$ de espessura); observou-se também que quando aumentou a espessura da base para $375 \mathrm{~mm}$ e colocou a geogrelha na interface houve um melhor desempenho se comparado com o ensaio de controle, entretanto, esse ganho foi inferior para a condição de base de $300 \mathrm{~mm}$ de espessura.

DeMerchant et al. (2002) concluíram que a otimização do reforço de geogrelha colocado em um agregado leve de argila expandida acontece quando a largura da geogrelha é quatro vezes o diâmetro da placa e a posição que maximiza o efeito da geogrelha é a profundidade igual ao diâmetro da área de atuação do carregamento. Avaliaram também a possibilidade de utilização de duas camadas de geogrelha no interior da camada de base, sendo as geogrelhas espaçadas de 305 mm uma da outra.

Verificaram que a variação do módulo do subleito era comandada apenas pelo primeiro reforço localizado na profundidade crítica. A Figura 2.21 ilustra as curvas do módulo do subleito vs $u / B$ (deslocamento/305 mm), comparando uma e duas geogrelhas. 


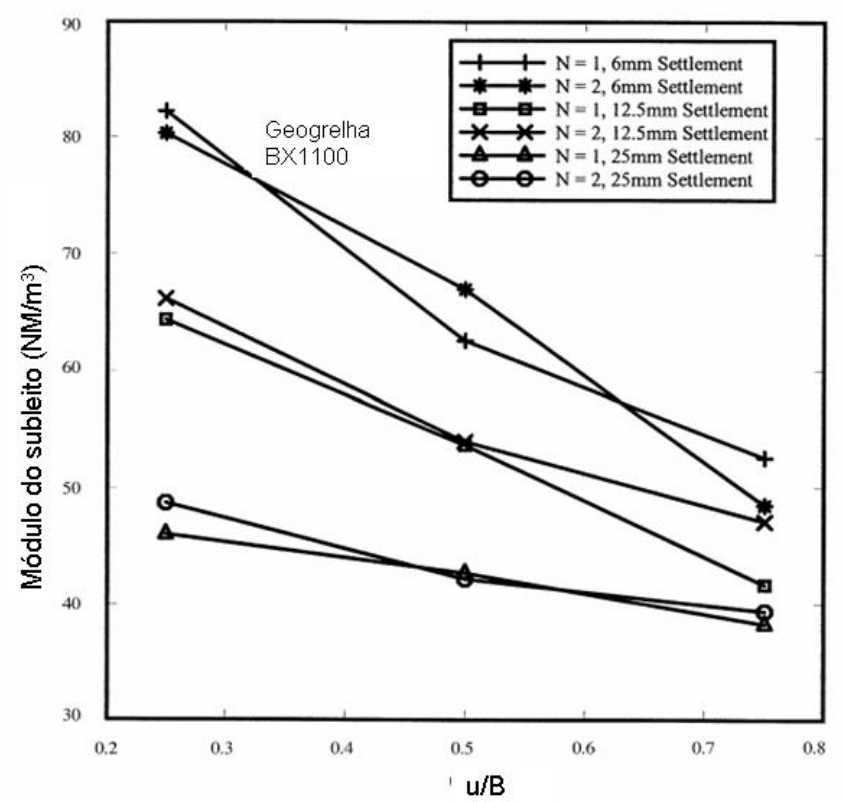

Figura 2.21 - Módulo do subleito vs u/B, para 1 e 2 geogrelhas (DEMERCHANT et al, 2002)

Tingle \& Jersey (2005), a partir de resultados de ensaios de laboratório, verificaram que quando aumentaram a espessura da base em $150 \mathrm{~mm}$, ou seja, passou de 360 para $500 \mathrm{~mm}$, o aumento na performance do pavimento devido ao uso de um geossintético, deixou de ser significativo.

\subsection{Efeito do tipo e características mecânicas do geossintético}

Baseado na literatura observa-se que os geossintéticos no reforço de camada de base de uma estrutura de pavimento flexível têm-se mostrado eficiente na melhora do desempenho do pavimento, dependendo da situação. As geogrelhas, na maioria das pesquisas, têm aumentado o TBR do pavimento, sendo que o módulo de rigidez do material tem tido uma parcela considerável nesse ganho. Para o geotêxtil, a melhora no comportamento estrutural do pavimento reforçado dar-se-á, 
principalmente, devido ao efeito membrana e separador, quando o subleito apresenta baixa capacidade de suporte.

O benefício gerado pelo geossintético em reforço de base se reflete na redução de afundamento em trilha de roda. Segundo Brown et al. (1983), a utilização de uma geogrelha de polipropileno como reforço de base de pavimento gerou uma redução de 20 a $58 \%$ no afundamento de trilha de roda.

Atualmente, existe no mercado uma grande diversidade de geogrelhas, variando quanto às dimensões de abertura de malha, o polímero utilizado, a resistência à tração na direção longitudinal e transversal, a rigidez e outros parâmetros. Para investigar qual geogrelha apresenta melhor desempenho, estudos foram desenvolvidos no sentido de averiguar essa variável.

Webster (1992) investigou o reforço da camada de base com seis tipos de geogrelhas (duas de polipropileno, uma biaxial de polipropileno e três de poliéster tecido), através de ensaios em escalas de campo, com a carga de $130 \mathrm{kN}$ aplicada por uma roda, o pavimento foi construído com $50 \mathrm{~mm}$ de espessura de revestimento, $355 \mathrm{~mm}$ de base de agregado e um subleito de CBR de $3 \%$.

A Figura 2.22 apresenta os valores de deslocamentos em função do número de carregamento para as seis geogrelhas analisadas e para uma seção de controle. Os melhores desempenhos foram obtidos pelas geogrelhas $\mathrm{B}$ e A sendo ambas de polipropilenos, divergindo no módulo secante a 5\%. 


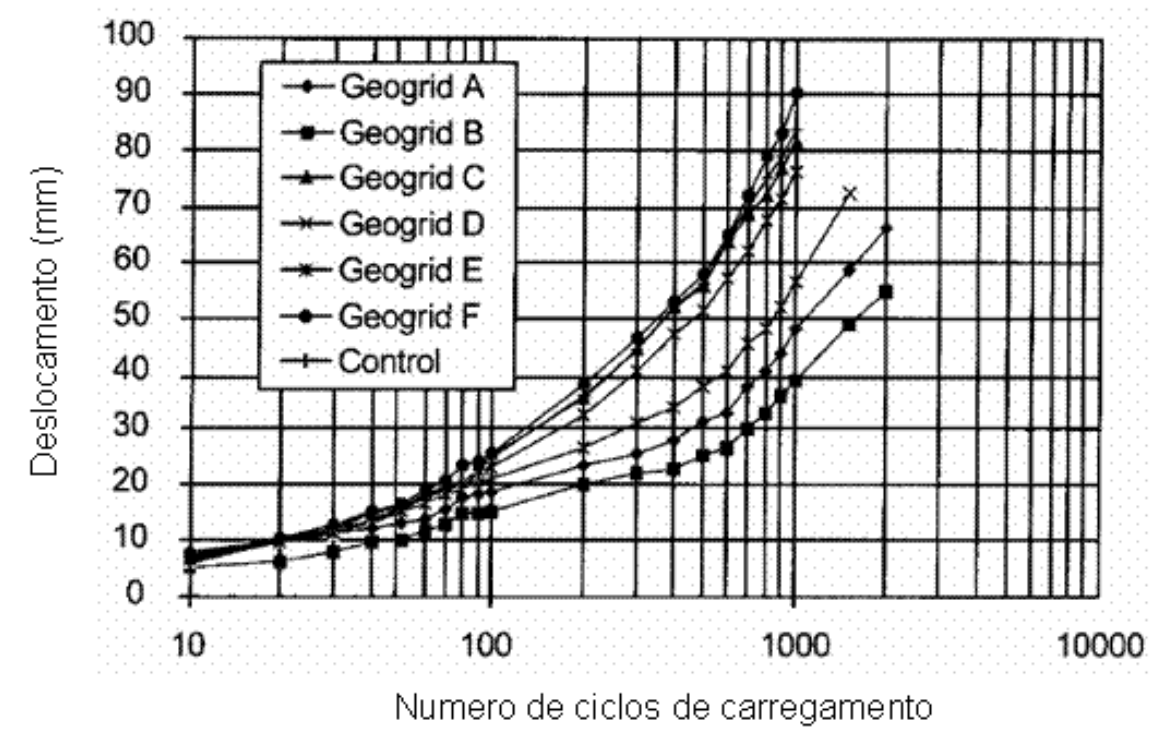

Figura 2.22 - Deslocamento versus numero de carregamento para diferentes
geogrelhas (WEBSTER, 1993) Ling et al (1998) avaliaram as resistências à tração de geogrelhas de diferentes polímeros sobre carregamento cíclico, os ensaios seguiram a ASTM D 4595. Observaram nos resultados de ensaio, que a resistência à tração da geogrelha de polipropileno não foi afetada significativamente pelo carregamento cíclico, já para as geogrelhas de poliéster e polietileno houve um aumento na resistência com os ciclos de carregamento. Sugeriram um modelo hiperbólico para expressar as tensões induzidas pelo carregamento cíclico nas geogrelhas analisadas.

Ao avaliar geogrelhas constituídas de mesmo polímero e mesma abertura de malha, divergindo apenas no módulo de rigidez (secante 5\%), observa-se que melhores desempenhos da estrutura reforçada são obtidos, quando se utiliza geogrelhas com maiores módulos (PERKINS, 1999). Collin et al. (1996) ao analisarem duas geogrelhas de polipropileno com diferentes módulos secantes a 5\% obtiveram valores de TBR 2,2 para a geogrelha de menor rigidez e TRB 4,8 para a 
geogrelha de maior módulo. Os valores de TBR foram obtidos a partir do deslocamento na superfície de $25 \mathrm{~mm}$.

O maior módulo de rigidez conduz a melhores desempenhos do reforço na camada granular, pois as geogrelhas flexíveis, para serem solicitadas por tração, necessitam de certa deformação para mobilizar sua resistência, para só assim propiciarem uma redução do afundamento da superfície na "trilha de roda".

Leng and Garb (2002) apresentam curvas da quantidade de ciclos de carregamento versus recalque da superfície da base, em que utilizaram $152 \mathrm{~mm}$ de espessura de base e duas geogrelhas de polipropileno de abertura de malha ( $25 \mathrm{x}$ $33 \mathrm{~mm}$ ) e resistência a tração a 2\%, de deformação de 4,1 kN/m (BX1) e 6,0 kN/m (BX2). A Figura 2.23 compara as curvas obtidas dos ensaios com a geogrelha BX1, geogrelha BX2 e sem utilização de geogrelha. A maior redução nos deslocamentos foi observada da BX2 com $67 \%$ se comparada a seção não reforçada, confirmando a importância do parâmetro de rigidez, no comportamento de uma estrutura reforçada.

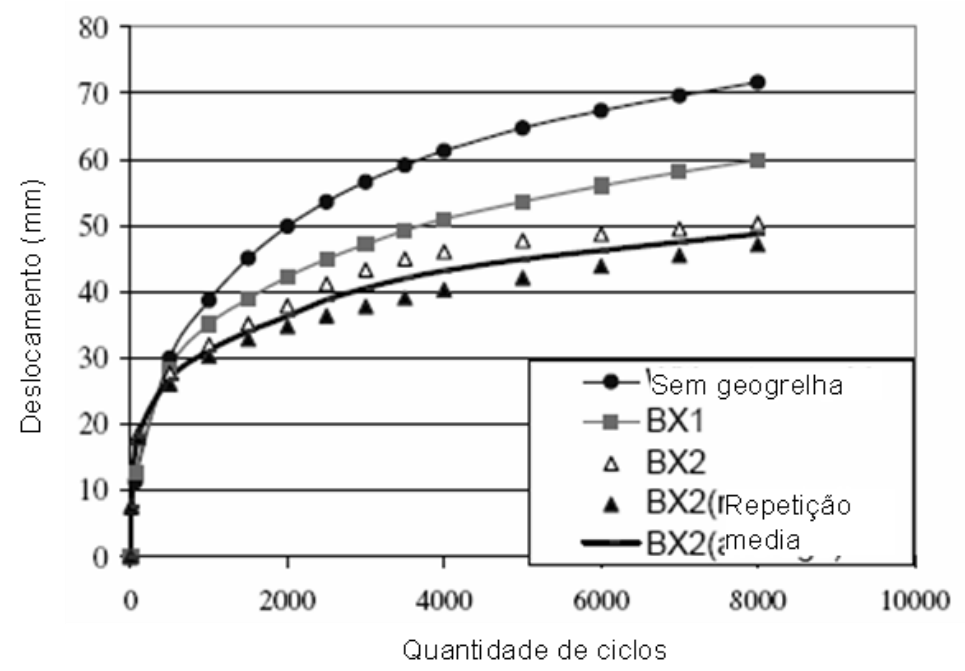

Figura 2.23 - Superfície de deslocamento para base de espessura $152 \mathrm{~mm}$ (LENG and GARB,2002) 
A utilização de geogrelha em base de pavimento pode também melhorar o desempenho do pavimento quanto à vida de fadiga do revestimento asfáltico. Dondi (1994 apud Vertematti, 2004) verificou a partir de segmento de rodovia instrumentada que quanto mais elevada a rigidez da geogrelha, maior é a vida de fadiga. Logo, a presença desta geogrelha propiciou um aumento da vida de fadiga da estrutura de 2 a 2,5 vezes, quando comparada a uma estrutura sem reforço.

\subsection{Efeito do geossintético na distribuição de tensão no topo do subleito}

Uma das principais funções de uma geogrelha em um sistema de reforço da camada de base de uma estrutura de pavimento é absorver partes das tensões horizontais e verticais, que chegam ao topo do subleito e redistribuir as tensões de forma a diminuir a sua concentração e magnitude.

Leng and Garb (2002) verificaram as tensões verticais que chegam no topo do subleito, utilizando quatro células de tensão totais com diâmetro de $50 \mathrm{~mm}$, posicionadas em relação ao centro de carregamento de 0, 152, 305 e $457 \mathrm{~mm}$. Observaram uma diminuição da tensão vertical no topo do subleito, sendo os maiores valores encontrados sobre o ponto de carregamento, apresentando uma diminuição de $360 \mathrm{kPa}$ (sem geogrelha) para $220 \mathrm{kPa}$ (com geogrelha BX2).

A Figura 2.24 visualiza as curvas da tensão vertical no topo do subleito vs distanciamento do centro de carregamento. Destaca-se destas curvas, a diminuição das tensões verticais logo abaixo do carregamento e a melhor distribuição das 
tensões, para as seções em que utilizaram a geogrelha, nota-se também que para distâncias radiais superiores a $400 \mathrm{~mm}$ não chegam tensões verticais no subleito.

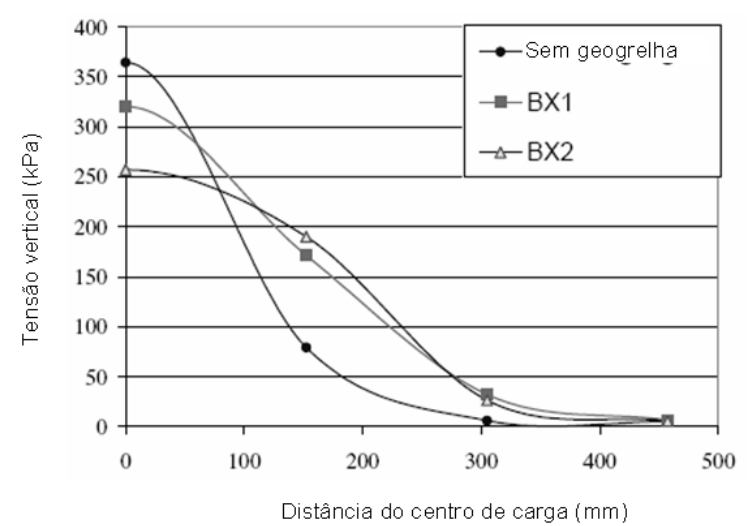

(a)

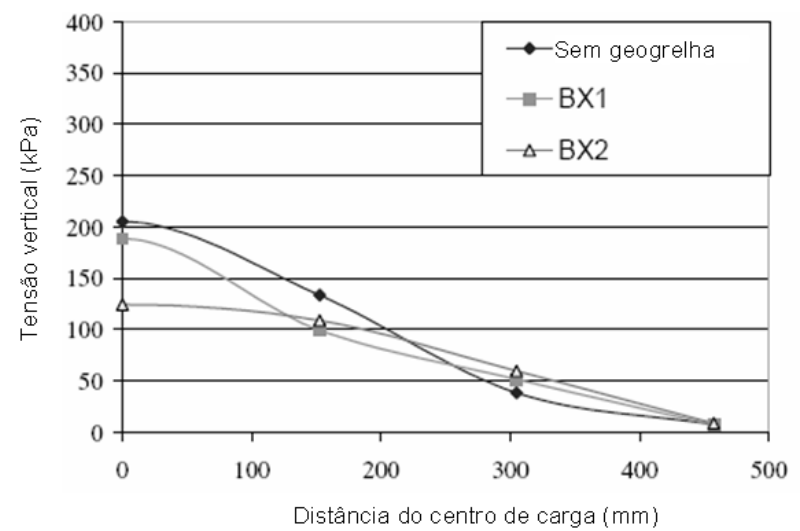

(b)

Figura 2.24 - Distribuição da tensão vertical para 8000 ciclos; a) $152 \mathrm{~mm}$ de base e b) $254 \mathrm{~mm}$ de base (LENG and GARB,2002)

\subsection{Efeito da capacidade de suporte do subleito}

O ganho de benefício de um geossintético em uma estrutura de pavimento reforçada passa a ser marginal quando este é aplicado em um subleito que apresente boa capacidade de suporte. A medida que o valor de CBR aumenta, a taxa de benefício diminui. Perkins et al. (1999) demonstraram que a utilização de geossintético proporcionou um significativo aumento na performance do pavimento, quanto às deformações permanentes na superfície, sendo mais efetivo quando se utilizou um subleito de argila de CBR $1,5 \%$ ao invés de um subleito de areia siltosa de CBR $15 \%$. 
Tingle and Jersey (2007) apresentam uma comparação entre os métodos empíricos de Giroud and Noiray (1981), Giroud and Han (2004) e Enginner Technical Letter 1110-1-189 (2003) para reforço de geossintéticos em rodovias de baixo volume de tráfego.

A Figura 2.25 apresenta as curvas de espessura de agregado requerido em função do CBR do subleito para os três modelos (não considerando a utilização de um geossintético).

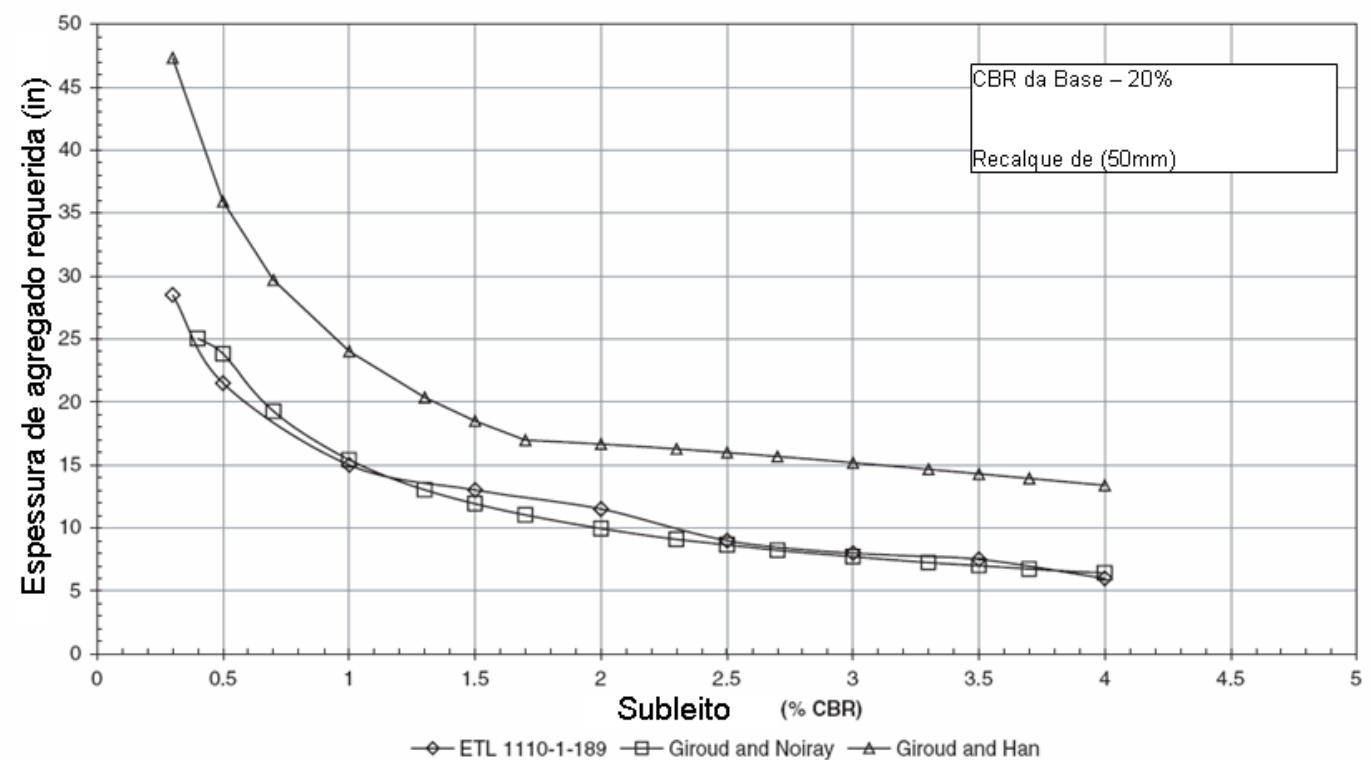

Figura 2.25 - Espessura da camada de agregado para um pavimento sem revestimento, recalque de $50 \mathrm{~mm}, 1000$ passadas de veículos (TINGLE AND JERSEY, 2007)

$\mathrm{Na}$ Figura 2.26 são apresentadas as curvas em que se utilizou um geossintético como reforço. 


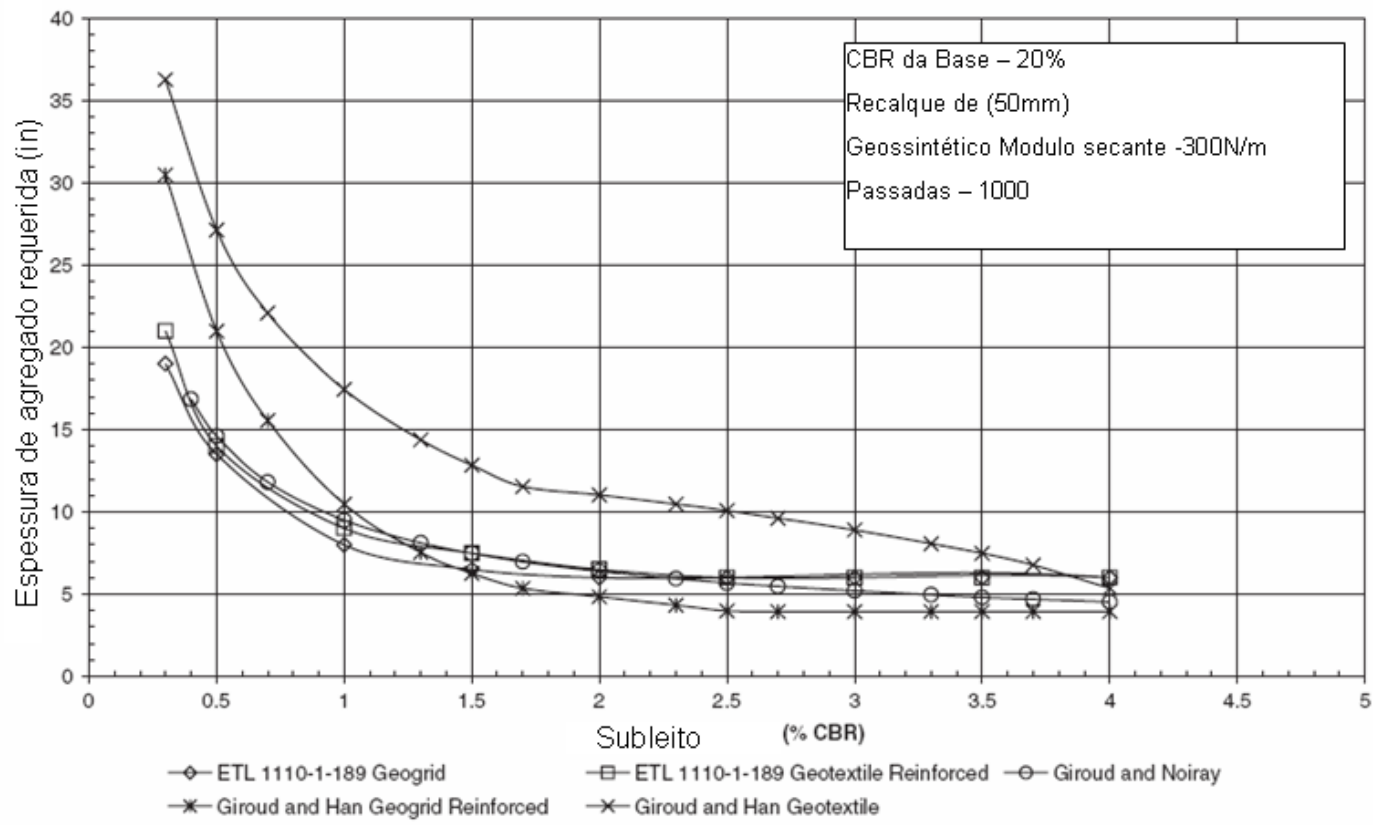

Figura 2.26 - Espessura da camada de agregado para um pavimento reforçado com geossintéticos, recalque de $50 \mathrm{~mm}, 1000$ passadas de veículos (TINGLE AND JERSEY, 2007)

Ao comparar as Figuras 2.25 e 2.26, observa-se que as espessuras requeridas para o mesmo $\mathrm{CBR}$ do subleito, considerando uma seção com e sem reforço, vão diminuindo a medida que o CBR aproxima-se de 4\%. A partir daí o benefício gerado pelo geossintético passa a ser mínimo. Na Figura 2.27 é apresentada a comparação de uma estrutura com e sem reforço, para diferentes níveis de passadas, segundo o método de Giroud and Nouray. 


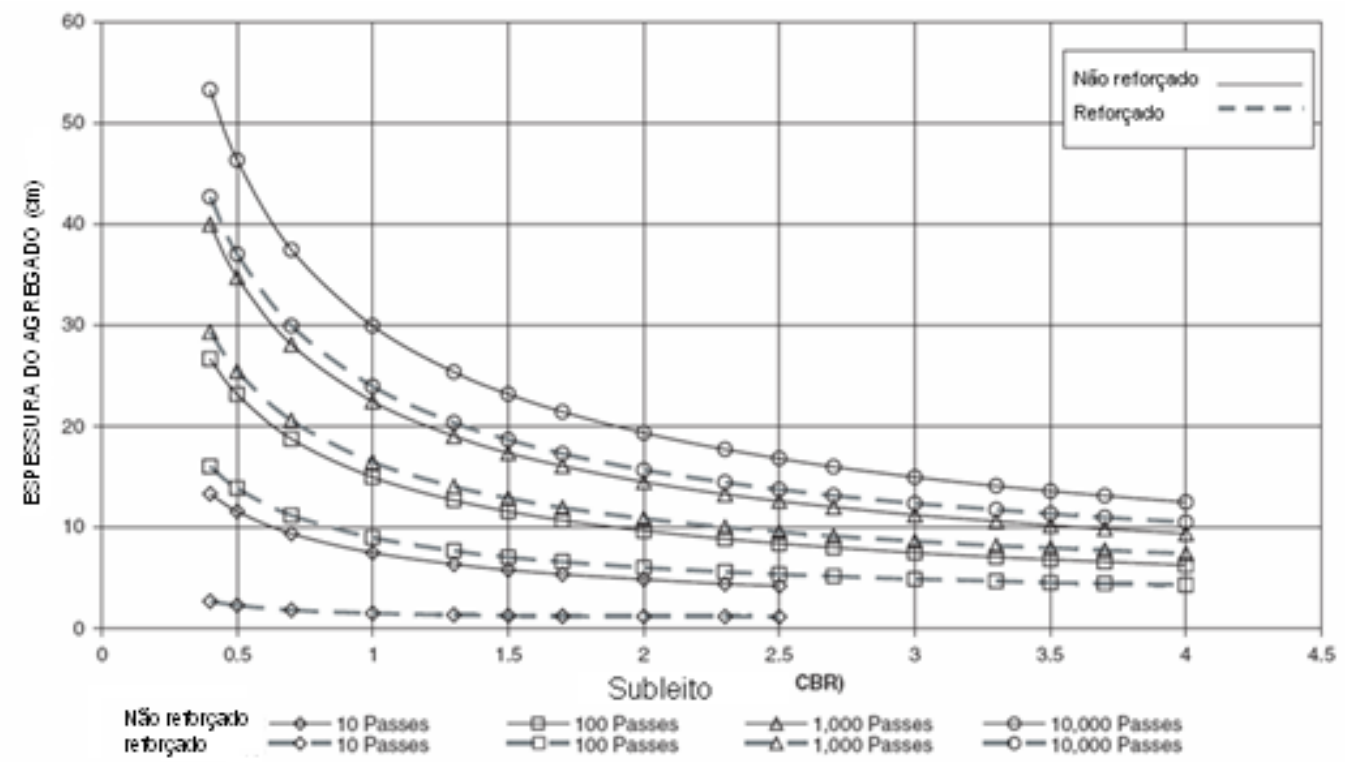

Figura 2.27 - Método para espessura do agregado em função do subleito de Giroud and Noiray, (TINGLE AND JERSEY, 2007)

\subsection{Efeito da forma de aplicação do carregamento nos ensaios}

O desempenho do pavimento com a inserção de um geossintético foi observado em experimentos de laboratório, tanto para carregamentos estáticos, como cíclicos. Os resultados mostraram que os pavimentos reforçados com geossintéticos apresentam período de projeto superior a um pavimento similar sem a utilização de reforço (KLEIN et al., 1996 e 2003; MIURA et al., 1990).

Haas (1988) comparou um pavimento convencional com um reforçado com geossintético, utilizando um carregamento dinâmico sobre uma placa circular rígida, com frequência de $10 \mathrm{~Hz}$ e carregamento de 40 kN. O pavimento reforçado aguentou 3 vezes o carregamento de um sem reforço, possibilitando uma redução de 25 a 40\% na espessura do concreto asfáltico. 
Perkins et al. (1998) utilizaram geogrelha de polipropileno e um geotêxtil tecido como reforço de pavimento, o carregamento foi sobre uma placa rígida circular colocada sobre uma almofada de borracha, concluíram que a diferença é insignificante para um carregamento estático, mas quando utilizaram carregamento cíclico, observaram diferença significativa entre um pavimento reforçado e sem reforço.

Hoe et al. (1998) investigaram o comportamento de três tipos de geogrelhas (polipropileno, poliéster e polietileno de alta densidade), quando solicitado sob carregamento estático e cíclico. Os testes foram realizados com deformações controladas (taxa de 10\%/ minuto) para 100 ciclos de diferentes taxas de carregamento. Os resultados mostraram que a resistência da geogrelha de polipropileno não foi significativamente afetada pelo carregamento cíclico. Já para as geogrelhas de poliéster e polietileno, a resistência foi aumentada pelo efeito do carregamento cíclico e pela taxa de carregamento. A rigidez das geogrelhas elevouse com o aumento dos ciclos de carregamentos e para maiores taxas de carregamento. Sugeriram uma relação hiperbólica para expressar as deformações induzidas pelo carregamento cíclico.

Hoe and Zheng (2001) concluíram que os resultados dos testes de carregamento estático e dinâmico indicaram que os geossintéticos contribuiram para o aumento da rigidez e da resistência do pavimento asfáltico analisado. Entretanto, esse ganho foi mais significativo nos ensaios sobre carregamento dinâmico se comparado com os ensaios sobre carregamento estático. 


\subsection{Efeito do geossintético no módulo de resiliência da camada de base}

Kinney et al (1998) utilizaram resultados de medidas de FWD em equipamento de laboratório em grande escala, para obterem os módulos resilientes da camada de base afetada pela inclusão de uma geogrelha, com o uso da retroanálise. Adotaram um revestimento asfáltico de $61 \mathrm{~mm}$ de espessura com módulo de $2990 \mathrm{MPa}$, um subleito com módulo de 137,8 MPa. A espessura da camada de base afetada pela geogrelha foi variada em 76, 102, 152 e $203 \mathrm{~mm}$ de espessura.

A Figura 2.28 apresenta as curvas dos módulos obtidos por retroanálise em função da espessura da base e da camada afetada pela geogrelha. Verificaram que a espessura afetada pela geogrelha foi de $153 \mathrm{~mm}$ e desta forma analisaram a variação do módulo com a espessura da camada de base em que utilizaram duas geogrelhas e uma seção de controle, conforme apresentado na Figura 2.29. 


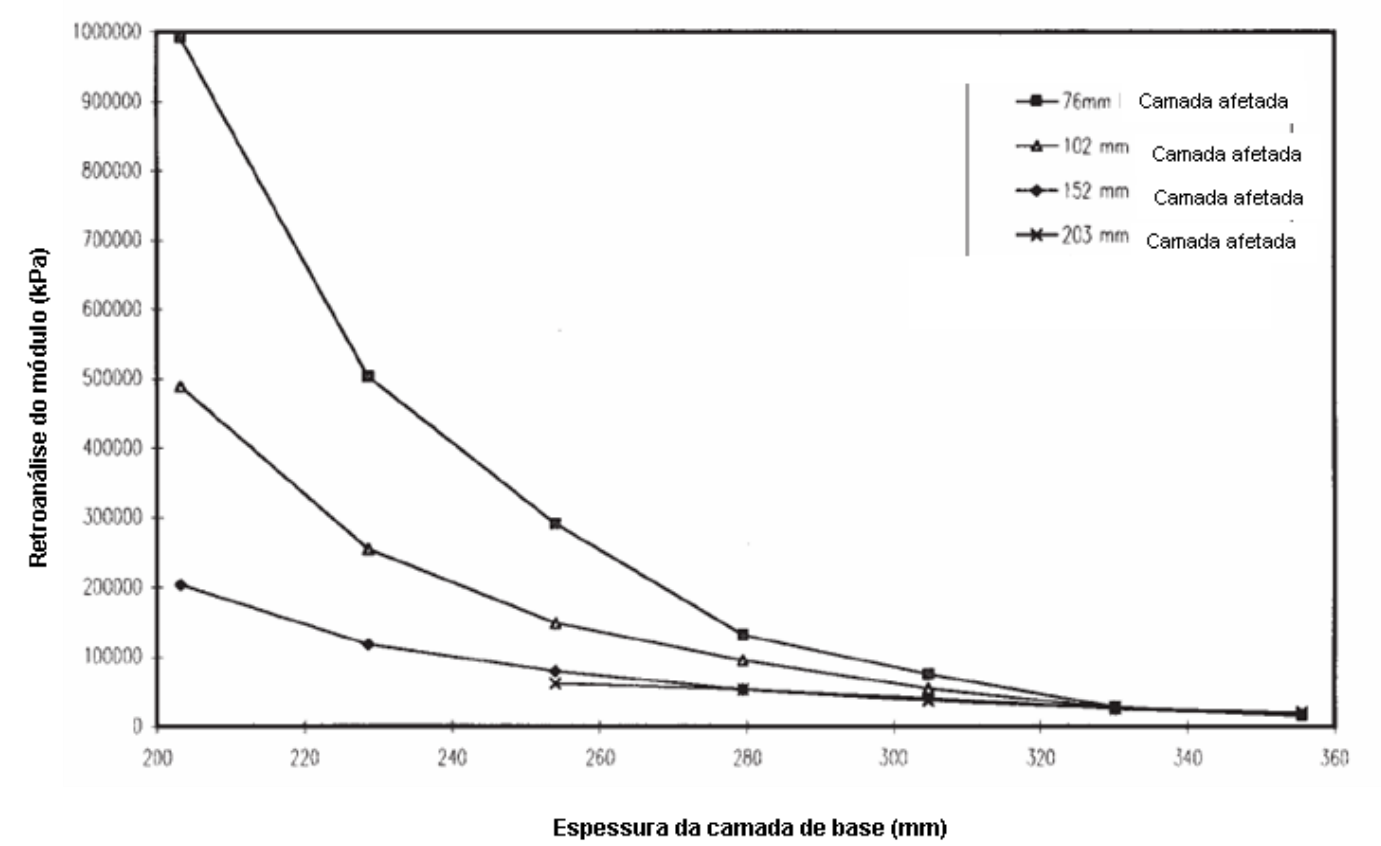

Figura 2.28 - Espessura da base vs retroanálise do módulo (KINNEY, 1998)

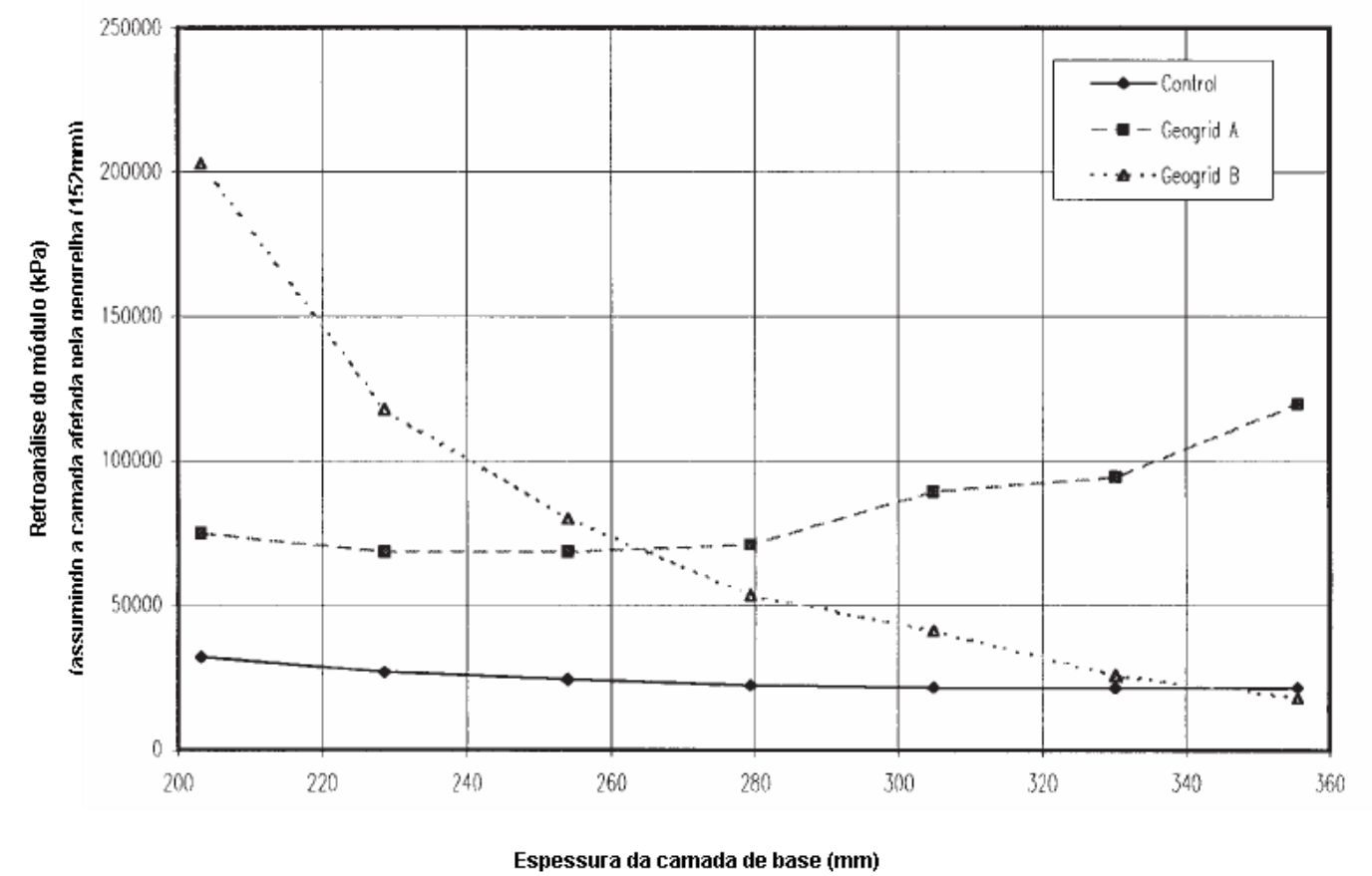

Figura 2.29 - Espessura da base vs retroanálise dos módulos variando a geogrelha (KINNEY, 1998)

Kim et al. (2005) avaliaram o efeito do geossintético na estrutura de pavimento, que foi expresso em termos de "fator de reforço" definido como a relação 
do módulo elástico da camada reforçada com geossintético e o módulo elástico da camada de controle (sem reforço).

Esses módulos foram obtidos por retroanálise de resultados de ensaios de laboratório, em que as estruturas comparadas apresentaram as mesmas espessuras e mesmo material granular. Observaram menores deflexões elásticas e maiores módulos elásticos de estrutura reforçadas quando comparadas com estruturas sem reforço. Os valores de fator de reforço foram da ordem de 1,7 a 2,0, sendo que as geogrelhas apresentaram maiores valores de módulos.Utilizaram para retroanálise do módulo elástico o program Kenlayer dado pela equação 2.33

$$
M_{R}=k_{1} \cdot \sigma_{b}^{k_{2}}
$$

Em que: $\quad k_{1}$ e $k_{2}$ : constantes empíricas; e.

$\sigma_{b}$ : tensões.

Leng and Garb (2006) para estimar os parâmetros de espessura equivalente, que transforma um sistema de várias camadas com diferentes módulos em uma única camada, máxima tensão vertical no topo do subleito e ângulo de propagação das tensões, por meio de retroanálise, utilizaram o método de Odemark, auxiliado pela solução de Boussinesq.

As equações $2.34,2.35,2.36,2.37$ e 2.38 . apresentam: a espessura equivalente, deflexão vertical no topo do subleito, compressão da camada de base, tensão vertical de interface e tangente do ângulo de propagação das tensões.

$$
h_{e}=h \cdot\left[\frac{E_{1} \cdot\left(-\mu_{2}^{2}\right.}{E_{2} \cdot\left(-\mu_{1}^{2}\right.}\right]^{1 / 3}
$$

Em que: $\quad h$ : constantes empíricas; 
$E_{1}$ : módulo elástico da base;

$E_{2}$ : módulo elástico do subleito

$\mu_{1}$ : poisson da base; e

$\mu_{2}$ : poisson do subleito.

$$
\sigma_{c}=p \cdot\left[1-\frac{h_{e}^{3}}{\left.\sigma^{2}+h_{e}^{2}\right)^{1 / 2}}\right]
$$

Em que: $\quad \sigma_{c}$ : máxima tensão vertical no topo do subleito;

a: raio da placa; e

p: pressão.

$$
w_{s}=\frac{\left(+\mu_{2} j p \cdot a\right.}{E_{2}}\left\{\frac{a}{\mathbf{G}^{2}+h_{e}^{2},}+\frac{1-2 \mu_{2}}{a} \cdot\left[\mathbf{g}^{2}+h_{e}^{2},-h_{e}\right]\right\}
$$

Em que: $\quad W_{s}$ : deflexão vertical no subleito.

$$
\Delta w_{s}=\frac{\mathbf{Q}+\mu_{1} j p \cdot a}{E_{1}}\left\{1-\frac{a}{\mathbf{g}^{2}+h_{e}^{20,5}}+\frac{1-2 \mu_{1}}{a} \cdot\left[a+h-\boldsymbol{\theta}^{2}+h^{2}{ }^{4,5}-h_{e}\right]\right\}
$$

Em que: $\quad \Delta W_{s}$ : compressão da camada de base.

$$
\tan \alpha=\frac{a}{h} \cdot\left(\sqrt{\frac{p}{\sigma_{c}}-1}\right)
$$

A Figura 2.30 apresenta as curvas $\tan \alpha$ em função de $a / h$ e $E_{1} / E_{2}$. 


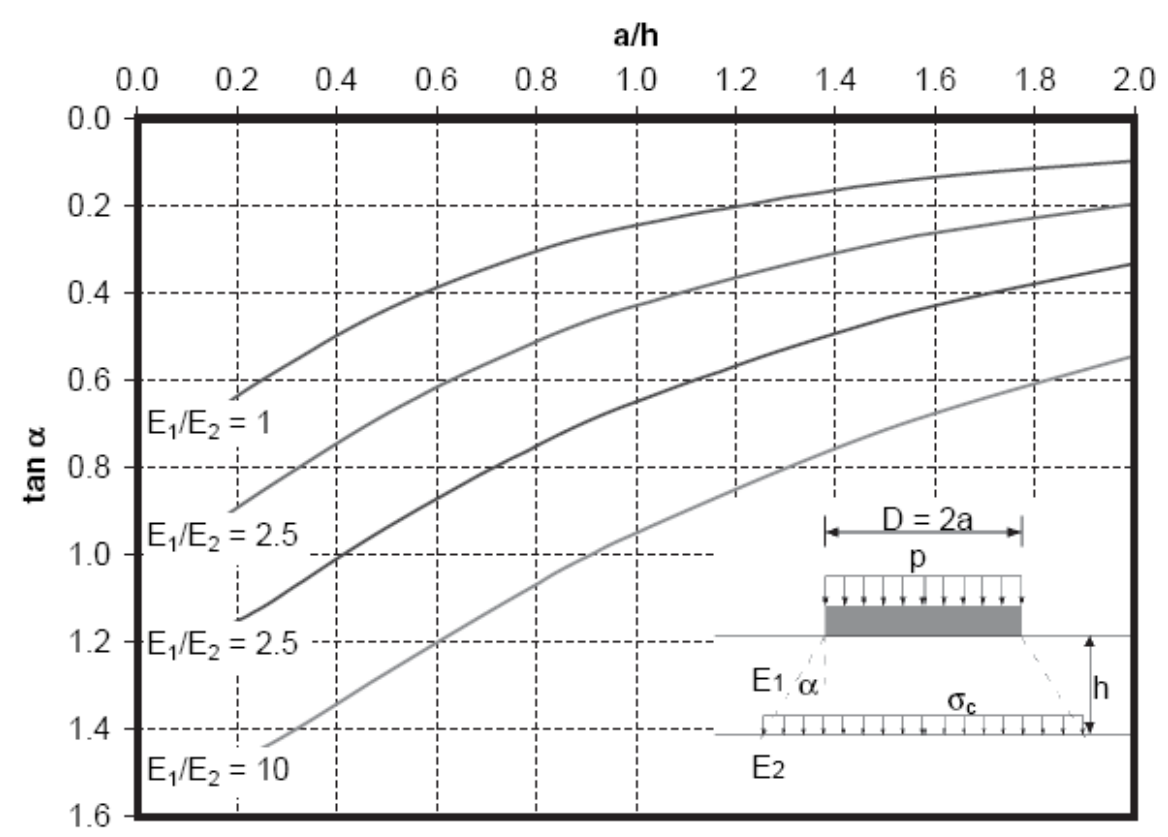

Figura 2.30 - Distribuição das tensões no fator $\tan \alpha$ para sistema de duas camadas (LENG AND GARB, 2006)

\subsubsection{Dimensionamento de pavimento considerando o uso de geossintético}

Os métodos, geralmente, utilizados para o dimensionamento estrutural de seções de pavimentos reforçados com geossintéticos são baseados em métodos analíticos, dos quais cita-se: Giroud e Noiray (1981), Burd (1995), Milligan et al. (1989) ,Housbly e Jewell (1990). Esses métodos fazem simplificações nas condições encontradas no campo, principalmente em relação ao carregamento cíclico.

De modo geral, os métodos analíticos consideram que a camada granular é responsável por suportar as cargas do tráfego e distribuir de forma trapezoidal as tensões oriundas do tráfego. Consideram que as deformações permanentes provem basicamente do subleito. Com relação às propriedades mecânicas do reforço, os 
métodos consideram, geralmente, a resistência à tração e o modulo de rigidez do geossintético. A seguir apresentam-se alguns métodos de dimensionamento de pavimento reforçados com geossintéticos.

\subsection{Giroud e Han (2003)}

Para o dimensionamento de rodovias não-pavimentadas com reforço de um geossintético, a espessura da camada granular será calculada pela equação 2.39.

$h=\frac{0,868+\left(\mathbf{0 , 6 6 1 - 1 , 0 0 6 \cdot J ^ { 2 }} j\left(\frac{r}{h}\right)^{1,5} \cdot \log N\right.}{1+0,204 \cdot \boldsymbol{R}_{E}-1} \cdot\left\{\sqrt{\frac{\frac{P}{\pi \cdot r^{2}}}{\left(\frac{s}{f_{s}}\right) \cdot\left[1-0,9 \cdot \exp \left(-\left(\frac{r}{h}\right)^{2}\right)\right] \cdot N_{c} \cdot f_{c}}}-1\right\} \cdot r$

Em que: $\quad h$ : espessura da base granular $(m)$;

J: módulo de estabilidade de abertura da geogrelha (m-N/grau);

N: número de repetições do eixo padrão (AASHTO);

$P$ : carga de roda $(\mathrm{kN})$;

$r$ r raio da área de contato da roda equivalente $(\mathrm{m})$;

$R_{E}: 3,48 .\left(\mathbf{C B R}_{\text {base }}\right)^{0,3} / \mathbf{C B R}_{\text {sub; }}$

$s:$ profundidade máxima permitida da trilha de roda $(\mathrm{mm})$;

$f_{s}:$ fator igual a $75 \mathrm{~mm}$;

$N_{c}$ : fator de capacidade de carga; e

$f_{c}$ : fator igual a $30 \mathrm{kPa}$. 
$\left(N_{c}=3,14\right.$ e $J=0$ para base não-reforçada; $N_{c}=5,14$ e $J=0$ para base reforçada com geotêxtil; $N_{c}=5,71$ e $J=0,32$ para base reforçada com geogrelha e limitar o valor de $R E$ em 5 para bases não-reforçadas)

\subsection{AASHTO (1993)}

O método da AASHTO (1993) é utilizado para rodovias pavimentadas com reforço de geossintético, conforme a equação 2.40 .

$9,36 \cdot \log _{10} \$ N+1 \ni \frac{\log _{10} \cdot\left[\frac{\Delta P S I}{4,2-1,5}\right]}{0,40+\frac{1.094}{N_{e}+1^{519}}}-\log W_{18}-2,32 \cdot \log M_{R} \ni+Z_{R} \cdot S_{0}-8,27=0$

Em que: $\triangle P S I$ : perda de serventia esperada durante o período de projeto (tipicamente entre 1,7 e 2,2);

$W_{18}$ : número de solicitações equivalentes ao eixo padrão de $82 \mathrm{kN}$, calculado com os coeficientes da AASHTO;

$M_{R}$ : módulo de resiliência do subleito (psi);

$Z_{R}$ : desvio padrão para a probabilidade de êxito, que se quer para a estrutura dimensionada (entre -0,84 e -1,34 para probabilidade de êxito de 80 e $91 \%$, respectivamente);

$S_{0}$ : desvio padrão que leva em conta as incertezas das variáveis medidas e do processo construtivo (entre 0,44 e 0,49); e. 
SN: número estrutural que representa a capacidade que o pavimento dimensionado deverá ter para atender ao tráfego estimado para o período de projeto.

O número estrutural é calculado pela equação 2. 41.

$$
S N=a_{1} D_{1}+a_{2} D_{2} m_{2}+a_{3} D_{3} m_{3}
$$

Em que: $\quad a_{i}$ : coeficiente estrutural do material da camada i;

$D_{\mathrm{i}}$ : espessura da camada i (polegadas); e.

$m_{i}$ : coeficiente de drenagem da camada i.

Da equação 2.41 , obtém o valor de $N_{e}$ que a torne nula e para contemplar o aumento da vida ou período de projeto que a geogrelha proporciona, utiliza-se a TBR conforme equação 2.42 .

$9,36 \cdot \log _{10} S N_{B R}+1+\frac{\log _{10} \cdot\left[\frac{\Delta P S I}{4,2-1,5}\right]}{0,40+\frac{1.094}{S N+1^{519}}}-\log \frac{W_{18}}{T B R}-2,32 \cdot \log M_{R}+Z_{R} \cdot S_{0}-8,27=0$

Em que: $\quad T B R$ : taxa de benefício de tráfego; e

$S N_{b r}$ : número estrutural considerando a contribuição de geogrelha.

\subsection{Milligan}

Este método é indicado tanto para estradas pavimentas, quanto para estradas não pavimentadas, construídas sobre argilas moles. O método considera que o 
geossintético absorve os esforços cisalhantes oriundos do tráfego, fazendo com que chegue ao subleito apenas as tensões verticais. Neste caso admite-se o valor clássico de ruptura sobre solos moles $(N c=2+\pi)$, para o fator de capacidade de carga.

Para o cálculo da carga que leva à ruptura do aterro os autores sugerem a correlação proposta por De Groot et al. (1986) entre a carga estática e a carga cíclica, conforme apresentado na equação 2.43 .

$$
\frac{P_{S}}{P_{n}}=N^{0,16}
$$

Em que: $\quad P_{s}$ : carga estática;

$P_{n}$ : carga cíclica; e

N: o no de repetições da carga $P n$.

Como a carga por unidade de área é igual tanto na superfície do pavimento quanto na superfície do subleito, por equilíbrio tem-se

$$
p \cdot B=p^{\prime} \cdot B^{\prime} \Rightarrow p=p^{\prime} \cdot \frac{B^{\prime}}{B}
$$

Em que: $\quad B$ : largura da área sobre a qual a tensão atua na superfície;

B': largura da área sobre a qual a tensão atua no subleito devido ao espraiamento;

p e $p^{\prime}:$ forças aplicadas na superfície e no subleito respectivamente.

Sendo $p$ ' igual a $N_{c} S_{u}$, tem-se a equação 2.45 .

$$
p=N_{c} \cdot S_{u} \cdot\left(\frac{B^{\prime}}{B}\right)
$$

Logo, obtém-se a pressão vertical admissível, apresentada pela equação 2.46 . 


$$
p=\mathbf{P}+\pi ; S_{u} \cdot\left(\frac{B^{\prime}}{B}\right)
$$

A tensão horizontal mínima desenvolvida ao longo da superfície $A D$, conforme apresentada na Figura 2.31 é dada pela equação 2.47 e a força passiva atuante na superfície CE pela equação 2.48 .

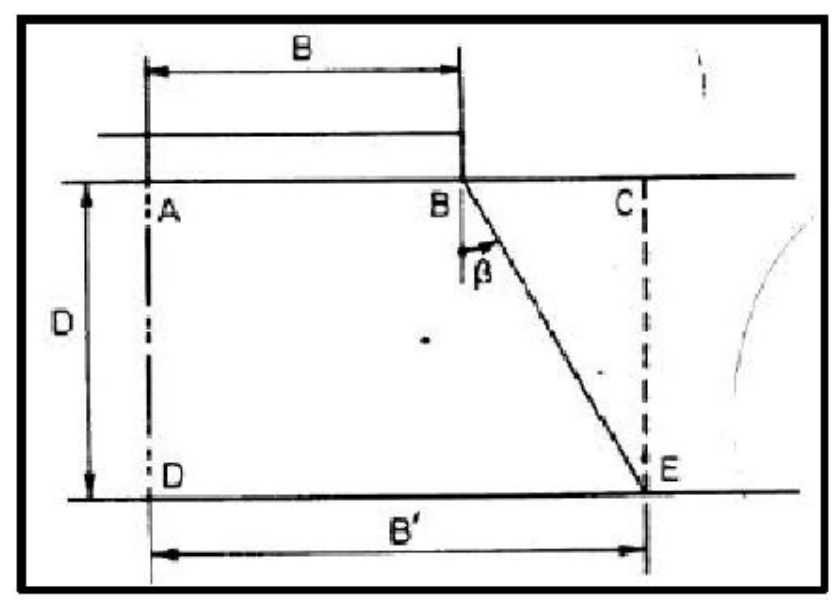

Figura 2.31 - Distribuição das tensões na camada de aterro (Milligan et al. 1989)

$$
\begin{gathered}
A D=k_{a} \cdot \sigma_{v}^{\prime} \\
C E=1 / 2 \cdot k_{p} \cdot \gamma \cdot D^{2}
\end{gathered}
$$

Em que: $\quad k_{a}=\frac{1-\operatorname{sen} \phi}{1+\operatorname{sen} \phi}$

$$
k_{p}=\frac{1+\operatorname{sen} \phi}{1-\operatorname{sen} \phi}
$$

O equilíbrio horizontal do bloco retangular ABCED implica a expressão 2.49, que fornece o valor mínimo da tensão de cisalhamento requerida na base do bloco, para um dado valor de carregamento.

$$
\tau_{r} \cdot B^{\prime}=\frac{K_{a}-K_{p}}{2} \cdot \gamma \cdot D^{2}+\frac{K_{a} \cdot p \cdot B}{\tan \beta} \cdot \ln \left[\frac{B^{\prime}}{B}\right]-p \cdot B \cdot \tan \delta
$$


Logo a tração é obtida pela expressão 2.50

$$
T=\tau_{r} \cdot B^{\prime}
$$

A verificação quanto à possibilidade de ruptura da camada de aterro granular por puncionamento, é baseada na proposta de Vesic (1975). A carga máxima suportada pela camada granular é dada pela equação 2.51 .

$$
p=\gamma \cdot B \cdot N_{\gamma}
$$

Em que: $\quad N_{\gamma}=2 N_{q}+1 j \tan \phi$;

$$
N_{q}=\frac{1+\operatorname{sen} \phi}{1-\operatorname{sen} \phi} \cdot e^{\pi \cdot \tan \phi}
$$

\subsection{Leng and Gabr (2006)}

Os autores propõem um modelo para avaliar os efeitos da geogrelha colocada na interface subleito/base em uma estrutura de pavimento sem revestimento. $O$ modelo é empírico, e os parâmetros de entrada são obtidos dos resultados de ensaio do equipamento apresentado Leng and Gabr (2002).

Os efeitos estimados pelo modelo são a transferência de tensão vertical, devido a interação da geogrelha e camada de base; capacidade de carga do subleito e a mobilização da capacidade de carga do subleito.

Em projetos de rodovias não pavimentadas, o ângulo de distribuição das tensões é usado para simplificar a transferência de tensão da camada de base para 
o subleito. A tensão vertical adicional no subleito pode ser expressa pela equação 2.52 .

$$
\sigma_{c}=\frac{p a^{2}}{a+h \tan \alpha^{2}}
$$

Em que: $\quad p$ : pressão do pneu que atua na base;

a: raio do circulo da área de carga;

$h$ : espessura da camada de base; e

$\alpha$ : ângulo de distribuição das tensões.

Baseado na teoria da plasticidade, o fator de capacidade de carga do subleito (Nc) para deformação plana pode ser expressa pela equação 2.53 .

$$
N_{C}=1+\frac{\pi}{2}+\operatorname{CoS}^{-1} \cdot \alpha_{a}+\sqrt{1-\alpha_{A}^{2}}
$$

Em que: $\quad \alpha_{a}=\tau_{a} / \mathrm{C}_{\mathrm{u}}$

$\tau_{\text {a: }}$ tensão cisalhante no topo do subleito; e

$C_{u}$ : resistência cisalhamento não drenada no subleito.

O fator de capacidade de carga depende da tensão de cisalhamento transferido pela camada de base. Para seções não reforçadas $N_{c}=(\pi / 2+1)$ e para pavimentos reforçados, o fator de capacidade de carga $N c=(\pi+2)$ (interface lisa) e $N c=(3 \pi / 2+1)$ (interface rugosa).

O método simplificado de duas camadas pode ser usado para avaliar a capacidade de carga mobilizada do subleito de uma rodovia não revestida. 0 carregamento no topo da camada de base é simplificada para um carregamento sobre uma placa circular flexível com raio (a). 
As tensões verticais são distribuídas sobre um ângulo $(\alpha)$ sendo a área no topo do subleito com raio $\left(a^{\prime}=a+h \tan \alpha\right)$. A capacidade de carga mobilizada do subleito pode ser calculada pela equação 2.54.e a superfície de deslocamento pela equação 2.55 .

$$
\begin{gathered}
N_{C m} \cdot C_{u}=p_{c m}=\frac{E_{s} \cdot w_{s}}{2 \cdot\left(-\mu_{s}^{2} j \cdot h+h \tan \alpha\right)}=\left(\frac{a / h}{a / h+\tan \alpha}\right) \cdot\left(\frac{w_{s}}{w_{c r}}\right) \cdot N_{c} \cdot C_{u} \\
w=w_{c r}=w_{s}+\Delta w_{1}
\end{gathered}
$$

Em que: $\quad N_{c m}$ : fator de capacidade de carga mobilizada correspondente ao recalque crítico;

$N_{c}$ : capacidade de carga do subleito; e

W: superfície de deslocamento.

A taxa de capacidade de carga mobilizada $\left(m=N_{c m} / N_{c}\right)$ foi introduzida para representar a resistência mobilizada do subleito como função do nível de deslocamento. A Figura 2.32 relaciona $\mathrm{m}$ em função de a/h e E1/E2 e a partir da curva encontrada por regressão obteve-se a equação 2.56 . 


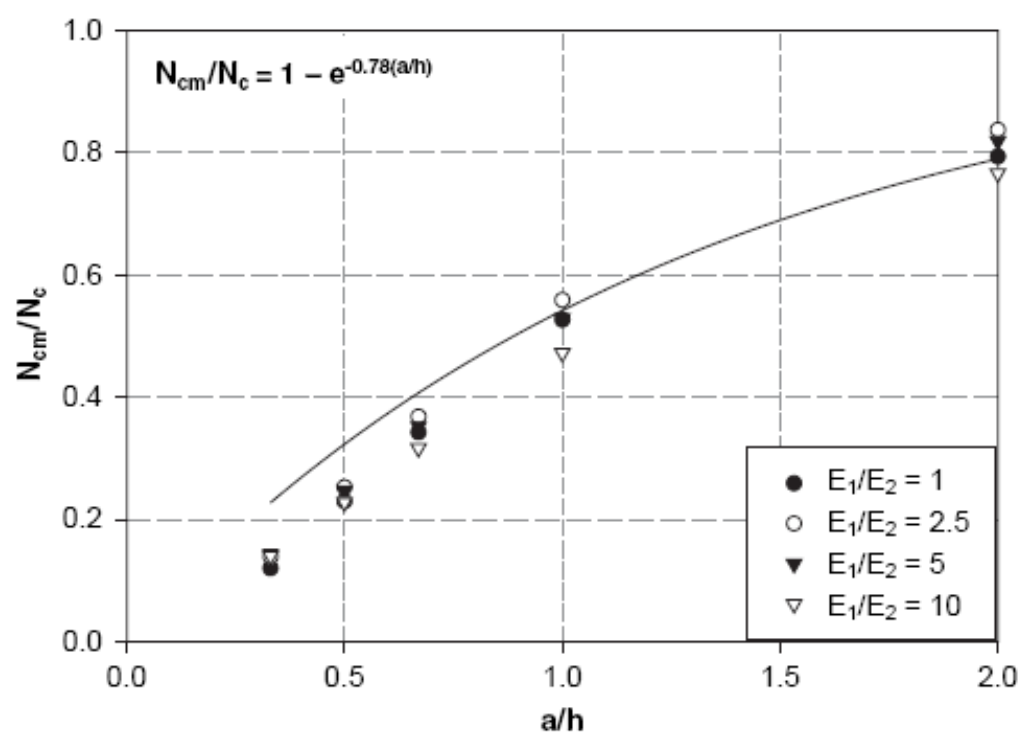

Figura 2.32 - Taxa de capacidade de carga mobilizada (LENG AND GARB, 2006)

$$
m=\frac{N_{c m}}{N_{c}}=1-e^{-0,78 / h^{\prime}}
$$

O $m$ é baseado na condição de deslocamento da superfície e é o deslocamento crítico que caracteriza a capacidade de carga mobilizada do subleito. Para projetos de pavimentos sem revestimento, um valor típico permitido é de 0,05 a 0,1 m. Considerando que o afundamento inclui compressão e movimentos laterais da base e recalque do subleito, é possível que a superfície de afundamento permitido seja maior que o deslocamento crítico do subleito. Logo, $m$ pode ser ajustado de acordo com o critério adotado (r), dado pela equação 2.57, e por fim a equação 2.58 para obter a capacidade de carga mobilizada.

$$
\begin{gathered}
m=\mathbf{I}-e^{-0,78 / h}=\frac{-r}{T_{c r}} \leq 1 \\
q_{c m}=m \cdot N_{c} \cdot C_{u}
\end{gathered}
$$




\subsection{Perkins and Cuelho (2007)}

Apresentam um modelo mecanístico-empírico desenvolvido para reforço de base de pavimento flexível com utilização de geossintéticos. As propriedades utilizadas nos modelos de material e danos foram determinadas a partir de testes de laboratório encontrados em Perkins, et al, (1999) e Perkins et al, (2002).

- Modelo da seção de pavimento em elementos finitos

O modelo de elementos finitos é bidimensional axissimétrico, usando quatro pontos (nós) por elemento quadrático para concreto asfáltico, base de agregado e subleito. A malha do modelo segue as regras básicas dadas pelo projeto NCHRT (137a). Uma pressão uniformemente distribuída de $540 \mathrm{kPa}$ foi aplicada sobre uma placa circular de $152,4 \mathrm{~mm}$ de raio no topo da superfície

- Modelos das camadas de pavimento

Um modelo elástico linear isotrópico foi utilizado para a camada de concreto asfáltico. O modelo de danos por trincas por fadiga do concreto asfáltico foi dado pela equação 2.59 .

$$
N_{f}=k_{1} \cdot \beta_{1} \cdot\left(\frac{1}{\varepsilon_{t}}\right)^{k_{2} \cdot \beta_{2}} \cdot\left(\frac{1}{E}\right)^{k_{3} \cdot \beta_{3}}
$$

Em que: $\quad N_{f}$ : repetição do tráfego para fadiga do concreto asfáltico;

$K_{1}, k_{2}$ e $k_{3}:$ propriedade do material (laboratório);

$\beta_{1}, \beta_{2}$ e $\beta_{3}$ : coeficientes de calibração (campo);

Et: deformação horizontal obtida do modelo adotado do valor máximo de deformação no concreto asfáltico; e 
E: módulo do concreto asfáltico obtido do modelo (psi).

O modelo por danos por deformação permanente é apresentado pela equação 2.60, que foi determinado pelo deslocamento permanente vertical para esta camada em função dos ciclos de carregamento do tráfego

$$
\log \left(\frac{\varepsilon_{p}}{\varepsilon_{r}}\right)=k_{1} \cdot \beta_{1}+k_{2} \cdot \beta_{2} \cdot \log T+k_{3} \cdot \beta_{3} \cdot \log N
$$

Em que: $\quad$ N: repetição do tráfego;

$T$ : temperatura do concreto asfáltico $\left({ }^{\circ} \mathrm{F}\right)$;

$K_{1}, k_{2}$ e $k_{3}:$ propriedade do material (laboratório);

$\beta_{1}, \beta_{2}$ e $\beta_{3}$ : coeficientes de calibração (campo);

$\varepsilon_{p}$ : deformação vertical permanente em função de $\mathrm{N}$; e

E्: deformação vertical resiliente obtida do modelo.

O modelo elástico não linear isotrópico foi usado para as camadas de base e subleito. O modelo para obtenção do módulo resiliente é o modelo da ASSHTO apresentado pela equação 2.61 .

$$
M_{R}=K_{1} \cdot p_{a} \cdot\left(\frac{\theta}{p_{a}}\right)^{k_{2}} \cdot\left(\frac{\tau_{o c t}}{p_{a}}+1\right)^{K_{3}}
$$

Em que: $\quad k_{1}, k_{2}$ e $k_{3}$ : constantes de regressão;

Pa: pressão atmosférica (usada para normalizar as unidades do MR);

$\theta$ : primeiro invariante de tensão;

$\sigma_{1}$ : tensão principal maior;

$\sigma_{2}$ : tensão principal intermediária $=\sigma_{3}$ para ensaios de MR em corpos de prova cilíndricos; 
$\sigma_{3}:$ tensão principal menor $=$ pressão de confinamento; e $\tau_{o c t}$ tensão cisalhante octaédrica;

O modelo de danos por deslocamentos permanentes usado para base e subleito é apresentado pela equação 2.62. Este modelo foi também usado para agregado reforçado e calibrado em equipamento triaxial cíclico de grande escala com utilização de um reforço.

$$
\delta_{a}=\xi_{1} \cdot\left(\frac{\varepsilon_{0}}{\varepsilon_{r}}\right) \cdot e^{-\left(\frac{p}{N}\right)^{\xi_{2} \cdot \beta}} \cdot e_{v} \cdot h
$$

Em que: $\quad \delta_{a}$ : deslocamentos permanentes das camadas;

$\varepsilon_{0}, \beta$ e $\rho$ : propriedades do material;

$\varepsilon_{r}$ : deformações resilientes utilizadas nos ensaios de laboratório;

$\varepsilon_{v}:$ média das deformações verticais resiliêntes das camadas como resposta do modelo;

$h$ : espessuras das camadas; e

$\xi_{1}, \xi_{2}:$ coeficientes de calibração de campo.

O modelo de danos por deformação permanente acumulada no reforço como uma função da aplicação do carregamento é apresentada pela equação 2.63. Esta equação é usada para descrever os efeitos da tensão cisalhante permanente na interface reforço-agregado.

$$
\log \left(\frac{\varepsilon_{p}}{\varepsilon_{r}}\right)=\log (A)+B \cdot \log \left(\frac{N}{N_{25 m m}}\right)
$$

Em que: $\quad \varepsilon_{p}$ : deformação permanente no reforço;

$\mathcal{E}_{r}$ : deformação resiliente no reforço; 
$A, B$ : parâmetros de tensões de cisalhamento que desenvolvem na interface; e

N/N25 mm: razão do número de passadas de tráfego atual pelas passadas necessárias pra um recalque de $25 \mathrm{~mm}$. 


\section{Capítulo 3 - Materiais e Métodos}

\subsection{CONSIDERAÇÕES INICIAIS}

Neste capítulo são apresentados os materiais, os equipamentos e os procedimentos utilizados na investigação experimental para se alcançar o objetivo da pesquisa, com destaque para a caixa de grandes dimensões para ensaios com carregamento cíclico de seções de pavimentos. As seções ensaiadas foram compostas de subleito e uma base reforçada ou não com geossintéticos. São também descritos os experimentos realizados e os critérios adotados para a análise dos resultados obtidos.

\subsection{MATERIAIS}

Para a construção das seções de pavimento ensaiadas na caixa de grandes dimensões foram utilizados dois solos e uma brita. Um dos solos foi usado como subleito, e o outro, juntamente com a brita, para a composição de uma mistura solo- 
brita na proporção de $30 \%$ de solo e $70 \%$ de brita, mistura esta usada como base. Também foi utilizada uma geogrelha biaxial, Fornit $J 600$ (30/30) produzida pela Empresa Huesker Ltda, como elemento de reforço da camada de base do pavimento analisado.

Para os solos foram determinados a massa específica dos sólidos segundo o método de ensaio "Determinação da Massa Específica" - NBR 6508 (1984); a análise granulométrica segundo o método de ensaio "Solo - Análise Granulométrica" - NBR 7181; os limites de Atterberg segundo os métodos descritos nas normas "Solo-Determinação do Limite de Liquidez - NBR 6459 (1984) e "Solo-Determinação do Limite de Plasticidade" - NBR 7180 (1984); e classificação segundo a Metodologia MCT (NOGAMI \& VILLIBOR, 1995).

Foram também realizados ensaios de compactação na energia normal e modificada do ensaio de Proctor, respectivamente para o subleito e base (DER-M1371). Para estes materiais, foram determinados o índice de suporte CBR e a expansão (DER-M53-71), sendo ainda realizados ensaios triaxiais cíclicos para a determinação dos módulos de resiliência segundo as normas da AASHTO Designation TP46-94.

\subsubsection{Solos}

Os dois solos são provenientes de taludes de rodovias do Estado de São Paulo. O solo utilizado como subleito, denominado Solo 1 , foi coletado no $\mathrm{km} 34$, do lado esquerdo da Rodovia Castelo Branco (SP-280), sentido Barueri - Capital, nas 


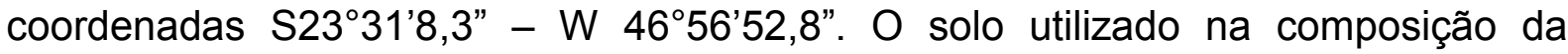
mistura solo-brita, denominado Solo 2, foi coletado no $\mathrm{km} 152+500 \mathrm{~m}$, do lado esquerdo da Rodovia Prof. Luis Augusto de Oliveira (SP-215), sentido São Carlos Ribeirão Bonito, nas coordenadas S22 04'0,1' - W 4754'32,2'.

A Figura 3.1 mostra as regiões de coleta dos Solos 1 e 2 no mapa do Estado de São Paulo e a Figura 3.2 ilustra aspectos destes locais.
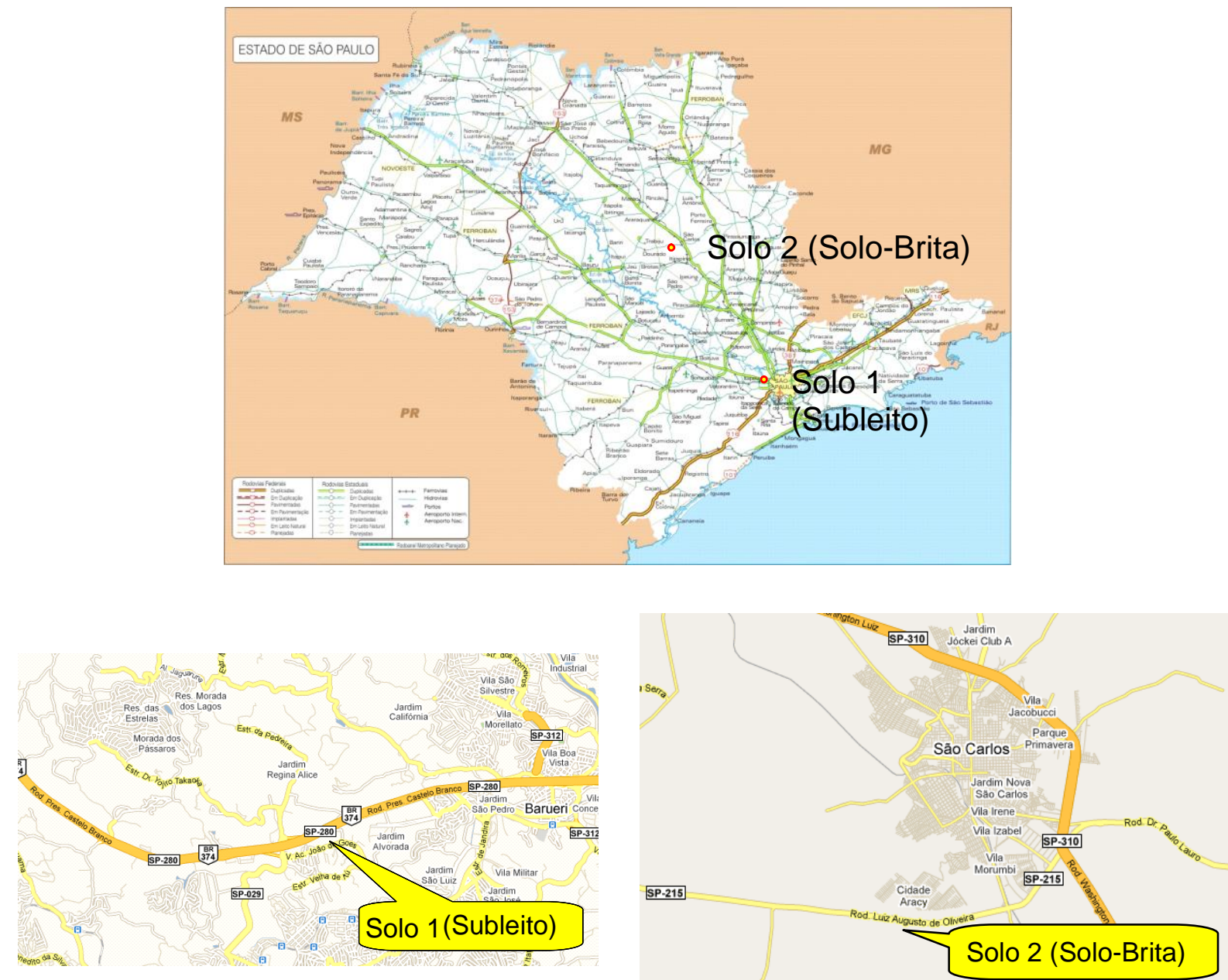

Figura 3.1 - Mapa do Estado de São Paulo com indicação aproximada das regiões de coleta dos Solos 1 e 2 


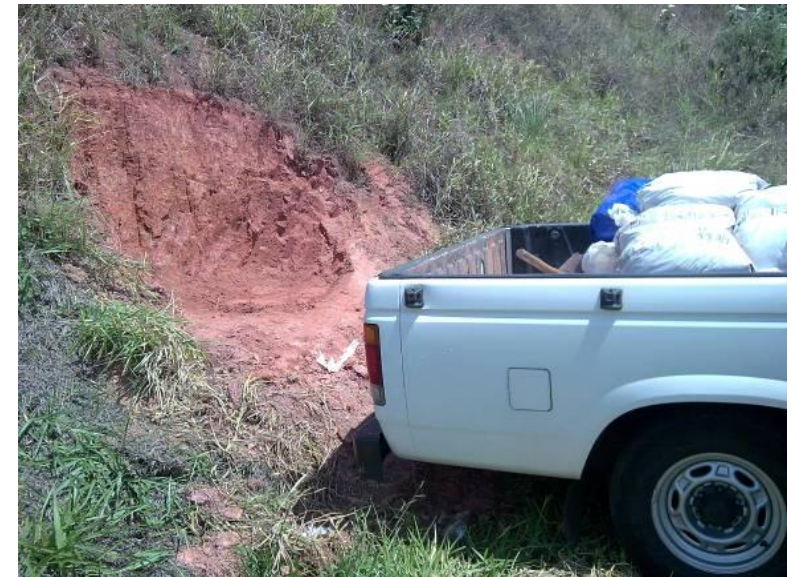

Solo 1 (Subleito)

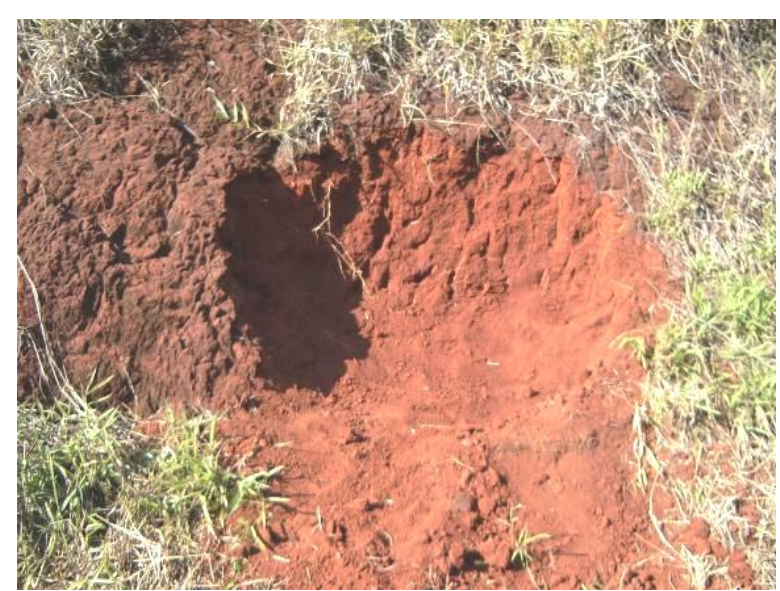

Solo 2 (Solo-Brita)

Figura 3.2 - Aspectos dos locais de coleta dos Solos 1 e 2

A Figura 3.3 mostra as curvas granulométricas dos Solos 1 e 2. Para estes materiais, a Tabela 3.1 apresenta os resultados dos ensaios de caracterização, percentuais de areia, silte e argila segundo as normas NBR 6459, NBR 7180 e NBR 7181 e as classificações dos materiais segundo os sistemas S.U.C.S. e H.R.B. Nesta tabela são também apresentados os resultados dos ensaios de compactação realizados na energia normal: umidade ótima, massa específica seca máxima e o grau de saturação correspondente, segundo a norma NBR 7182.

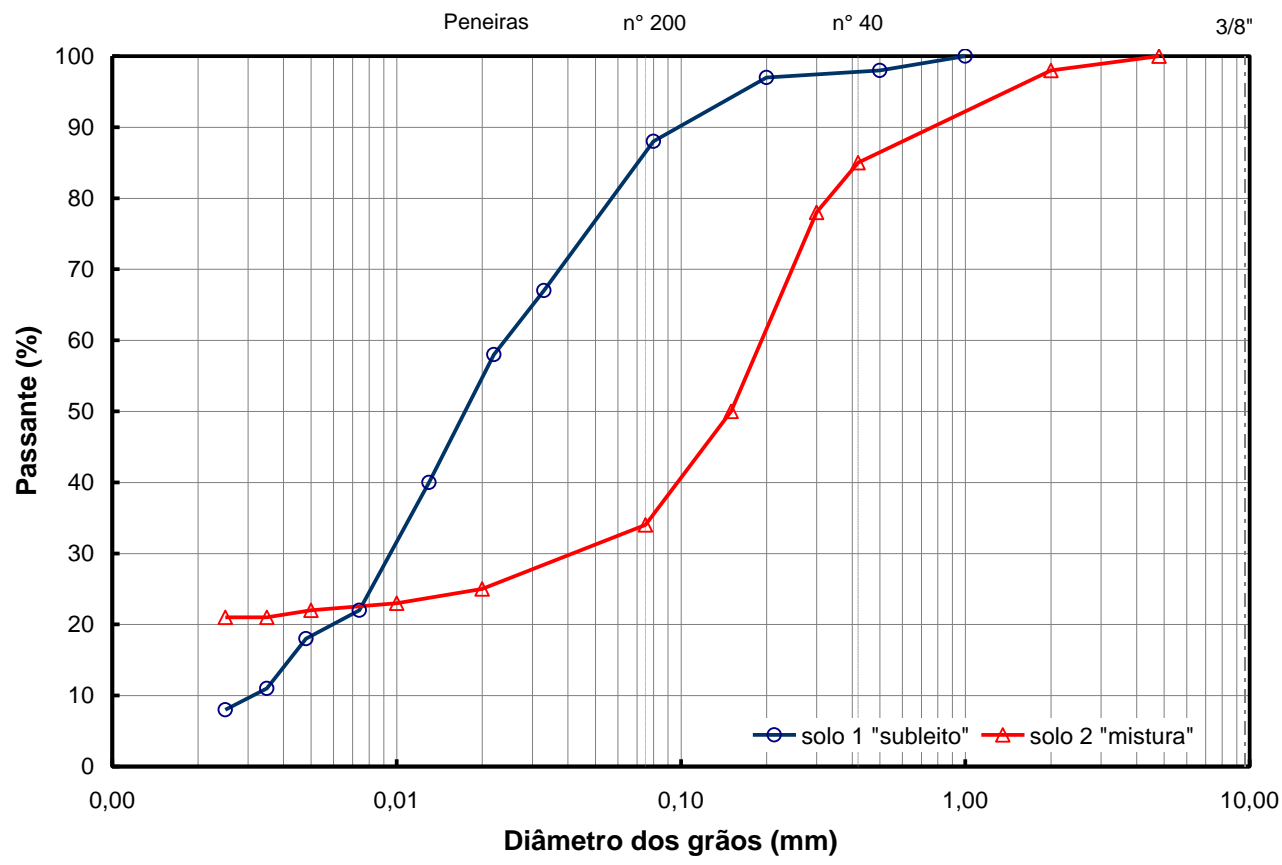

Figura 3.3 - Curvas granulométricas dos Solos 1 e 2 
Tabela 3.1 - Características e propriedades dos Solos 1 e 2

\begin{tabular}{ccc}
\hline Características e & \multicolumn{2}{c}{ Solo } \\
Propriedades & 1 (Subleito) & 2 (Mistura Solo-Brita) \\
\cline { 2 - 3 }$\rho_{\mathrm{s}}\left(\mathrm{g} / \mathrm{cm}^{3}\right)$ & 2,661 & 2,633 \\
\% passa \#200 & 89 & 34 \\
Areia (\%) & 11 & 66 \\
Silte (\%) & 82 & 13 \\
Argila (\%) & 7 & 22 \\
LL (\%) & $\mathrm{NP}$ & 34 \\
LP (\%) & $\mathrm{NP}$ & 21 \\
IP (\%) & $\mathrm{NP}$ & 13 \\
Classificação HRB & $\mathrm{A}-4$ & $\mathrm{~A}-2-6$ \\
Classificação SUCS & $\mathrm{CL}$ & $\mathrm{SC}$ \\
W $_{\text {ot }}(\%)$ & 25,7 & 13,2 \\
$\rho_{\text {dmáx }}\left(\mathrm{g} / \mathrm{cm}^{3}\right)$ & 1,459 & 1,905 \\
S $_{\mathrm{r}}$ & 83,1 & 90,1 \\
\hline
\end{tabular}

As Figuras 3.4 e 3.5 apresentam respectivamente as curvas de compactação do solo utilizado no subleito e da mistura solo-brita utilizada na base, juntamente com as linhas correspondentes às saturações de $80 \%, 90 \%$ e $100 \%$ para cada um dos materiais. 


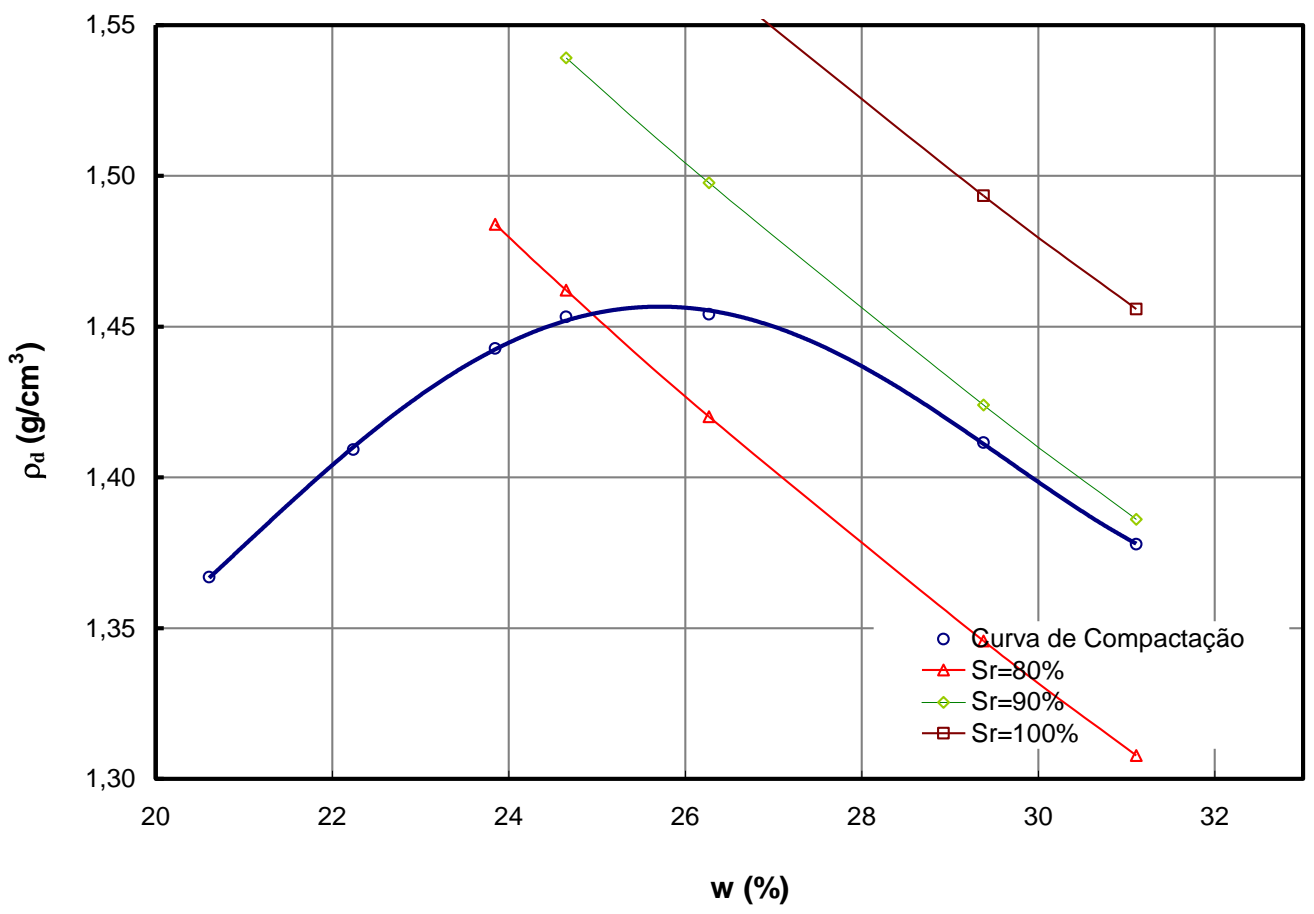

Figura 3.4 - Curva de compactação do solo 1 (Subleito)

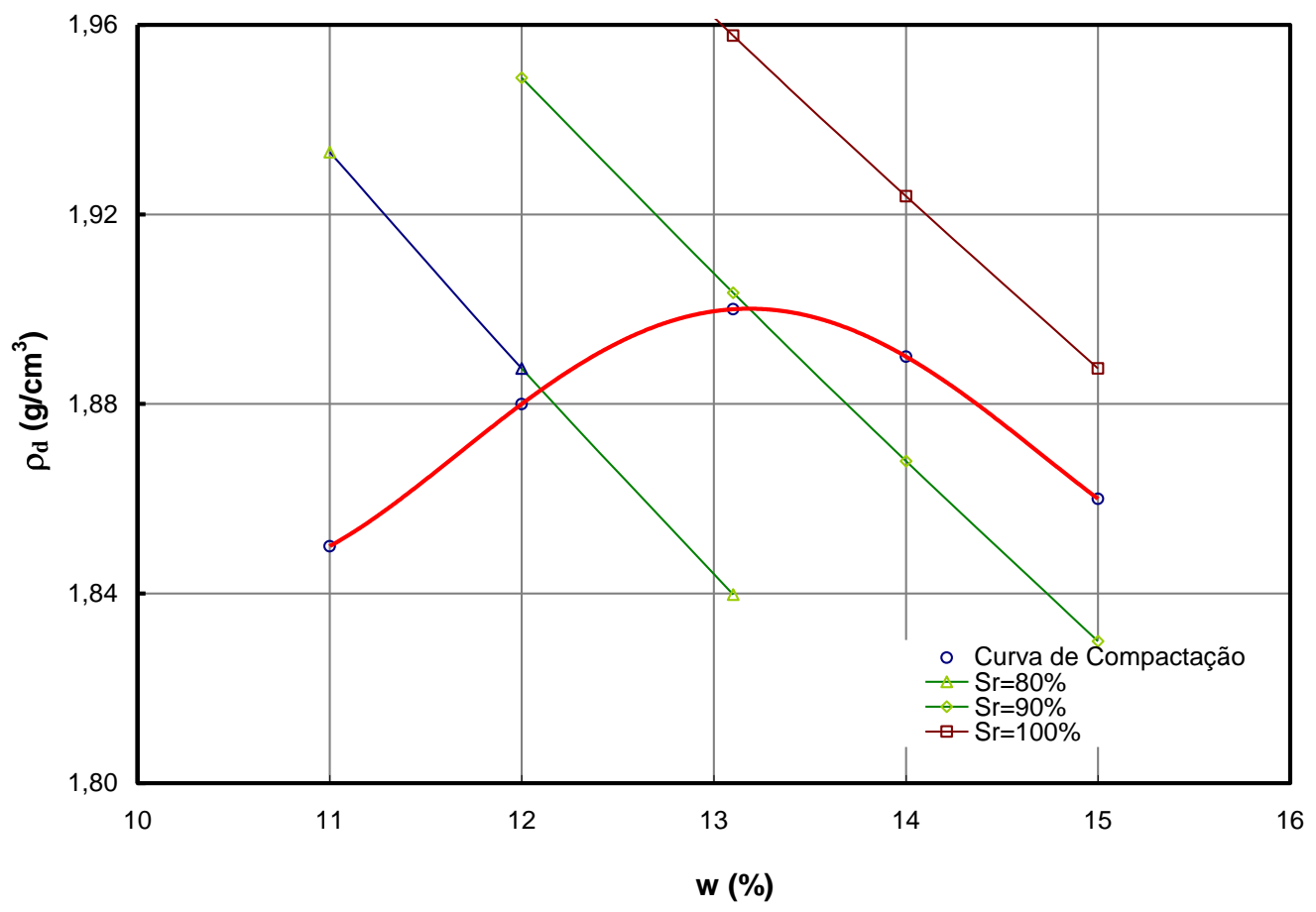

Figura 3.5 - Curva de compactação do solo 2 (Solo-Brita)

Para a classificação dos solos segundo a Metodologia MCT, adotou-se o procedimento descrito nas normas DNER-M 256-94 e DER-M 196-89. Os valores de 
perda por imersão (PI), bem como os coeficientes c', e' e a classificação dos solos segundo essa metodologia estão apresentados na Tabela 3.2.

Tabela 3.2 - Resultados dos ensaios da Metodologia MCT e a classificação dos solos

\begin{tabular}{ccccc}
\hline Solo & Pi & c' $^{\prime}$ & $\mathrm{e}^{\prime}$ & Classe \\
\hline Subleito & 315 & 1,28 & 1,63 & NS' \\
Mistura (Solo-Brita) & 122 & 0,80 & 1,10 & LA' $^{\prime}$ \\
\hline
\end{tabular}

A Figura 3.6 apresenta os solos posicionados no gráfico da classificação MCT e as imagens de microscopia eletrônica de varredura dos dois solos utilizados nesta pesquisa. Para os dois solos foi possível identificar padrões de imagem que pudessem distinguir os solos segundo a sua gênese laterítica ou não laterítica.

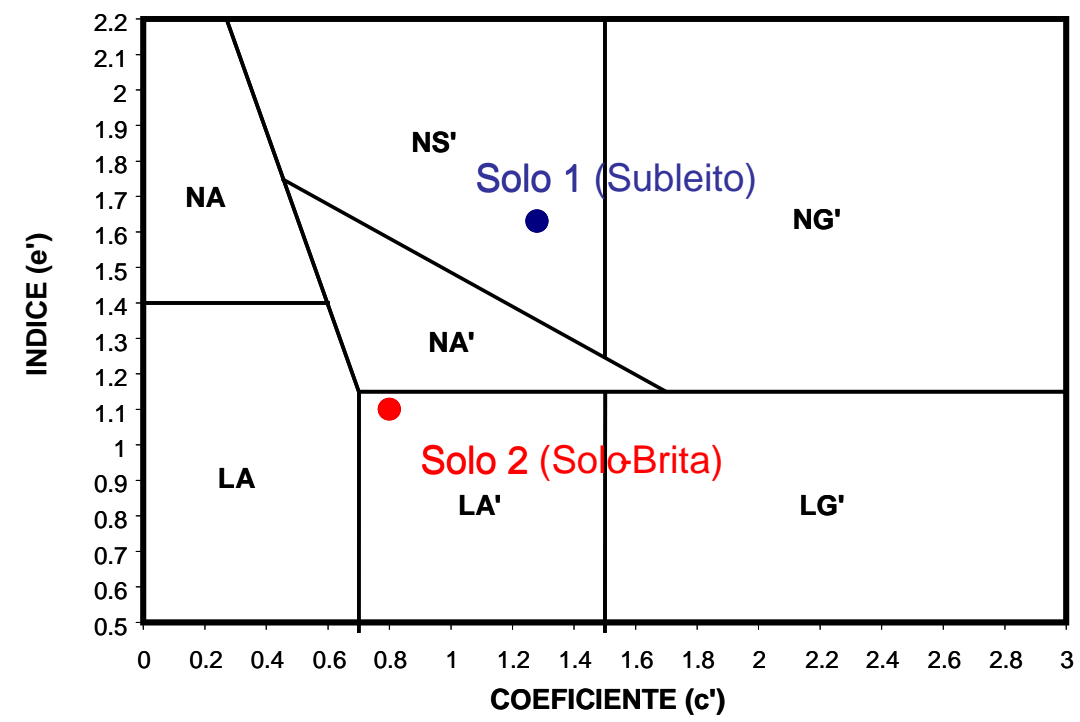

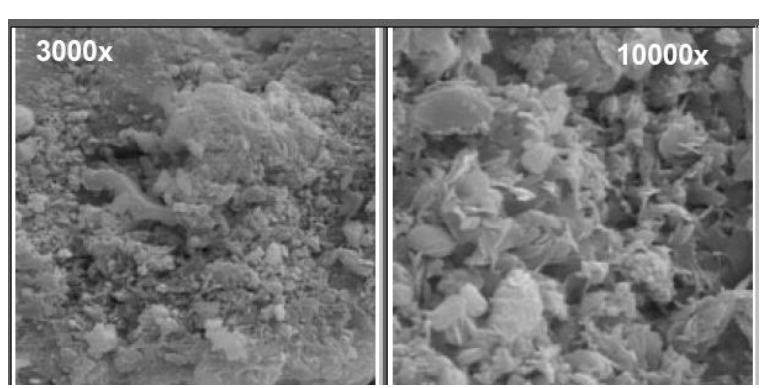

Solo 1

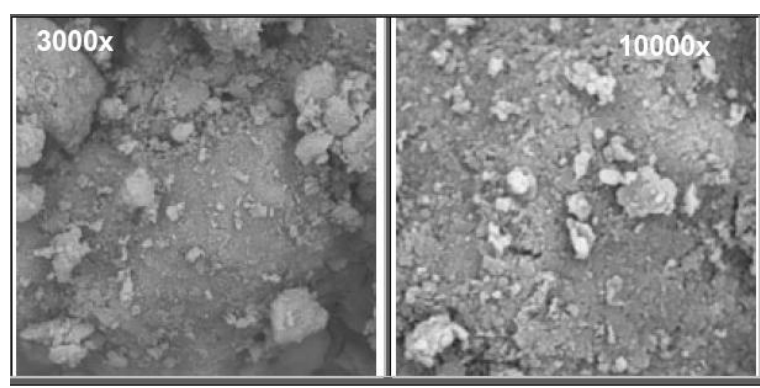

Solo 2

Figura 3.6 - Gráfico de classificação MCT (Nogami \& Villibor, 1995) com a indicação do posicionamento dos Solos 1 e 2 e suas respectivas imagens eletrônicas. 
$\mathrm{Na}$ Figura 3.6 verifica-se que os dois solos utilizados nesta pesquisa coincidem as classificações MCT, onde os solos lateríticos caracterizam-se por possuírem a sua fração argila constituída pelo argilomineral caulinita. Estes ainda contém elevada porcentagem de óxido e hidróxido de ferro e de alumínio que recobrem a caulinita conferindo ao conjunto um aspecto "cimentado". No caso do solo 1, não lateritico, os argilominerais e, eventualmente, outros minerais presentes não se apresentam recobertos por óxidos e hidróxidos de ferro e aluminio, como no caso dos solos lateriticos.

\subsubsection{Brita}

O agregado pétreo empregado na composição da mistura solo-brita usada na base da seção do pavimento a ser ensaiado é de natureza basáltica. O material foi coletado na Pedreira Bandeirantes localizada no município paulista de São Carlos. As Figuras 3.7 e 3.8 ilustram, respectivamente, o local de coleta e a curva granulométrica do agregado, que correspondente a uma 'brita 1'.

O agregado foi submetido ao ensaio de Abrasão Los Angeles (DNER ME 03/94) e apresentou uma perda da ordem de $17 \%$, valor inferior ao limite de $55 \%$ para materiais utilizados na construção de bases de pavimentos rodoviários estabilizados granulometricamente. 

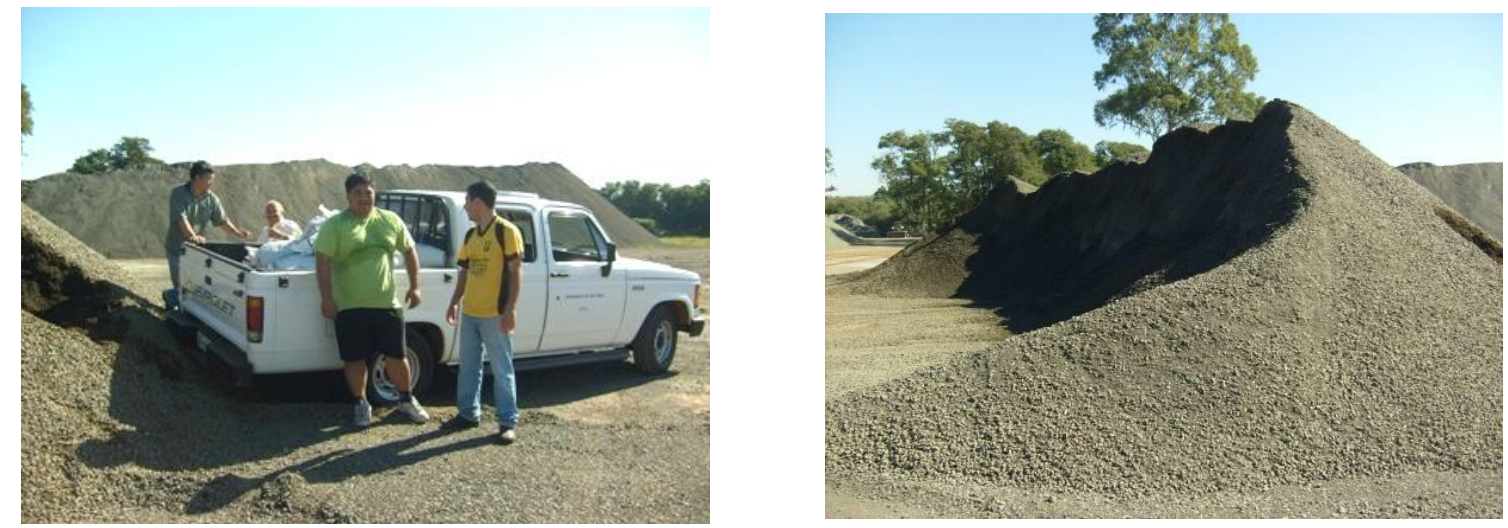

Figura 3.7 - Coleta do agregado

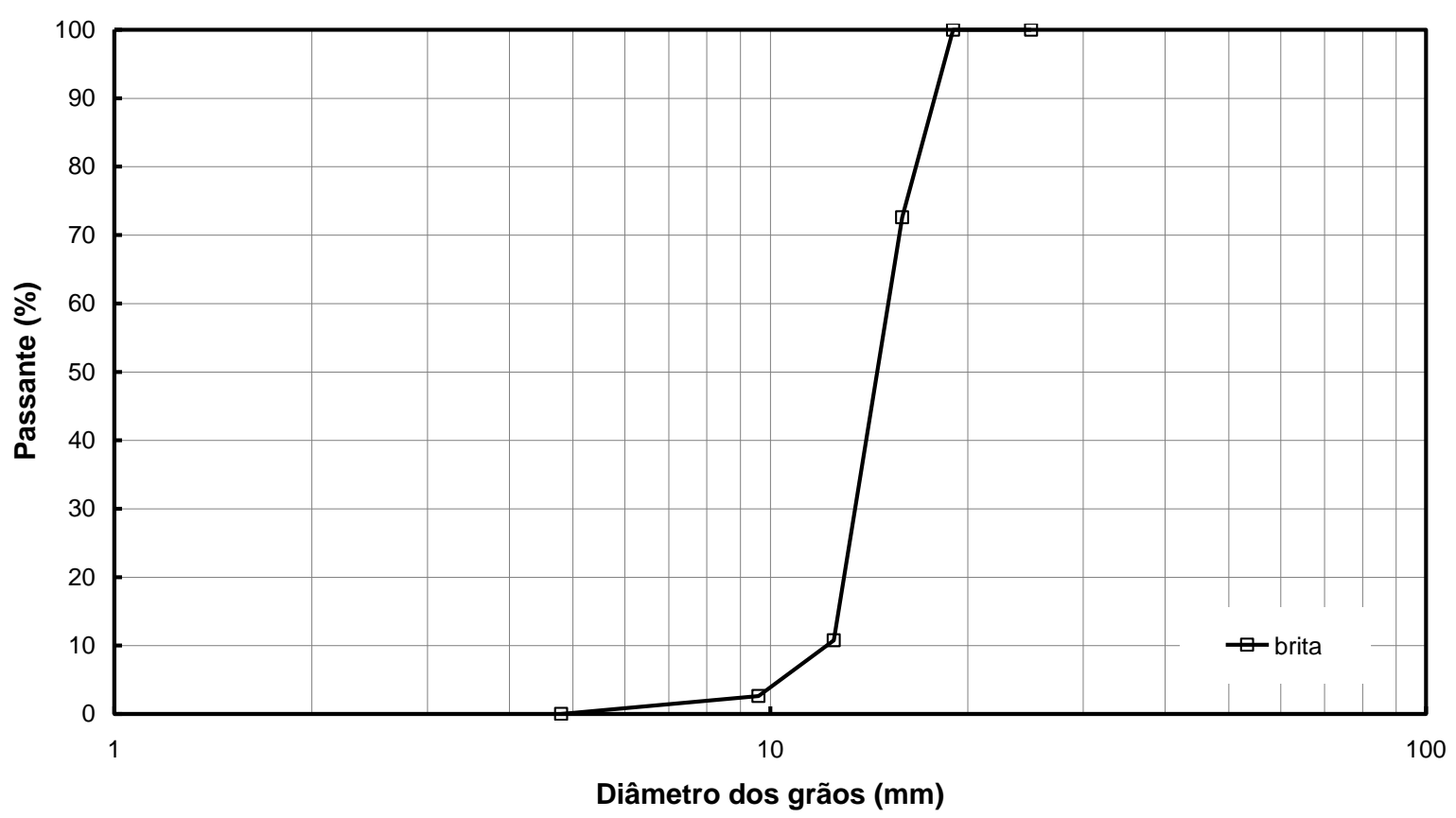

Figura 3.8 - Curva granulométrica da brita

\subsubsection{Mistura solo-brita}

Conforme destacado anteriormente, a base da seção do pavimento a ser ensaiado é composta por uma mistura solo-brita na proporção de $30 \%$ de solo e 
70\% de brita. A Figura 3.9 apresenta a curva granulométrica da mistura solo-brita, conjuntamente com as curvas da brita e do solo 2 .

O material foi preparado observando-se os critérios estabelecidos por Nogami \& Villibor (1995) para misturas constituídas de solos lateríticos e britas descontinuas, ou seja:

- O solo deverá apresentar comportamento laterítico, isto é, pertencer a um dos grupos LA', LA e LG' da classificação MCT;

- A brita deverá possuir um diâmetro máximo menor que $25,4 \mathrm{~mm}$ e uma perda no ensaio abrasão Los Angeles menor que $30 \%$.

- A porcentagem mínima de brita na mistura, em termos de massa seca, deverá ser de $50 \%$;

- A granulometria da mistura deverá ser descontínua;

- A mistura deverá possuir um CBR maior ou igual a $80 \%$ e uma expansão menor ou igual a $0,2 \%$.

Considerando-se que a mistura solo-brita estudada apresenta abrasão Los Angeles, índice de suporte CBR e expansão iguais a 17\%, $190 \%$ e $0 \%$, respectivamente, conforme discutido no item 4.1 do Capítulo 4, e observando o formato descontínuo de sua curva granulométrica, pode-se afirmar que o material atende a todos os requisitos nomeados por Nogami \& Villibor (1995). 


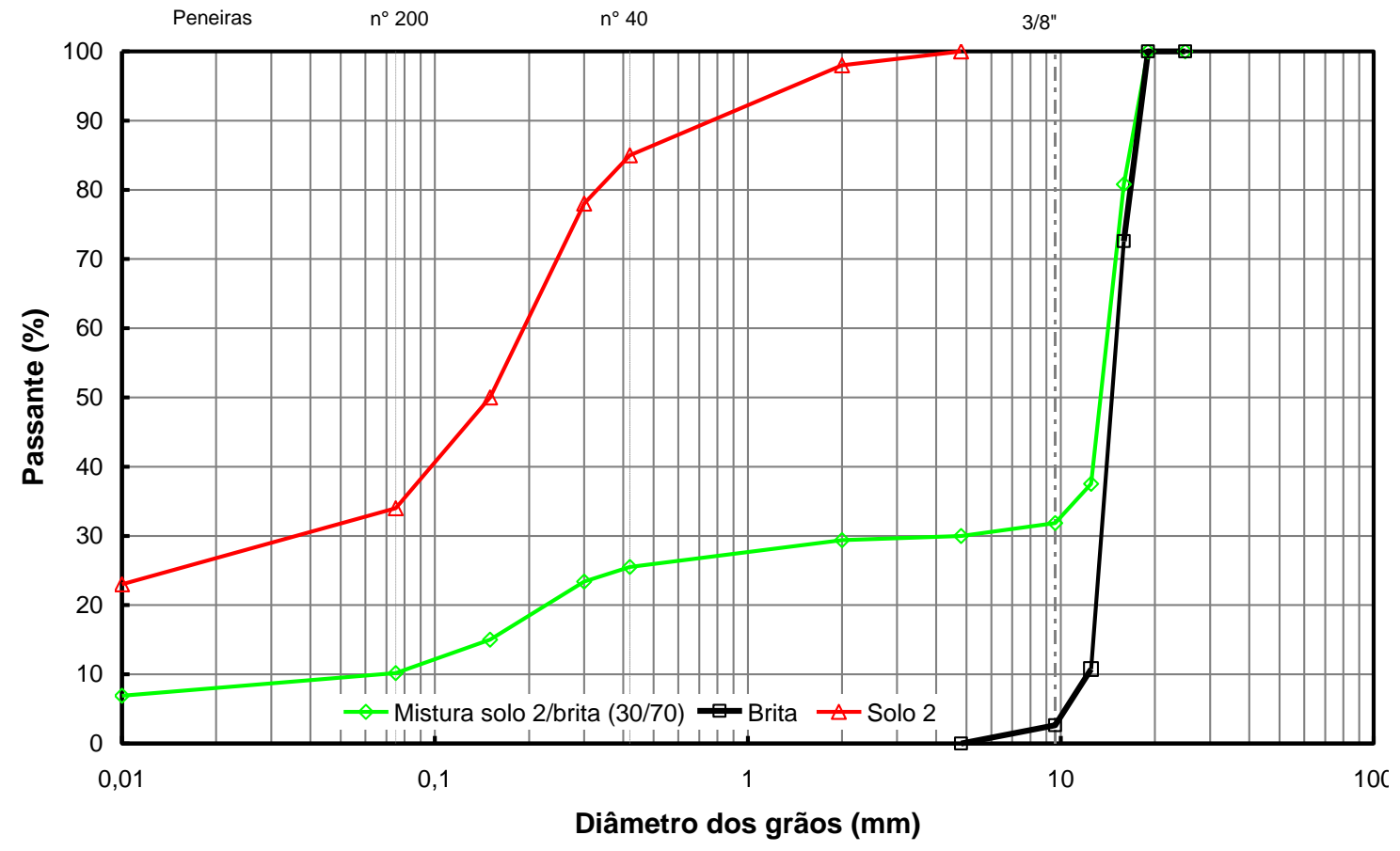

Figura 3.9 - Curva granulométrica da mistura solo-brita, do solo 2 e da brita

\subsubsection{Elemento de reforço da base}

Para o reforço da base da seção do pavimento foi utilizada uma geogrelha modelo Fornit J600 (30/30) fabricada pela Empresa Huesker Ltda. A preferência pelo uso de geogrelhas ao invés de geotêxteis, deve-se ao fato deste material apresentar rigidez superior à deste último, e assim permitir que a mobilização de sua resistência se dê com deformações menores, compatíveis com as observadas nos pavimentos. E ainda, conforme resultados de estudos anteriores onde foram empregadas no reforço de bases de pavimentos, as geogrelhas mostraram melhor desempenho que os geotêxteis (PERKINS, 1999; LENG AND GARB, 2002). 
A geogrelha Fornit J600 (30/30) é uma geogrelha biaxial de filamentos de polipropileno (PP) com revestimento polimérico protetor de alta rigidez. A Tabela 3.3 apresenta as propriedades fornecidas pelo fabricante da geogrelha em questão.

Tabela 3.3 - Propriedades mecânicas da geogrelha Fornit J600 (30/30) (Dados fornecidos pelo fabricante)

\begin{tabular}{cccc}
\hline Propriedades & Unidade & Método & $\begin{array}{c}\text { Fornit } \\
\text { J600 (30/30) }\end{array}$ \\
\hline Gramatura & & & 240 \\
Abertura de malha direção longitudinal & $\mathrm{m} / \mathrm{m}^{2}$ & ASTM D5261 & 40 \\
$\begin{array}{c}\text { Abertura de malha direção transversal } \\
\text { Resistência a 5\% de deformação - }\end{array}$ & $\mathrm{mm}$ & - & 40 \\
direção longitudinal & $\mathrm{kN} / \mathrm{m}$ & $\mathrm{D} 6637$ & 24 \\
Resistência a 5\% de deformação - & $\mathrm{kN} / \mathrm{m}$ & D 6637 & 24 \\
direção transversal & $\mathrm{kN} / \mathrm{m}$ & $\mathrm{D} 6637$ & 30 \\
$\begin{array}{c}\text { Tensão última - direção longitudinal } \\
\text { Tensão última - direção transversal } \\
\text { Deformação nominal na ruptura }\end{array}$ & $\mathrm{kN} / \mathrm{m}$ & D 6637 & 30 \\
Coeficiente de interação & $\mathrm{kN} / \mathrm{m}$ & ABNT 12824 & $\leq 10$ \\
Módulo de rigidez à tração nominal (à & $\mathrm{kN} / \mathrm{m}$ & ABNT 12824 6706 & $\geq 0,95$ \\
2\% de deformação) & & & $\geq 600$ \\
\hline
\end{tabular}

A Figura 3.10 ilustra a geogrelha Fornit $\mathrm{J} 600$ (30/30), quanto a seu aspecto. As propriedades mecânicas mínimas requeridas pela U. S. Army Corps of Engineers (2003) para a utilização como reforço de base de pavimento estão apresentadas na Tabela 3.4. 


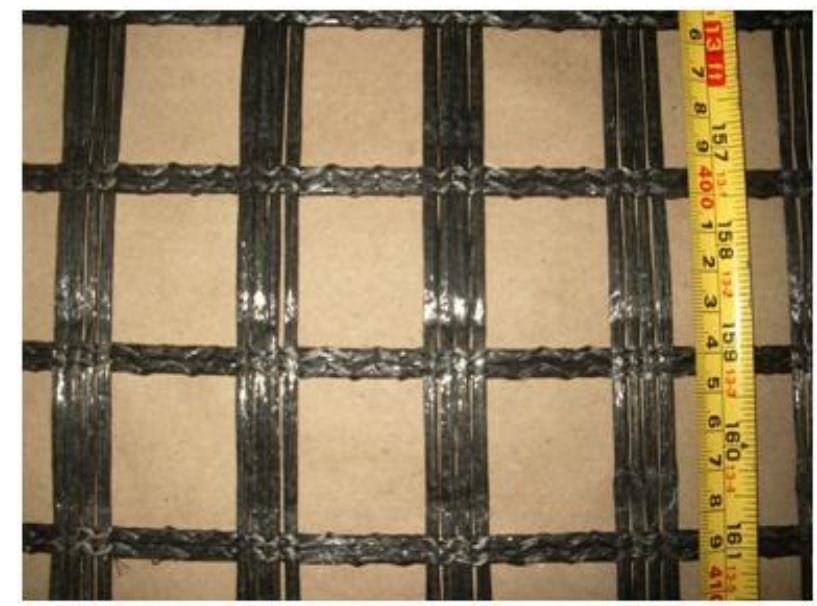

Figura 3.10 - Geogrelha Fornit J600 (30/30)

Tabela 3.4 - Características e propriedades mecânicas da geogrelha (Modificado do U.S. Army Corps of Engineers, 2003)

\begin{tabular}{cccc}
\hline Propriedades & Unidade & Método de ensaio ASTM & Mínimo \\
requerido
\end{tabular}

Comparando os valores das propriedades mecânicas da geogrelha do modelo Fornit J600 (30/30) apresentado na Tabela 3.3, com os valores mínimos requeridos pela U.S. Army Corps of Engineers (2003) apresentado na Tabela 3.4, pode-se verificar que a geogrelha atende a todas as recomendações. 


\subsection{ENSAIOS LABORATORIAIS CONVENCIONAIS}

Em seguida são descritos os ensaios de Índice de Suporte Califórnia (CBR) e triaxiais cíclicos a que foram submetidos os materiais que constituíram o subleito e a base da seção do pavimento.

\subsection{1 Índice de Suporte California (CBR)}

Os ensaios de Índice de Suporte Califórnia (CBR) para o solo do subleito e para a mistura solo-brita usada como base foram realizados de acordo com a norma DNER-ME 049/94, sendo determinados o Índice de Suporte Califórnia e a expansão após quatro dias de imersão em água.

Os resultados de CBR foram obtidos a fim de auxiliar nas escolhas dos materiais constituintes de uma estrutura hipotética de pavimento. Para o material do subleito foi moldado apenas um corpo de prova no teor de umidade ótimo e massa específica seca máxima obtida do ensaio de Proctor na energia Normal.

Para a camada de base optou-se por utilizar uma mistura solo-brita na composição de 30/70. Para essa mistura foi realizado o ensaio CBR simultâneo com a compactação na energia Modificada.

A Figura 3.11a apresenta a curva de CBR e a Figura 3.11b a curva da massa específica seca em função da umidade da mistura solo-brita. A Tabela 3.5 apresenta 
os valores de $C B R$ na $W_{o}$ do solo utilizado para camada de subleito e da mistura solo/brita utilizada como camada de base.

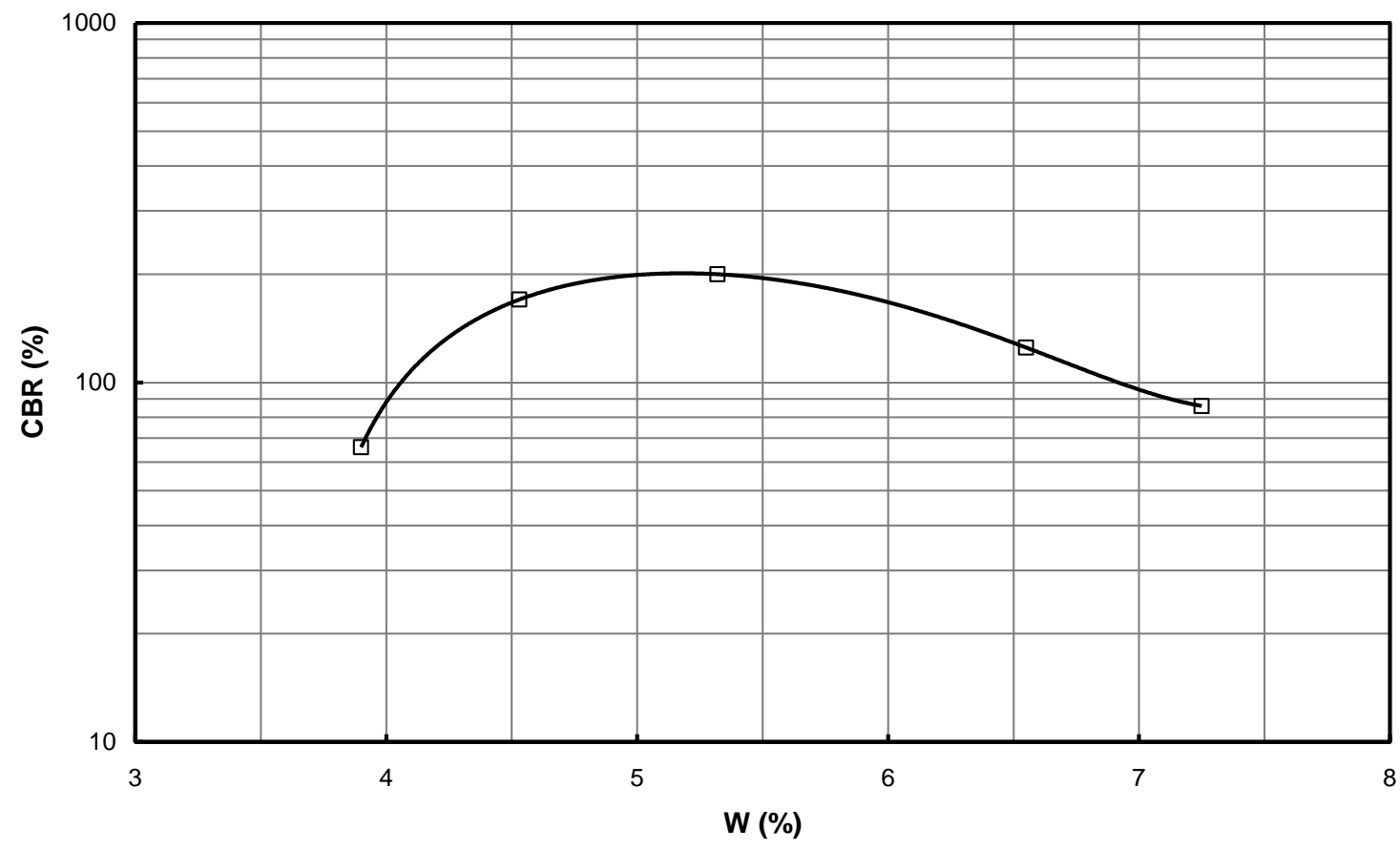

(a)

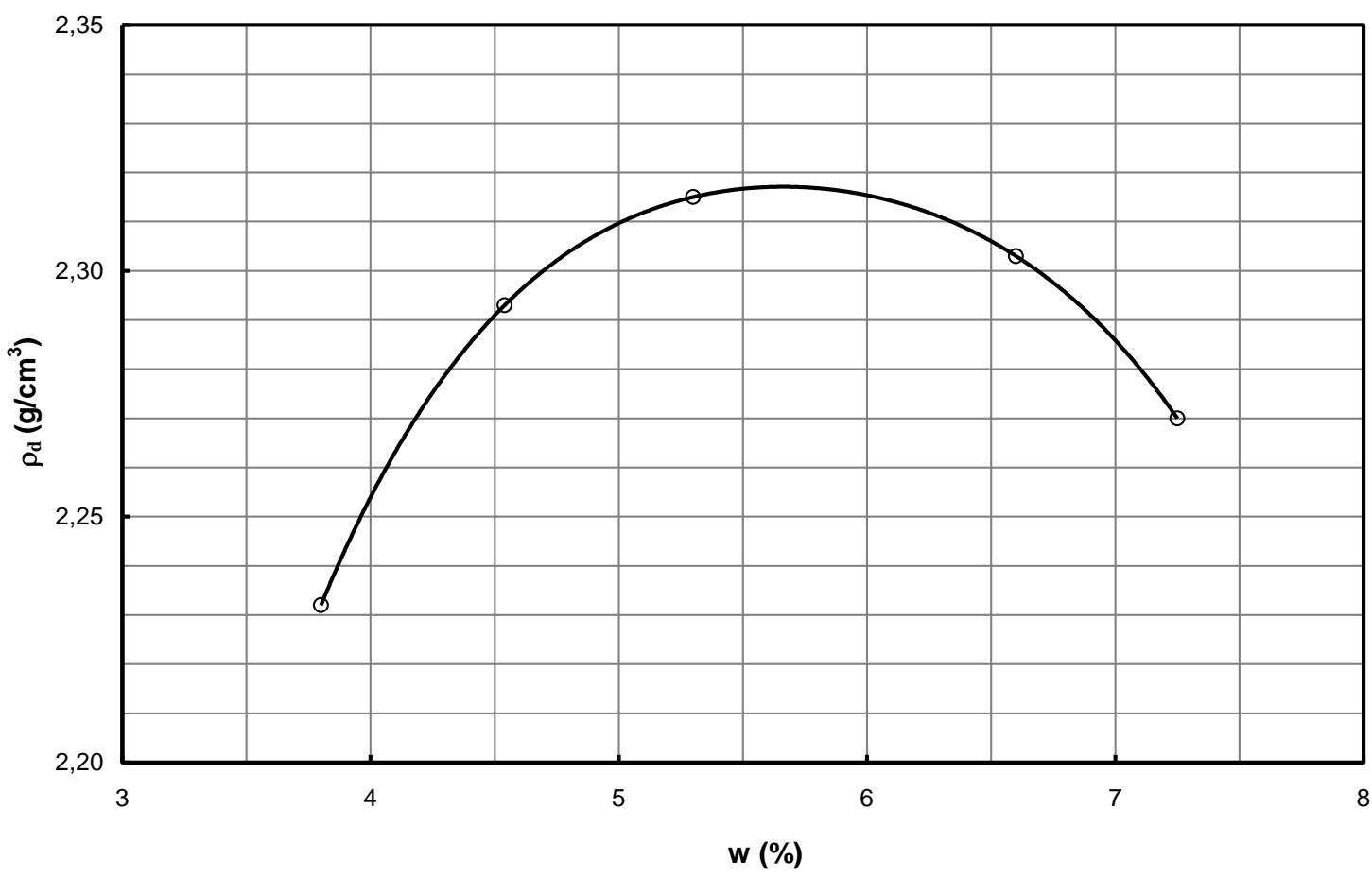

(b)

Figura 3.11 - Curvas para a mistura solo-brita: a) CBR e b) Compactação 
Tabela 3.5 - Resultados dos ensaios de compactação e CBR para os materiais geotécnicos utilizados na pesquisa na umidade ótima de compactação

\begin{tabular}{ccccccc}
\hline Material & $\begin{array}{c}\text { Energia de } \\
\text { Compactação }\end{array}$ & Aplicação & $\begin{array}{c}\mathrm{W}_{\circ} \\
(\%)\end{array}$ & $\begin{array}{c}\rho_{\text {dmax }} \\
\left(\mathrm{g} / \mathrm{cm}^{2}\right)\end{array}$ & $\begin{array}{c}\text { Exp. } \\
(\%)\end{array}$ & $\begin{array}{c}\text { CBR na Wo } \\
(\%)\end{array}$ \\
\hline Solo & Normal & Subleito & 25,7 & 1,459 & 3,5 & 8 \\
Solo-brita & Modificado & Base & 5,6 & 2,315 & 0 & 190 \\
\hline
\end{tabular}

\subsubsection{Ensaio triaxial cíclico}

Os ensaios triaxiais foram realizados de acordo com a norma "Standard Method of Test for Determining the Resilient Modulus of Soil and Aggregate Materials" (AASHTO Designation: T307-99), sendo determinados os módulos de resiliência (MR) do solo do subleito e da mistura solo-brita usada como base. A norma descreve o procedimento de preparação dos corpos de prova e a execução do ensaio de solos de subleito e materiais não tratados de base e sub-base, sendo realizado em 16 fases, em que a primeira fase corresponde ao condicionamento do corpo de prova onde são aplicados entre 500 a 1000 ciclos de carregamento. As fases seguintes são destinadas às leituras das deformações. A Tabela 3.6 apresenta as sequências de tensões utilizadas nos ensaios dos materiais de base.

Foram utilizados corpos de prova de $200 \mathrm{~mm}$ de altura por $100 \mathrm{~mm}$ de diâmetro moldados estaticamente em prensa hidráulica em cinco camadas na umidade ótima e massa específica seca máxima obtida nos ensaios de compactação. 
Tabela 3.6 - Sequência de tensões de ensaio para base/sub-base segundo a AASHTOT 307-99

\begin{tabular}{|c|c|c|c|c|c|}
\hline Sequência & $\begin{array}{c}\text { Tensão } \\
\text { confinante } \\
\sigma_{3}(\mathrm{kPa})\end{array}$ & $\begin{array}{l}\text { Tensão } \\
\text { máxima } \\
\sigma_{\mathrm{a}}(\mathrm{kPa})\end{array}$ & $\begin{array}{c}\text { Tensão de } \\
\text { contato } \\
\sigma_{\mathrm{c}}(\mathrm{kPa})\end{array}$ & $\begin{array}{l}\text { Tensão } \\
\text { desvio } \\
\sigma_{d}(\mathrm{kPa})\end{array}$ & $\begin{array}{c}\text { Número de } \\
\text { aplicações de } \\
\text { carga }\end{array}$ \\
\hline 0 & 103,4 & 103,4 & 10,3 & 93,1 & $500-1000$ \\
\hline 1 & 20,7 & 20,7 & 2,1 & 78,6 & 100 \\
\hline 2 & 20,7 & 41,4 & 4,1 & 37,3 & 100 \\
\hline 3 & 20,7 & 62,1 & 6,2 & 55,9 & 100 \\
\hline 4 & 34,5 & 34,5 & 3,5 & 31 & 100 \\
\hline 5 & 34,5 & 68,9 & 6,9 & 62 & 100 \\
\hline 6 & 34,5 & 103,4 & 10,3 & 93,1 & 100 \\
\hline 7 & 68,9 & 68,9 & 6,9 & 62,2 & 100 \\
\hline 8 & 68,9 & 137,9 & 13,8 & 124,1 & 100 \\
\hline 9 & 68,9 & 206,8 & 20,7 & 186,1 & 100 \\
\hline 10 & 103,4 & 68,9 & 6,9 & 62 & 100 \\
\hline 11 & 103,4 & 103,4 & 10,3 & 93,1 & 100 \\
\hline 12 & 103,4 & 206,8 & 20,7 & 196,1 & 100 \\
\hline 13 & 137,9 & 103,4 & 10,3 & 93,1 & 100 \\
\hline 14 & 137,9 & 137,9 & 13,8 & 124,1 & 100 \\
\hline 15 & 137,9 & 275,8 & 27,6 & 248,2 & 100 \\
\hline
\end{tabular}

A Tabela 3.7 apresenta as sequências de tensões utilizadas nos ensaios dos materiais de subleito. 
Tabela 3.7- Sequência de tensões de ensaio para subleito segundo AASHTO T307-99

\begin{tabular}{|c|c|c|c|c|c|}
\hline Sequência & $\begin{array}{c}\text { Tensão } \\
\text { confinante } \\
\sigma_{3}(\mathrm{kPa})\end{array}$ & $\begin{array}{l}\text { Tensão } \\
\text { máxima } \\
\sigma_{\mathrm{a}}(\mathrm{kPa})\end{array}$ & $\begin{array}{c}\text { Tensão de } \\
\text { contato } \\
\sigma_{\mathrm{c}}(\mathrm{kPa})\end{array}$ & $\begin{array}{c}\text { Tensão } \\
\text { desvio } \\
\sigma_{d}(\mathrm{kPa})\end{array}$ & $\begin{array}{c}\text { Número de } \\
\text { aplicações } \\
\text { de carga }\end{array}$ \\
\hline 0 & 41,4 & 27,6 & 2,8 & 24,8 & $500-1000$ \\
\hline 1 & 41,4 & 13,8 & 1,4 & 12,4 & 100 \\
\hline 2 & 41,4 & 27,6 & 2,8 & 24,8 & 100 \\
\hline 3 & 41,4 & 41,4 & 4,1 & 37,3 & 100 \\
\hline 4 & 41,4 & 55,2 & 5,5 & 49,7 & 100 \\
\hline 5 & 41,4 & 68,9 & 6,9 & 62,0 & 100 \\
\hline 6 & 27,6 & 13,8 & 1,4 & 12,4 & 100 \\
\hline 7 & 27,6 & 27,6 & 2,8 & 24,8 & 100 \\
\hline 8 & 27,6 & 41,4 & 4,1 & 37,3 & 100 \\
\hline 9 & 27,6 & 55,2 & 5,5 & 49,7 & 100 \\
\hline 10 & 27,6 & 68,9 & 6,9 & 62,0 & 100 \\
\hline 11 & 13,8 & 13,8 & 1,4 & 12,4 & 100 \\
\hline 12 & 13,8 & 27,6 & 2,8 & 24,8 & 100 \\
\hline 13 & 13,8 & 41,4 & 4,1 & 37,3 & 100 \\
\hline 14 & 13,8 & 55,2 & 5,5 & 49,7 & 100 \\
\hline 15 & 13,8 & 68,9 & 6,9 & 62,0 & 100 \\
\hline
\end{tabular}

O equipamento utilizado nos ensaios triaxiais cíclicos é do tipo pneumático e foi projetado e desenvolvido no Departamento de Transportes da Escola de Engenharia de São Carlos - USP, sendo que o controle e a aquisição de dados é realizada através de programa em plataforma LabView, desenvolvido pelo Prof. Dr. Glauco Tulio Pessa Fabbri. O sistema de aplicação é composto por duas válvulas proporcionais e uma célula de carga Gefran de capacidade de 5,0kN e as leituras de deslocamentos são obtidos por dois LVDTs posicionados no terço médio do corpo de prova. 
A Figura 3.12 apresenta uma vista geral do equipamento utilizado para a realização dos ensaios triaxiais cíclicos.

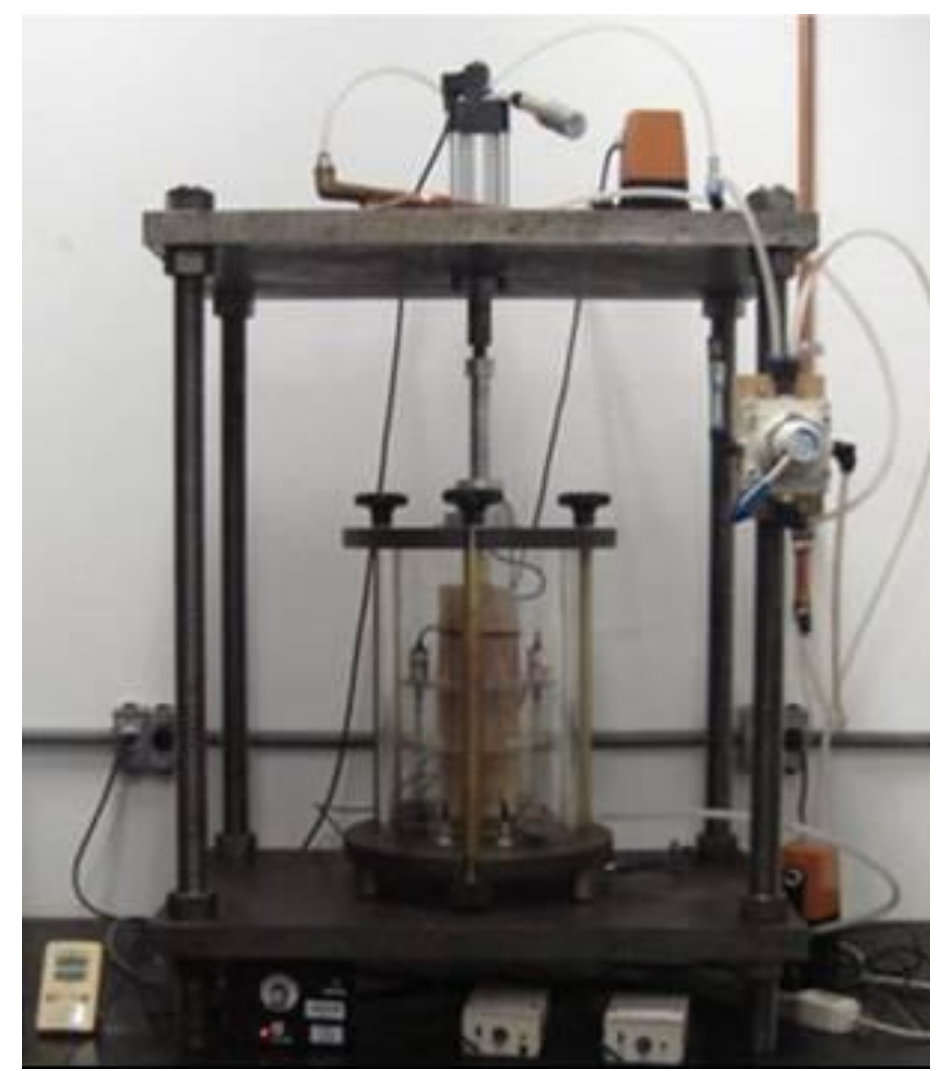

Figura 3.12 - Equipamento usado nos ensaios triaxiais cíclicos

Para a representação da variação do MR em função do estado de tensão foram avaliados os desempenhos de quatro modelos matemáticos a partir do coeficiente de determinação $\left(R^{2}\right)$ obtidos para cada um deles. A Tabela 3.8 apresenta os modelos avaliados.

$\mathrm{Na}$ Tabela 3.8, as variáveis que descrevem os quatro modelos são as seguintes: $M_{R}$ é o módulo de resiliência $(\mathrm{MPa}) ; \sigma_{d}$ é a tensão desvio $(\mathrm{kPa}) ; \sigma_{\mathrm{c}}$ é a tensão confinante $(\mathrm{kPa})$; $\theta$ é a tensão volumétrica $(\mathrm{kPa})$; $\tau_{\text {oct }}$ é a tensão cisalhante 
octaédrica $(\mathrm{kPa})$; $\mathrm{P}_{\mathrm{a}}$ é a pressão atmosférica $(\mathrm{kPa})$; e $\mathrm{K} 1$, $\mathrm{K} 2$ e $\mathrm{K} 3$ são parâmetros de regressão.

Tabela 3.8 - Modelos avaliados para representação do $M_{R}$ em função do estado de tensão

\begin{tabular}{lcc}
\hline & Modelo & Equação \\
\hline $\begin{array}{l}\text { Modelo em função da tensão } \\
\text { desvio }\end{array}$ & $M_{R}=K_{1} \cdot \sigma_{d}^{k_{2}}$ & (3.1) \\
Modelo em função da tensão & $M_{R}=K_{1} \cdot \sigma_{3}^{k_{3}}$
\end{tabular}

A calibração dos quatro modelos apresentados na Tabela 3.8 foram realizados pelo programa computacional desenvolvido pelo Prof. Dr. Glauco Túlio Pessa Fabbri em plataforma LabView. A Tabela 3.9 apresenta os valores das constantes determinado para o solo utilizado nesta pesquisa como camada de subleito.

Tabela 3.9 - Valores das constantes dos modelos avaliados para o solo utilizado

\begin{tabular}{|c|c|c|c|c|c|}
\hline \multicolumn{2}{|l|}{ Modelo } & \multirow[t]{2}{*}{$\mathrm{R}^{2}$} & \multicolumn{3}{|c|}{ Constantes } \\
\hline & & & $\mathrm{K}_{1}$ & $\mathrm{~K}_{2}$ & $\mathrm{~K}_{3}$ \\
\hline$M_{R}=K_{1} \cdot \sigma_{d}^{k_{2}}$ & & 0,11 & 85,20 & $-0,18$ & - \\
\hline$M_{R}=K_{1} \cdot \sigma_{3}^{k_{3}}$ & & 0,42 & 9,45 & - & 0,33 \\
\hline$M_{R}=K_{1} \cdot \sigma_{3}^{k_{2}} \cdot \sigma_{d}^{k_{3}}$ & & 0,93 & 28,99 & 0,52 & $-0,44$ \\
\hline$M_{R}=K_{1} \cdot p_{a} \cdot\left(\frac{\theta}{p_{a}}\right)^{k_{2}}$ & $\left(\frac{\tau_{o c t}}{p_{a}}+1\right)^{k_{3}}$ & 0,80 & 379,79 & 0,63 & $-1,95$ \\
\hline
\end{tabular}


Observa-se na Tabela 3.9, que o modelo composto foi o que apresentou um melhor $\mathrm{R}^{2}$, sendo assim, esse modelo foi escolhido para a representação do módulo resiliente deste material.

A Tabela 3.10 apresenta os valores das constantes determinados para a mistura solo-brita utilizada nesta pesquisa como camada de base.

Tabela 3.10 - Valores das constantes dos modelos avaliados para a mistura solo-brita

\begin{tabular}{lcccc}
\hline \multicolumn{1}{c}{ Modelo } & $\mathrm{R}^{2}$ & \multicolumn{3}{c}{ Constantes } \\
\hline$M_{R}=K_{1} \cdot \sigma_{d}^{k_{2}}$ & & $\mathrm{~K}_{1}$ & $\mathrm{~K}_{2}$ & $\mathrm{~K}_{3}$ \\
$M_{R}=K_{1} \cdot \sigma_{3}^{k_{3}}$ & 0,13 & 110,30 & 0,26 & - \\
$M_{R}=K_{1} \cdot \sigma_{3}^{k_{2}} \cdot \sigma_{d}^{k_{3}}$ & 0,83 & 33,80 & - & 0,56 \\
$M_{R}=K_{1} \cdot p_{a} \cdot\left(\frac{\theta}{p_{a}}\right)^{k_{2}} \cdot\left(\frac{\tau_{o c t}}{p_{a}}+1\right)^{k_{3}}$ & 0,96 & 63,58 & 0,78 & $-0,35$ \\
\hline
\end{tabular}

Novamente, o modelo composto apresentou melhor $\left(R^{2}\right)$, sendo escolhido para a representação do módulo de resiliência para ambos os materiais.

\subsection{ENSAIO DE CARREGAMENTO CÍCLICO EM EQUIPAMENTO DE GRANDES DIMENSÕES}

Para o estudo do comportamento de pavimentos, foi construída uma caixa de ensaios metálica retangular com dimensões que possibilitaram a inserção de uma seção de pavimento com medidas próximas às reais e a sua solicitação através de 
carregamento cíclico similar ao imposto pelo tráfego rodoviário. A instrumentação do experimento forneceu medidas para o cálculo de deformações elásticas e permanentes na superfície, tensões aplicadas e tensões desenvolvidas no interior da estrutura.

O equipamento foi projetado visando aproximar as condições do experimento laboratorial às de campo, permitindo medidas numa dimensão intermediária entre as obtidas no ensaio de corpos de prova e as obtidas no monitoramento de trechos experimentais.

Para determinação das dimensões da caixa de ensaio foram realizadas algumas análises em que se utilizaram dois programas: Plaxis - versão 8.2 e Elsym5, e levou-se em consideração limitações quanto ao espaço físico disponível no Laboratório da EESC para a instalação da mesma. Estas análise são0 mostradas a seguir.

\subsubsection{Análise da espessura do subleito e das dimensões da caixa de ensaio}

A espessura do subleito utilizado na composição do pavimento e as dimensões da caixa de ensaio foram definidas a partir de análises numéricas elásticas realizadas utilizando o programa de elementos finitos Plaxis.

O programa Plaxis é um programa computacional em elementos finito bidimensional especialmente concebido para realizar análises de deformações, 
deslocamentos e estabilidade para vários tipos de aplicações geotécnicas. Situações reais podem ser modeladas por um modelo plano ou simétrico (elásticas lineares, elásticas perfeitamente plásticas, e outros). O programa utiliza uma interface gráfica que permite ao usuário gerar rapidamente um modelo geométrico e uma malha de elementos finitos (triangulares de 6 ou 15 nós) baseados sobre uma seção transversal vertical representativa da situação em estudo.

Para as análises, foi definida uma estrutura de pavimento flexível composta de uma capa de CBUQ e uma base granular sobreposta a um subleito, representado por uma camada de solo. Estes elementos foram inseridos em uma estrutura indeformável, simulando a caixa de ensaios de aço. Assumiu-se que os materiais apresentam comportamento elástico-linear com características mecânicas compatíveis com as de materiais encontrados em rodovias brasileiras. A Tabela 3.11 apresenta os módulos de elasticidade, os coeficientes de Poisson dos materiais e a espessura das camadas que compõem este pavimento modelado. Destaca-se que esta etapa do estudo foi realizada anteriormente à escolha dos materiais que comporiam a seção do pavimento analisada durante os ensaios da fase final da pesquisa.

Tabela 3.11 - Programa Plaxis - Módulo de elasticidade e coeficiente de Poisson dos materiais e espessura das camadas que compõem o pavimento

\begin{tabular}{cccc}
\hline Materiais & $\begin{array}{c}\text { Módulo de elasticidade } \\
\left(\mathrm{kN} / \mathrm{m}^{2}\right)\end{array}$ & $\begin{array}{c}\text { Coeficiente de } \\
\text { Poisson }\end{array}$ & $\begin{array}{c}\text { Espessura } \\
(\mathrm{cm})\end{array}$ \\
\hline Capa asfáltica & $3,5 \times 10^{6}$ & 0,33 & 7 \\
Base granular & $4,5 \times 10^{5}$ & 0,35 & 40 \\
Subleito & $4,5 \times 10^{4}$ & 0,30 & 50 \\
\hline
\end{tabular}


Para o carregamento da seção do pavimento, supôs-se uma roda de um eixopadrão de rodas duplas com pressão de contato de $5,6 \mathrm{kgf} / \mathrm{cm}^{2}$ e raio de $10,8 \mathrm{~cm}$ (MEDINA 2005), representada por uma placa flexível. A Figura 3.13 ilustra os vínculos, o carregamento e a malha de elementos finitos de uma simulação da seção do pavimento para as condições estabelecidas conforme a saída gráfica do Programa Plaxis.

É importante destacar que os vínculos nas paredes verticais da caixa permitem movimentação nesta direção. Simulações preliminares realizadas com vínculos fixos nas duas direções mostraram que nesta condição existe uma influência das paredes da caixa nos resultados, o que exigiria a construção de uma estrutura de dimensões não compatíveis com o espaço disponível no laboratório. Para se garantir o movimento vertical livre da estrutura do pavimento com relação à caixa, providenciou-se a minimização do atrito nas laterais durante a compactação.

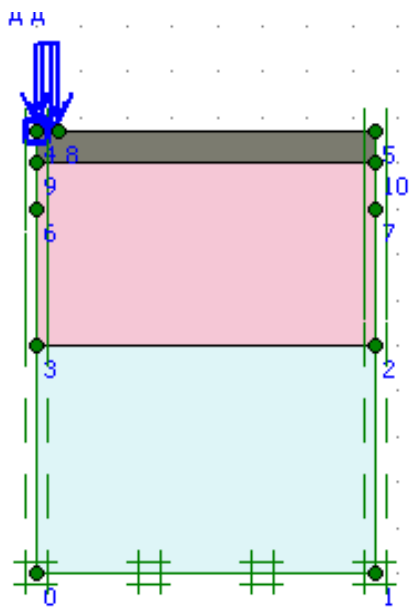

(a)

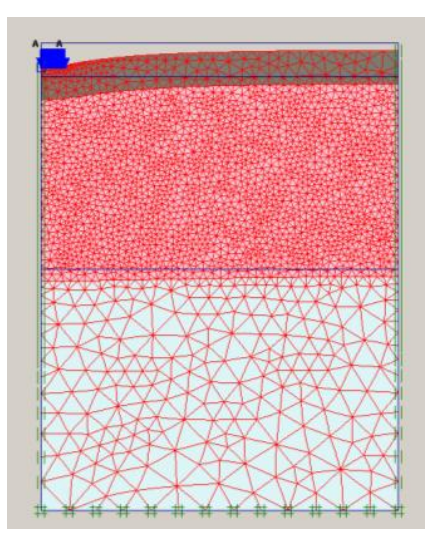

(b)

Figura 3.13 - Simulação de uma seção de pavimento segundo saída gráfica do Programa Plaxis, vínculos e carregamento: a) Malha não-deformada e b) Malha-deformada pelo carregamento 
Para a definição das dimensões mínimas da caixa de ensaios a partir da qual as paredes não interferem nos resultados do experimento, foram realizadas simulações simétricas para caixas circulares com diâmetros de 1,5, 2,0 e 3m, determinando-se as correspondentes bacias de recalque na superfície da seção analisada.

A Figura 3.14 apresenta as bacias de recalques fornecidas pelo Programa Plaxis para as três dimensões de caixas e também a bacia obtida por meio de uma simulação usando o programa computacional Elsym-5, que corresponde a uma situação onde não existiria nenhuma restrição lateral ao desenvolvimento dos deslocamentos.

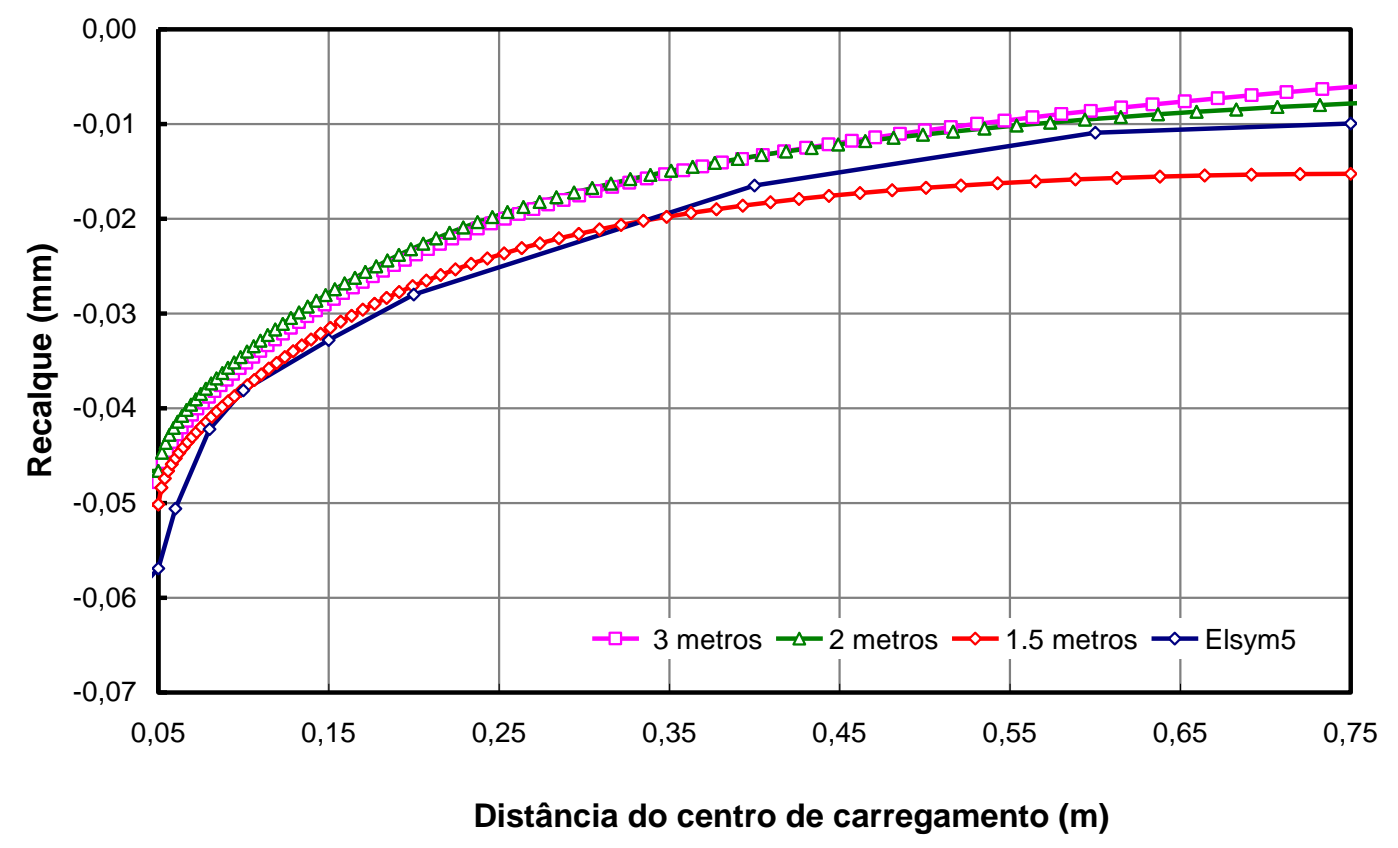

Figura 3.14 - Programa Plaxis e Elsym-5 - Bacias de recalque para caixas com dimensões variadas

Analisando-se a Figura 3.14, observa-se que as bacias previstas pelo programa Plaxis diferem pouco para 2 e $3 \mathrm{~m}$, principalmente no trecho central da curva, podendo-se concluir que a partir deste último valor, as paredes não mais 
influenciariam os resultados. A bacia para 1,5 m apresenta recalques maiores que os correspondentes às maiores dimensões e crescentes com a redução do diâmetro da caixa, entretanto a forma conserva-se. Com base nestes resultados, poder-se-ia concluir que o diâmetro de $3 \mathrm{~m}$ seria o ideal e que a partir de $2 \mathrm{~m}$, a influência das paredes seria muito pequena. Entretanto, o espaço disponível no Laboratório de Estradas da EESC/USP era reduzido, dificultando a instalação de uma caixa quadrada com lados maiores que 1,5m. Assim, procurou-se avaliar a conseqüência de se adotar a medida de $1,5 \mathrm{~m}$ para a construção da caixa.

Comparando-se as bacias obtidas nas simulações usando o Plaxis para 1,5 e 3,0m, esta última considerada a medida ideal, observa-se que a diferença, no centro do carregamento, é de aproximadamente $5 \%$. Comparando-se a bacia de 1,5m com a obtida a partir do programa Elsym-5, muito utilizado na análise e retro-análises de pavimentos, observa-se que os recalques no centro do carregamento são coincidentes. E ainda, que a bacia do Elsym-5 aproxima-se mais da bacia de 1,5m que da $3,0 \mathrm{~m}$, considerada a ideal.

Finalmente, com base nas análises anteriores, no grande volume de material e no trabalho exigido para a compactação das seções a serem ensaiadas para caixas com dimensões muito avantajadas e nas limitações de espaço no Laboratório de Estradas da EEESC/USP, optou-se por construir uma caixa de ensaios de seção quadrada com 1,5m de largura e altura de 1,2m. A altura foi definida de maneira a permitir a construção de uma seção de pavimento composta por um subleito de $50 \mathrm{~cm}$ e uma base e uma capa com espessuras compatíveis com a de pavimentos reais. A Figura 3.15 apresenta uma perspectiva da caixa de ensaios, destacando as laterais dotadas de nervuras tipo colméia para se garantir a rigidez das paredes. 


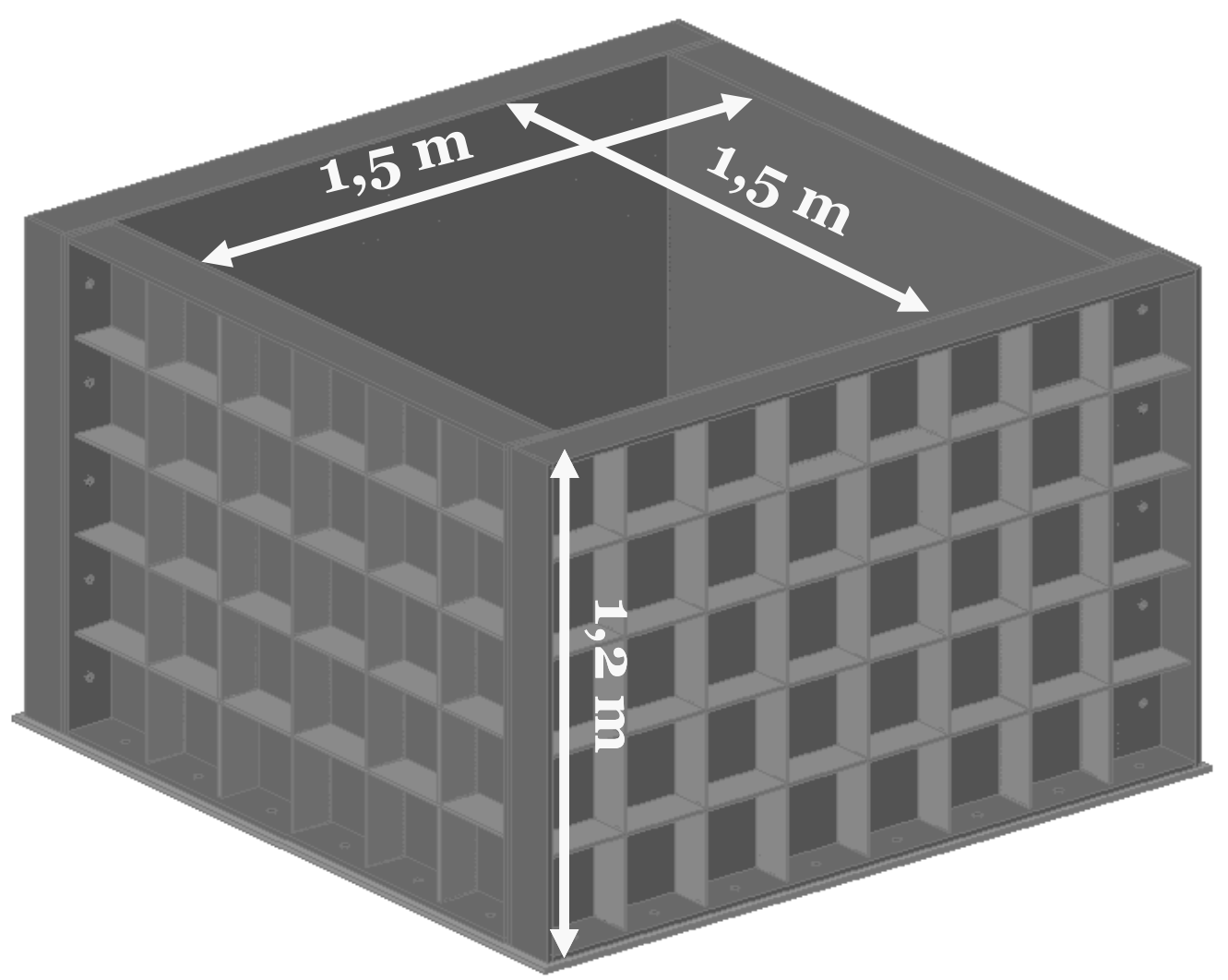

Figura 3.15 - Perspectiva e dimensões da caixa de ensaios

\subsubsection{Montagem e calibração do equipamento e testes}

Neste item, são apresentadas informações detalhadas sobre a preparação da sala de ensaio, montagem do equipamento e particularidade dos sistemas de umedecimento do subleito, do carregamento, da instrumentação e da aquisição de dados. 


\subsubsection{Adaptação da sala de ensaio e montagem da caixa metálica}

Como o Laboratório de Estradas da EESC não tinha um espaço adequado para a disposição do equipamento foi necessário adaptar uma sala do laboratório. A primeira medida a ser tomada foi construir uma laje de reação para o equipamento de maneira que resistisse aos esforços solicitados pelo peso próprio e pelo carregamento cíclico. Para isso, foi necessário construir uma laje de concreto armado de $50 \mathrm{~cm}$ de espessura para servir de apoio para o equipamento. $O$ dimensionamento e verificação desta laje de reação foram realizados com colaboração do Prof. Dr. Toshiaki Takeya e do aluno de Pós-doutorado Rodrigo Dalalibera, ambos do Departamento de Estruturas, EESC/USP.

As Figuras 3.16, 3.17 e 3.18 mostram o projeto de adaptação da sala de ensaio, aspectos da construção da laje e montagem da caixa de ensaio, respectivamente. 


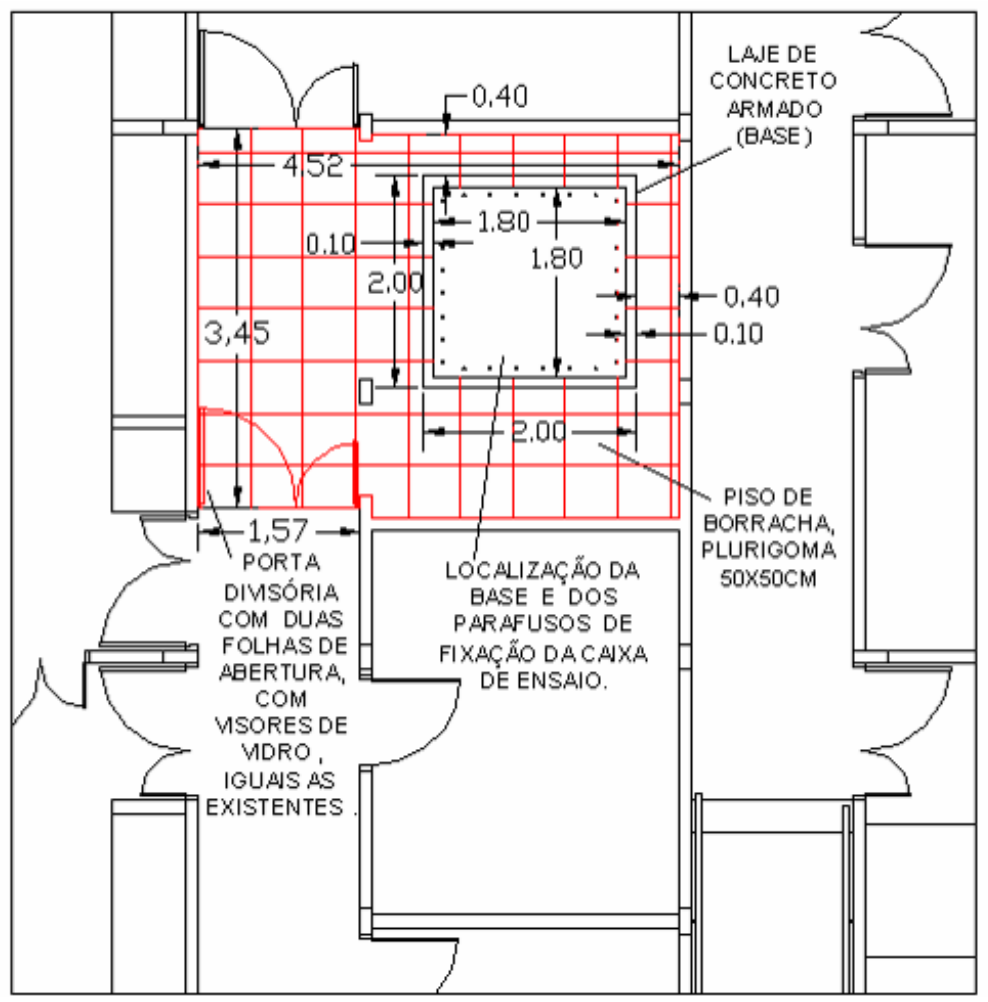

Figura 3.16 - Sala de ensaios e localização da laje de concreto para fixação da caixa

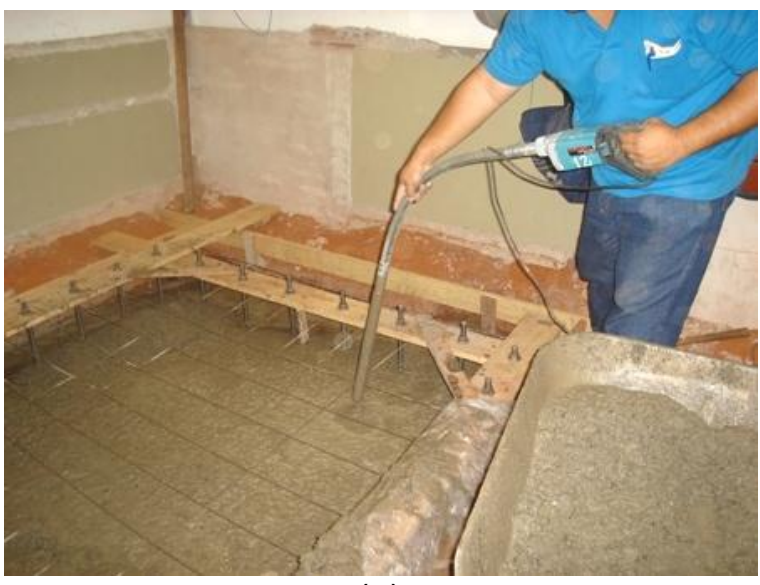

(a)

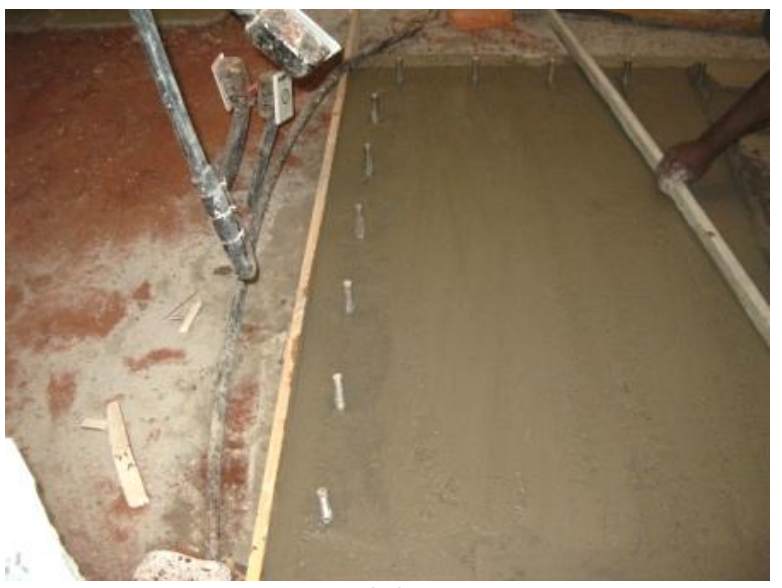

(b)

Figura 3.17 - Construção da laje de apoio: a) Concretagem e b) Fixação dos fusos

Na Figura 3.18, observa-se que a caixa foi construída de forma que pudesse ser instalada no local, e se necessário, desmontada e remontada em um outro local. A caixa é constituída de cinco elementos, uma base e quatro laterais que são unidas por meio de parafusos e porcas. Observa-se na Figura 3.18a uma das laterais da caixa sendo revestida, na Figura $3.18 \mathrm{~b}$ que os fusos que foram chumbados na laje 
de reação ligam as quatro laterais da caixa sendo ao todo 28 fusos e na Figura 3.18c uma vista geral com viga de reação do cilindro pneumático.

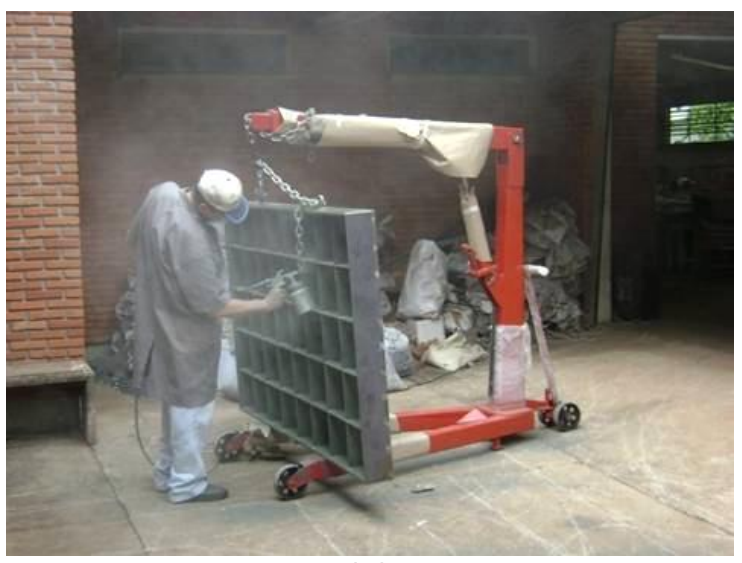

(a)

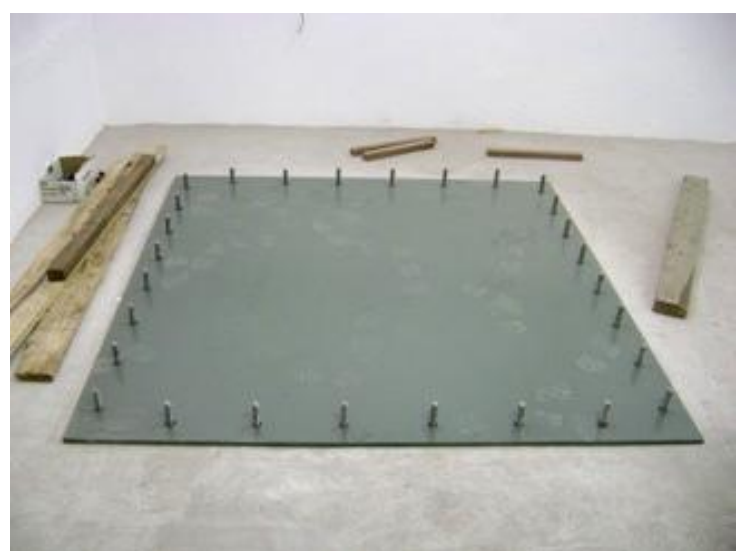

(b)

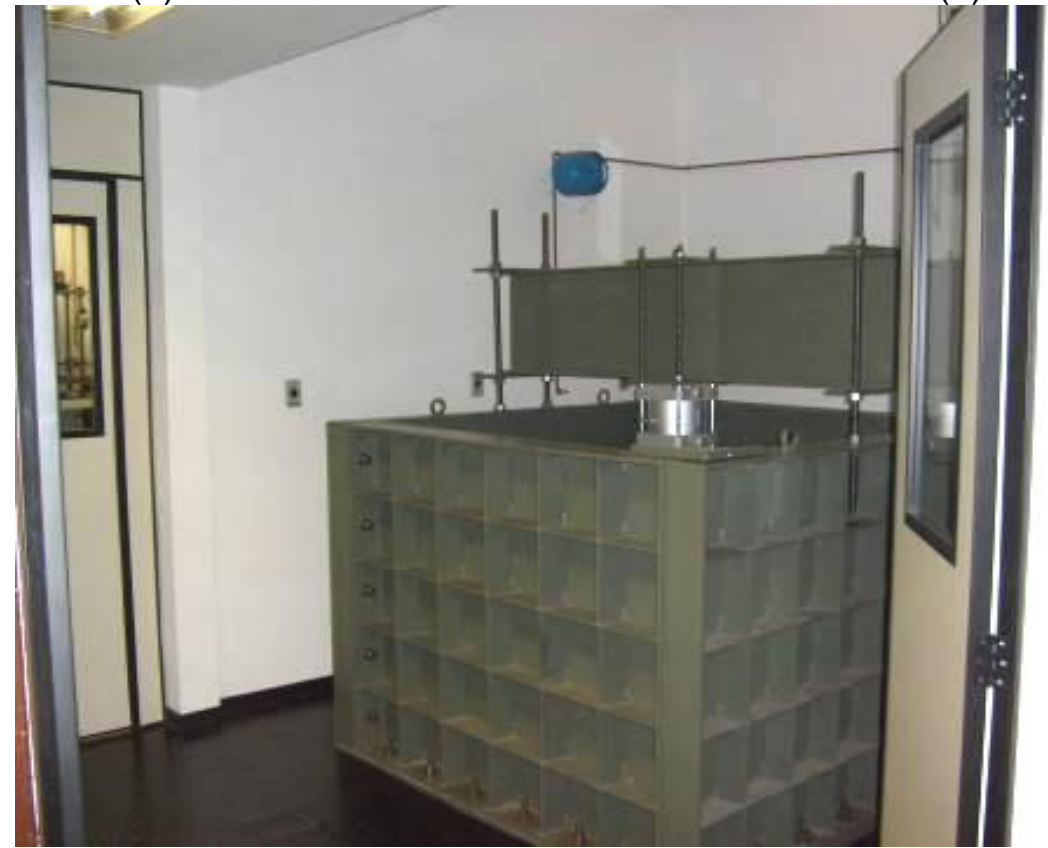

(c)

Figura 3.18 - Caixa de ensaios: a) Uma das laterais; b) Base e c) Caixa montada

Observa-se na Figura 3.19a, a primeira tentativa de fixação da viga de reação foi por meio de quatro fusos de $30 \mathrm{~mm}$ de diâmetro nominal fixados em furos na aba das laterais da caixa. Entretanto, nos testes em que se utilizou uma carga de $40 \mathrm{kN}$, verificou-se, por medida de segurança, a necessidade de reforçar essa fixação. Então, substituíram os fusos originais por quatro barras de $100 \mathrm{~mm}$ de diâmetro, sendo estas soldadas na lateral interna da caixa, além de se adicionar uma 
cantoneira de meia polegada de espessura no apoio da viga metálica, conforme visualizado na Figura 3.19b.

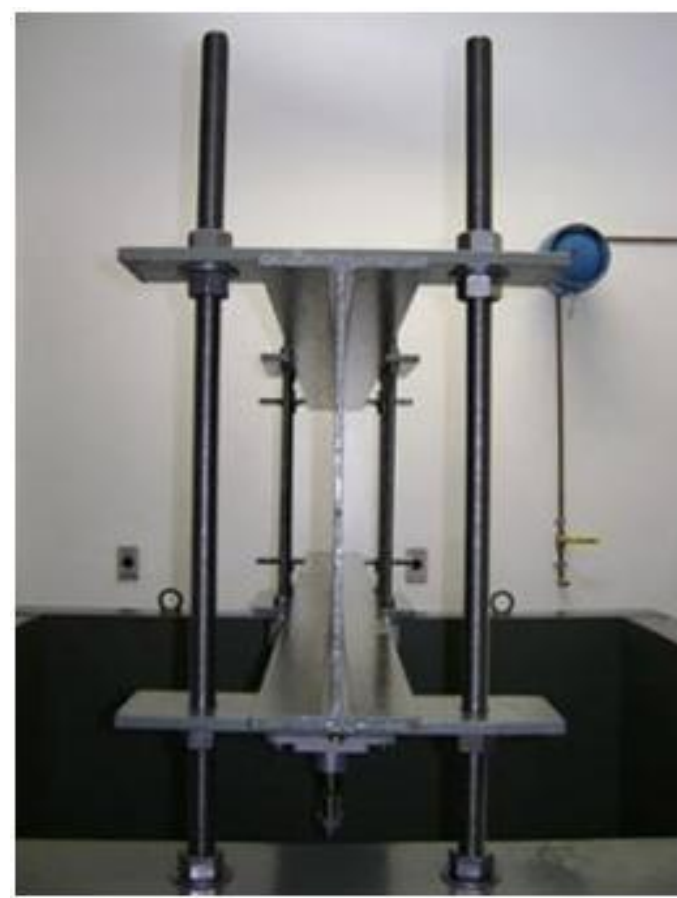

(a)

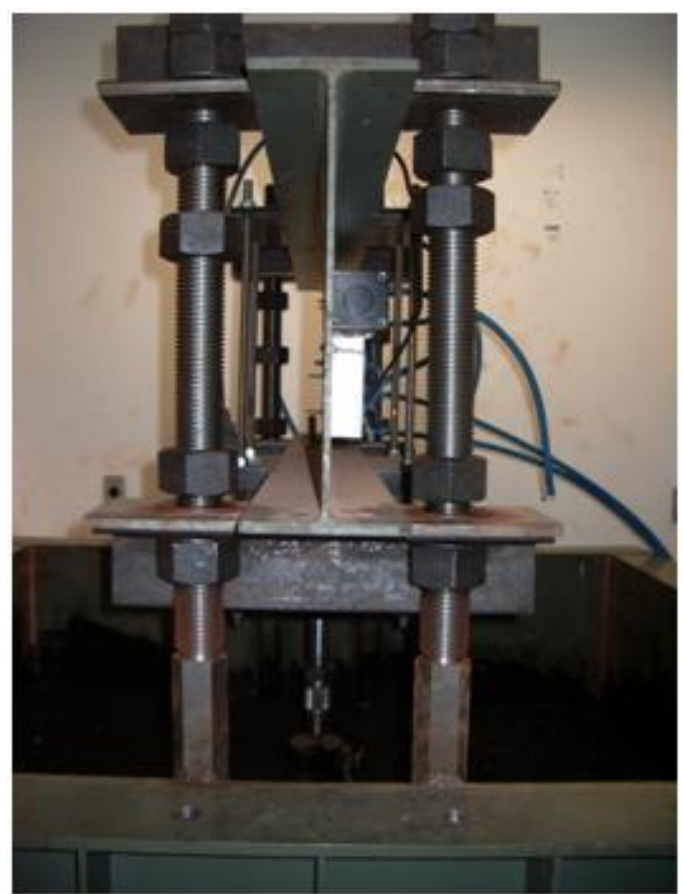

(b)

Figura 3.19 - Fixação da viga de reação: a) Fixação por fusos e b) Fixação por barras soldadas

\subsubsection{Sistema de umedecimento da camada de subleito}

Para a realização dos ensaios com o umedecimento do subleito foram instalados segmentos de tubos de cobre no contorno das laterais da caixa apoiadas na sua face inferior, conforme mostrado na Figura 3.20a. Estes tubos são ligados a uma fonte de água e dotados de furos a cada $10 \mathrm{~cm}$. A Figura $3.20 \mathrm{~b}$ mostra a entrada de água por meio deste sistema. 


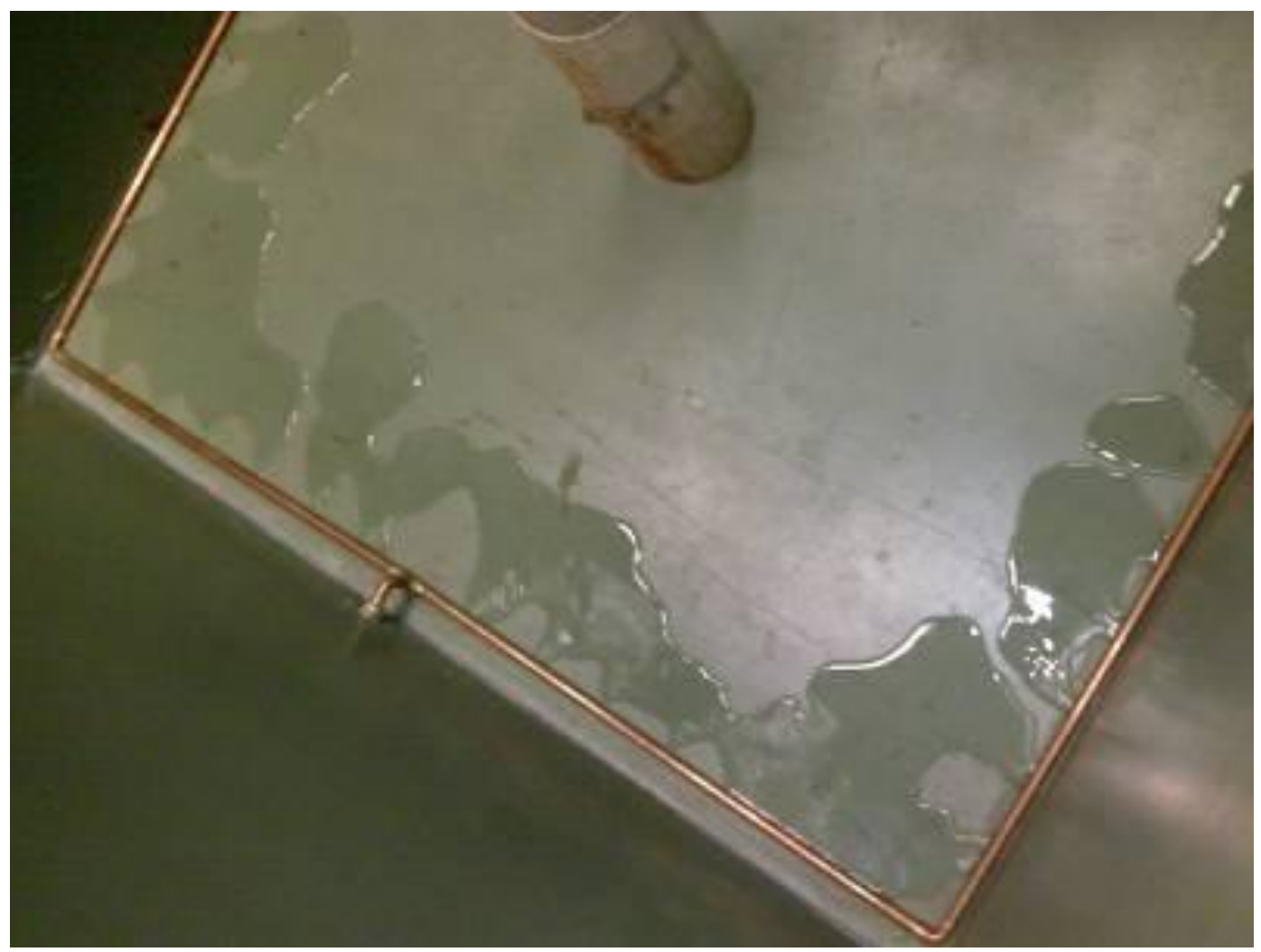

Figura 3.20 - Sistema de umedecimento do subleito

Preliminarmente à compactação da seção do pavimento, foi colocada uma camada de pedrisco de $10 \mathrm{~cm}$ de espessura de maneira a permitir melhor homogeneização e agilização do umedecimento, recoberta de uma manta de geotextil usada para impedir a penetração do material do subleito no dispositivo de umedecimento, conforme mostra a Figura 3.21. 


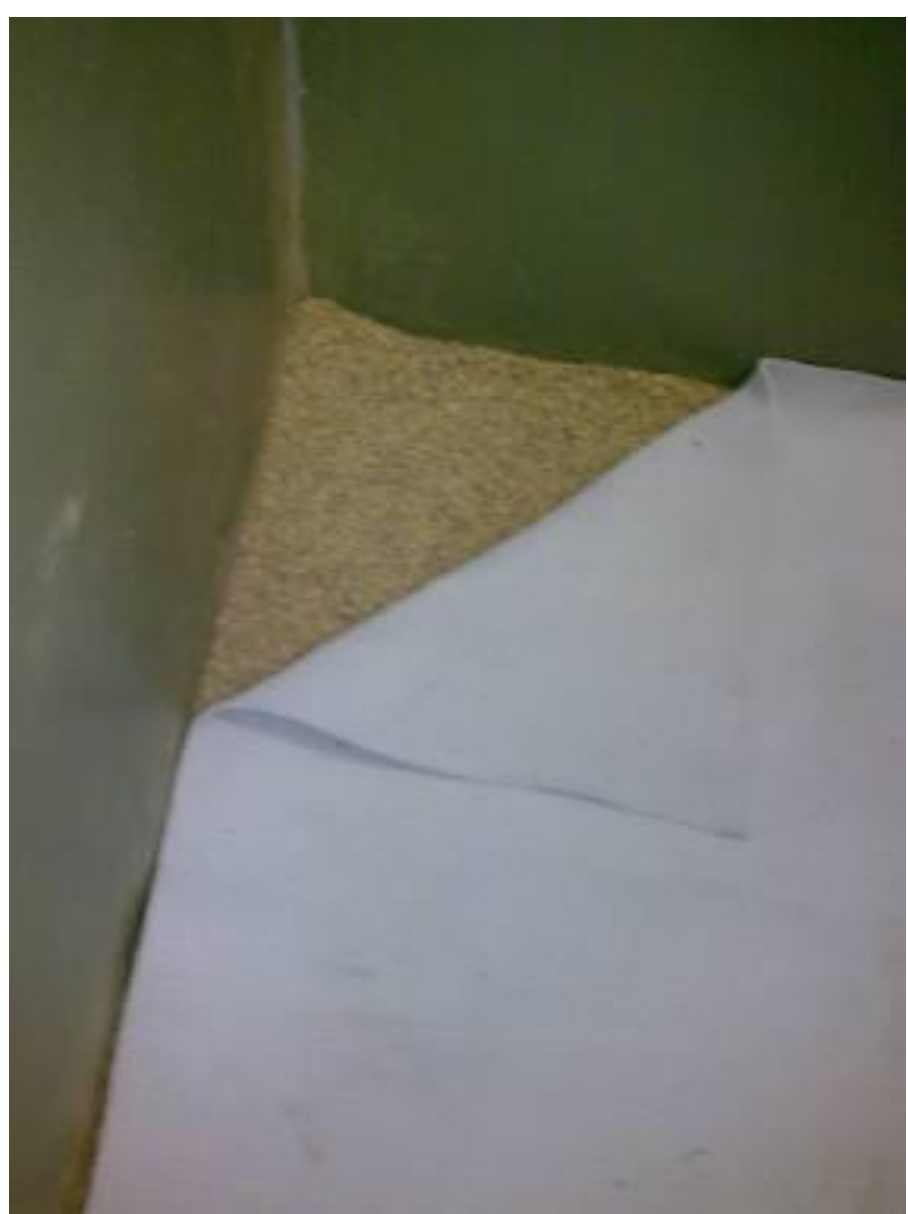

Figura 3.21 - Camada drenante com destaque para a brita e o recobrimento com o geotêxtil

Associado ao dispositivo de umedecimento foi instalado um tubo externo graduado para a indicação da carga da água (piezômetro) no interior da caixa, conforme mostra a Figura 3.22. 


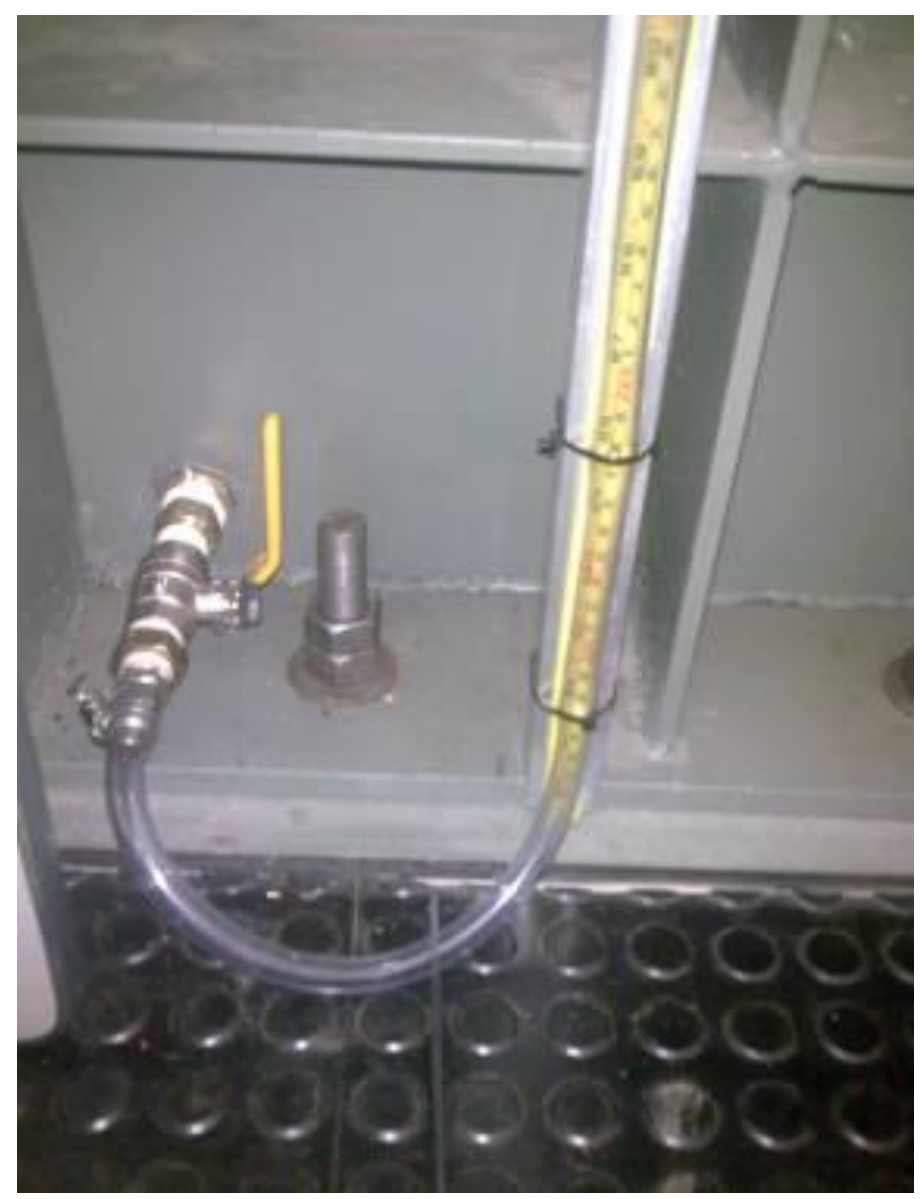

Figura 3.22 - Dispositivo de indicação da carga da água (piezômetro)

\subsubsection{Sistema de carregamento}

O sistema de carregamento escolhido foi o pneumático ao invés do hidráulico tendo em vista envolver menores custos e ainda se poder contar com a experiência do Professor Glauco Tulio Pessa Fabbri nesta área, visto que outros equipamentos utilizados no Laboratório de Estradas da EESC-USP utilizam este mesmo sistema.

O sistema é composto de um cilindro pneumático, um compressor de ar, filtros coalecentes e purgadores e válvulas de controle de entrada e saída de ar. 
O compressor adquirido foi da marca Pressure com capacidade de 450litros e potência de 15HP. Devido ao seu grande porte e aos ruídos gerados durante seu funcionamento, foi necessária a sua instalação num local externo ao laboratório e para isso foi construída uma edificação apropriada, vide Figura 3.23a, e também providenciado um sistema independente de alimentação elétrica.

Para ter uma vazão de ar adequada utilizaram-se tubulações de cobre de diâmetro de três quartos de polegada, sendo ainda instalados filtros purgadores e coalescentes encarregados de reduzir a umidade do ar comprimido ao longo da linha, conforme mostrado na Figura 3.23b.

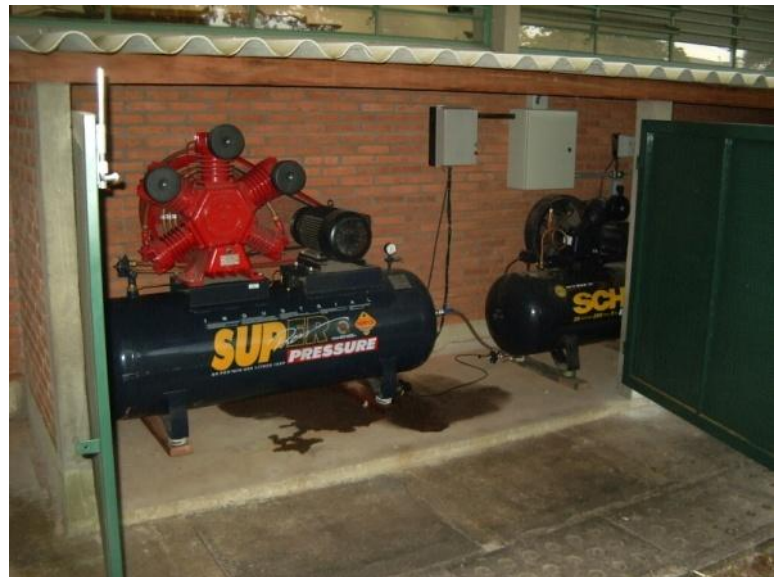

(a)

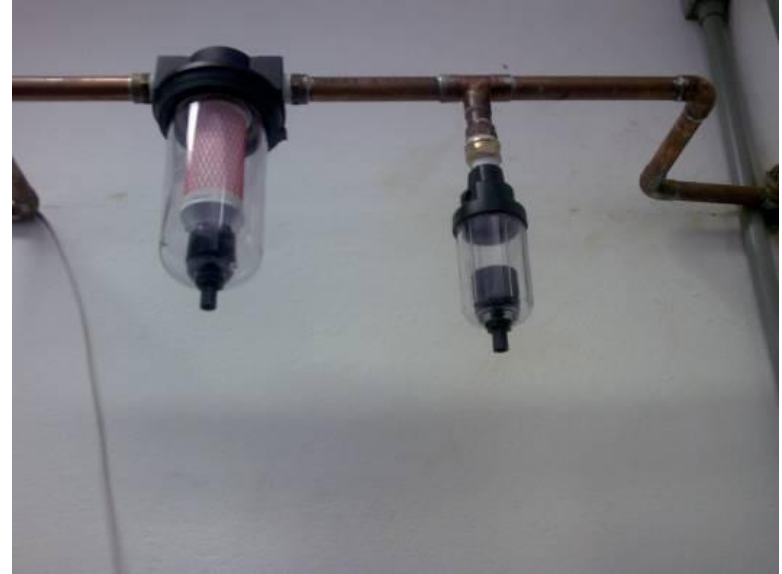

(b)

Figura 3.23 - Ar comprimido: a) Compressor e b) Filtro purgador e filtro coalescente

A Figura 3.24a apresenta uma vista geral onde se destacam a viga de reação, o cilindro pneumático acoplado às duas válvulas encarregadas do controle da vazão e da pressão de entrada de ar, sendo uma de serviço pesado e a outra proporcional, associadas em série e alimentadas por um reservatório auxiliar de 2l de capacidade, usado com a função de abreviar o tempo de aplicação do pulso. Observa-se ainda que o sistema descrito foi fixado na própria viga com o objetivo de diminuir as perdas na tubulação flexível que interliga os controles. 
A Figura 3.24b ilustra a elevação da viga de reação juntamente com todo sistema pneumático, por meio de uma talha fixada na laje de sala de ensaio, providência necessária quando da compactação da seção do pavimento.

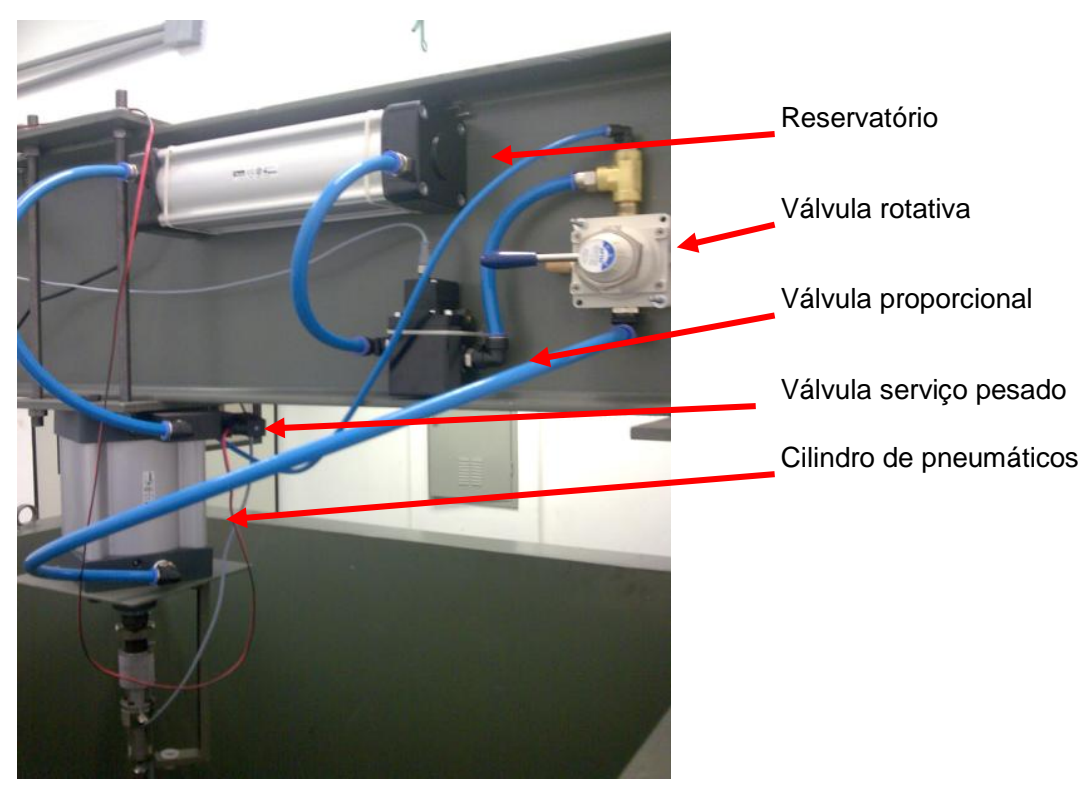

(a)

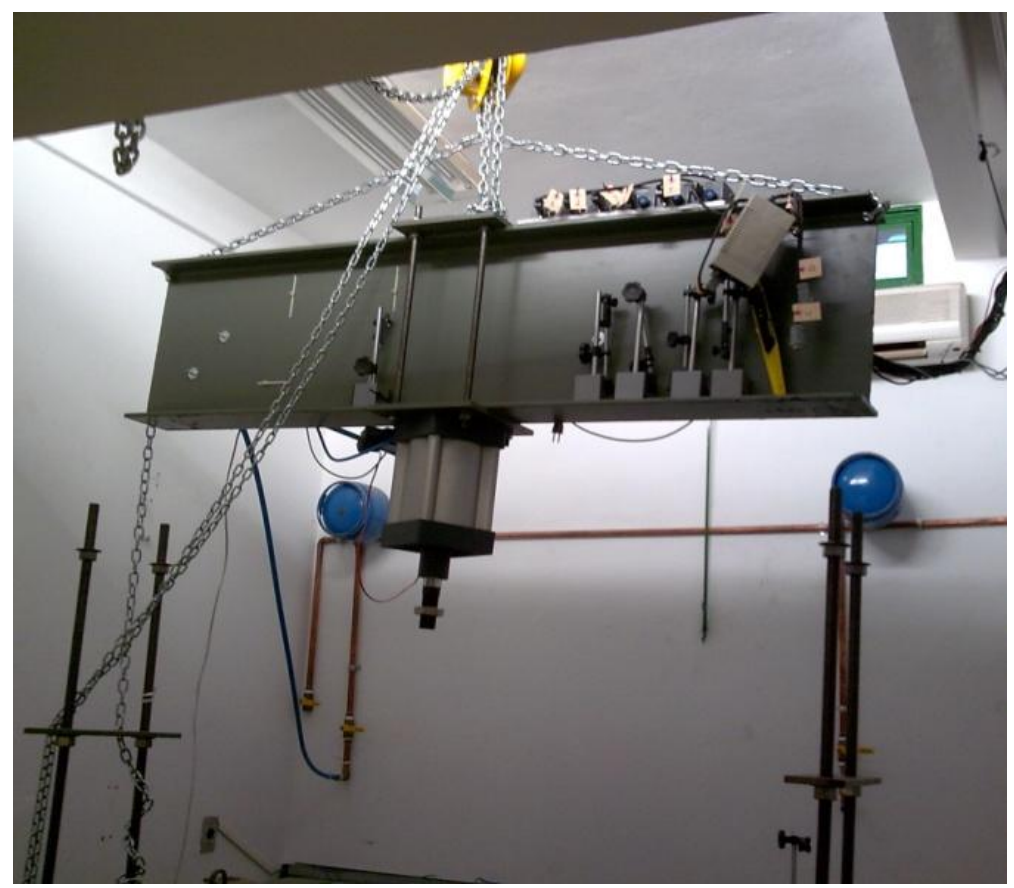

(b)

Figura 3.24 - Viga de reação: a) Disposição das válvulas fixadas na viga e b) Vista da retirada do sistema pneumático 
O carregamento é aplicado na superfície da seção ensaiada por meio de uma placa metálica circular. Um elemento de borracha com $4 \mathrm{~mm}$ de espessura foi instalado na face inferior da placa para torná-la semi-flexível e evitar que ocorram rupturas localizadas no terreno sob as suas extremidades e aproximar as condições do experimento às condições de campo.

O equipamento permite a aplicação de cargas variadas a partir de diferentes combinações de forças fornecidas por dois tipos de cilindros pneumáticos, um de $17,5 \mathrm{~cm}$ de diâmetro e outro de $30 \mathrm{~cm}$ de diâmetro, e de placas com diâmetros de 21,6 e $30 \mathrm{~cm}$ com espessuras de $2,54 \mathrm{~cm}$. A Figura 3.25 apresenta as placas circulares com diâmetros de 21,6 e 30,0cm.
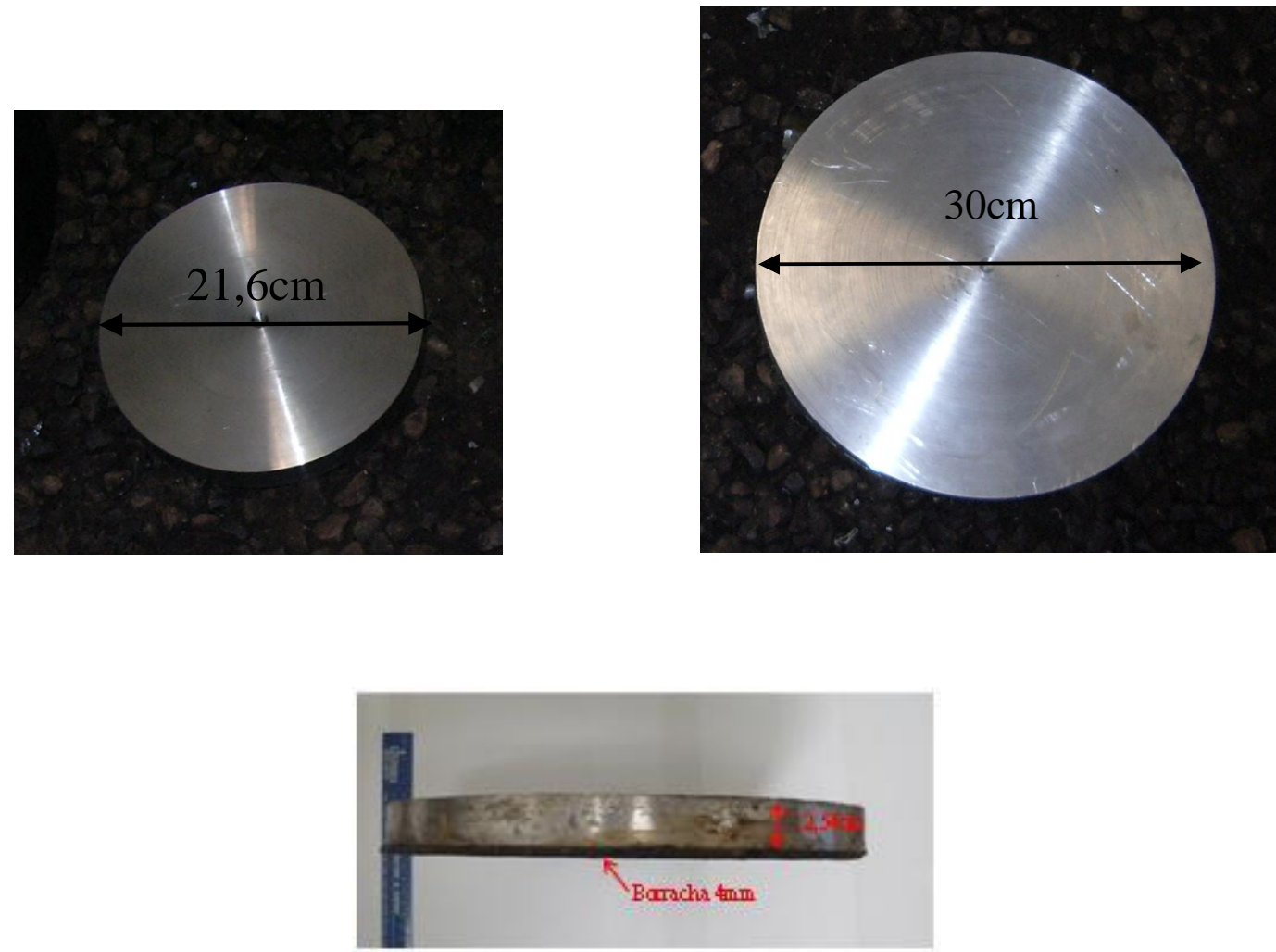

Figura 3.25 - Placas metálicas: a) Diâmetro de 21,6cm; b) Diâmetro de $30 \mathrm{~cm} \mathrm{e} \mathrm{c)} \mathrm{Perfil}$ da placa

$\mathrm{Na}$ Figura 3.26 apresenta os cilindros pneumáticos de 17,5 e $30 \mathrm{~cm}$ de diâmetro. 


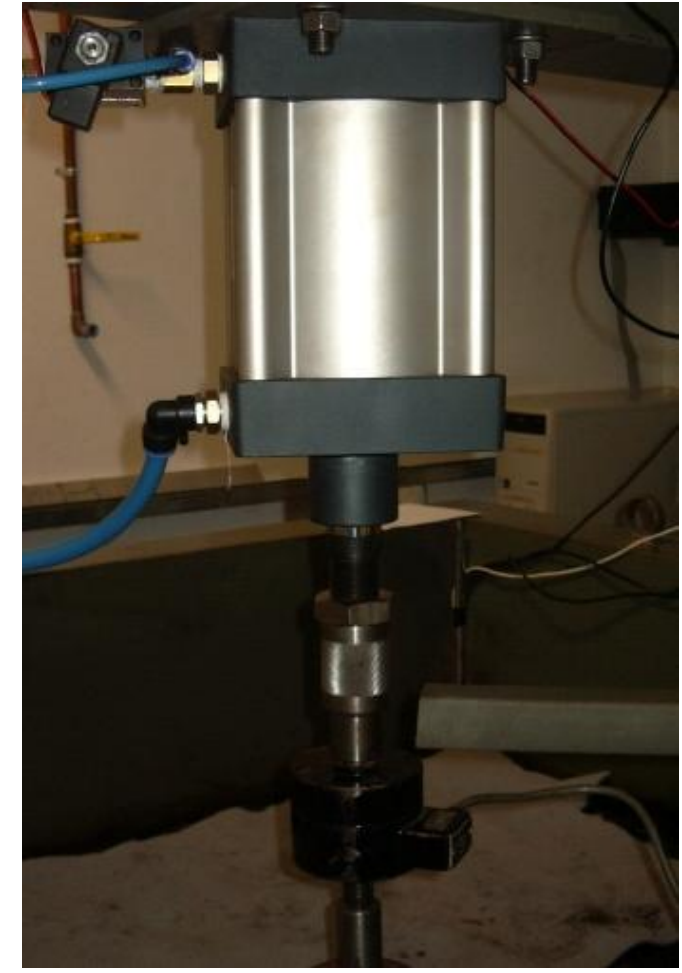

(a)

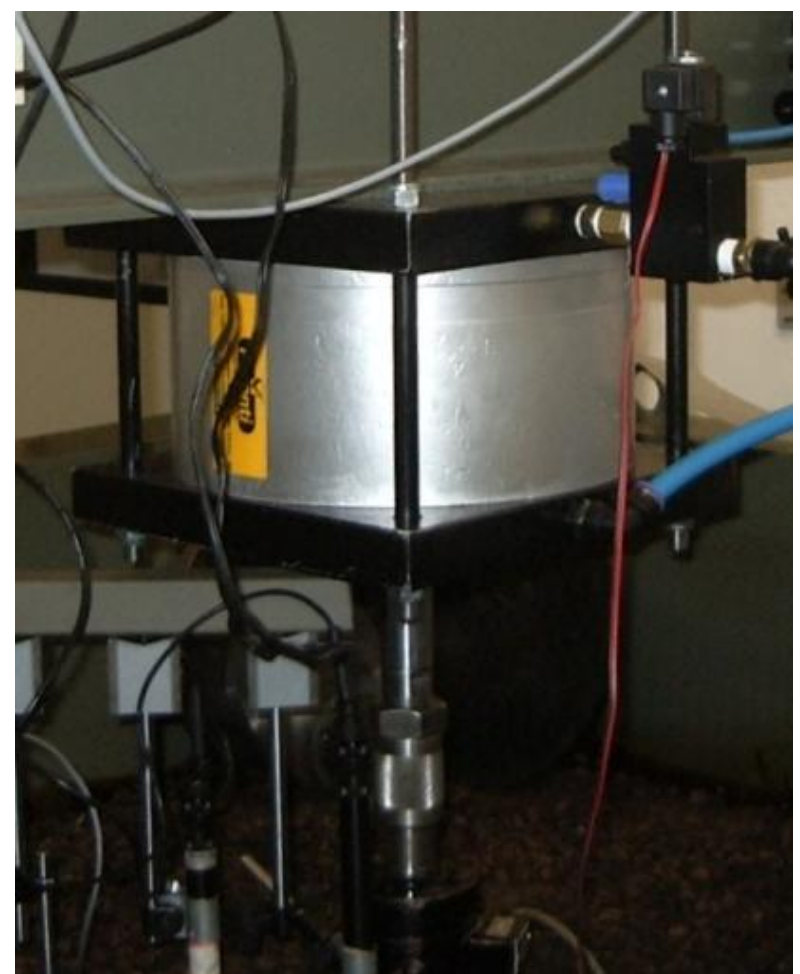

(b)

Figura 3.26 - Cilindros pneumáticos: a) Diâmetro de 175mm e b) Diâmetro de $300 \mathrm{~mm}$

$\mathrm{Na}$ pesquisa foram aplicados carregamentos de $550 \mathrm{kPa}$ em ciclos com duração de $1 \mathrm{~s}(1 \mathrm{~Hz})$, sendo que quando se utilizou a placa de $30 \mathrm{~cm}$ de diâmetro, procurou-se reproduzir a condição preconizada para o ensaio 'Determinação das Deflexões Utilizando o Deflectômetro de Impacto Tipo Falling Weight Deflectometer - FWD', segundo a norma DNER-PRO 273/96. Quando se utilizou a placa de $21,6 \mathrm{~cm}$ de diâmetro procurou-se representar o carregamento de uma roda do eixo padrão segundo o Manual de Pavimentação do DNER (DNER-96).

A proposta original da pesquisa era que o carregamento tivesse uma duração de $0,1 \mathrm{~s}$, seguido de um repouso de 0,9 s. Entretanto, os testes do equipamento mostraram que a carga desejada só era alcançada aumentando-se o tempo de aplicação para 0,3s. Assim, os ciclos de carregamento foram complementados com 0,7s de repouso. Essa dificuldade foi também observada por Perkins (1999) que 
realizou seus ensaios com um tempo de 0,8s de atuação da carga e também relatados por Leng and Garb (2002), Al-Qadi et AL. (1994), Miura et al. (1990).

\subsubsection{Sistema de instrumentação}

A instrumentação é composta por transdutores para as medidas da força aplicada, deslocamentos elásticos e permanentes na superfície da seção ensaiada e tensões no interior das camadas. A força é monitorada por uma célula de carga acoplada ao cilindro pneumático, os deslocamentos superficiais são monitorados por seis LVDTs alinhados e apoiados sobre a superfície do pavimento, cinco deles posicionados fora da região carregada, e um posicionado em um pequeno orifício da placa, próximo ao seu centro, evitando-se o efeito da vibração da placa, e quatro células de tensão total instaladas sob a vertical do carregamento nos horizontes da interface subleito/base e centro da base.

A Figura 3.27a apresenta uma vista esquemática em corte da caixa de ensaios e a disposição dos transdutores e a Figura 3.27b uma vista em planta do posicionamento dos LVDTs. 


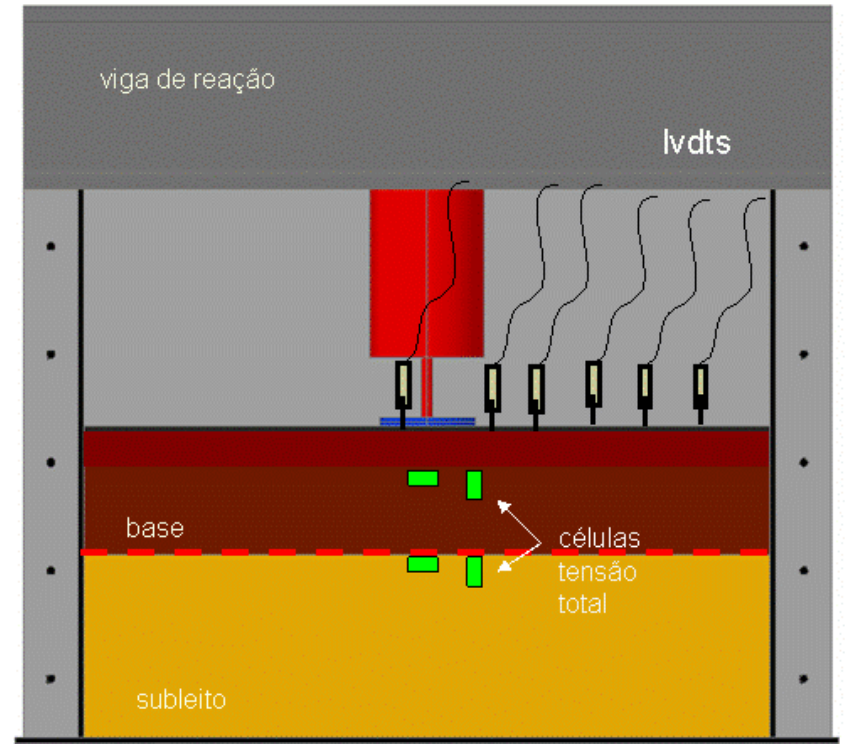

(a)

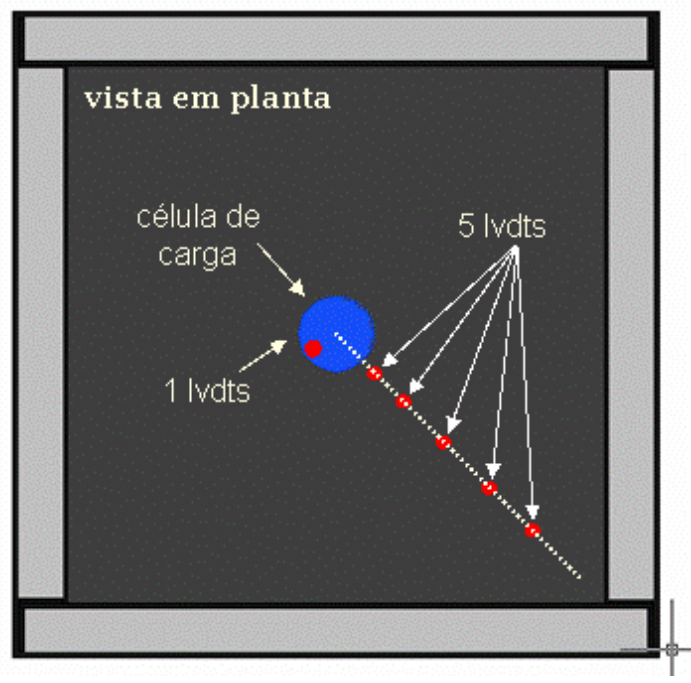

(b)

Figura 3.27 - Posicionamento dos LVDTs: a) Vista em corte e b) Vista em planta

Os LVDTs são da marca Transtek sendo: 3 de curso de +/-0,05", 1 de curso de $+/-0,1 ", 3$ de curso de $+/-0,25 "$ e 1 de curso de $+/-1$ ". Deste conjunto composto de 8 LVDTs utilizaram-se nos ensaios apenas 6 , ficando 2 de reserva.

O posicionamento dos LVDTs seguiu a seguinte disposição:

- 1 LVDT de curso 0,25 " sobre a placa rígida, distante $7,5 \mathrm{~cm}$ do eixo do pistão do cilindro;

- 1 LVDT de curso 0,25" distante de $20 \mathrm{~cm}$ do centro de carregamento;

- 1 LVDT de curso 0,1" distante de $30 \mathrm{~cm}$ do centro de carregamento;

- 3 LVDTs de cursos 0,05" distantes de 40, 50 e $60 \mathrm{~cm}$ do centro de carregamento;

As calibrações dos LVDTs foram feitos no Laboratório de Estrada da EESCUSP com o auxílio de um extensômetro digital com precisão de milésimo de milímetro, conforme Figura 3.28. 


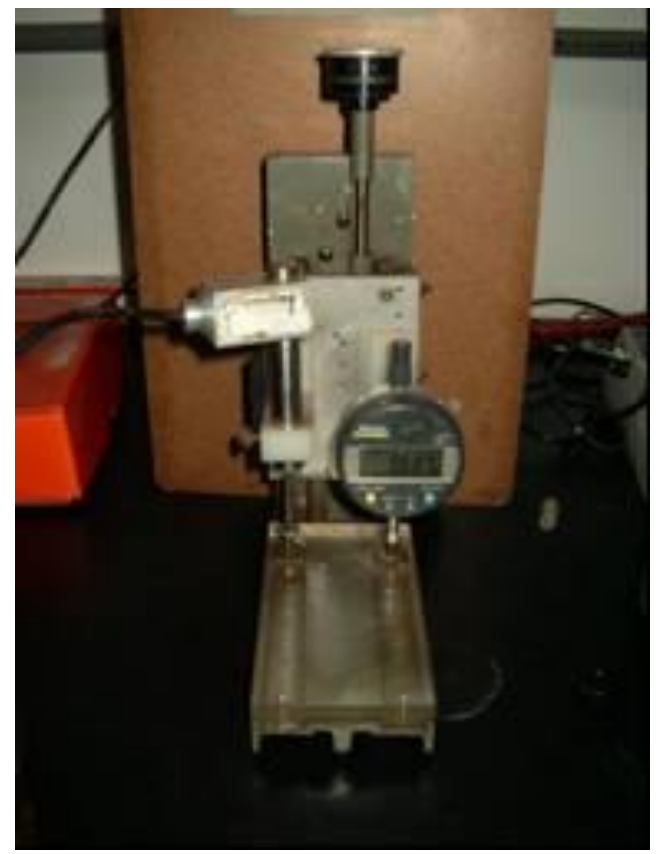

Figura 3.28 - Extensômetro digital para calibração de LVDTs

A primeira idéia para a fixação dos LVDTs foi prendê-los a uma régua metálica, sendo esta ancorada no cilindro pneumático, conforme apresentado na Figura 3.29. O principal motivo desta alternativa foi que o sistema de instrumentação ficaria fixo à viga e desta forma quando a viga fosse movimentada não seria necessário desmontar o sistema de leitura. Entretanto, esta alternativa não se mostrou eficiente, uma vez que logo nos primeiros carregamentos foi observado que o cilindro ao ser solicitado provocava vibrações que introduziam erros que impossibilitavam o bom funcionamento dos LVDTs. 


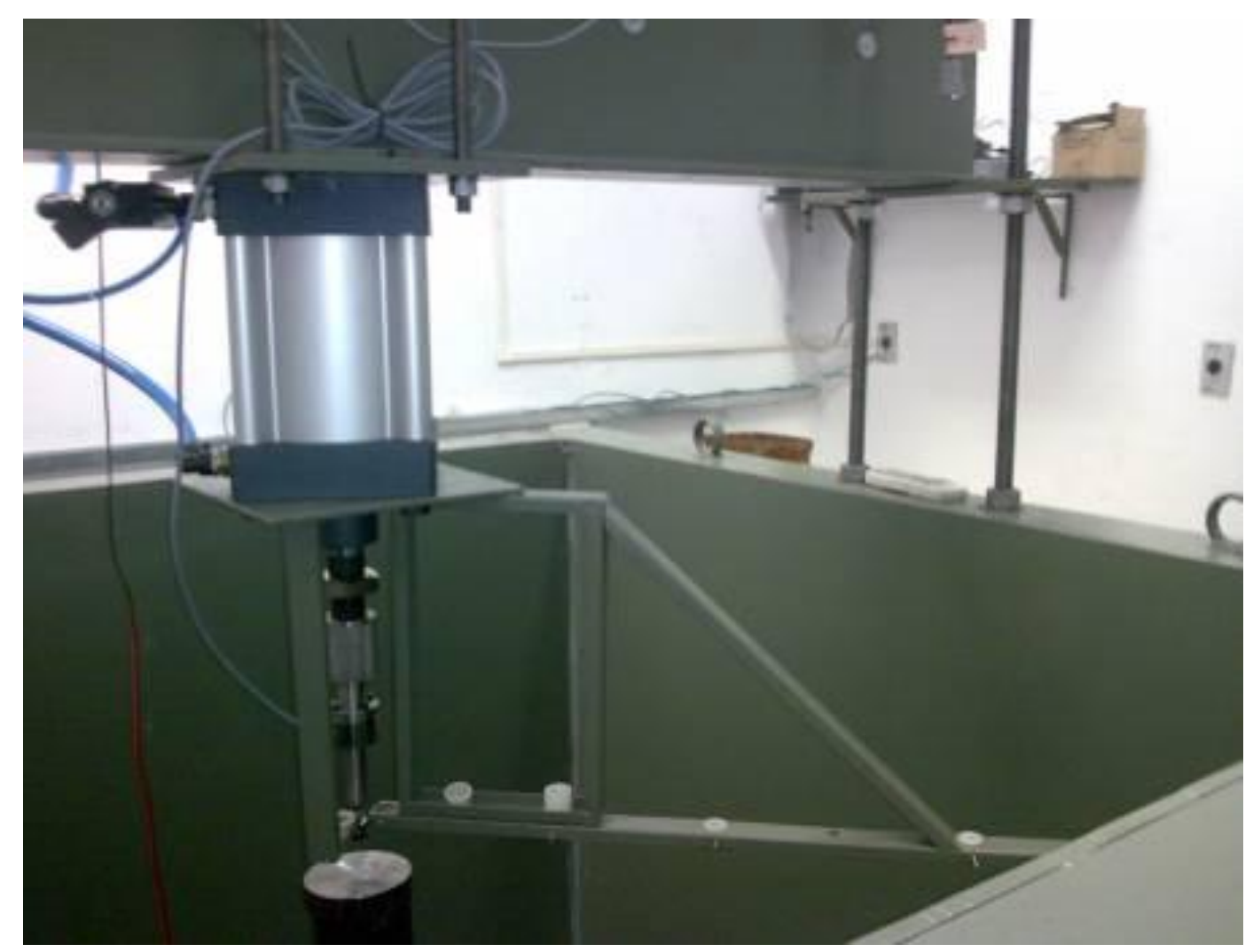

Figura 3.29 - Fixação da régua no cilindro pneumático

A alternativa à fixação da régua ao cilindro pneumático foi a sua fixação à lateral da caixa de ensaios. Neste caso, os LVDTs foram instalados na régua usando bases magnéticas. A Figura 3.30a ilustra a fixação dos LVDTs na régua e a Figura 3.30b apresenta o posicionamento dos LVDTs sobre a superfície da seção do pavimento. 


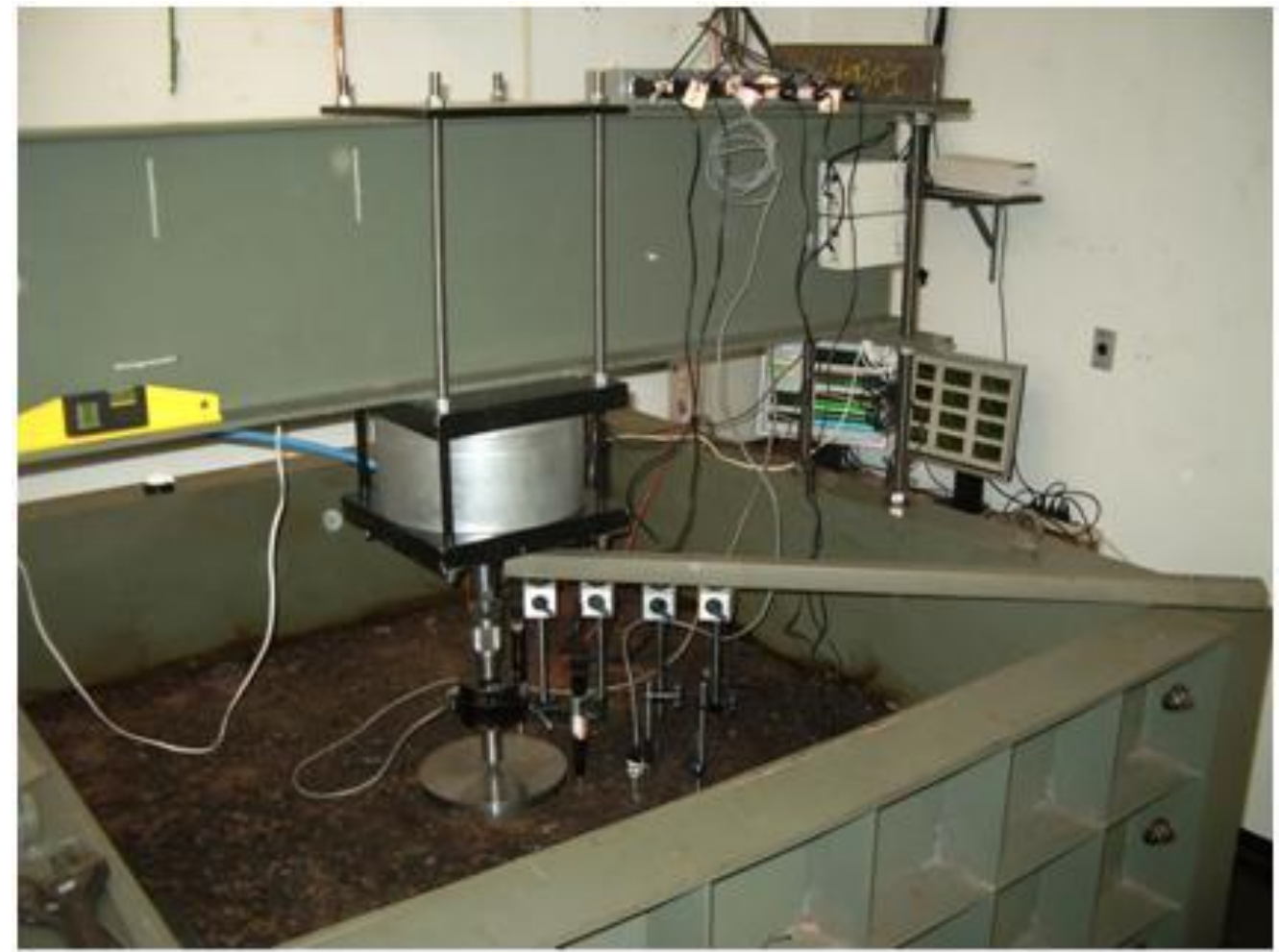

(a)

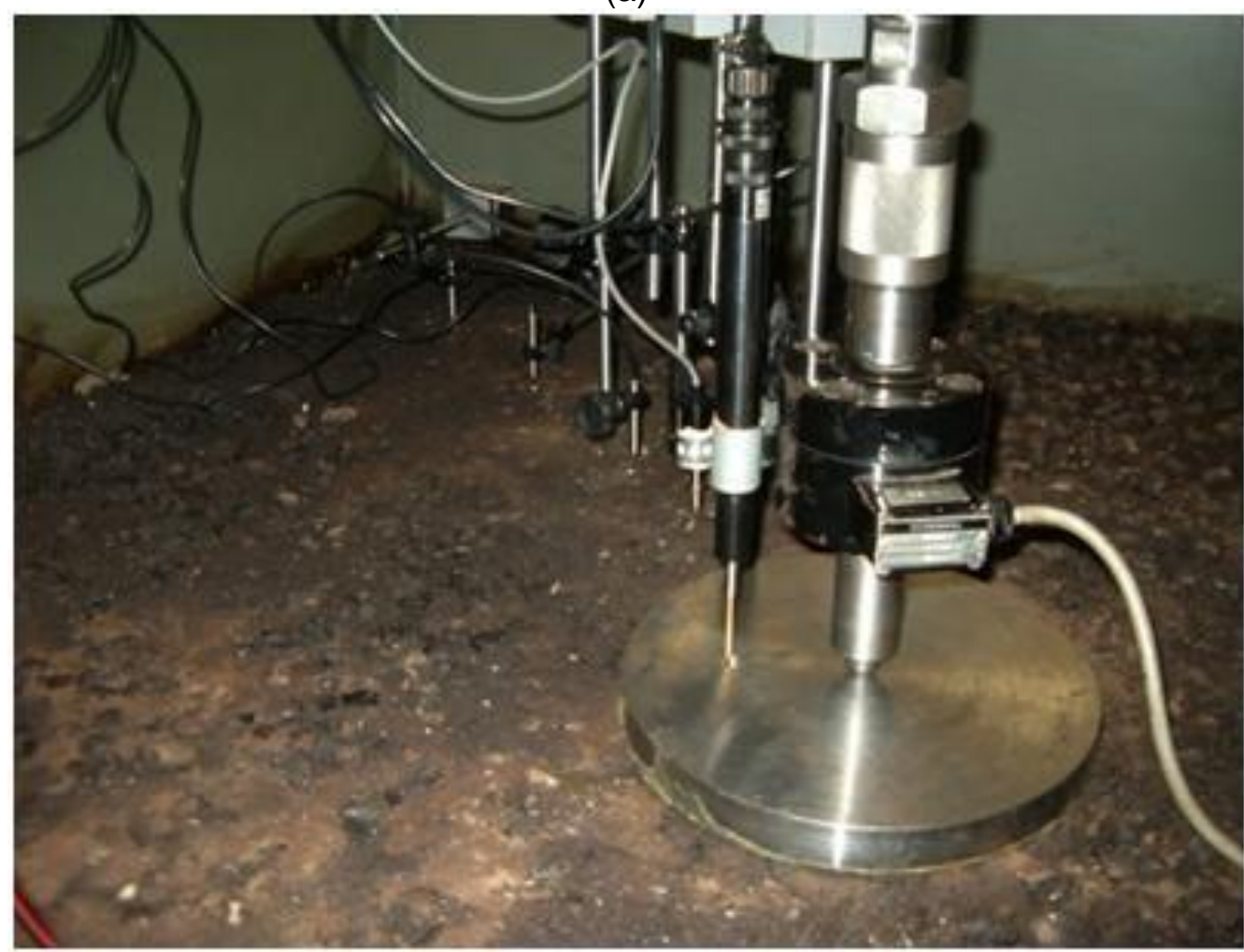

(b)

Figura 3.30 - LVDTs: a) Fixação da régua na lateral da caixa e b) Posicionamento dos LVDTs 
A Figura 3.30 mostra o conjunto de LVDTs sobre a superfície da seção do pavimento e em primeiro plano, destaca-se um dos LVDTs posicionado em um furo através da placa de carregamento. Evitou-se apoiar este LVDT sobre a placa para anular a interferência da vibração do carregamento sobre as leituras.

No tocante à aquisição das células de pressão total que foram instaladas no interior das camadas do pavimento, os valores orçados no mercado extrapolavam o recurso disponível, assim, optou-se pela construção destes transdutores segundo um projeto em desenvolvimento no Laboratório de Geossintéticos da EESC/USP pelo Prof. Dr. Benedito de Souza Bueno.

A Figura 3.31 ilustra uma célula de tensão total. Em cada um dos horizontes, as células foram posicionadas em pares, sendo uma instalada na direção horizontal e a outra na direção vertical. O primeiro conjunto foi colocado na interface subleitobase e o segundo conjunto no meio da camada de base.

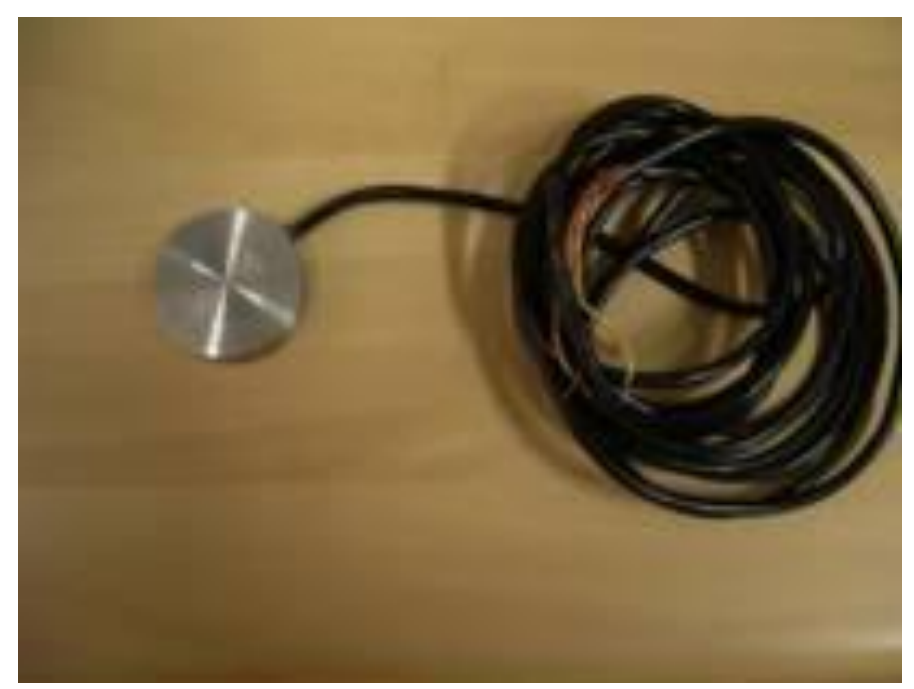

Figura 3.31 - Célula de tensão total

As células de tensão total foram calibradas no Laboratório de Geossintéticos da EESC-USP com o auxílio de um pórtico metálico, sendo que a aplicação do 
carregamento foi feito por meio de um sistema de câmera de borracha onde se controlava a pressão de ar e se registrava a variação de tensão em mV.

Para o controle e medida das forças aplicadas à superfície do pavimento foi utilizada uma célula de carga da marca Gefran com capacidade de 5000kgf instalada no pistão do cilindro pneumático conforme a ilustra a Figura 3.32.

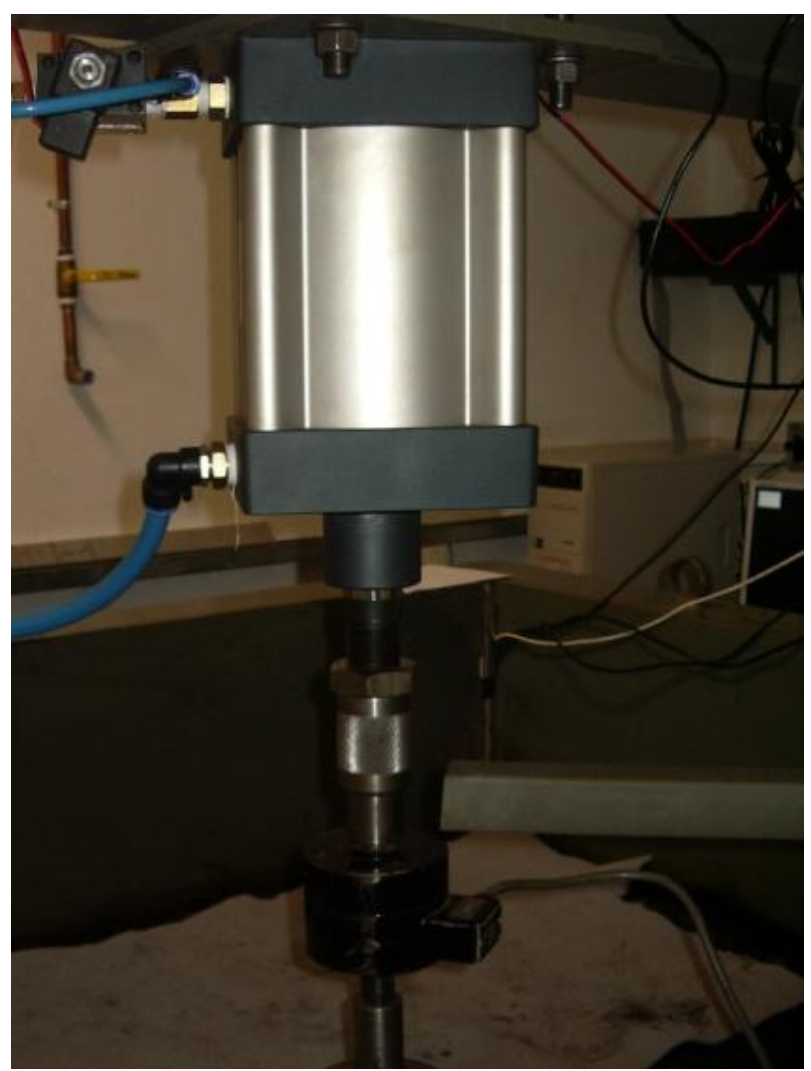

Figura 3.32 - Célula de carga instalada no pistão do cilindro pneumático

\subsubsection{Sistema de aquisição de dados e programação}

O sistema de aquisição de dados foi desenvolvido pelo Prof. Dr. Glauco Tulio Pessa Fabbri. O sistema é composto por fontes e condicionadores de sinais que são conectados a duas caixa de interface com as placas da National Instruments PCl- 
$6014 \mathrm{~m}$ instaladas em um microcomputador. O programa utilizado para leituras das células de carga e tensão total, e dos LVDTs foi elaborado em plataforma Lab View.

A Figura 3.33a ilustra a montagem do circuito das caixas que controlam as válvulas proporcionais e solenóide e que servem ainda para a conexão da instrumentação com as placas PCl-6014. Cada caixa possui 11 canais, sendo oito deles usados como entrada de transdutores, dois para as válvulas proporcionais e o último, para a válvula solenóide. A Figura 3.33b ilustra as fontes de alimentação dos LVDTs e os condicionadores de sinais das células. Para melhor visualização e acompanhamento simultâneo de todas informações fornecidas pelo sistema de aquisição e controle de dados foram utilizados dois monitores, conforme apresentado na Figura 3.33c.

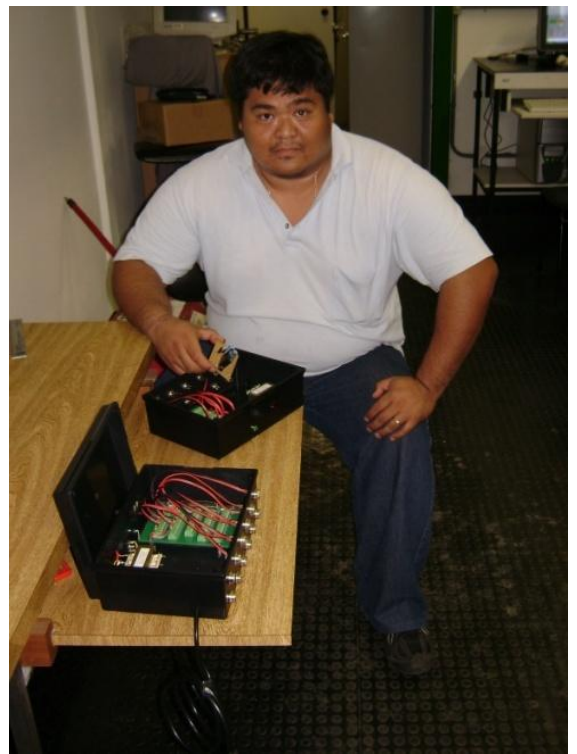

(a)

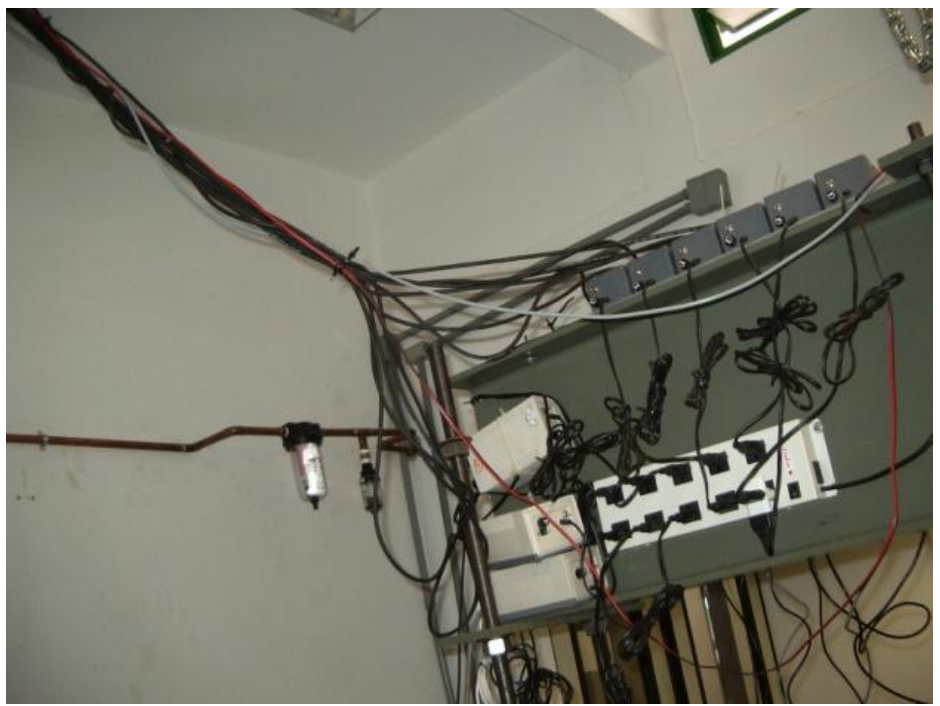

(b) 


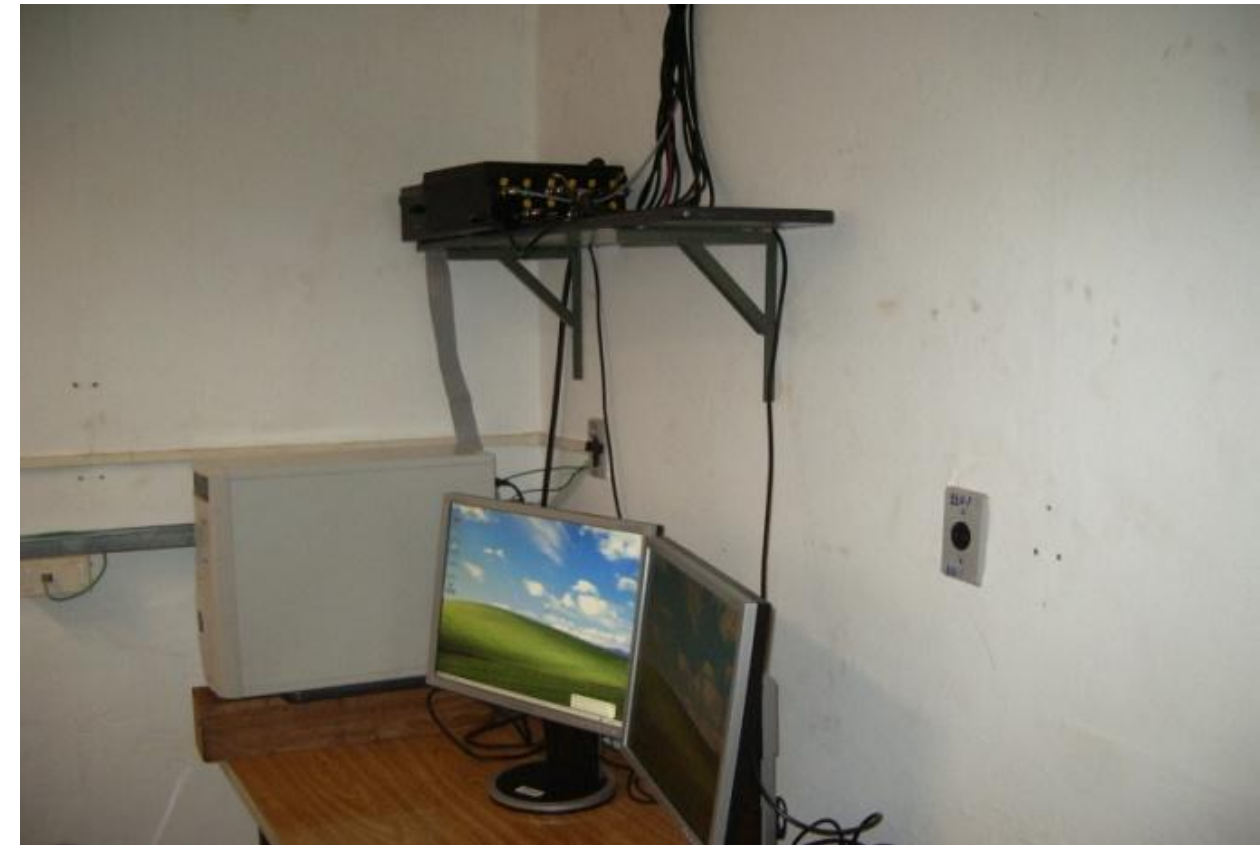

(c)

Figura 3.33 - Sistema de controle e aquisição de dados: a) Montagem das caixas de interface; b) Fontes e condicionadores de sinais e c) Computador e monitores

As Figuras 3.34 e 3.35 lustram a saída gráfica do programa de controle e aquisição de dados conforme apresentados nos monitores 1 e 2, respectivamente. Nestas figuras, cada um dos campos da tela foi numerado para facilitar a descrição de seus conteúdos.

Na Figura 3.34 foram destacados sete campos, sendo que suas funções são descritas em seguida. Campo 1: bacia de recalque atualizada a cada aplicação de carga; 2: deformação permanente acumulada no centro da placa; 3: tensões totais nos dois horizontes instrumentados; 4: deslocamentos de cada um dos LVDTs a cada ciclo de carga; 5: deslocamento acumulado da placa; 6 : deslocamento da placa a cada ciclo de carga e 7: carga aplicada.

Na Figura 3.35 foram destacados 12 campos, sendo que suas funções são descritas em seguida. Campos de 1 a 4 : tensões totais horizontais e verticais nos horizontes instrumentados; 5: distribuição da força durante cada pulso de carga; 6 a 
11: distribuição dos deslocamentos durante cada pulso de carga para cada um dos transdutores apresentados isoladamente; 12: mesma variável descrita anteriormente apresentada para o conjunto dos transdutores.

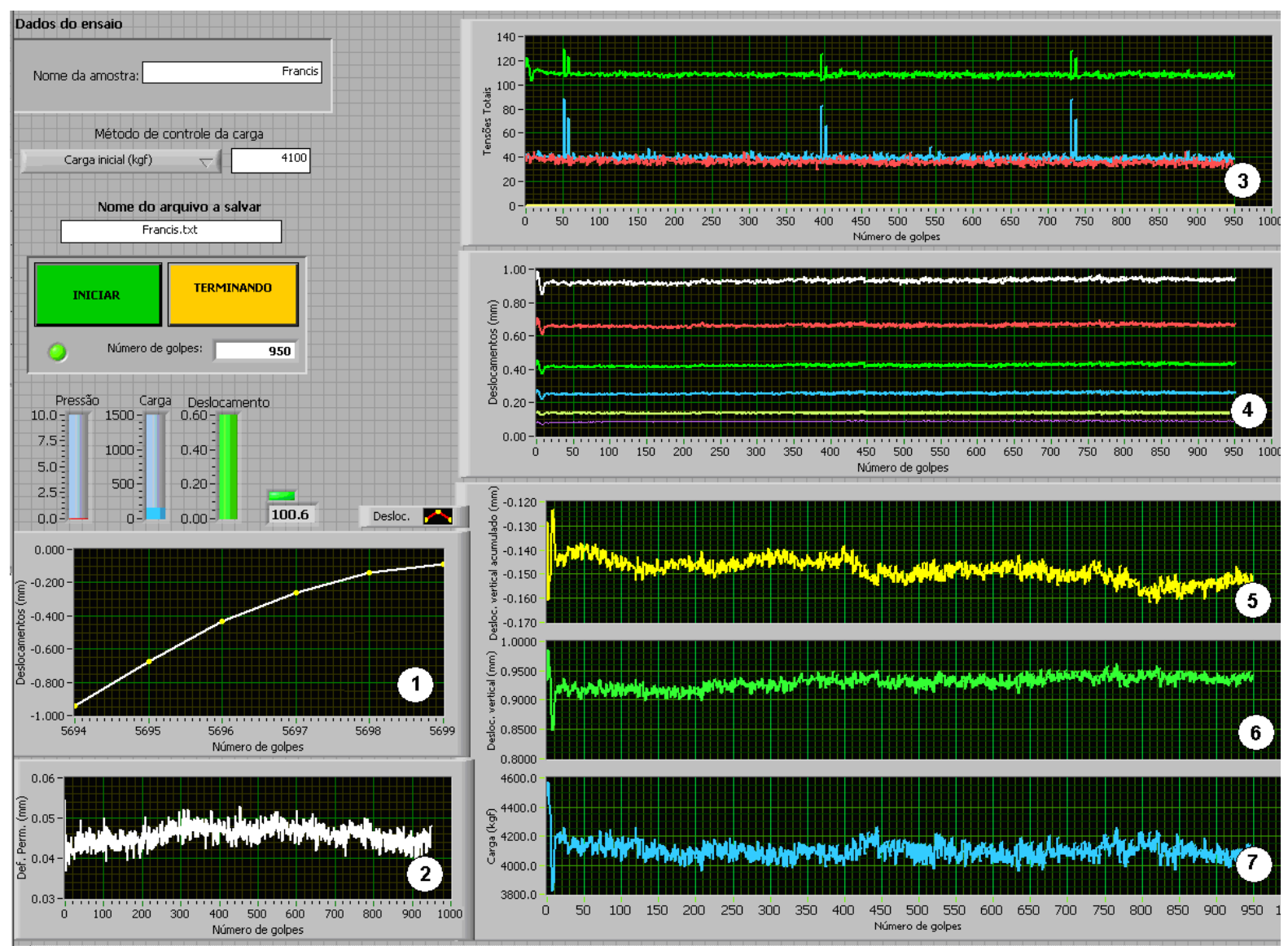

Figura 3.34 - Ilustração da saída gráfica do programa - monitor 1 


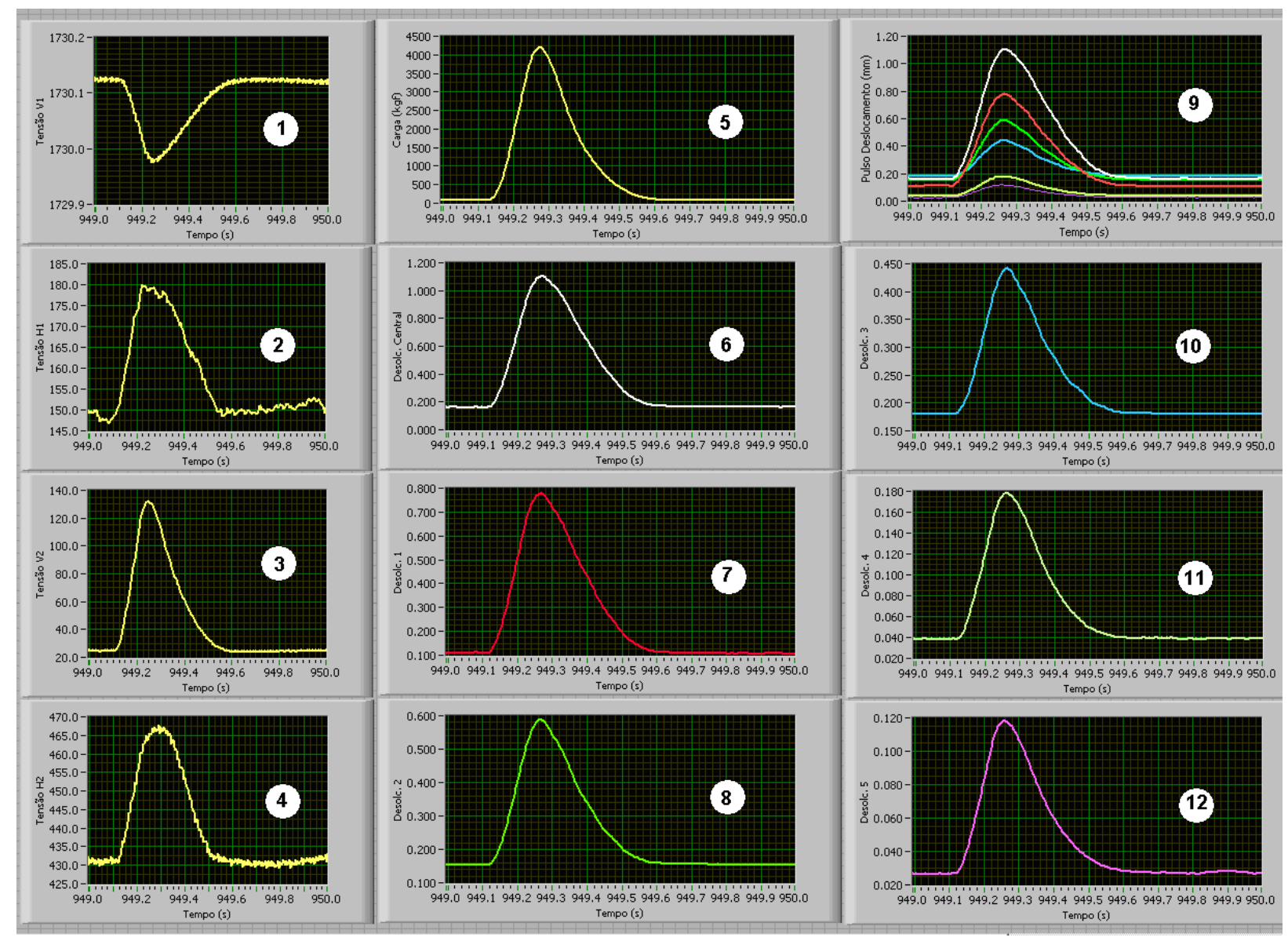

Figura 3.35 - Ilustração da saída gráfica do programa - monitor 2

\subsubsection{Compactação das seções ensaiadas}

Inicialmente, os solos coletados para a composição do subleito e da mistura solo-brita foram homogenizados e armazenados. A quantidade necessária para preencher um volume de $1,13 \mathrm{~m}^{3}(1,5 \mathrm{~m} \times 1,5 \mathrm{~m} \times 0,5 \mathrm{~m})$ na densidade especificada na pesquisa é de aproximadamente 70 sacos de 40 litros $(2063,2 \mathrm{~kg})$. Visto a grande quantidade de material, foi realizado um ajuste fino da umidade no ato da compactação, para isso um dia antes da compactação foi determinado o teor de 
umidade do solo de cada saco. De posse do teor de umidade de cada saco foi possível ajustar o teor de umidade àquele pretendido.

Para a mistura solo-brita utilizada na camada de base foram necessários $1100 \mathrm{~kg}$ da mistura na umidade ótima de compactação. A correção da umidade foi realizada no ato da mistura do solo com a brita, sendo esta armazenada em sacos plásticos devidamente vedados.

A compactação das camadas seguiu a sequência:

- A compactação foi realizada em 10 camadas de $5 \mathrm{~cm}$ de espessura para 0 subleito e em 3 camadas para a mistura solo-brita;

- O material é distribuído uniformemente dentro da caixa (Figura 3.36a e $3.36 b)$;

- Compacta-se o contorno da caixa com a ajuda de um soquete manual (Figura $3.36 \mathrm{c})$;

- Com um compactador a percussão da marca Wacker com potência máxima de $3 \mathrm{~kW}$, peso de $64 \mathrm{~kg}$, sapata de 250 x330 mm, altura do salto de $72 \mathrm{~mm}$ fazse a compactação de toda superfície (Figura 3.36d);

- Controla-se a espessura e o nível das camadas compactadas utilizando-se uma régua graduada e um nível de bolha (Figura 3.36e);

- Retira-se uma porção do material para a determinação da umidade (Figura $3.36 \mathrm{~g})$

- Para o subleito, observou-se um grau de compactação de 98,5\% e um desvio de umidade de até $0,1 \%$. Para a base, observou-se o grau de compactação de $100 \%$ e um desvio de umidade de até $0,3 \%$. 


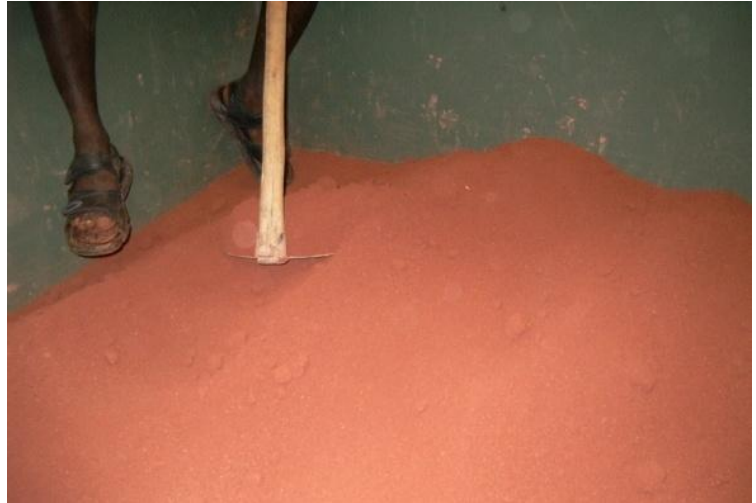

(a)

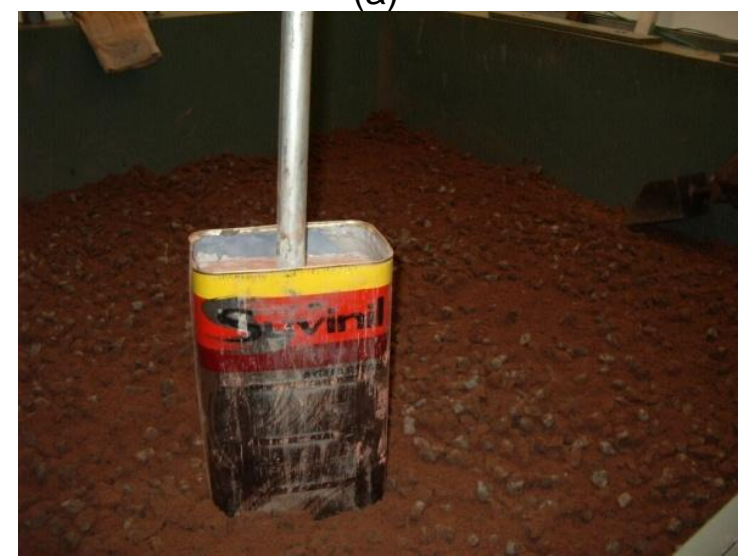

(c)

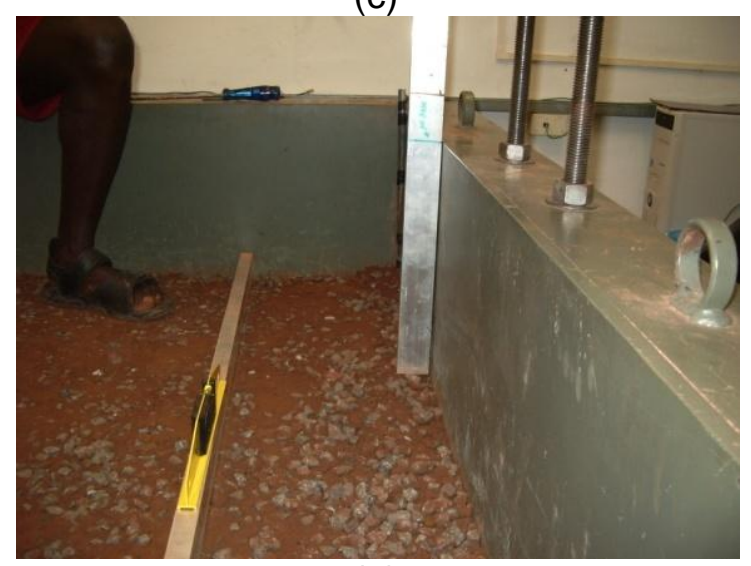

(e)

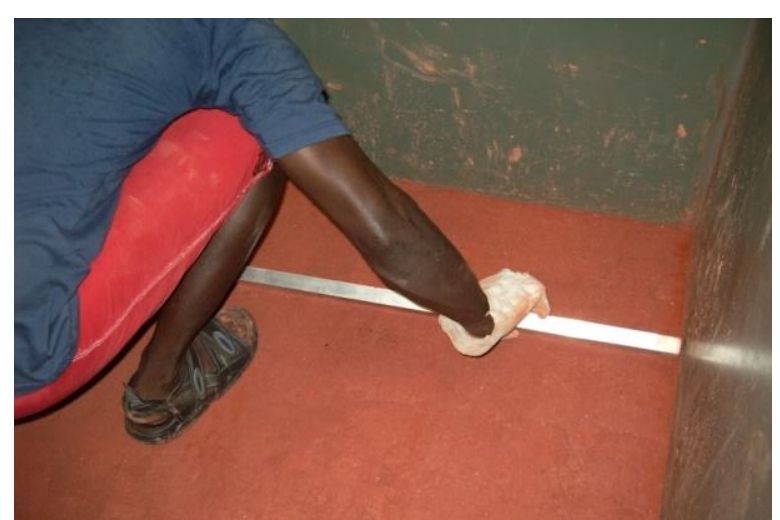

(b)

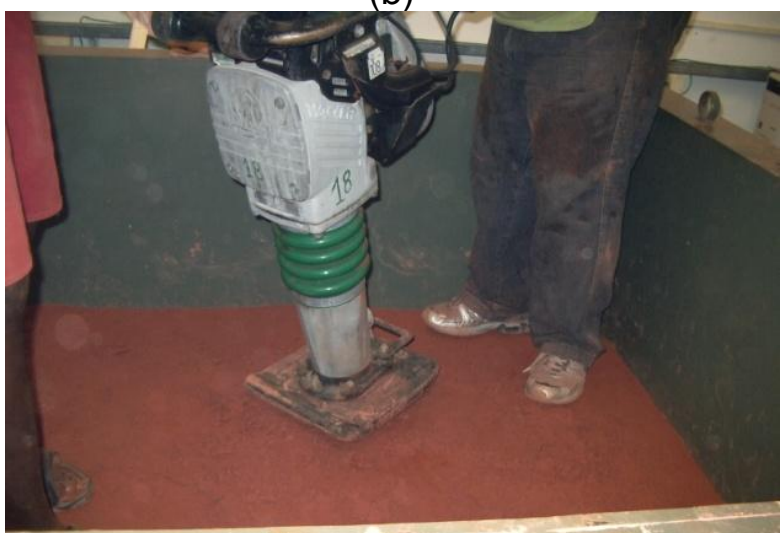

(d)

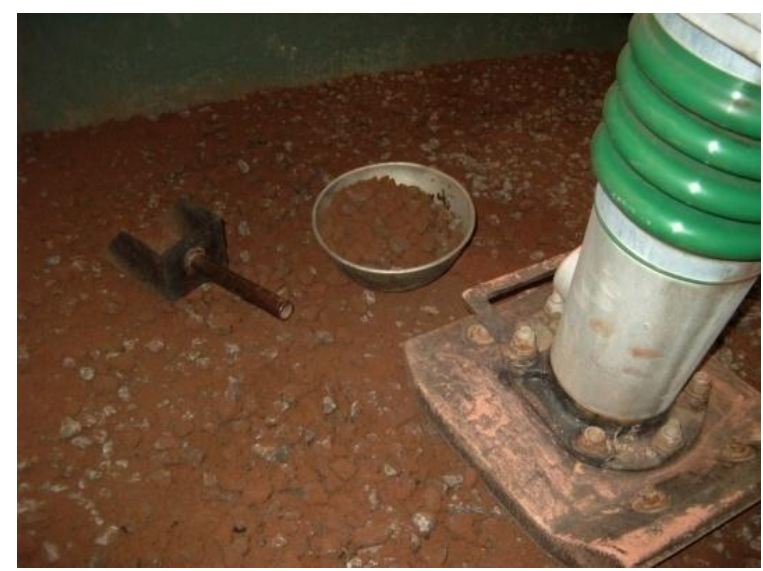

(f)

Figura 3.36 - Procedimento de compactação das camadas: a) Colocação do material; b) Distribuição uniforme; c) Compactação manual das laterais; d) Compactação mecânica; e) Controle da espessura da camada e f) Controle da umidade

A Figura $3.37 a$ e $3.37 b$ mostram a instalação das células de tensão total durante a compactação do subleito e da base, respectivamente. 


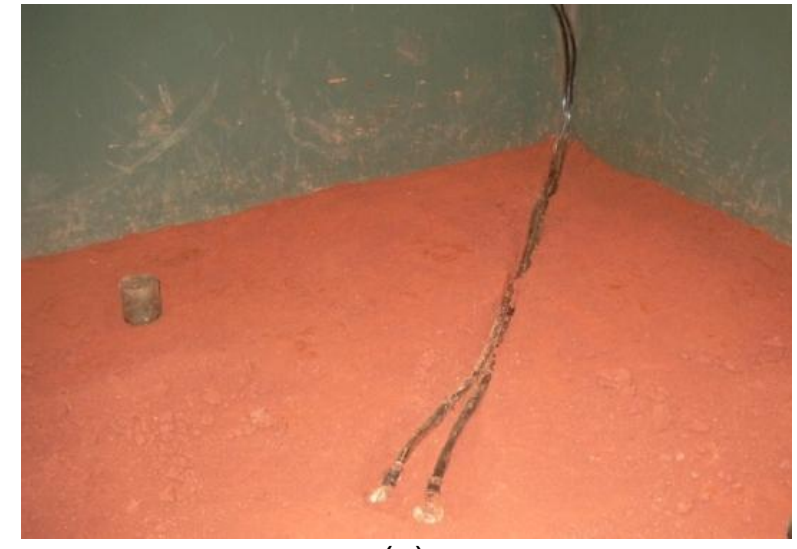

(a)

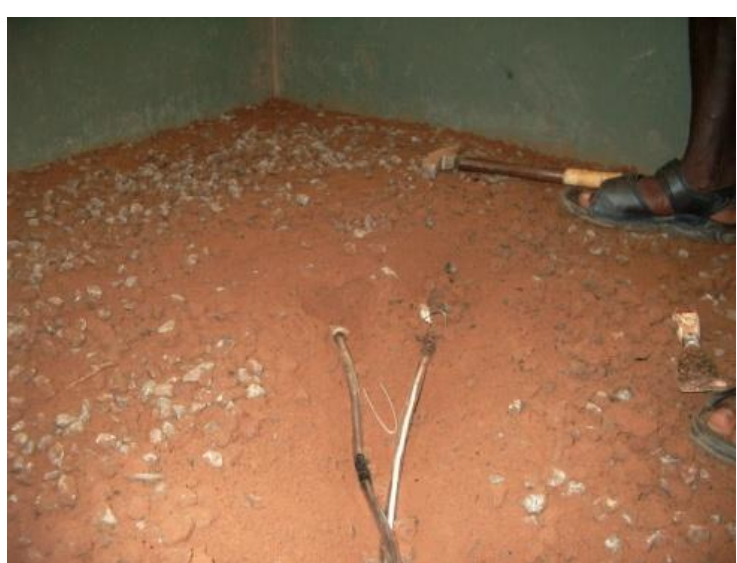

(b)

Figura 3.37 - Instalação das células de tensão total: a) No subleito e b) Na base

Ao final da compactação da seção do pavimento, foi realizada a impermeabilização da sua superfície com o asfalto diluído CM30 aplicado com uma taxa de $1,5 \mathrm{l} / \mathrm{m}^{2}$ conforme a norma DNER- ES 306/97 (Pavimentação - imprimação). A Figura 3.38 ilustra o aspecto da superfície ao final da imprimação.

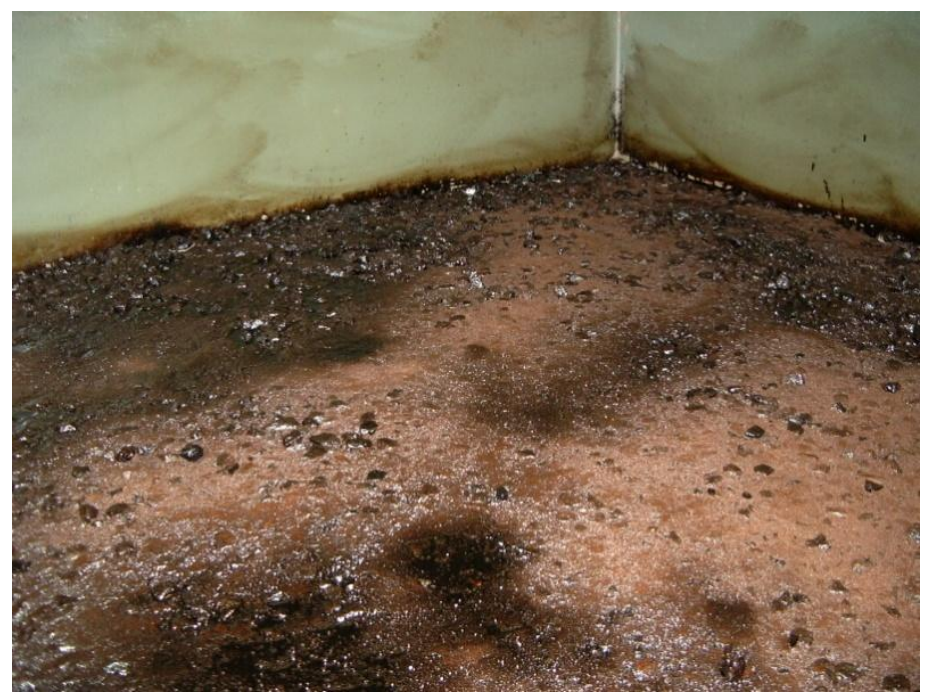

Figura 3.38 - Superfície do pavimento após a imprimação 


\subsection{PROGRAMA DOS ENSAIOS REALIZADOS NO EQUIPAMENTO}

A pesquisa foi conduzida a fim de verificar a eficiência e o benefício do uso de geossintéticos na estrutura de pavimentos flexíveis, com ênfase no reforço de camadas de base de pavimento. $\mathrm{O}$ estudo pautou-se nos resultados de ensaios realizados no equipamento de grandes dimensões, desenvolvido nesta pesquisa.

O programa experimental para os ensaios no equipamento de grandes dimensões dividiu-se em duas etapas, sendo que na primeira etapa foram realizados três ensaios sem a utilização de reforço. Nestes ensaios variaram-se a espessura da camada de base em 15, 20 e 25cm; a área de aplicação do carregamento por meio do uso de placas de 21,6, 25 e $30 \mathrm{~cm}$ de diâmetro; e também a condição de umidade do subleito. A Tabela 3.12 apresenta a configuração dos ensaios realizados nesta etapa.

Tabela 3.12 - Configuração dos ensaios da primeira etapa

\begin{tabular}{cccc}
\hline & & Montagem & \\
& 1 & 2 & 50 \\
\hline Subleito $(\mathrm{cm})$ & 50 & 50 & 25 \\
Base $(\mathrm{cm})$ & 15 & 20 & 21,$6 ; 30 \mathrm{~cm}$ \\
Diâmetro da placa $(\mathrm{cm})$ & 21,$6 ; 30$ & 21,$6 ; 25 ; 30 \mathrm{~cm}$ & $\mathrm{~W}_{\mathrm{o}}$ \\
Umidade do subleito & $\mathrm{W}_{\mathrm{o}}$ & $\mathrm{W}_{\mathrm{o}}$ e umedecido & \\
\hline
\end{tabular}

$\mathrm{Na}$ segunda etapa, realizaram-se três montagens, sendo uma seção de pavimento sem reforço, uma seção com reforço de uma geogrelha posicionada na interface subleito-base e por fim, uma seção com uma geogrelha posicionada no horizonte médio da camada de base. Para as três montagens, foram realizados 
ensaios com a camada de subleito na umidade ótima de compactação e depois de umedecida. A Tabela 3.13 apresenta as configurações dos ensaios realizados nesta etapa.

Tabela 3.13 - Configuração dos ensaios da segunda etapa

\begin{tabular}{cccc}
\hline & \multicolumn{3}{c}{ Montagem } \\
& 1 & 2 & 3 \\
\hline Subleito $(\mathrm{cm})$ & 50 & 50 & 50 \\
Base $(\mathrm{cm})$ & 20 & 20 & 20 \\
Reforço & - & Geogrelha & Geogrelha \\
Posição & - & Interface & Horizonte médio da \\
biâse & 30 \\
Diâmetro da placa $(\mathrm{cm})$ & 30 & 30 & 550 \\
Pressão de contato $(\mathrm{kPa})$ & 550 & 550 & $\mathrm{~W}_{\text {o e umedecido }}$ \\
Umidade do subleito & $\mathrm{W}_{\mathrm{o}}$ e umedecido & $\mathrm{W}_{\mathrm{o}}$ e umedecido & \\
\hline
\end{tabular}

A partir dos resultados dos ensaios, determinaram-se as deformações elásticas e permanentes na superfície da seção de pavimento. Com as deformações elásticas obtiveram-se a bacia de deflexão, o raio de curvatura e a deflexão máxima. E por meio de retro-análise pôde-se obter os módulos resilientes das camadas de base e de subleito. E com as curvas de deformações permanentes determinaram-se os modelos de deformações permanentes em função do número de ciclos de carregamento, $\varepsilon^{P}=f(N)$. Estas análises encontram-se detalhadas no Capítulo 4 . 


\section{Capítulo 4 - Apresentação e Análise dos Resultados}

\subsection{CONSIDERAÇÕES INICIAIS}

Neste capítulo são apresentados e analisados os resultados de ensaios em equipamento de grandes dimensões utilizados para verificar o comportamento de uma estrutura de pavimento flexível reforçada ou não com uma geogrelha.

\subsection{ENSAIOS PRELIMINARES}

Primeiramente, são apresentados os resultados de ensaios preliminares utilizados para o ajuste e verificação do bom funcionamento do equipamento. Nesta etapa, foi analisada a influência da variação das dimensões da placa de carregamento e da espessura da base no desenvolvimento das deformações elásticas na superfície do pavimento sem reforço. 


\subsubsection{Variação da deflexão com o número de ciclos}

Nesta análise, utilizou-se uma carga cíclica de 20kN (2050 kgf) sobre uma placa de $25 \mathrm{~cm}$ de diâmetro, com frequência de aplicação de $1 \mathrm{~Hz}$, sendo $0,3 \mathrm{~s}$ de tempo de atuação do carregamento seguido de um descanso de 0,7s. Foram aplicados $10^{5}$ ciclos de carga não consecutivos, pois durante a execução do ensaio foi necessário interrompê-la algumas vezes para a realização de alguns ajustes nos instrumentos de medição. Em função das várias interrupções do ensaio, não foi possível acompanhar o desenvolvimento das deformações permanentes nesta primeira montagem.

A Figura 4.1 apresenta as bacias de deflexões obtidas para 500, 1.000, 5.000, $10.000,50.000$ e 100.000 aplicações do carregamento.

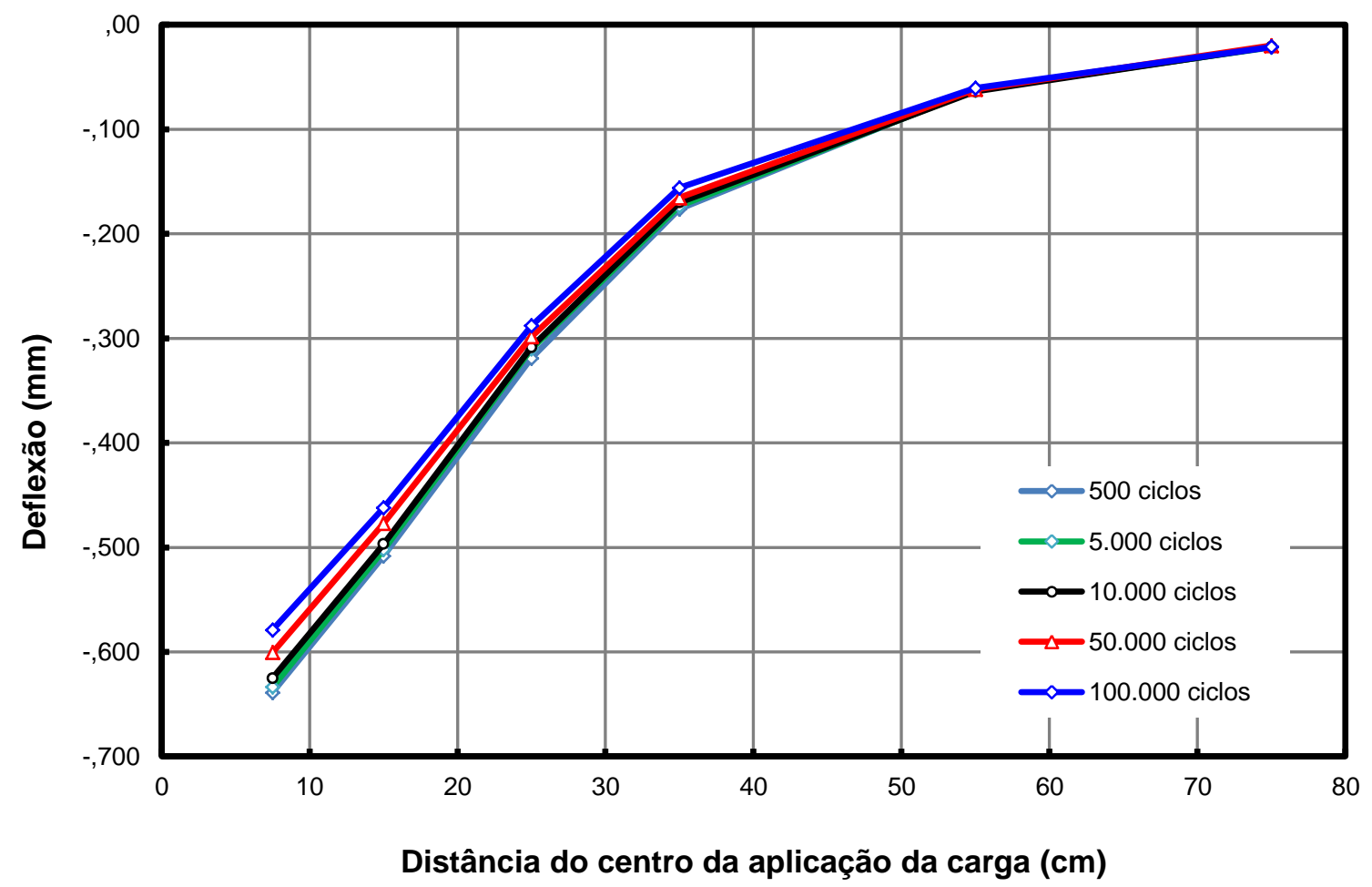

Figura 4.1- Bacia de deflexão obtida em diferentes estágios 
Observa-se nas curvas apresentadas na Figura 4.1 que as deflexões diminuem com o aumento do número de ciclos de carga. Acredita-se que esse fato aconteça devido a densificação das camadas de base e subleito, à semelhança de uma compactação, que tem como consequência o aumento da rigidez dos materiais e consequentemente o aumento do módulo de resiliência, isto acontece em ensaios triaxiais cíclicos conforme apresentado por Guimarães, 2009.

Quanto às leituras fornecidas pelos LVDTs localizados nas posições mais distantes do carregamento, nota-se que as leituras se mantiveram constantes, possivelmente devido às medidas serem muito pequenas, inferiores a décimo de milímetro e, portanto, dentro da resolução dos instrumentos.

A Figura 4.2 apresenta a variação da deflexão máxima medidas, ou seja, do LVDT posicionado sobre a placa de carregamento com relação ao número de ciclos de carga. Observa-se na Figura 4.2 que as deflexões máximas variam com o aumento do número de ciclos de carga, entretanto não é possível observar-se uma tendência nítida da estabilização do processo de ganho de rigidez até $10^{5}$ ciclos de carga. Este fato fica evidenciado nos ensaios apresentados e discutidos no item 4.3.2, onde os ciclos de carga atingem $4.10^{5}$, e também até $10^{5}$ não é possível observar-se uma estabilização das deflexões. 


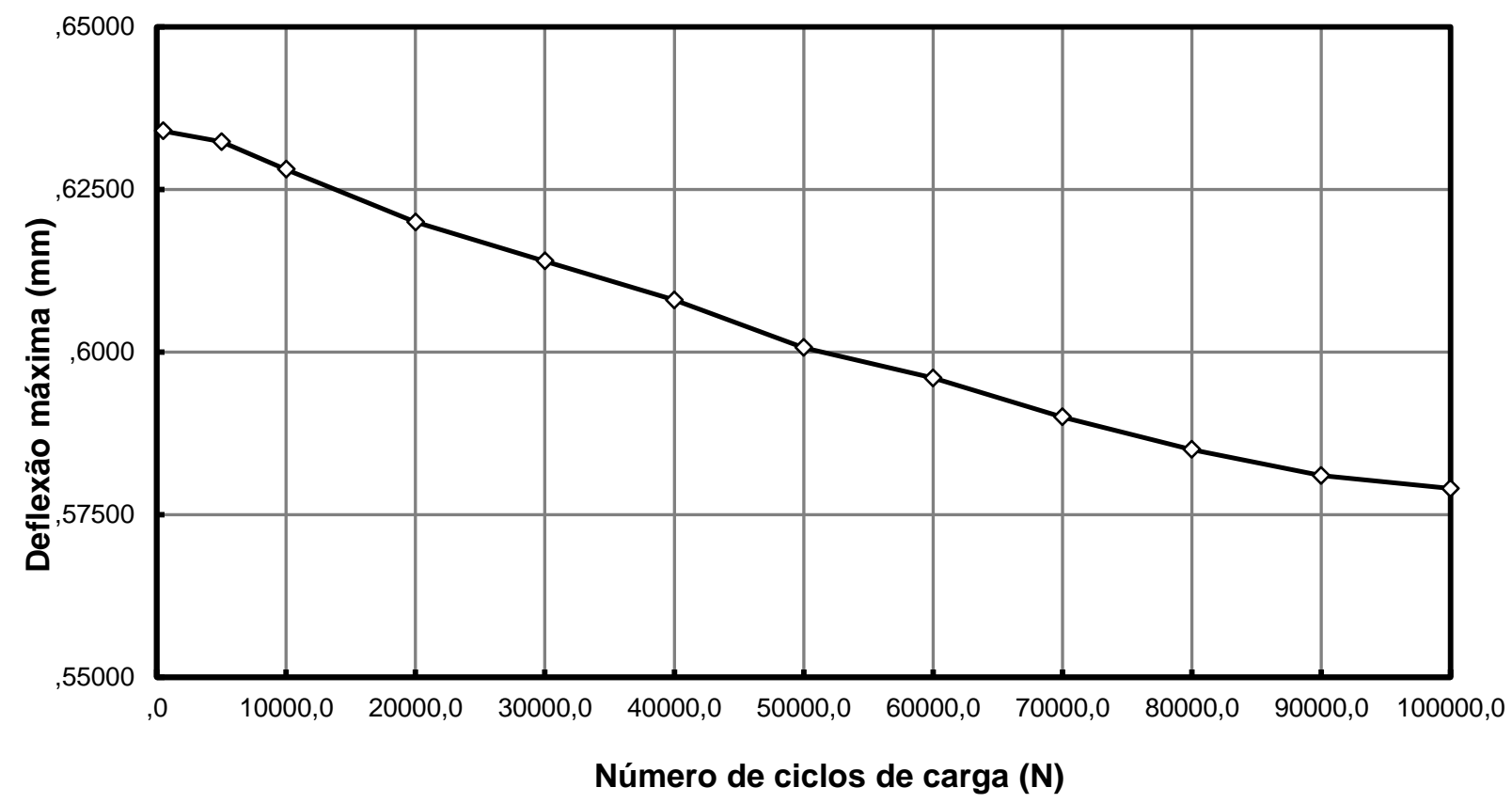

Figura 4.2 - Deflexão máxima em função do número de ciclos de carga

Utilizando-se a bacia de deflexão ao final de $10^{5}$ ciclos, determinaram-se os módulos de resiliência das camadas de base e subleito por retroanálise, que foram comparados com os valores de módulos obtidos para estes materiais a partir dos resultados dos ensaios triaxiais cíclicos.

Para a determinação dos módulos, a partir da retroanálise da bacia de deflexão, foi utilizado o programa de retroanálise desenvolvido pelo Prof. Dr. Glauco Tulio Pessa Fabbri em Plataforma LabView, a partir do programa Elsym-5. Os dados de entrada do programa são: número de camadas (limitado em cinco); número de pontos da bacia (limitado a 10); número de cargas (1 ou 2); valor da carga (kgf); pressão exercida pelo pneu $\left(\mathrm{kgf} / \mathrm{cm}^{2}\right)$; distância entre rodas $(\mathrm{cm})$; espessura das camadas $(\mathrm{cm})$; módulos de resiliência $\left(\mathrm{kgf} / \mathrm{cm}^{2}\right)$; coeficientes de Poisson; distâncias até o carregamento $(\mathrm{cm})$; deflexões medidas $(0,01 \mathrm{~mm})$. O programa apresenta como saída a visualização gráfica das bacias medida e retro-analisada e ainda as medidas de deflexões retro-analisadas com seus respectivos erros (\%) em relação às 
deflexões medidas. Para determinação dos módulos de resiliência representativos de cada camada é realizado um processo interativo, onde se muda os valores dos módulos das camadas até que as curvas medida e retro-analisada fiquem coincidentes. Nesta pesquisa, adotou-se como limite da somatória dos erros de cada uma das leituras o valor máximo de 15\%. A Figura 4.3 apresenta a visualização da saída gráfica, sendo que os valores apresentados são meramente ilustrativos.

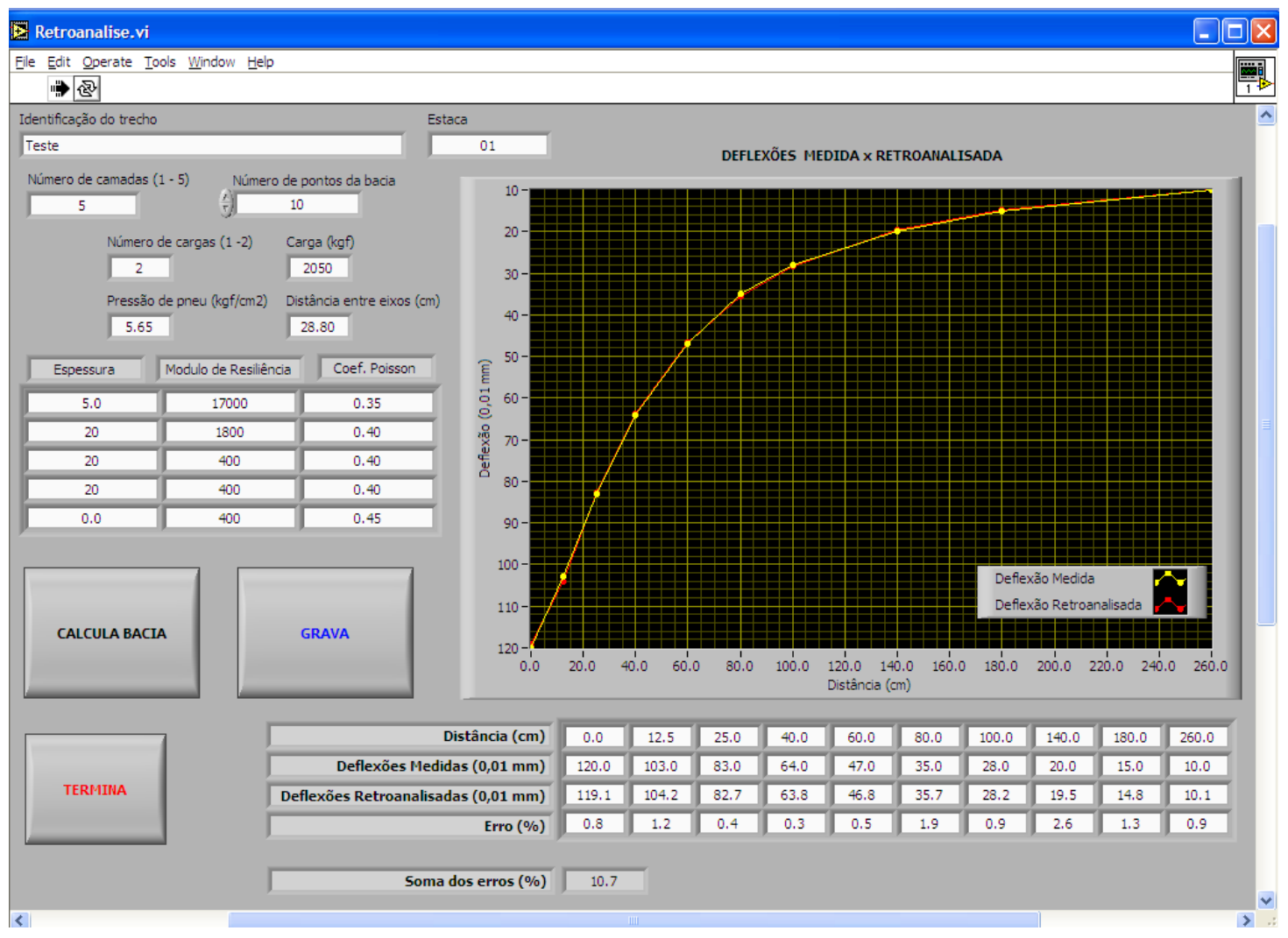

Figura 4.3- Saída gráfica do programa utilizado para retroanálise

Para a determinação de um valor único de módulo de resiliência a partir dos ensaios cíclicos representativos de cada um dos materiais, utilizou-se o modelo composto (Eq. 3.3) ajustadas para os mesmos e as tensões no centro das respectivas camadas usando o programa Elsym-5. Como o programa Elsym-5 é elástico linear e não incorpora o modelo composto, utilizou-se um processo interativo 
para o cálculo das tensões. Primeiramente, adotavam-se valores iniciais para os módulos de resiliência da camada analisada, base ou subleito, e calculavam-se as tensões no centro da mesma. Em seguida, a partir dessas tensões e do modelo, determinava-se um novo valor de módulo. Repetia-se o cálculo, até que o processo convergisse.

A Tabela 4.1 apresenta os valores dos módulos de resiliência dos materiais que compõem o subleito e a camada de base determinados a partir de resultados dos ensaios triaxiais cíclicos e a partir da retroanálise da bacia de deflexão.

Tabela 4.1- Módulos de resiliência obtidos a partir do ensaio triaxial cíclico e a partir da retroanálise da bacia de deflexão

\begin{tabular}{ccc}
\hline & MR (MPa) & MR (MPa) \\
Camadas & Triaxial cíclico & Retroanálise da bacia de deflexão \\
\hline Subleito & 19 & 29 \\
Base & 250 & 265 \\
\hline
\end{tabular}

Analisando-se os módulos obtidos por retroanálise e por resultados de ensaio triaxial cíclico, conforme apresentados na Tabela 4.1, verifica-se que os valores são de mesma ordem de grandeza, apesar da diferença ser pequena para a base e maior para o subleito.

Supõe-se que a maior concordância dos resultados referentes à base deva-se à associação de alguns fatos: a menor espessura desta camada, $20 \mathrm{~cm}$ comparados com o $50 \mathrm{~cm}$ do subleito, faz com que as tensões no horizonte médio da camada usadas no cálculo do MR, por meio do modelo composto, sejam mais representativas das tensões ao longo deste elemento do que as tensões no horizonte médio do subleito usadas nas mesmas condições; o valor do MR do subleito é muito baixo se comparado com a rigidez da maioria do materiais 
presentes em obras rodoviárias, logo, os erros associados às medidas realizadas nos ensaios são relativamente elevados se comparados ao valor real do módulo; o material usado no subleito mostrou-se de difícil manipulação durante a compactação dos corpos-de-prova e compactação desta camada na caixa de ensaios, apesar destas operações terem merecido todo cuidado e atenção.

Considerando-se que a seção ensaiada no equipamento de grandes dimensões aproxima-se mais da realidade de campo e que os resultados obtidos nesta condição levem em conta aspectos relacionados à interação dos diferentes materiais e camadas, diferentemente dos ensaios triaxiais cíclicos, acredita-se que este enfoque agregue maior confiabilidade às análises do comportamento de pavimentos.

\subsubsection{Variação da espessura da camada de base}

Ainda nesta fase de teste do equipamento, buscou-se avaliar o comportamento de estruturas de pavimentos com diferentes espessuras de camada de base. Foram realizados três ensaios com espessuras de base de 15, 20 e $25 \mathrm{~cm}$, sendo aplicadas cargas cíclicas de $40 \mathrm{kN}$ sobre uma placa de $30 \mathrm{~cm}$ de diâmetro, resultando numa pressão de contato de $550 \mathrm{kN}$.

É importante observar que a variação da espessura da base não foi acompanhada da construção de novas seções de pavimento, sendo que o subleito foi mantido. Inicialmente, foi ensaiada a base de $20 \mathrm{~cm}$ e em seguida, foram retiradas 
$5 \mathrm{~cm}$ de material e ensaiou-se a base de $15 \mathrm{~cm}$. Finalmente, compactou-se uma nova camada de $10 \mathrm{~cm}$ e ensaiou-se a base de $25 \mathrm{~cm}$. A Figura 4.4 apresenta as três curvas de deflexões ao final de cada ensaio em que se variou a espessura da camada de base em 15, 20 e $25 \mathrm{~cm}$. Cabe ressaltar que as curvas obtidas para cada ensaio foram determinadas para um número de ciclos de carga a partir do qual observou-se que as deflexões mantinham-se constantes.

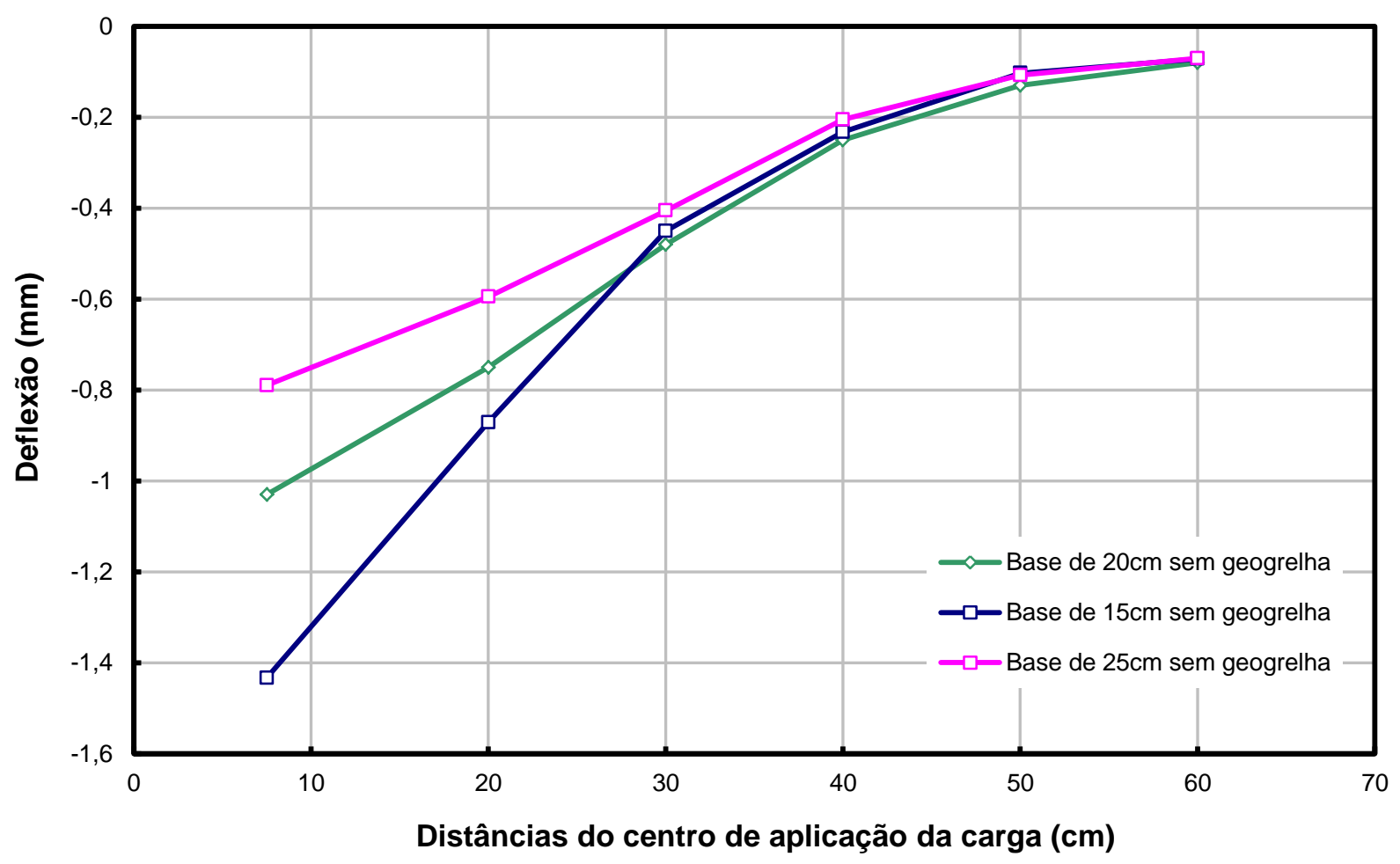

Figura 4.4 - Curva de deflexão para diferentes espessuras de camada de base

Analisando-se a Figura 4.4, observa-se que na região mais próxima ao centro do carregamento, até a distância de $30 \mathrm{~cm}$, as deflexões diminuem com o aumento da espessura da camada de base. Em termos relativos, o aumento de 15 para $20 \mathrm{~cm}$ e 20 para $25 \mathrm{~cm}$, ocasiona uma redução, respectivamente, de $29 \%$ e $15 \%$ na deflexão sob o centro do carregamento, calculado com base na deflexão máxima obtida para a base de $15 \mathrm{~cm}$. 
Este resultado justifica-se, pois a camada de base, material de maior rigidez, ao ter a sua espessura aumentada, age diminuindo a contribuição do subleito, material de baixa rigidez, no desenvolvimento das deflexões na superfície do terreno.

Ainda na Figura 4.4, observa-se que o efeito do aumento da espessura da camada de base nas regiões mais distantes do carregamento, a partir de $30 \mathrm{~cm}$, é pequena, isto se deve ao fato de que os pontos situados nos limites da bacia estão sob a influência predominante do subleito, que neste caso manteve-se inalterado.

\subsubsection{Variação do diâmetro da placa de carregamento}

Com o objetivo de analisar a influência do diâmetro da placa de carregamento no desenvolvimento das deflexões elásticas do pavimento, foram utilizadas placas de carregamento com diâmetros de 21,6 e 30,0cm, conforme apresentado no item 3.4.2.3. Nesta análise não foi considerada a base de $20 \mathrm{~cm}$.

As Figuras 4.5 e 4.6 apresentam as deflexões obtidas para as duas placas, considerando-se bases com as espessuras de 15 e $25 \mathrm{~cm}$, respectivamente. 


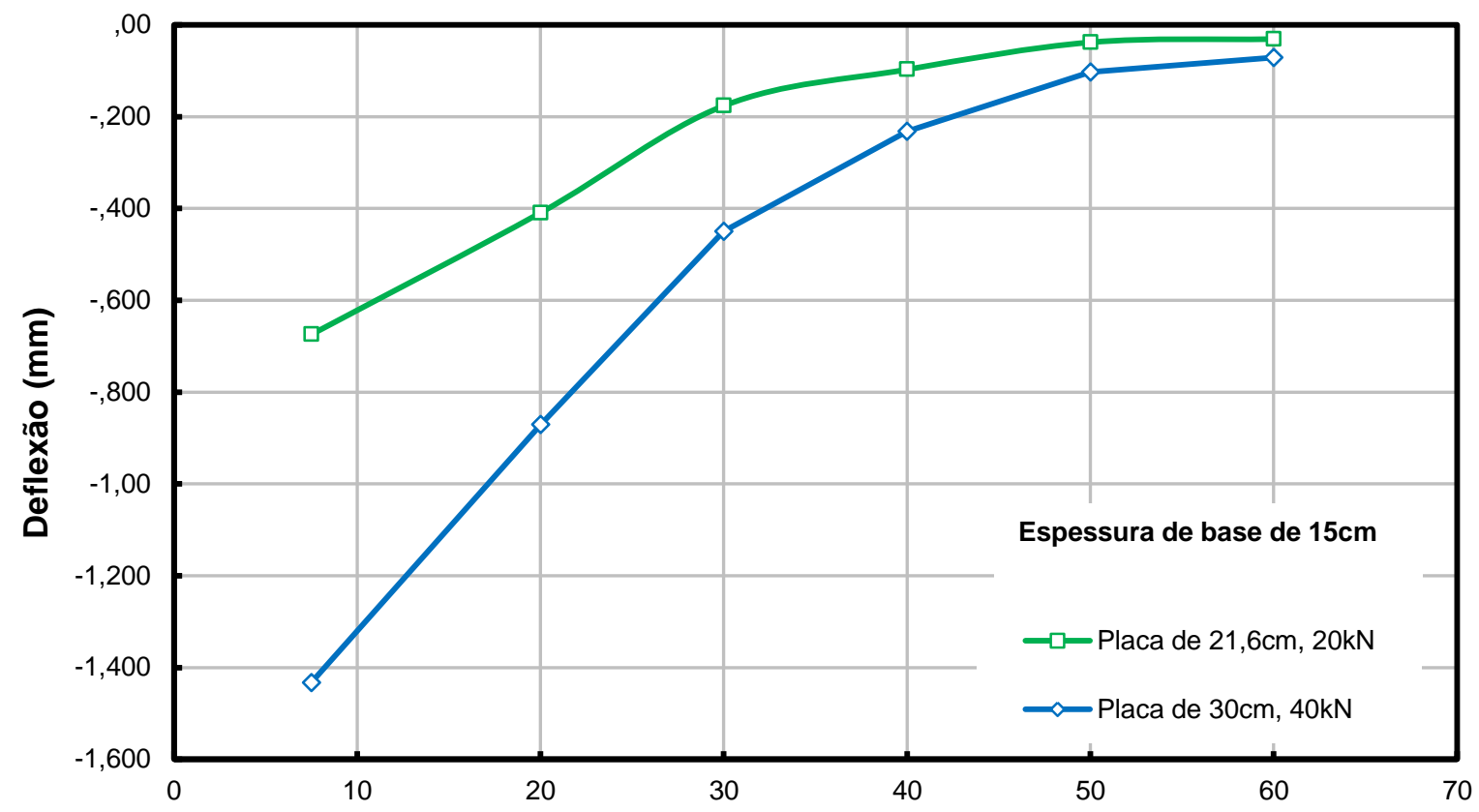

Distância do centro de aplicação da carga (cm)

Figura 4.5- Deflexão para espessuras de camada de base de $15 \mathrm{~cm}$ com placa de carregamento de 21,6 e $30 \mathrm{~cm}$

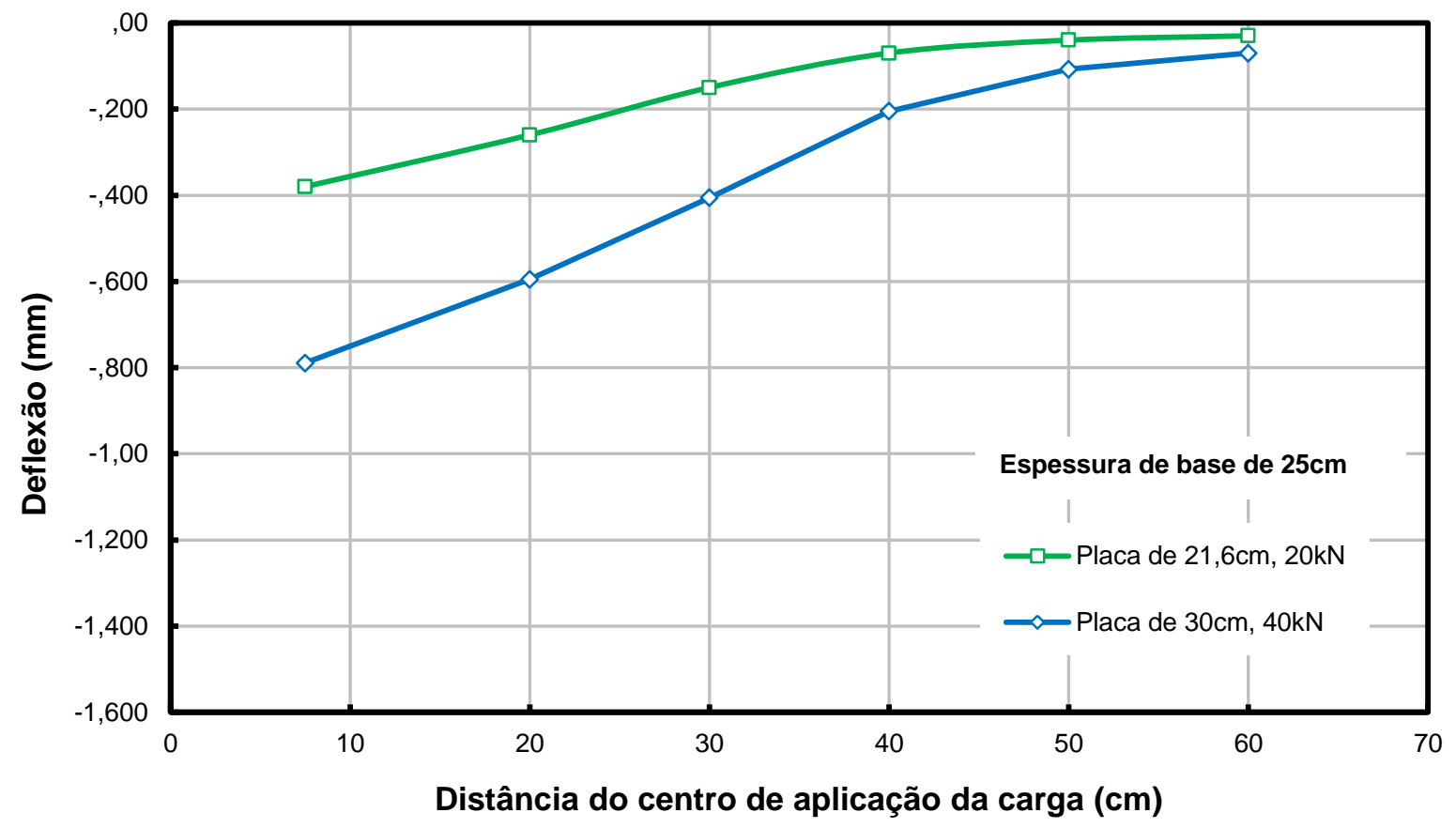

Figura 4.6 - Deflexão para espessuras de camada de base de $25 \mathrm{~cm}$ com placa de carregamento de 21,6 e $30 \mathrm{~cm}$ 
Analisando-se as curvas de deflexões apresentadas nas Figuras 4.5 e 4.6, observa-se para ambas as espessuras de base, que as deflexões crescem com o aumento da dimensão da placa. Considerando-se a deflexão sob o centro da placa, o aumento é de 2,1 e 2,3 vezes, respectivamente para as bases de 15 e $25 \mathrm{~cm}$ de espessura. Como a tensão aplicada, $550 \mathrm{kPa}$, é comum para ambas as placas, o aumento do bulbo acarreta o aumento das tensões que se propagam na base e no subleito, conduzindo a deformações mais elevadas.

\subsection{RESULTADOS DOS ENSAIOS DA ETAPA DEFINITIVA}

Neste item, são analisados os resultados de três ensaios no equipamento de grandes dimensões, sendo um ensaio sem a utilização de reforço, um com o reforço posicionado na interface subleito-base e por fim, um ensaio com o reforço no horizonte médio da camada de base. Consideraram-se, nesta etapa, duas condições de umidade para o subleito, umidade ótima e umidade após inundação.

A carga aplicada foi de $40 \mathrm{kN}$ sobre uma placa rígida de $30 \mathrm{~cm}$ de diâmetro, resultando numa pressão de contato de $550 \mathrm{kPa}$. Foram realizadas $4.10^{5}$ aplicações de carga com frequência de $1 \mathrm{~Hz}(0,3 \mathrm{~s}$ de atuação do carregamento por $0,7 \mathrm{~s}$ de repouso), com o subleito na umidade ótima e $10^{5}$ aplicações após a inundação. 


\subsubsection{Ensaio sem a utilização de geogrelha}

A estrutura de pavimento no ensaio sem a utilização do reforço é constituída de uma base de solo-brita de $20 \mathrm{~cm}$ sobreposta a um subleito de $50 \mathrm{~cm}$ de espessura. Nos itens 4.3.1.1 e 4.3.1.2 são analisadas as deformações elásticas e permanentes, respectivamente, para a condição em que o subleito encontra-se na umidade ótima de compactação, e nos itens 4.3.1.3 e 4.3.1.4 são analisadas as deformações elásticas e permanentes, respectivamente, para a condição após a inundação do subleito.

\subsubsection{Análise das deformações elásticas na superfície sem a utilização de geogrelha e subleito na umidade ótima de compactação}

As Figuras 4.7 e 4.8 apresentam, respectivamente, as bacias de deflexão para $50.000,100.000,200.000,300.000$ e 400.000 ciclos de carga e a variação da deflexão máxima com o número de carregamentos. 


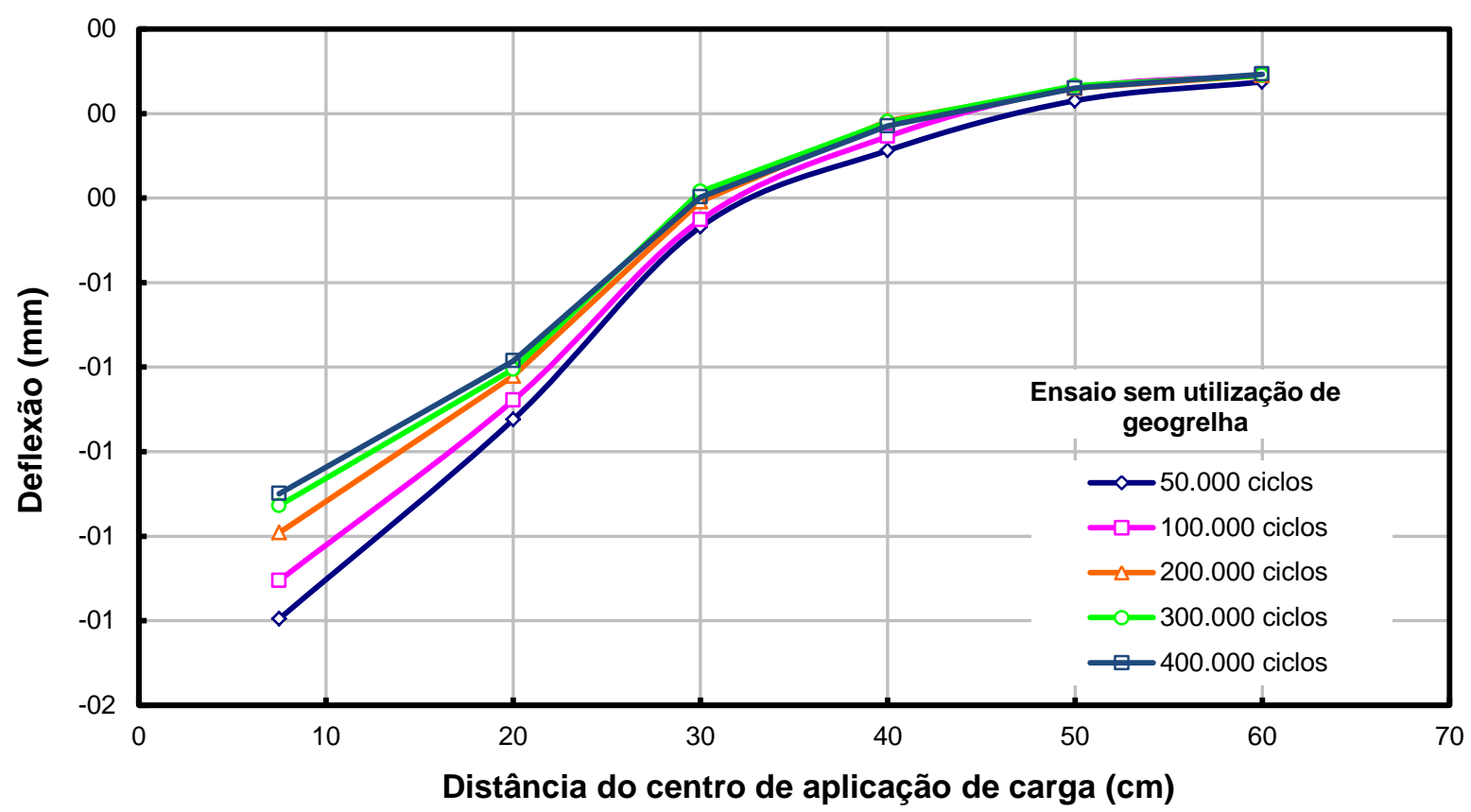

Figura 4.7 - Bacia de deflexão obtida em diferentes ciclos de carga sem a utilização da geogrelha

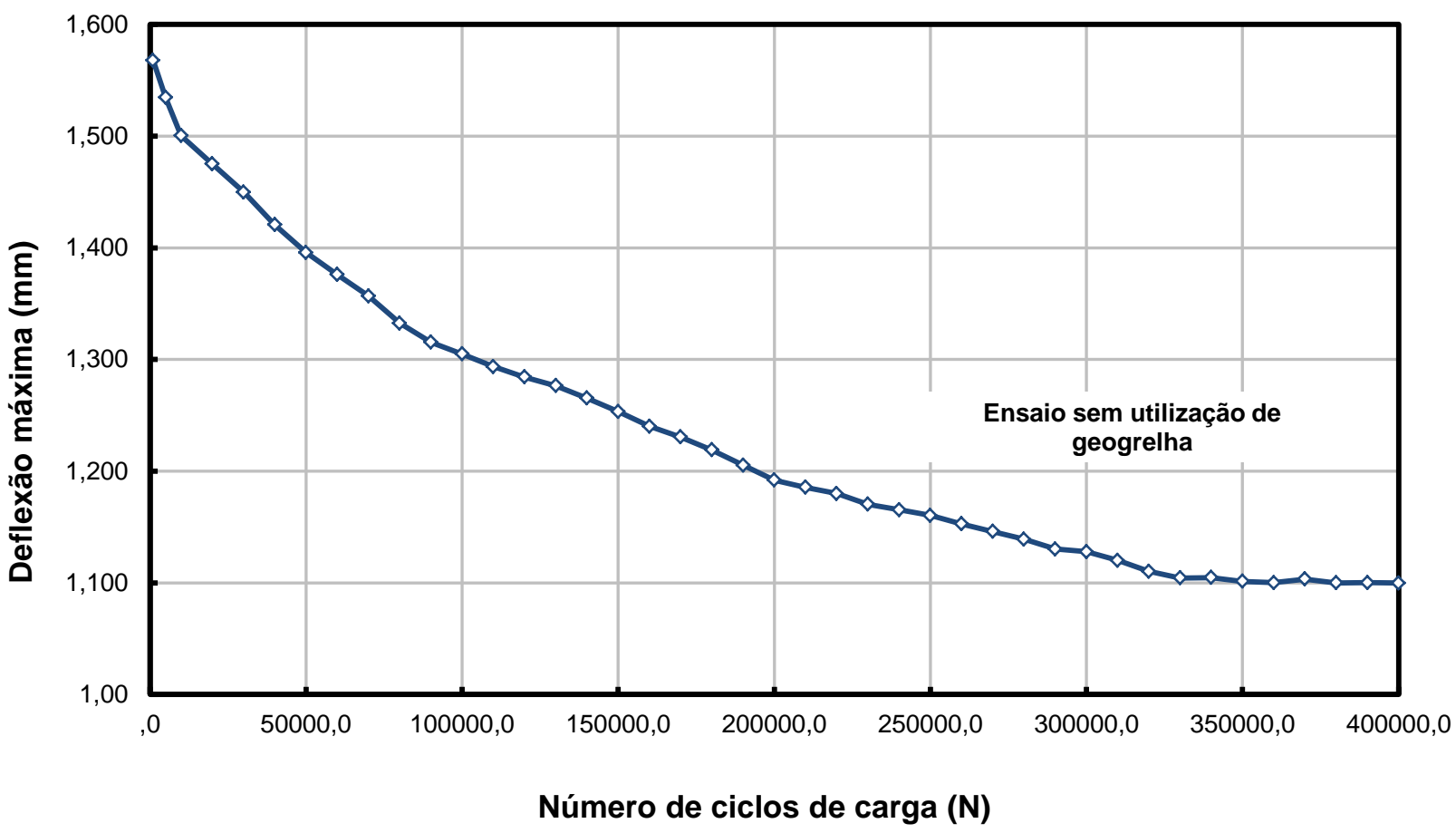

Figura 4.8 - Deflexão máxima em função do número de ciclos de carga sem a utilização da geogrelha 
Analisando-se as bacias de deflexão apresentadas na Figura 4.7, observa-se que as deflexões diminuem com o aumento do número de ciclos de carga, conforme já comentado no item 4.2.1.

Considerando-se a evolução das bacias com o número de ciclos de carga, observa-se nas Figuras 4.7 e 4.8 que a partir de $3,4 \times 10^{5}$ aplicações existe a convergência para um valor único, a partir do qual o processo estabiliza-se. Comparando-se as deflexões máximas para 1.000 e 400.000 ciclos de carga, observa-se uma redução de $30 \%$ no seu valor.

Para tensões aplicadas em condições similares às desta pesquisa, Perkins (1999), Woon-Hyung et al. (2005), Tingle and Jersey (2005) e Kinney et al. (1998), obtiveram, respectivamente, deflexões máximas aproximadas de 3, 3,5, 3,8 e $1,1 \mathrm{~mm}$. Sendo os três primeiros resultados obtidos para um número de ciclos de $50.000,10.000$ e 10.000 de carga, respectivamente, e o último para um ensaio de FWD (Falling Weight Deflectometer).

Os pesquisadores citados utilizaram brita graduada como base, com espessura variando entre 15 e $30 \mathrm{~cm}$, sendo que as deflexões citadas anteriormente correspondem, para as duas primeiras pesquisas, a bases de $30 \mathrm{~cm}$, e para as duas últimas, a bases de $20 \mathrm{~cm}$. Para a composição do subleito, Perkins (1999) empregou uma argila altamente plástica com CBR de 1,5\%, compactada com um teor de umidade de 44,8\%; Woon-Hyung et al. (2005) empregaram poliestileno extrudado (EPS) com rigidez de 7MPa, Tingle and Jersey (2005) empregaram uma argila com CBR de 1\%, compactada com teor de umidade de 47\%; e Kinney et al. (1998) empregaram uma mistura de areia siltosa e pedregulho com CBR de $1 \%$, compactada com teor de umidade de $11 \%$. Nestas pesquisas, à exceção daquela 
onde se utilizou o EPS, o subleito foi compactado com umidades superiores à ótima, de maneira que fossem obtidos valores de CBR muito baixos.

Comparando-se as deflexões máximas obtidas nesta etapa da presente pesquisa para 50.000 e 10.000 ciclos de carga, 1,4 e 1,5mm, respectivamente, com os fornecidos pela literatura, observa-se que as mesmas são da ordem de metade daquelas relatadas pelos três primeiros autores destacados anteriormente. Os menores valores de deflexões determinados nesta pesquisa poderiam ser creditados ao fato de ter-se utilizado como subleito um silte argiloso com CBR de $8 \%$ e módulo de resiliência da ordem de $20 \mathrm{MPa}$, compactado na umidade ótima de $25,6 \%$, material com comportamento muito superior aos dos utilizados pelos autores citados. Com relação à deflexão determinada pelo último autor, esta coincide com a determinada nesta pesquisa, $1,1 \mathrm{~mm}$, após a estabilização das deflexões, a partir de 350.000 ciclos de carga. Neste caso, supõe-se que o subleito utilizado por Kinney et al. (1998), uma mistura de areia siltosa com pedregulho, tenha comportamento superior aos utilizados pelos outros autores e portanto, mais próximo ao comportamento do subleito desta pesquisa. Entretanto, esta última comparação deve ser vista com precaução, pois a forma de aplicação do carregamento, FWD, difere da utilizada nas demais pesquisas.

No Brasil, para uma seção de pavimento composta por um subleito arenoso com CBR igual a 12\%, uma subbase de laterita com CBR igual a 39\% e uma base de brita graduada com CBR igual a 106\%, com espessuras 100, 20 e $20 \mathrm{~cm}$, respectivamente, carregada ciclicamente com uma placa de 15,2cm de diâmetro, Silva (2009) obteve uma deflexão de $0,23 \mathrm{~mm}$, valor determinado por interpolação para uma pressão de $550 \mathrm{kPa}$. Comparando-se este valor com a deflexão 
determinada na presente pesquisa após a estabilização das deformações elásticas, $1,1 \mathrm{~mm}$, o mesmo é da ordem de um quinto. Supõe-se que o menor valor obtido seja decorrente da melhor qualidade do subleito e de ter sido utilizada uma camada de subbase. Entretanto, é importante destacar que em ambas as pesquisas, a magnitude das deflexões é inferior à das pesquisas americanas.

\subsubsection{Análise das deformações permanentes na superfície sem a utilização de geogrelha e subleito na umidade ótima de compactação}

As deformações permanentes desenvolvidas durante a realização do ensaio foram determinadas na superfície do pavimento sob a placa de carregamento. A Figura 4.9 apresenta o desenvolvimento do recalque com o número de ciclos de carga e as curvas correspondentes aos modelos das equações 4.1 e 4.2 que serão discutidos posteriormente. Nesta figura, no trecho em que os recalques crescem mais rapidamente, até 10.000 aplicações de carga, os pontos apresentados correspondem à média de dez pontos tomados a cada 100 leituras. No restante da curva, tomou-se a média de 100 pontos a cada 1.000 leituras. Nas curvas similares apresentadas nos itens 4.3.2.2 e 4.3.3.2, adotou-se o mesmo critério. 


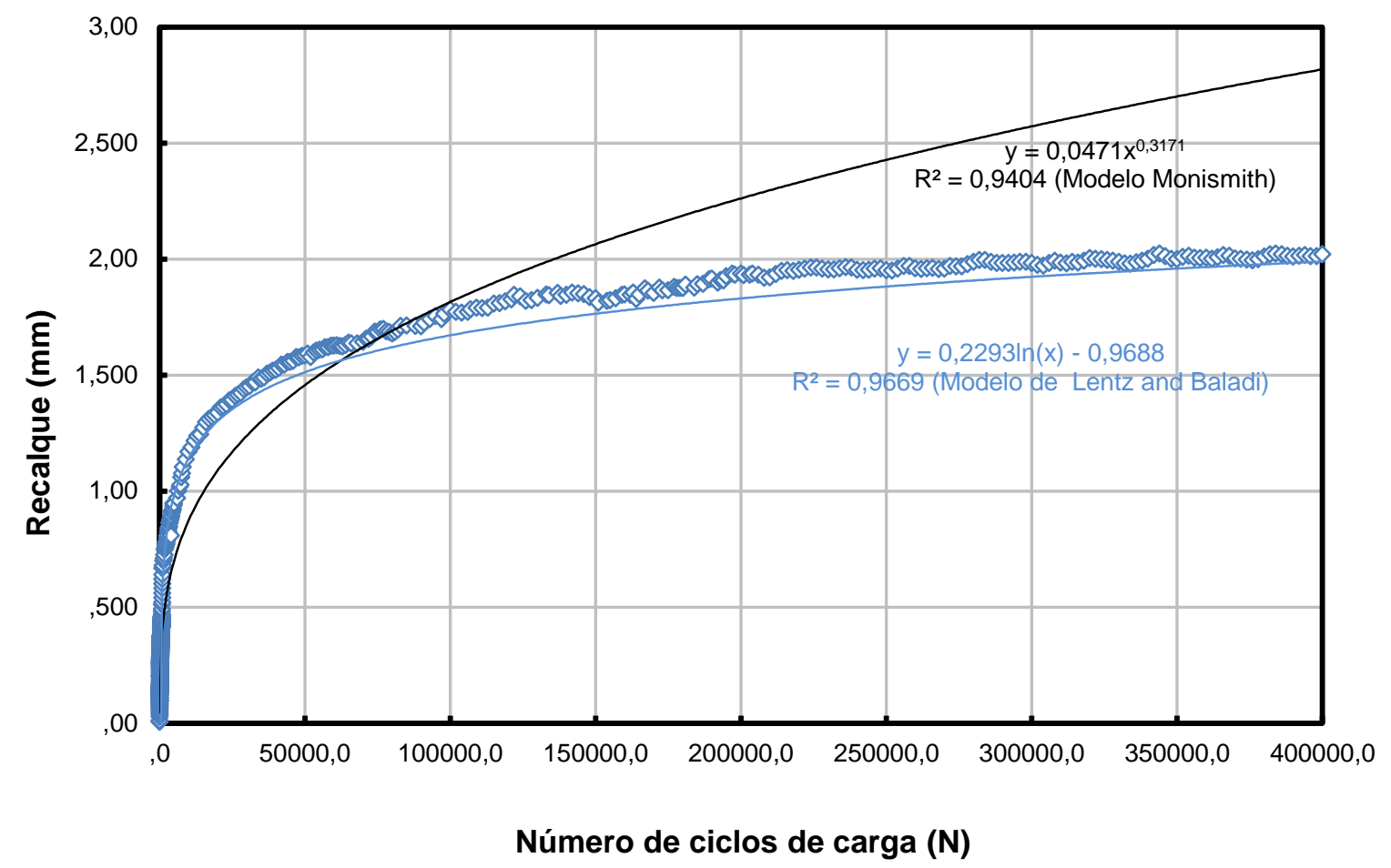

Figura 4.9 - Recalque em função do número de ciclos de carga sem a utilização de geogrelha e curvas correspondentes às equações 4.1 e 4.2

Analisando-se o desenvolvimento do recalque em função do número de ciclos de carga, conforme apresentado na Figura 4.9, observa-se que a taxa de crescimento do recalque é mais acentuado nos primeiros 10.000 ciclos de carga, onde se atinge $55 \%$ do recalque total. Verifica-se ainda, uma tendência de acomodamento das deformações permanentes com o aumento dos ciclos de cargas, evidenciado pelo fato da curva tornar-se praticamente paralela ao eixo das abscissas a partir de 300.000 ciclos de carga.

$\mathrm{Na}$ literatura são encontrados diversos modelos usados na representação da variação da deformação permanente com o número de ciclos de carga, dentre eles destacam-se o modelo de Monismith et al. (1975) e Lentz and Baladi (1981), cujas equações estão apresentas no Capítulo 2. Para a curva de recalque apresentada na Figura 4.9 foram obtidas as equações 4.1 e 4.2 , respectivamente, para Monismith et 
al (1975) e Lentz and Baladi (1981). A Figura 4.9 apresenta as curvas correspondentes a estes modelos descritos em termos de recalques. Analisando-se estes modelos, observa-se que o do Monismith et al. (1975), apesar do coeficiente de correlação ser elevado, não representa bem o desenvolvimento dos recalques principalmente para números de ciclos maiores, sendo que $\circ \mathrm{R}^{2}$ reflete a concordância no trecho inicial da curva, onde a concentração de pontos é maior se comparada a do restante da curva. Para o modelo de Lentz e Baladi (1981), a concordância com os pontos experimentais é bastante boa ao longo de toda a curva.

$$
\begin{array}{cc}
\varepsilon_{\mathrm{P}}=7 \cdot 10^{-5} \cdot \mathrm{N}^{0,3171} & \mathrm{R}^{2}=0,94 \\
\varepsilon_{\mathrm{P}}=0,0003 . \text { Ln } \mathrm{N}-0,0014 & \mathrm{R}^{2}=0,91
\end{array}
$$

Em que: $\quad \begin{aligned} \varepsilon_{\mathrm{P}}=\text { deformação permanente }(\%) ; \\ \mathrm{N}=\text { número de ciclos de carga. }\end{aligned}$

Para tensões aplicadas em condições similares às desta pesquisa, Perkins (1999), Tingle and Jersey (2005), Jianjun and Mohammed (2002), Woon-Hyung et al. (2006) e Kinney et al. (1998) obtiveram recalques de, respectivamente, 25, 60, 50, 18 e $35 \mathrm{~mm}$, para $50.000,10.000,10.000,1.000$ e 2.160 ciclos de carga, tomados na mesma ordem dos recalques. Ainda com relação às deformações permanentes, Jianjun and Mohammed (2002), para um subleito constituído de uma mistura de areia e caulinita compactada com $18,5 \%$ de umidade e com CBR de $1 \%$ obtiveram $50 \mathrm{~mm}$ de recalque para 10.000 ciclos de carga.

Analisando-se o número de ciclos de carga pequeno adotado por alguns autores, supõe-se que o encerramento precoce do ensaio seja decorrente dos 
elevados valores de recalques observados, a partir dos quais, extrapolava-se a capacidade de leitura dos transdutores de deslocamentos.

Comparando-se os recalques obtidos nesta etapa da presente pesquisa para $50.000,10.000,2.160$ e 1.000 ciclos de carga, 1,6, 1,2, 0,8 e 0,6mm, respectivamente, com os fornecidos na literatura, observa-se que, na média, os mesmos são 36 vezes menores. Esta discrepância poderia ser creditada novamente ao fato do subleito utilizado ser de melhor qualidade que os das pesquisas citadas, conforme já destacado anteriormente no item 4.3.1.1, onde foram analisadas as deflexões.

Em função da grande diferença observada nas deformações permanentes desta pesquisa com as das pesquisas mencionadas anteriormente, buscou-se compará-las com os resultados de ensaios, onde foram utilizados solos brasileiros. Entretanto, não foi possível identificar nenhuma outra pesquisa realizada no país onde se tivesse determinado deformações permanentes a partir de ensaios conduzidos em condições similares aos desta pesquisa. Assim, para efeito de comparação, foram tomadas as deformações permanentes obtidas por Guimarães (2009) em ensaios triaxiais cíclicos para uma argila classificada como argila laterítica segundo a classificação MCT, coletada na região de Ribeirão Preto-SP e ensaiada sob tensões compatíveis com às atuantes no subleito de rodoviais.

As deformações permanentes obtidas por Guimarães (2009) após 250.000 ciclos de carga situam-se, em média, no intervalo de 0,01 e $0,5 \%$, correspondente a variações da altura de corpos-de-provas de $20 \mathrm{~cm}$, de $0,2 \mathrm{~mm}$ e $1 \mathrm{~mm}$, respectivamente. Considerando-se que na presente pesquisa, o recalque máximo de $2 \mathrm{~mm}$ determinado após a estabilização das deformações é decorrente da 
contribuição do subleito e da camada de base, com espessuras de 50 e $20 \mathrm{~cm}$, respectivamente, a deformação correspondente é de 0,29\%, valor compatível com os encontrados pelo autor citado.

Atualmente, o desenvolvimento das deformações permanentes tem sido analisado à luz da Teoria do skakedown por pesquisadores no país e no exterior (COLLIN, 2000; WEKMEISTER et al., 2001; GUIMARÃES, 2009). O conceito da teoria do shakedown, segundo Faria (1999) é: "Quando em um corpo submetido a um carregamento de cargas repetidas cessam as deformações permanentes, a partir de um determinado número de aplicações de cargas, diz-se que ele entrou em shakedown. A partir desse instante a resposta do material à solicitação externa será estritamente elástica, e a inexistência de deformação plástica é justificada a partir do surgimento de tensões residuais. Portanto, o surgimento de tensões residuais é condição essencial para o surgimento do shakedown"

Com o objetivo de averiguar se as deformações permanentes obtidas nesta pesquisa encontram-se na fase de acomodamento correspondente ao shakedown, utilizou-se a análise proposta por Wekmwister et al. (2001), onde a partir de gráficos onde a abscissa é o recalque $\left(\times 10^{-3} \mathrm{~mm}\right)$ e a ordenada é o recalque $\left(\times 10^{-3} \mathrm{~mm}\right)$ dividido pelo número de ciclos de carga em escala logarítmica, é possível delinearem-se três diferentes tipos de curvas correspondentes a três tipos de comportamento, denominados níveis A, B e C. O nível A corresponde ao estado shakedown ou acomodamento plástico, o nível B corresponde a uma situação na qual a amostra se deforma a uma taxa quase constante não nula, e o nível C, a amostra tende ao colapso, conforme apresentado na Figura 4.10. 


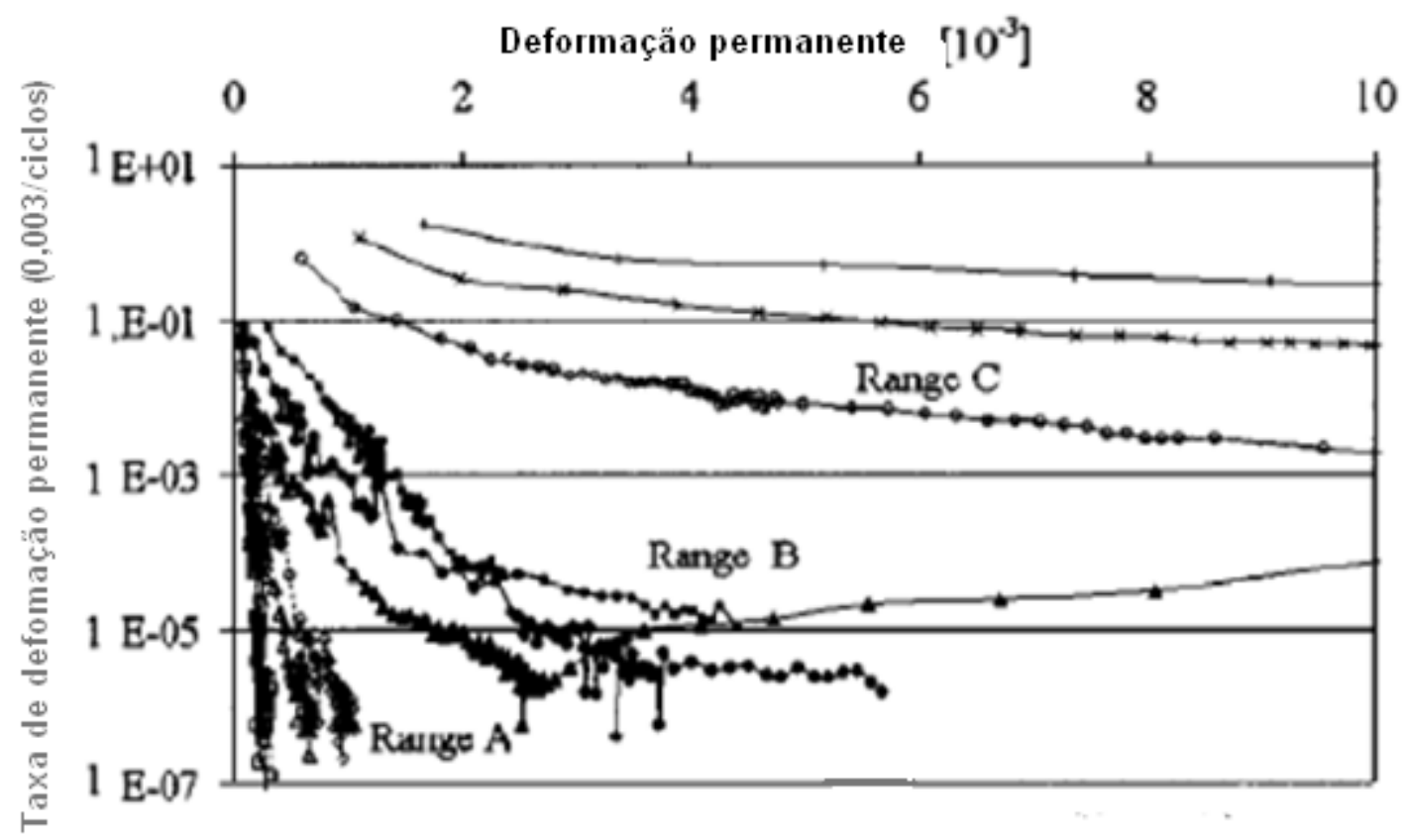

Figura 4.10 - Modelo de Wekmeister et al. (2001) apud Guimarães (2009)

A Figura 4.11 mostra o desenvolvimento dos recalques determinados nesta pesquisa apresentado segundo o modelo de Wekmeister et al. (2001). Analisandose a curva, observa-se que o pavimento encontra-se no estado de shakedown, ou seja, o crescimento das deformações permanentes tende a valores muito reduzidos com o aumento dos ciclos de carga, caracterizado por acréscimos de recalques da ordem de $10^{-4} \mathrm{~mm}$ a cada nova aplicação do carregamento. 


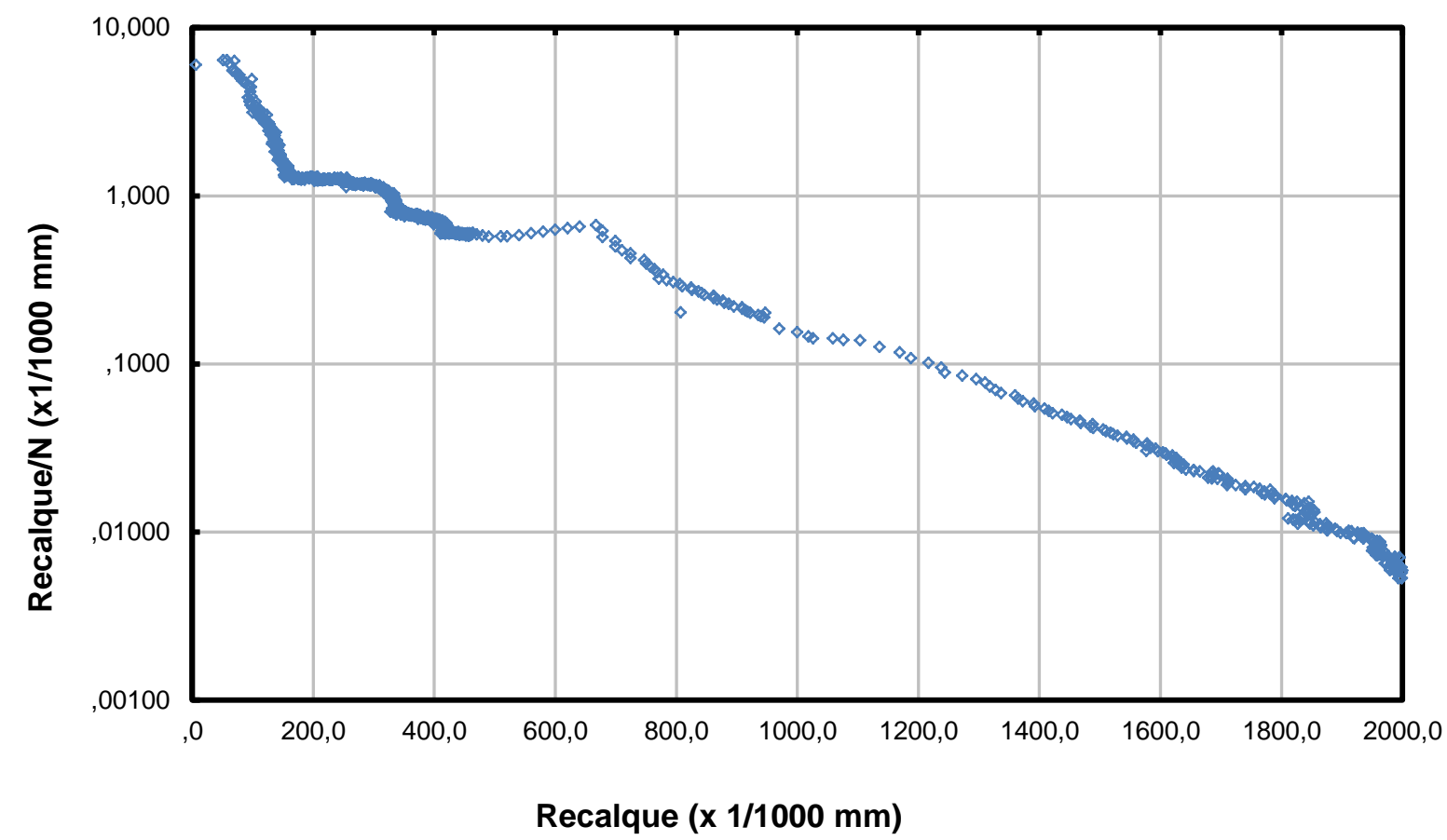

Figura 4.11 - Enquadramento no Modelo de Wekmeister et al. (2001) do ensaio sem geogrelha

Finalmente, comparando-se a relação entre deslocamentos plásticos e elásticos máximos determinados nesta pesquisa, ela é da ordem de 1,8, menor que as observadas em pesquisas realizadas no exterior, a exemplo de Perkins (1999), Woon-Hyung et al. (2005) e Tingle and Jersey (2005), onde esta relação vale 8,3, 5,1 e 15, respectivamente. Assim, pode-se concluir que a pior qualidade dos subleitos encontrados em países de clima temperado tem uma repercussão mais importante no desenvolvimento das deformações permanentes do que no desenvolvimento das deformações elásticas. Este fato tem como decorrência a notada preocupação que as formulações estrangeiras usadas na análise de pavimentos dedica ao estudo de deformações permanentes originadas no subleito de rodovias. 


\subsubsection{Análise das deformações elásticas na superfície sem a utilização de geogrelha após o umedecimento do subleito}

Esta etapa do ensaio foi realizada após o término da etapa apresentada no item 4.3.1.2, mantendo-se a estrutura de pavimento inalterada e inundando-se o subleito por ascensão capilar. Nesta etapa, foi observado um intervalo de dez dias após o início do umedecimento para a realização do ensaio com a finalidade de garantir uma melhor homogeneização da umidade ao longo do perfil do subleito.

Nesta etapa foram aplicados 100.000 ciclos de carga nas mesmas condições adotadas anteriormente. Ao final do ensaio foram coletadas amostras de solo ao longo do perfil do subleito e determinadas as respectivas umidades, conforme apresentado na Figura 4.12.

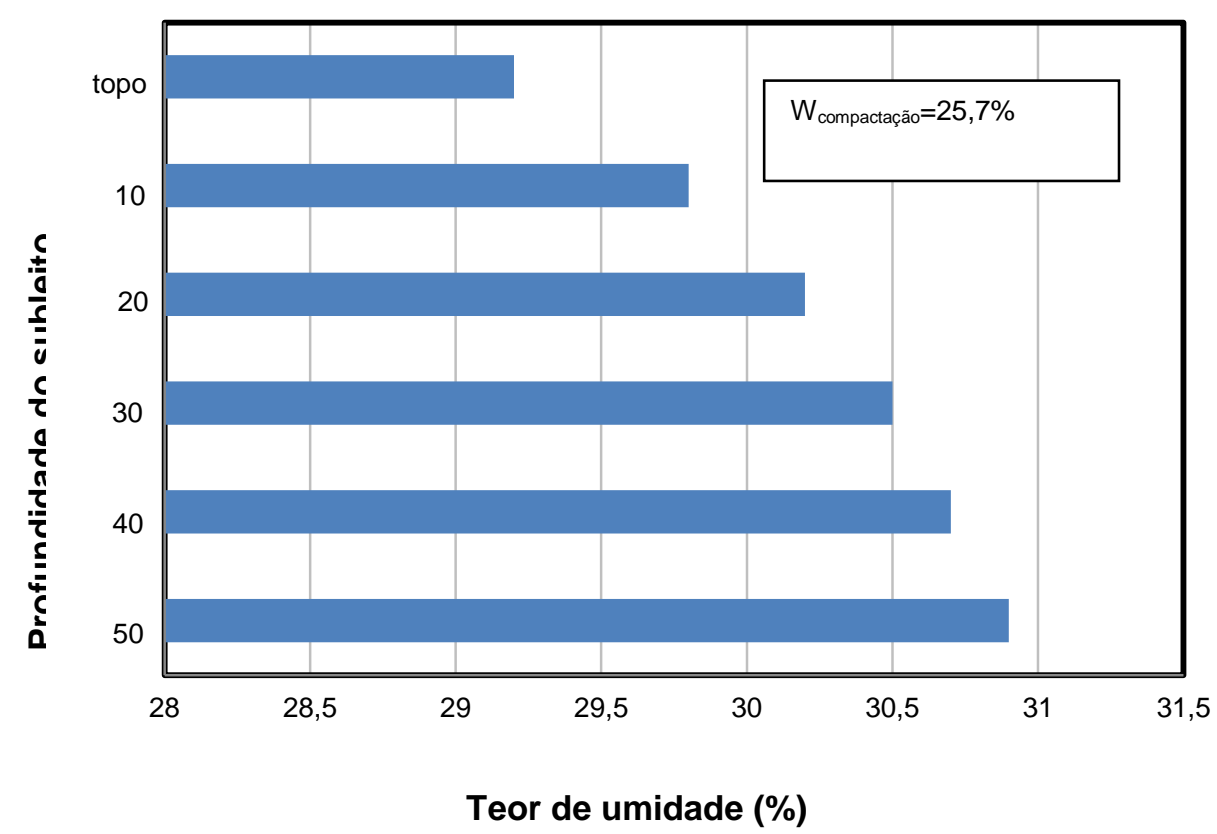

Figura 4.12 - Variação do teor de umidade com a profundidade do subleito após o umedecimento 
Analisando a umidade ao longo do subleito conforme apresentado na Figura 4.12, observa-se que a mesma é crescente da maior para a menor profundidade, variando de $30,7 \%$ a $29,2 \%$. Tomando-se a média de todos os teores, igual a $30,2 \%$, ocorreu uma variação da umidade a partir da umidade de compactação, igual a $25,7 \%$, de $4,5 \%$. Com relação ao grau de saturação, este variou de $83 \%$ para $98 \%$, considerando-se a umidade ótima e a média das umidades após o umedecimento, respectivamente.

As Figuras 4.13 e 4.14 apresentam as bacias de deflexão para 10.000, 50.000 e 100.000 ciclos de carga e a variação da deflexão máxima com o número de carregamentos, sendo que para esta última figura, também foi incluído o resultado da etapa sem umedecimento do subleito.

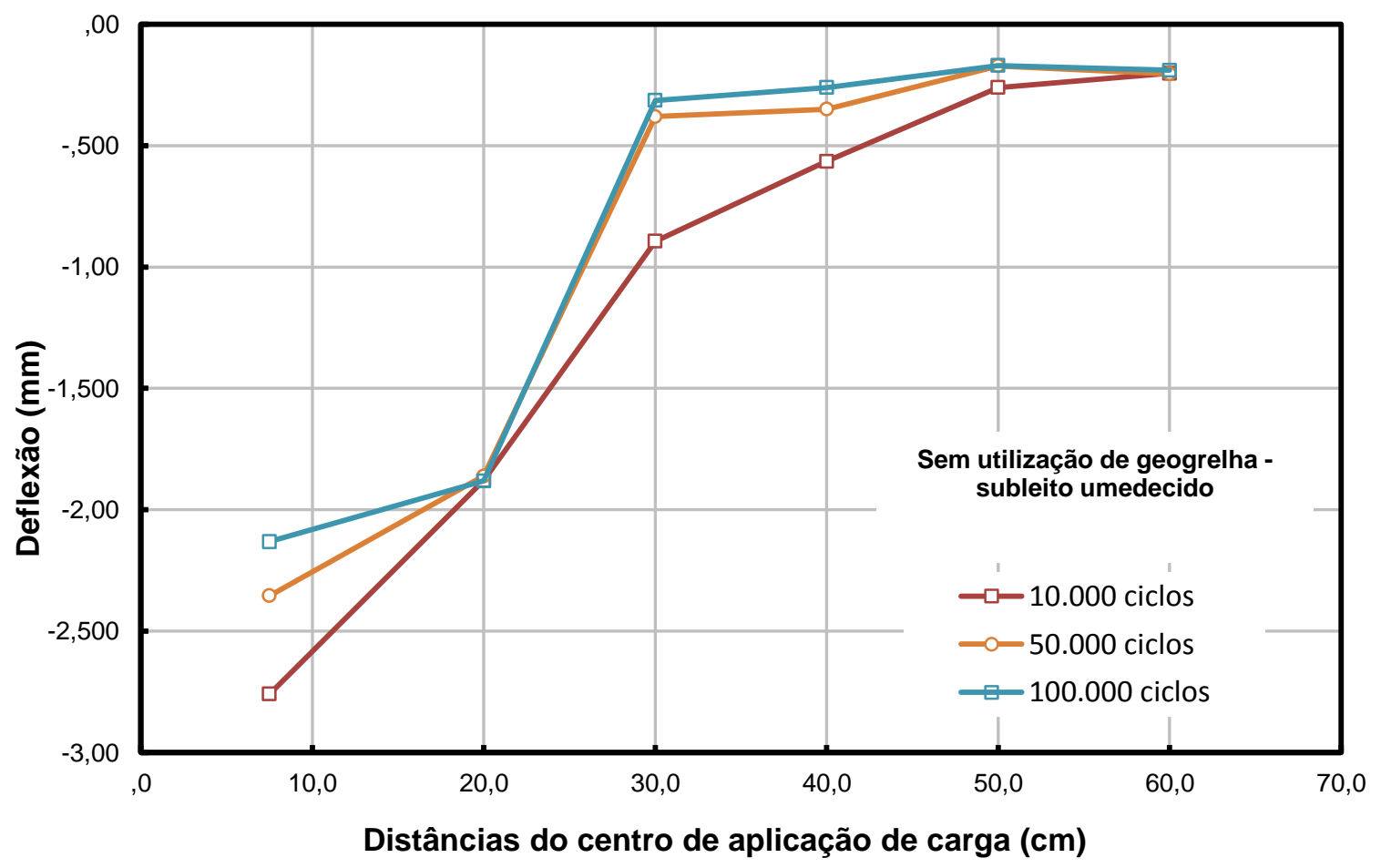

Figura 4.13 - Bacia de deflexão obtida em diferentes ciclos de carga, sem a utilização da geogrelha na condição após umedecimento do subleito 


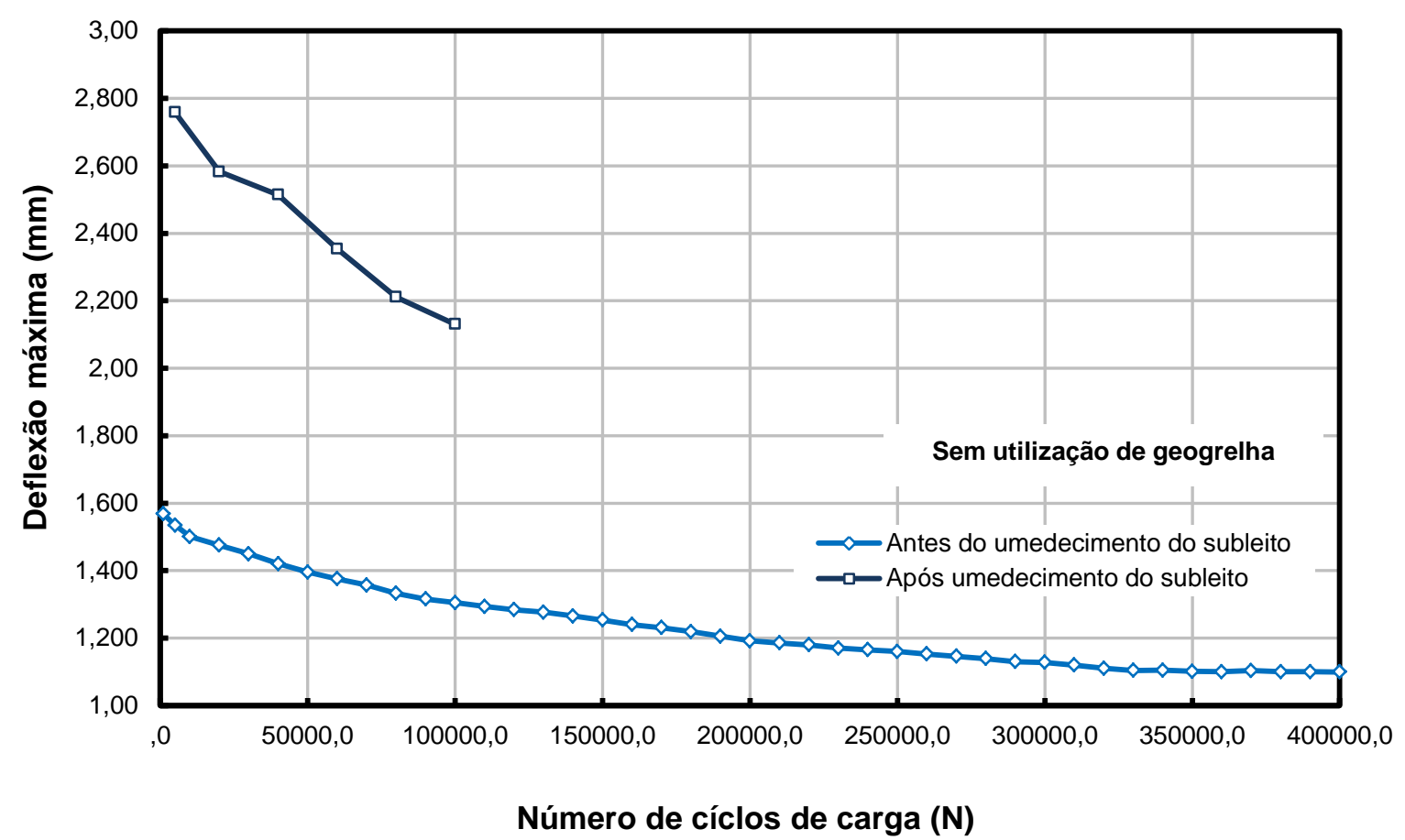

Figura 4.14 - Deflexão máxima em função do número de ciclos de carga sem a utilização da geogrelha na condição antes e após o umedecimento do subleito

Analisando-se a Figura 4.13 conjuntamente com as bacias de deflexão determinadas nas diversas etapas da pesquisa, Figuras 4.7, 4.17, 4.21, 4.23, 4.25, 4.29 e 4.31, pode-se concluir que as leituras realizadas a 20 e $30 \mathrm{~cm}$ de distância da aplicação do carregamento nesta etapa da pesquisa, onde se observa uma variação mínima das leituras, provavelmente não estão corretas, fato que se supõe decorrente de algum problema nos transdutores localizados nestas posições e não identificado durante o ensaio.

Analisando-se na Figura 4.14 o desenvolvimento da deflexão máxima com o número de ciclos de carga para as situações sem umedecimento e após umedecimento, observa-se que nesta última condição, ainda não se alcançou a estabilização das deformações elásticas com 100.000 ciclos. Possivelmente, se o desenvolvimento das deflexões após o umedecimento apresentasse o mesmo 
padrão de variação da etapa sem umedecimento, o valor de 2,1 $\mathrm{mm}$ alcançado para 100.000 aplicações poderia reduzir-se a um valor próximo a 1,8mm após a estabilização das deformações, obtido por extrapolação.

A Figura 4.15 apresenta conjuntamente as bacias de deflexão obtidas sem umedecimento e após umedecimento para 100.000 ciclos de carga. Este valor foi adotado de maneira a permitir a comparação das duas bacias, tendo em vista que após o umedecimento, o ensaio não prosseguiu até a estabilização das deformações elásticas, conforme discutido anteriormente.

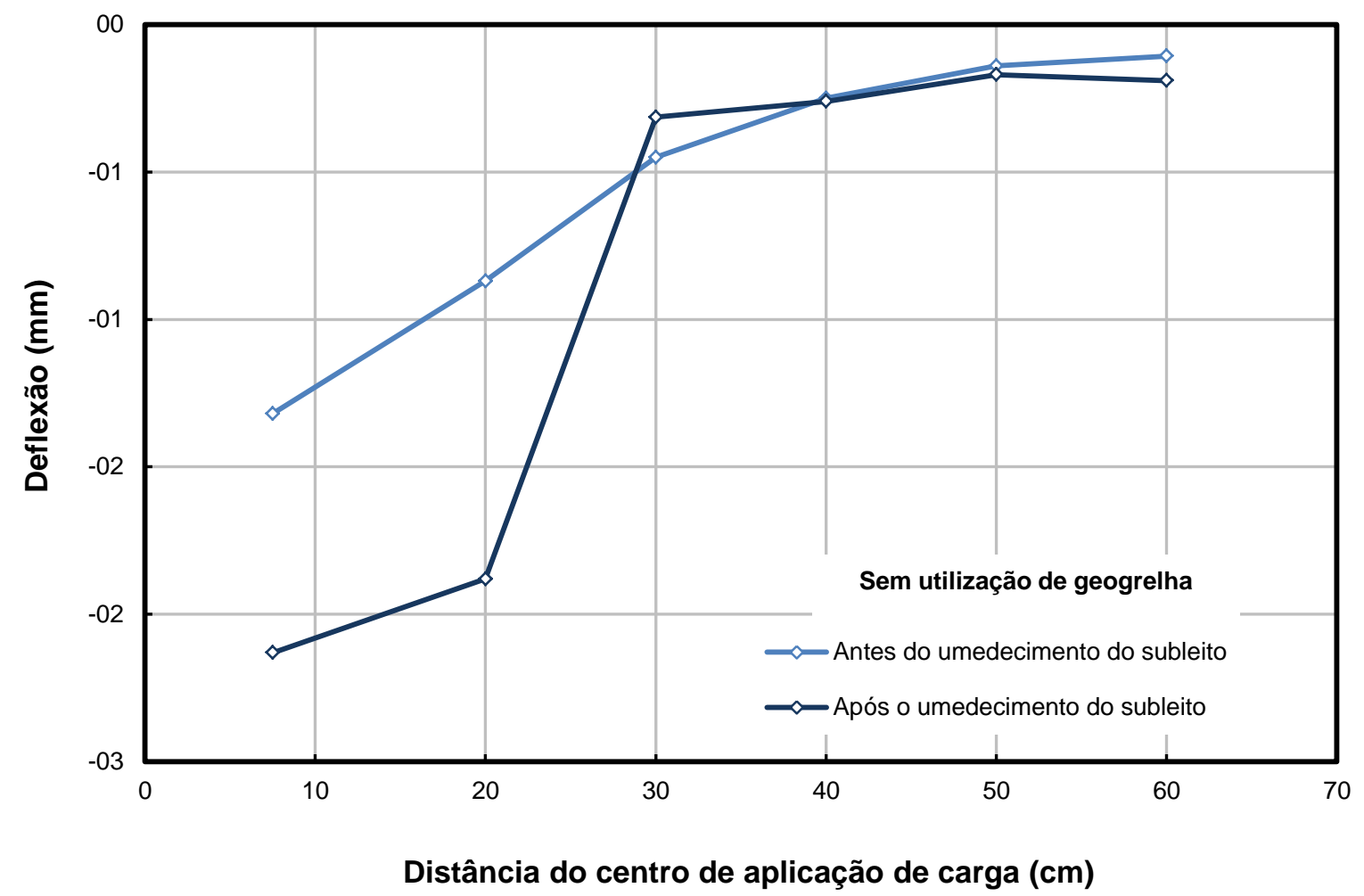

Figura 4.15 - Bacia de deflexão, sem a utilização da geogrelha na condição antes e após o umedecimento do subleito

Analisando-se a Figura 4.15, observa-se que a deflexão máxima obtida após o umedecimento, 2,1 mm, é 1,6 vezes maior que a obtida sem o umedecimento, igual 
a 1,3mm. Supõe-se que a diminuição de rigidez seja decorrente do efeito do umedecimento do material do subleito.

\subsubsection{Análise das deformações permanentes na superfície sem a utilização de geogrelha após o umedecimento do subleito}

As deformações permanentes desenvolvidas durante a realização do ensaio foram determinadas na superfície do pavimento sob a placa de carregamento. A Figura 4.16 apresenta o desenvolvimento do recalque com o número de ciclos de carga antes e após o umedecimento do subleito e ainda as curvas correspondentes aos modelos das equações 4.3 e 4.4 cujas aplicações serão discutidas posteriormente.

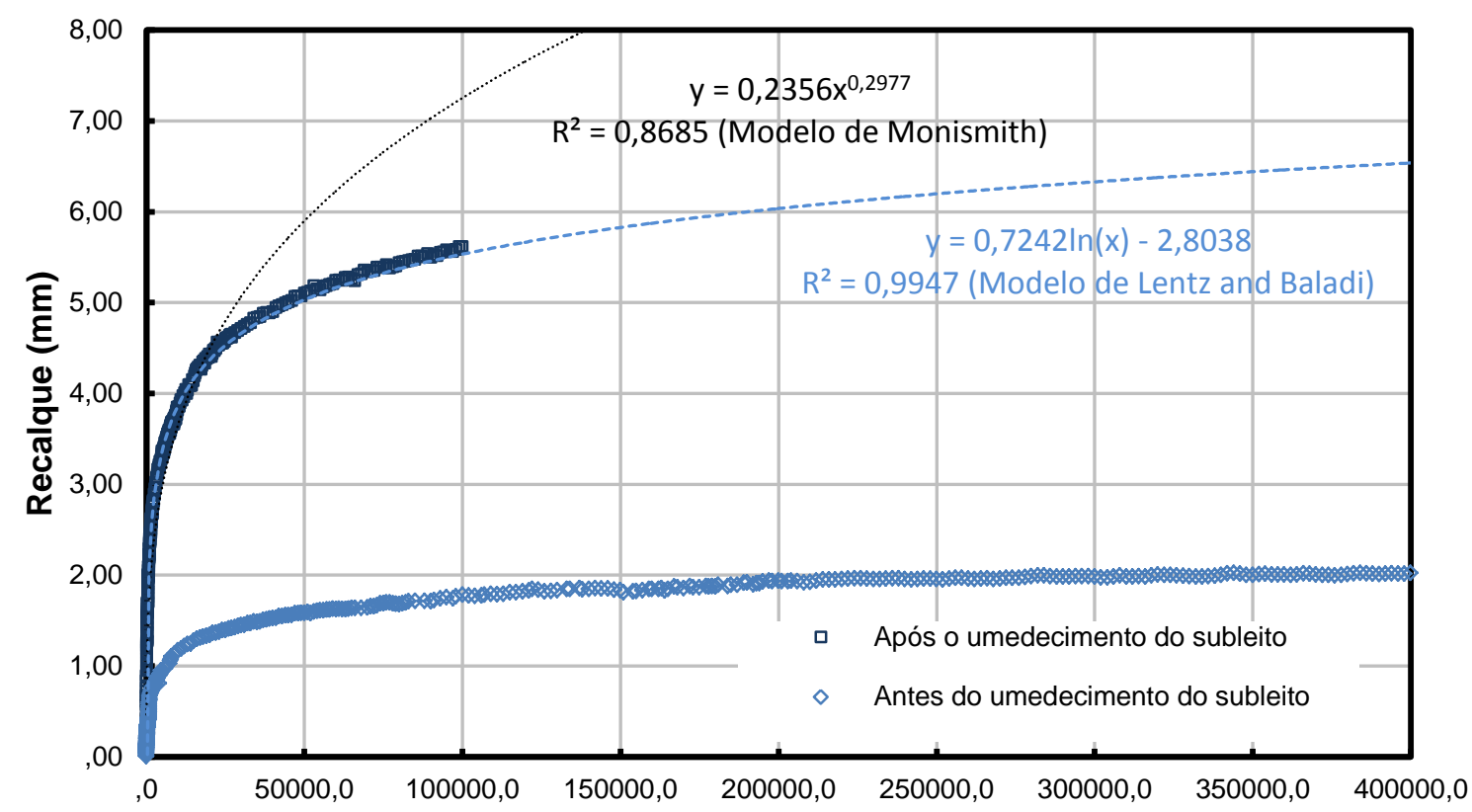

Número de ciclos de carga $(\mathrm{N})$

Figura 4.16 - Recalque em função do número de ciclos de carga, sem a utilização da geogrelhas na condição antes e após o umedecimento do subleito e os modelos correspondentes às equações 4.3 e 4.4 
Analisando-se o desenvolvimento do recalque em função do número de ciclos de carga, conforme apresentado na Figura 4.16, observa-se, que após o umedecimento do subleito e para 100.000 ciclos de carga ainda não se alcançou a estabilização das deformações permanentes. Se aos pontos experimentais forem ajustados os modelos de Monismith et al. (1975) e Lentz e Baladi (1981), conforme discutido anteriormente, obtém-se as equações 4.3 e 4.4, respectivamente. Assumindo-se que esta última equação representa bem a variação das deformações permanentes e observando-se os pontos obtidos por extrapolação após 100.000 ciclos de carga, poder-se-ia concluir que a deformação permanente alcançaria a estabilização após 300.000 ciclos de carga, de maneira muito semelhante à estabilização observada para a condição sem umedecimento.

$$
\begin{array}{cc}
\varepsilon_{\mathrm{P}}=3 \cdot 10^{-4} \cdot \mathrm{N}^{0,2977} & \mathrm{R}^{2}=0,87 \\
\varepsilon_{\mathrm{P}}=0,001 . \text { Ln } \mathrm{N}-0,004 & \mathrm{R}^{2}=0,99
\end{array}
$$

Em que: $\quad \varepsilon_{\mathrm{P}}=$ deformação permanente $(\%)$;

$\mathrm{N}=$ número de ciclos de carga.

Comparando-se os recalques obtidos sem umedecimento e após umedecimento do subleito para 100.000 ciclos de carga, número de ciclos comum aos dois ensaios, conforme a Figura 4.16, observa-se que o recalque é igual a $1,8 \mathrm{~mm}$ e 5,6mm, respectivamente, para a primeira e segunda condições. Portanto, o umedecimento conduz a um aumento da deformação plástica da ordem de 3 vezes. Aplicando-se o modelo da equação 4.4 que melhor se ajusta ao comportamento após umedecimento, obtém-se por extrapolação, o valor de 6,2mm para o recalque correspondente a 400.000 ciclos de carga. Comparando-se este valor com o obtido 
sem o umedecimento para igual número de ciclos, $2 \mathrm{~mm}$, a relação entre os mesmo é igual à determinada para 100.000 ciclos, fazendo supor que o desenvolvimento dos recalques após o umedecimento teria alcançado a sua estabilização de forma semelhante à da condição sem umidade, conforme já observado anteriormente.

Conclui-se que a variação da umidade do subleito conduziu a um aumento tanto na deformação permanente quanto na deformação elástica, sendo esse aumento proporcionado pela perda de rigidez do subleito devido à elevação do teor de umidade.

\subsubsection{Ensaio com a utilização de geogrelha na interface subleito-base}

Neste ensaio procurou-se manter as mesmas configurações do ensaio apresentado no item 4.3.1, diferindo-se na inserção de uma geogrelha de polipropileno (Fornit J600 (30/30)) posicionada na interface subleito-base com a função de reforço. Nos itens 4.3.2.1 e 4.3.2.2 são analisadas as deformações elásticas e permanentes, respectivamente, para a condição em que o subleito encontra-se na umidade ótima de compactação, e nos itens 4.3.2.3 e 4.3.2.4, são

analisadas as deformações elásticas e permanentes, respectivamente, para a condição após a inundação do subleito. 
4.3.2.1 Análise das deformações elásticas na superfície com a utilização da geogrelha posicionada na interface subleito-base e subleito na umidade ótima de compactação

As Figuras 4.17 e 4.18 apresentam, respectivamente, as bacias de deflexão para $50.000,100.000,200.000,300.000$ e 400.000 ciclos de carga, e a variação da deflexão máxima com o número de carregamentos.

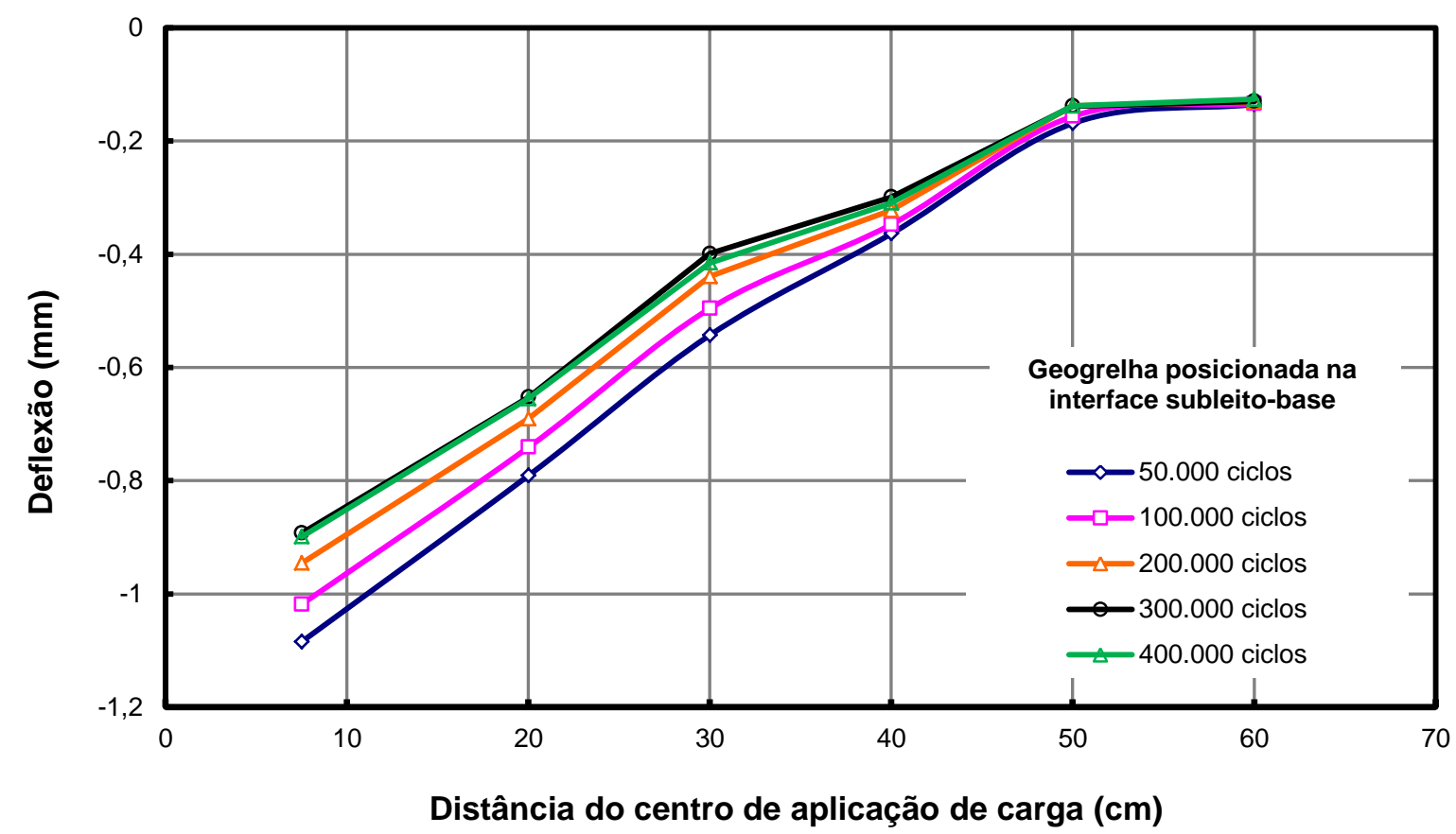

Figura 4.17 - Bacia de deflexão obtida em diferentes ciclos de carga com a utilização da geogrelha posicionada na interface subleito-base 


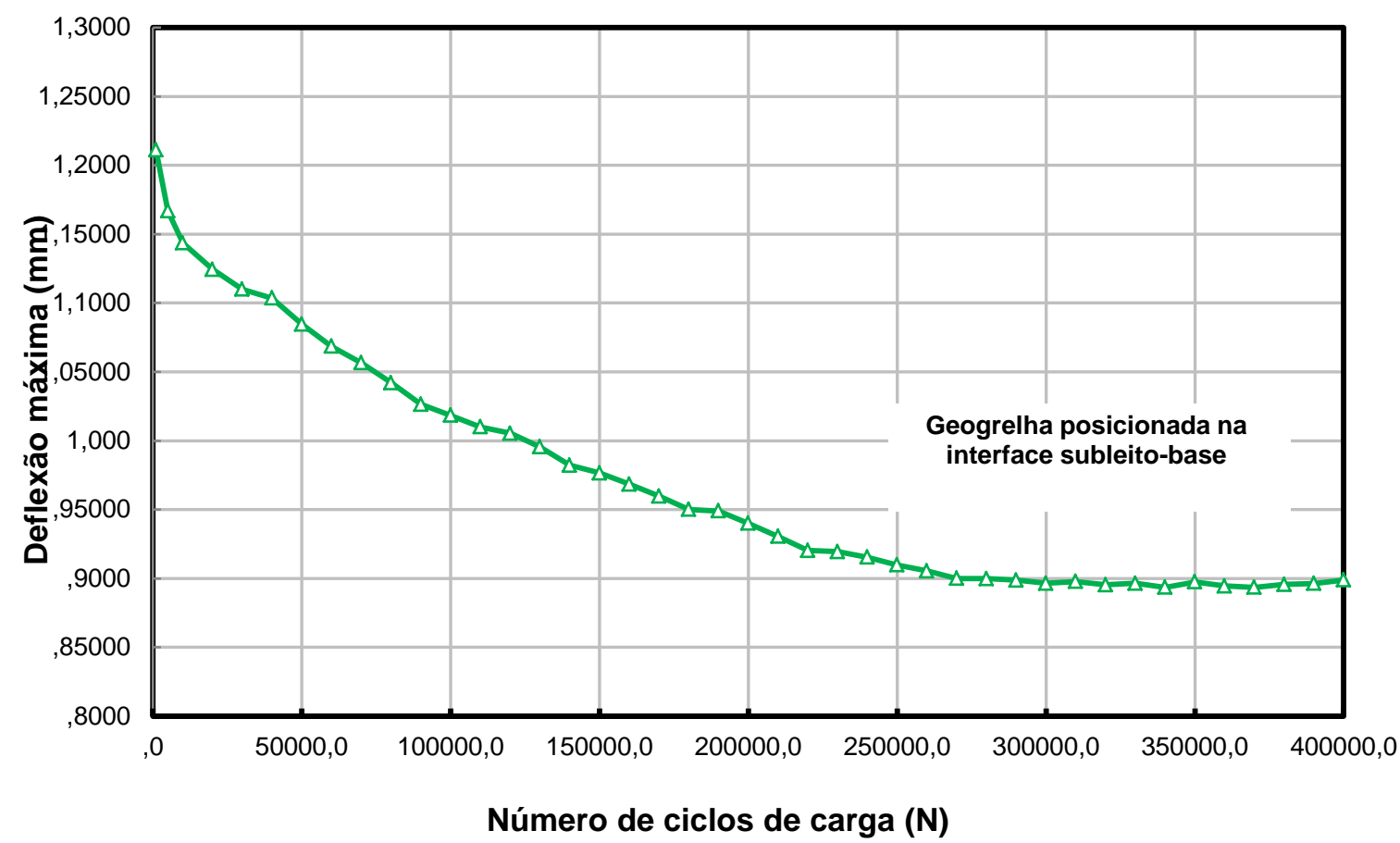

Figura 4.18 - Deflexão máxima em função do número de ciclos de carga com a geogrelha posicionada na interface subleito-base

Analisando-se as bacias de deflexão apresentadas na Figura 4.17, observase que as deflexões diminuem com o aumento do número de ciclos de carga. $A$ tendência do desenvolvimento das deflexões segue o mesmo padrão apresentado no ensaio sem a utilização da geogrelha.

Considerando-se a evolução das bacias com o número de ciclos de carga, observa-se nas Figuras 4.17 e 4.18 que a partir de 300.000 ciclos existe a convergência para um valor único, a partir do qual o processo estabiliza-se. Comparando-se as deflexões máximas para 1.000 e 400.000 ciclos de carga, observa-se uma redução de $25 \%$ no seu valor.

Comparando o número de aplicações para a convergência da deflexão máxima no ensaio sem e com a utilização do reforço, verifica-se que a estabilização 
do valor da deflexão máxima para o ensaio com utilização de geogrelha é atingida com uma redução de 50.000 ciclos.

Para condições de tensões aplicadas e propriedades mecânicas das geogrelhas similares às utilizadas nesta pesquisa, buscou-se levantar resultados da literatura para uma possível analogia com os resultados obtidos neste estudo. A Tabela 4.2 apresenta algumas das propriedades mecânicas mais relevantes da geogrelha utilizada nesta pesquisa e de geogrelhas utilizadas por por Perkins (1999), Woon-Hyung et al. (2005), Tingle and Jersey (2005) e Kinney et al. (1998).

Tabela 4.2 - Propriedades mecânicas das geogrelhas utilizadas como reforço de base nesta pesquisa e na literatura

\begin{tabular}{ccccccc}
\hline $\begin{array}{c}\text { Propriedades } \\
\text { da geogrelha }\end{array}$ & Unidades & $\begin{array}{c}\text { Nesta } \\
\text { pesquisa }\end{array}$ & $\begin{array}{c}\text { Perkins } \\
(1999)\end{array}$ & $\begin{array}{c}\text { Tingle and } \\
\text { Jersey } \\
(2005)\end{array}$ & $\begin{array}{c}\text { Woon- } \\
\text { Hyng et } \\
\text { al. } \\
(2005)\end{array}$ & $\begin{array}{c}\text { Kinney et } \\
\text { al. (1998) }\end{array}$ \\
\hline $\begin{array}{c}\text { Polímero } \\
\text { Gramatura }\end{array}$ & $\mathrm{g} / \mathrm{m}^{2}$ & 240 & 215 & 305 & 253 & - \\
$\begin{array}{c}\text { Abertura da } \\
\text { malha }\end{array}$ & $\mathrm{Mm}$ & $40 / 40$ & $25 / 33$ & $25,4 / 33$ & 32 & $15,2 / 9,5$ \\
$\begin{array}{c}\text { Resistência } \\
\text { última }\end{array}$ & $\mathrm{kN} / \mathrm{m}$ & $30 / 30$ & $13 / 20$ & $17,9 /$ & & \\
\hline
\end{tabular}

$\left.{ }^{*}\right)$ PP: polipropileno; PE: polietileno

Perkins (1999), Woon-Hyung et al. (2005), Tingle and Jersey (2005), e Kinney et al. (1998) obtiveram, respectivamente, deflexões máximas aproximadas de 2,2, 4,4, 3,1 e $0,9 \mathrm{~mm}$. Sendo os três primeiros valores obtidos para um número de ciclos de 50.000, 10.000 e 5.000, respectivamente, e o último para um ensaio de FWD. As configurações dos ensaios e os materiais utilizados nos trabalhos apresentados pelos autores citados estão apresentados no item 4.3.1.1, diferindo apenas na utilização do reforço no topo do subleito. 
Comparando-se a deflexão máxima obtida nesta etapa da pesquisa para $50.000,10.000$ e 5.000 ciclos de carga, 1,08, 1,14 e 1,17mm, respectivamente, com as fornecidas pela literatura para iguais números de ciclos, observa-se que as mesmas são da ordem de 1/2, 1/4 e 1/3 das relatadas pelos três primeiros autores. Com relação à deflexão determinada por Kinney et al (1998), esta coincide com a determinada nesta pesquisa, $0,9 \mathrm{~mm}$, após a estabilização das deflexões, a partir de 300.000 ciclos de carga. Supõe-se que os maiores valores observados na literatura devam-se ao fato do subleito utilizado nesta presente pesquisa apresentar comportamento muito superior aos dos utilizados pelos autores citados, conforme já discutido no item 4.3.1.1. Destaca-se que em todas as pesquisas citadas na Tabela 4.2, a utilização da geogrelha no topo do subleito conduziu a uma redução significativa na deflexão máxima, igualmente ao observado nesta pesquisa. $O$ efeito da inserção do reforço será discutido de maneira detalhada no item 4.3.4, onde serão comparados os resultados obtidos para as três estruturas de pavimentos estudadas.

\subsubsection{Análise das deformações permanentes na superfície com a utilização da geogrelha posicionada na interface subleito-base e subleito na umidade ótima de compactação}

As deformações permanentes desenvolvidas durante a realização do ensaio foram determinadas na superfície do pavimento sob a placa de carregamento. A 
Figura 4.19 apresenta o desenvolvimento do recalque com o número de ciclos de carga e as curvas correspondentes aos modelos das equações 4.5 e 4.6 cujas aplicações serão discutidas posteriormente.

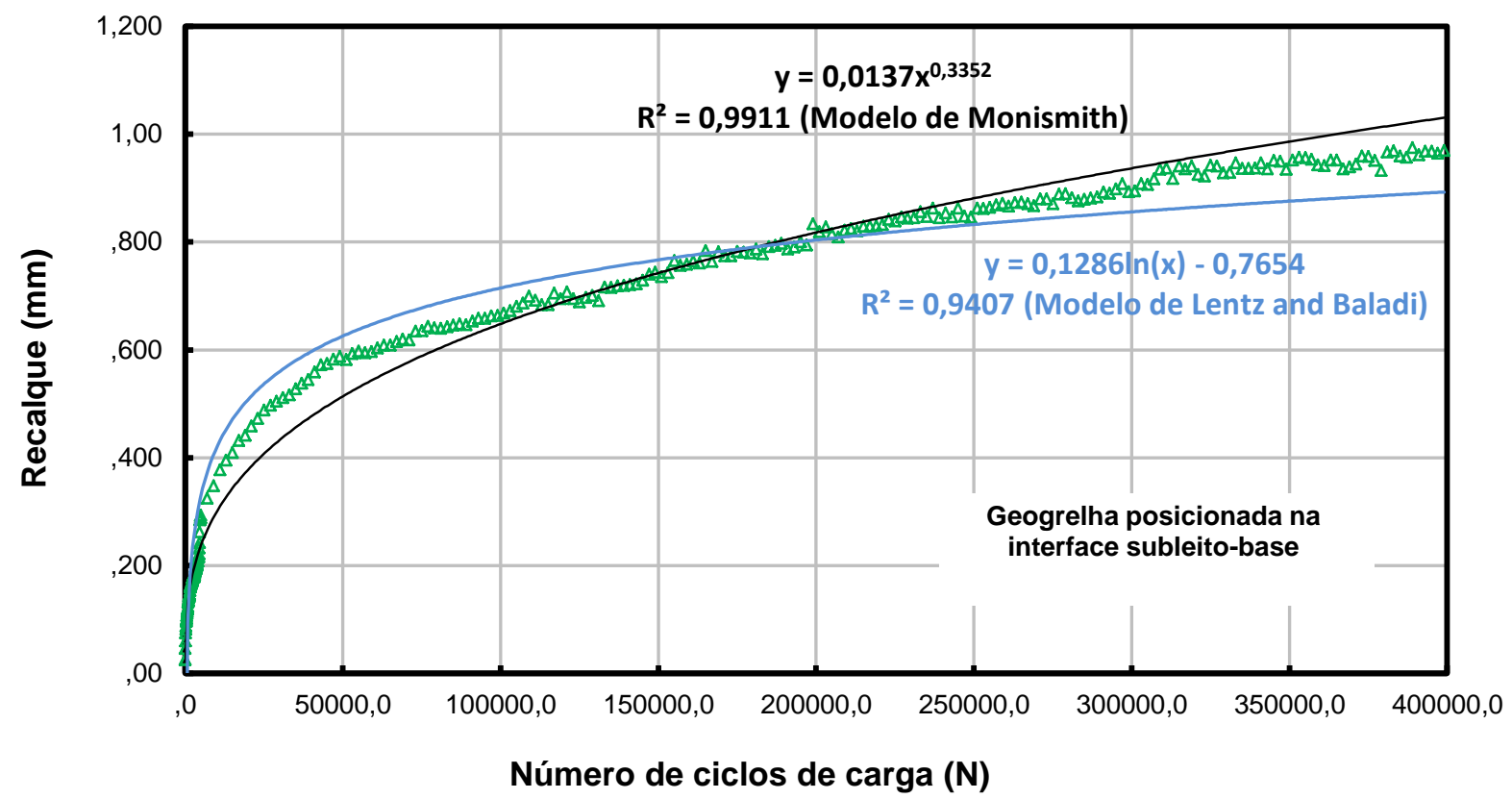

Figura 4.19 - Recalque em função do número de ciclos de carga com a geogrelha posicionada na interface subleito-base e os modelos correspondentes as equações 4.5 e 4.6

Analisando-se o desenvolvimento do recalque em função do número de ciclos de carga, conforme apresentado na Figura 4.19, observa-se que a taxa de crescimento do recalque é mais acentuado nos primeiros 10.000 ciclos de carga, onde se atinge $30 \%$ do recalque total. Verifica-se ainda, que o recalque estabiliza-se quando o ensaio atinge 350.000 ciclos de carga, quando se alcança um recalque máximo de $0,9 \mathrm{~mm}$.

Conforme discutido anteriormente, foram aplicados os modelos de Monismith et al. (1975) e Lentz and Baladi (1981) na representação da variação das deformações permanentes com o numero de ciclos de carga, sendo obtidas as 
equações 4.5 e 4.6, respectivamente. Analisando-se o desempenho destes dois modelos observa-se, que neste caso, ao contrário do verificado para a condição sem reforço, ambos representam bem a variação das deformações permanentes ao longo de todo o ensaio.

$$
\begin{array}{cc}
\varepsilon_{\mathrm{P}}=2 \cdot 10^{-5} \cdot \mathrm{N}^{0,3352} & \mathrm{R}^{2}=0,98 \\
\mathcal{E}_{\mathrm{P}}=0,0002 \cdot \mathrm{Ln} \mathrm{N}-0,0011 & \mathrm{R}^{2}=0,94
\end{array}
$$

Em que: $\quad \varepsilon_{\mathrm{P}}=$ deformação permanente $(\%)$;

$\mathrm{N}=$ número de ciclos de carga.

Para tensões aplicadas em condições similares às desta pesquisa Perkins (1999), Tingle and Jersey (2005), Jianjun and Mohammed (2002), Woon-Hyung et al. (2006) e Kinney et al. (1998) obtiveram recalques de, respectivamente, 20, 75, 40, 20 e $12 \mathrm{~mm}$, para um número de ciclos de 400.000, 10.000, 10.000, 1.000 e 2.160, tomados na mesma ordem dos recalques.

Comparando-se os recalques obtidos nesta etapa da presente pesquisa para 400.000, 10.000, 1.000 e 2.160 ciclos de carga, 0,9, 0,4, 0,2 e 0,3mm, respectivamente, com os fornecidos na literatura, observa-se que na média, os mesmos são 76 vezes menores. Esta discrepância, conforme já discutido anteriormente, deve-se ao fato de na literatura considerarem-se subleitos piores que o da presente pesquisa.

Analisando-se o desenvolvimento das deformações permanentes segundo a teoria de shakedown, a Figura 4.20 mostra a curva obtida para o modelo de 
Wekmeister et al. (2001), onde se observa que o pavimento encontra-se em shakedown.

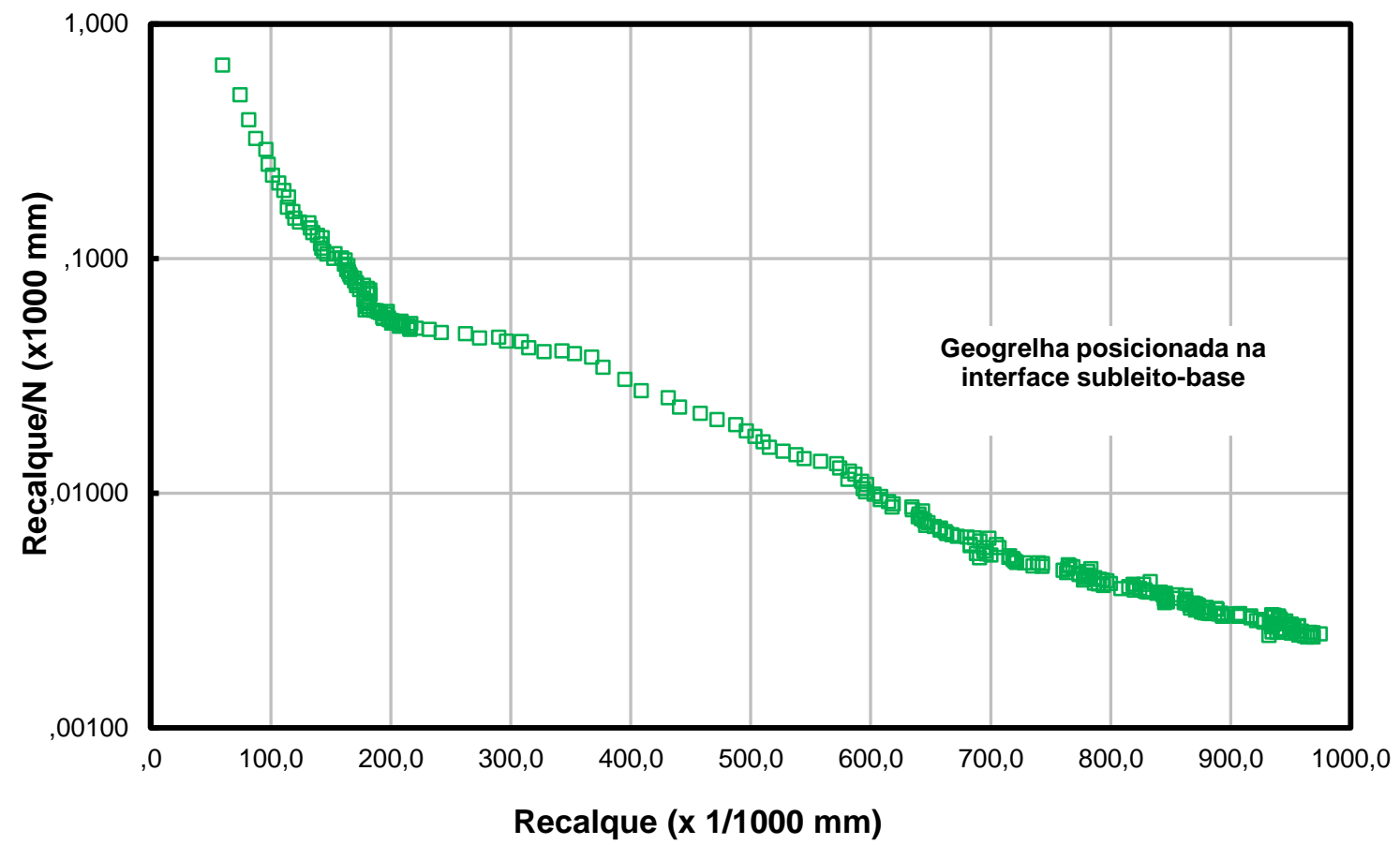

Figura 4.20 - Enquadramento no Modelo de Wekmeister et al. (2001) do ensaio com geogrelha na interface subleito-base

4.3.2.3 Análise das deformações elásticas na superfície com a utilização da geogrelha posicionada na interface subleito-base após o umedecimento do subleito

Esta etapa do ensaio foi realizada após o término da etapa apresentada no item 4.3.2.2, mantendo-se a estrutura de pavimento inalterada e inundando-se o subleito por ascensão capilar. Nesta etapa, foi observado um intervalo de dez dias 
após o início do umedecimento para a realização do ensaio com a finalidade de garantir uma melhor homogeneização da umidade ao longo do perfil do subleito.

Após o umedecimento foram aplicados 100.000 ciclos de carga, nas mesmas condições apresentadas no item anterior. Ao final do ensaio foram coletadas amostras de solo ao longo do perfil do subleito e determinadas as respectivas umidades, conforme apresentado na Figura 4.21.

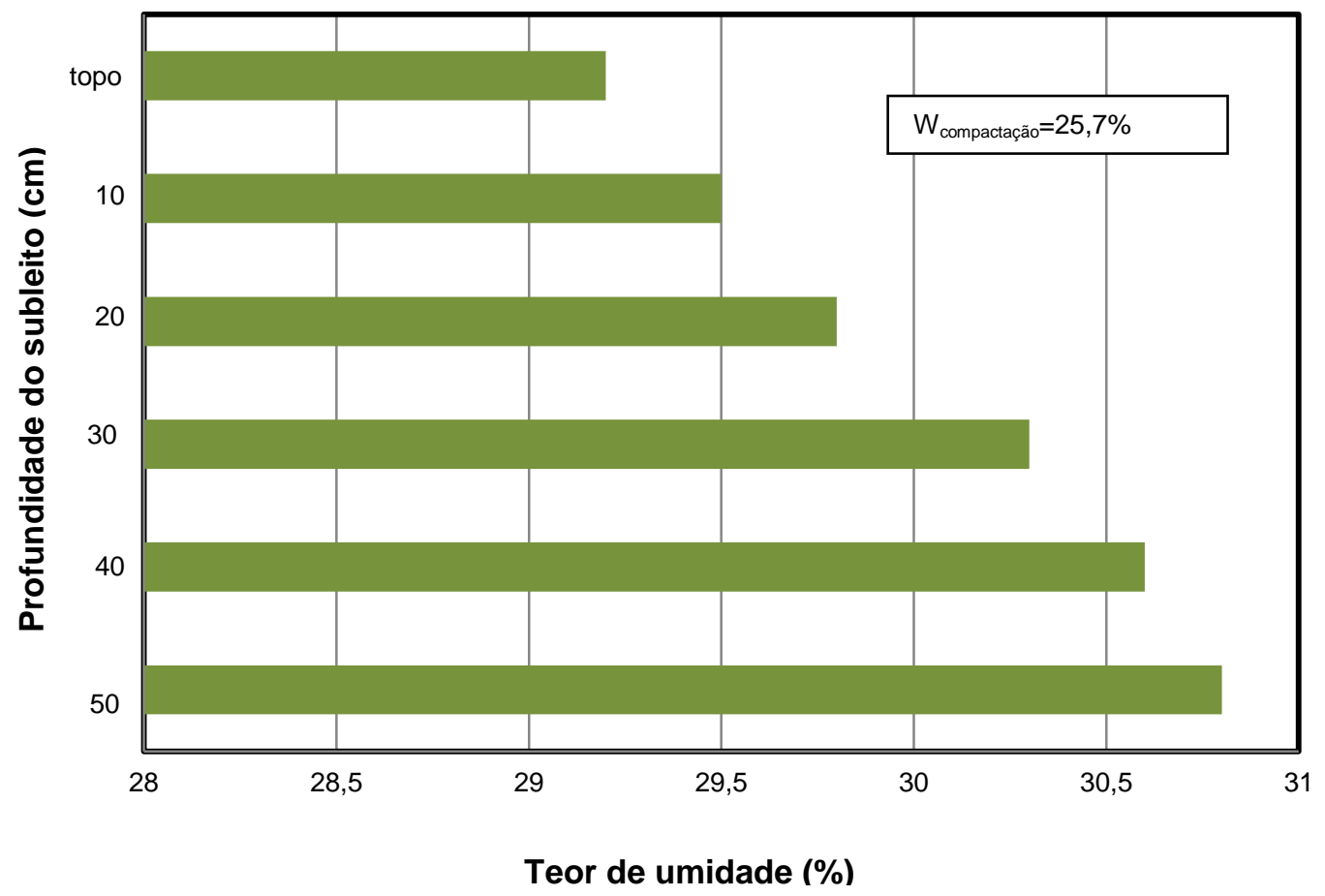

Figura 4.21- Variação do teor de umidade com a profundidade do subleito após o umedecimento, ensaio com geogrelha na interface

Analisando a umidade ao longo do subleito conforme apresentado na Figura 4.21, observa-se que a mesma é crescente da maior para a menor profundidade, variando de $32 \%$ a $30 \%$. Tomando-se a média de todos os teores, igual a $31 \%$, ocorreu uma variação da umidade a partir da umidade de compactação, igual a $25,7 \%$, de $5,3 \%$. Com relação ao grau de saturação, este variou de $83 \%$ para $99 \%$, considerando-se a umidade ótima e a média das umidades após o umedecimento, 
respectivamente. Assim, neste caso alcançou-se um umedecimento ligeiramente maior que o do item 4.3.1.3, onde o grau de saturação final foi de $98 \%$.

As Figuras 4.22 e 4.23 apresentam as bacias de deflexão para 1.000, 10.000, 50.000 e 100.000 ciclos de carga e a variação da deflexão máxima com o número de carregamentos, sendo que para esta última figura, também foi incluído o resultado da etapa sem umedecimento do subleito.

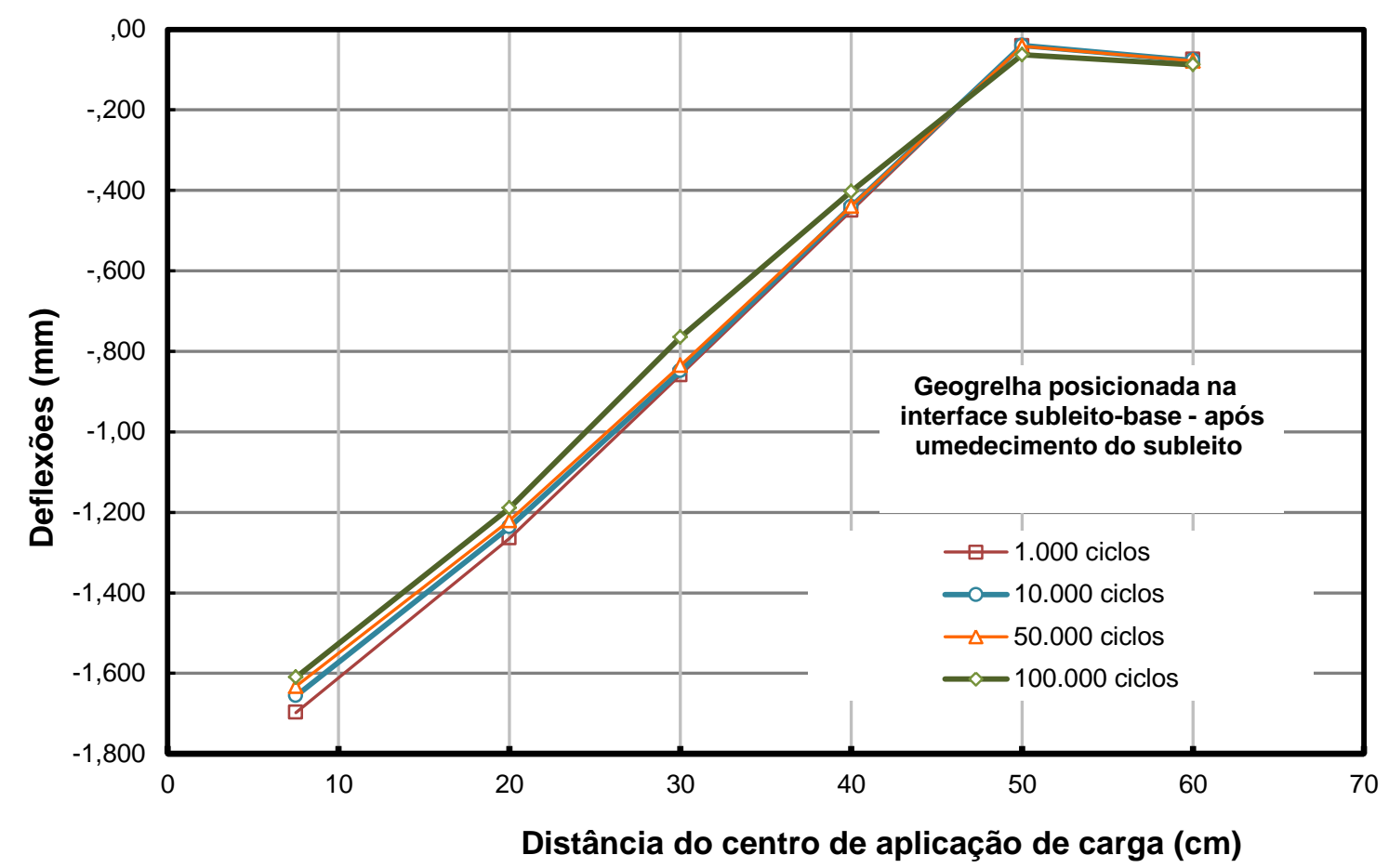

Figura 4.22 - Bacia de deflexão obtida em diferentes ciclos de carga com a utilização da geogrelha posicionada na interface, situação após o umedecimento do subleito 


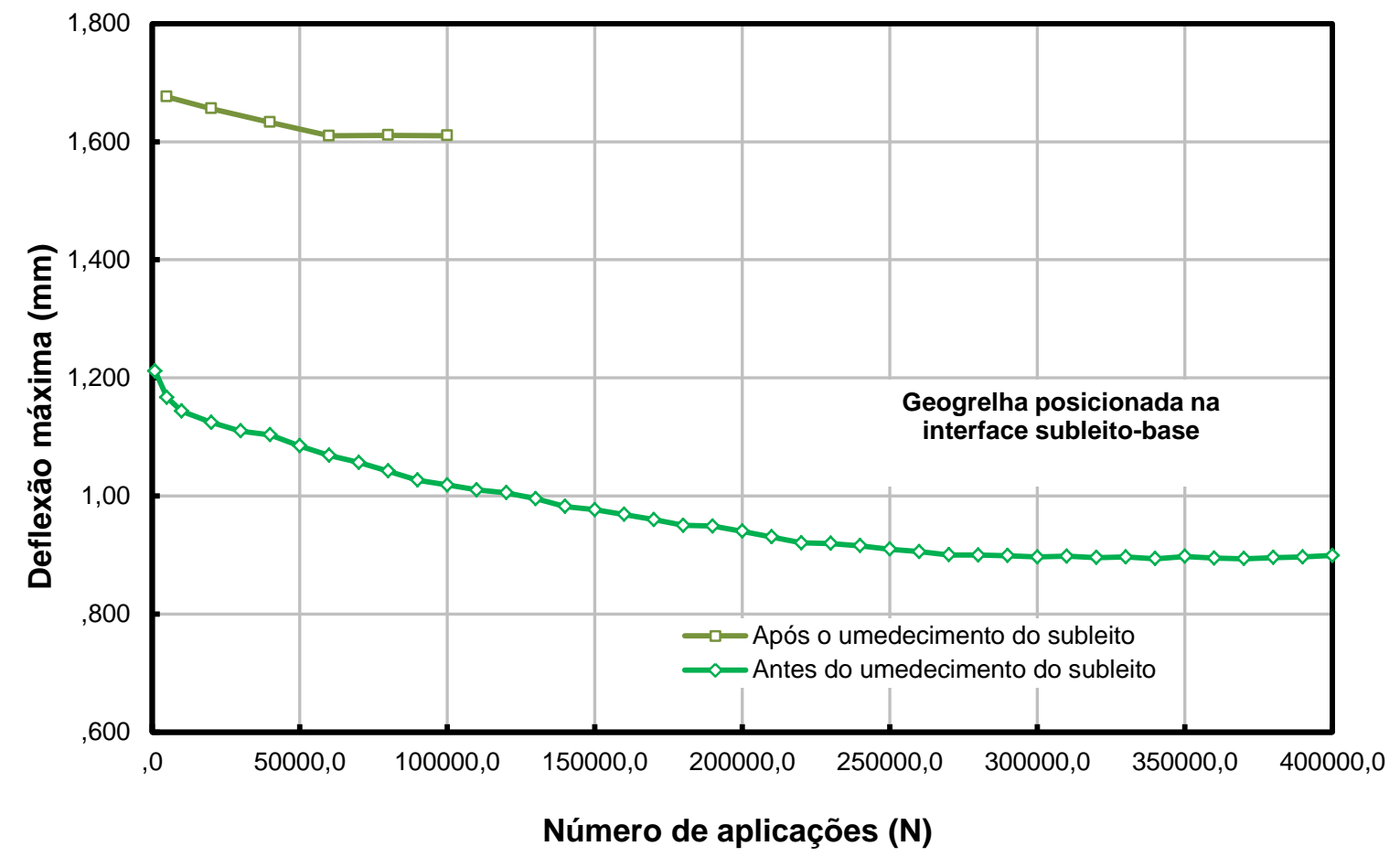

Figura 4.23 - Deflexão máxima em função do número de ciclos de carga, com a utilização da geogrelha na interface na condição antes e após o umedecimento do subleito

Analisando-se as Figuras 4.22 e 4.23, observa-se que as deflexões crescem com o aumento do número de ciclos de carga, mas estabilizam-se a partir de 60.000 ciclos, ao contrário do observado para a condição sem geogrelha, onde a estabilização não é alcançada para 100.000 ciclos, número máximo de ciclos aplicados. A Figura 4.24 apresenta conjuntamente as bacias de deflexão obtidas sem umedecimento e após umedecimento para 400.000 e 100.000 ciclos de carga, respectivamente, quando já se alcançou a estabilização das deflexões. Comparando-se as deflexões máximas obtidas para as condições com e sem umedecimento, 1,6 e 0,9mm, respectivamente, a primeira é 1,8 vezes maior que a segunda, fato decorrente da diminuição da rigidez do subleito. Esta relação é próxima à obtida para estrutura sem reforço, igual a 1,6mm. 


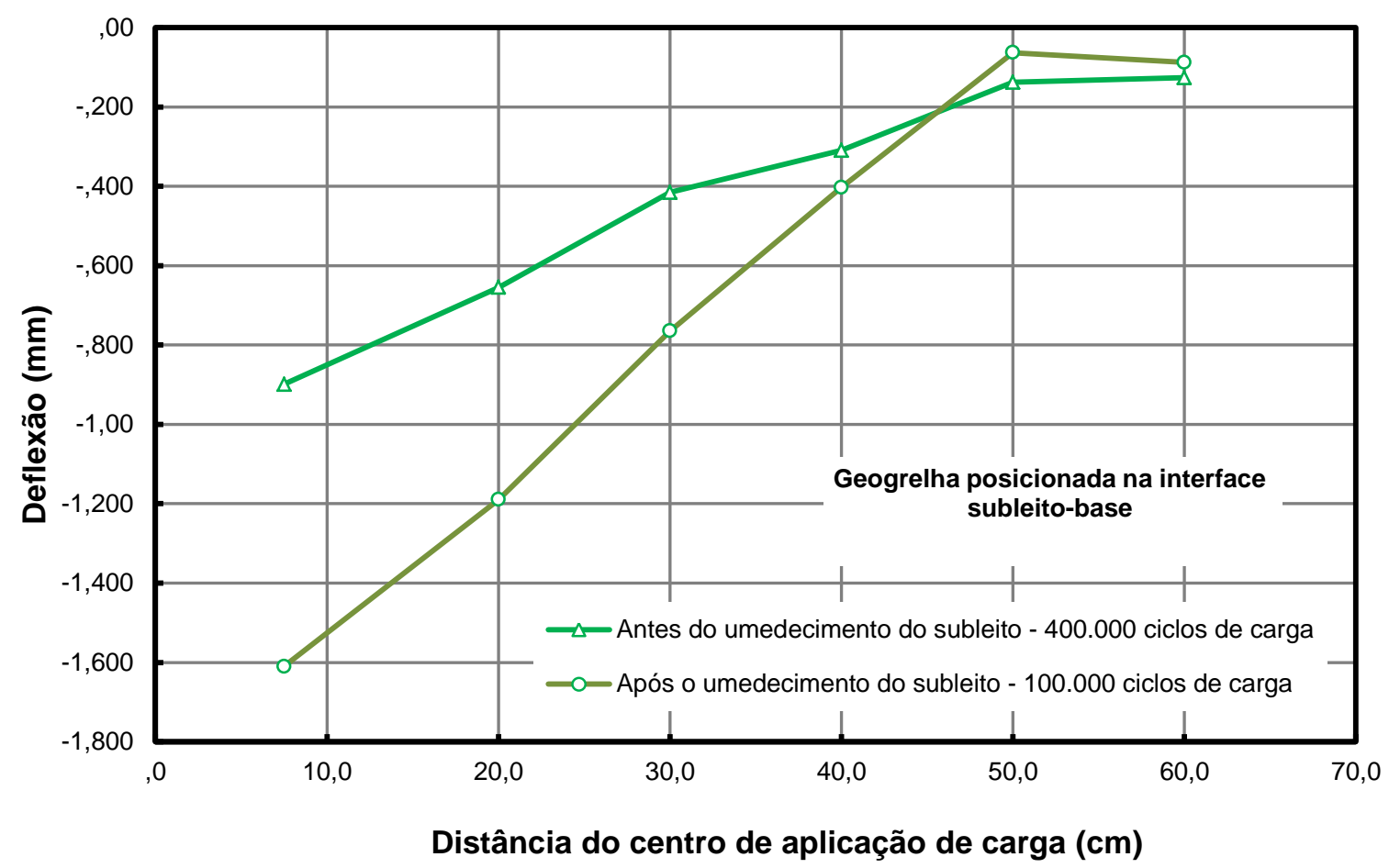

Figura 4.24 - Bacia de deflexão com a utilização da geogrelha na interface na condição antes e após o umedecimento do subleito

4.3.2.4 Análise das deformações permanentes na superfície, com a utilização da geogrelha posicionada na interface subleito-base após o umedecimento do subleito

As deformações permanentes desenvolvidas durante a realização do ensaio foram determinadas na superfície do pavimento sob a placa de carregamento. A Figura 4.25 apresenta o desenvolvimento do recalque com o número de ciclos de carga antes e após o umedecimento do subleito e ainda as curvas correspondentes aos modelos das equações 4.7 e 4.8 cujas aplicações serão discutidas posteriormente. 


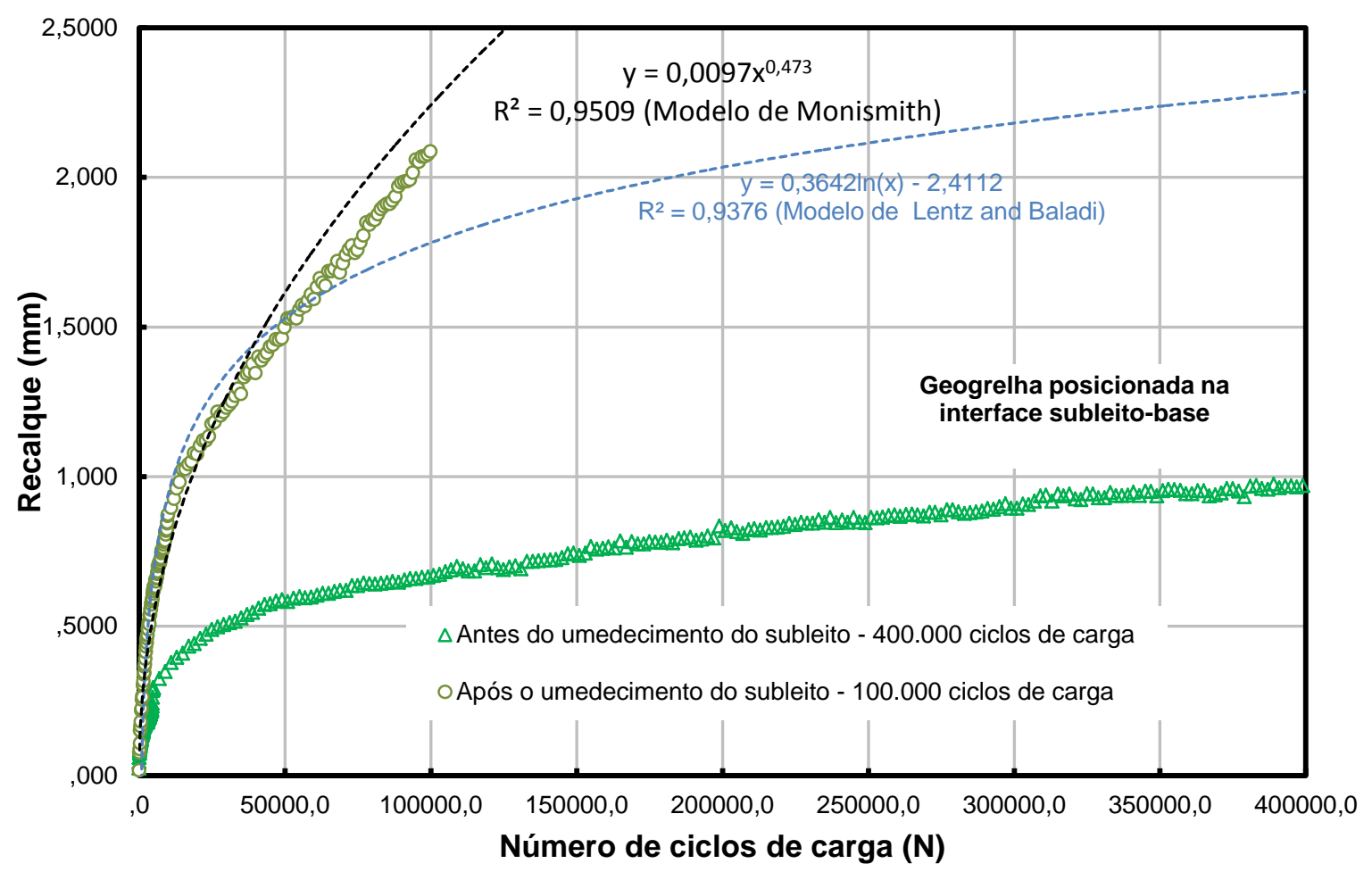

Figura 4.25 - Recalque em função do número de ciclos de carga, com a utilização da geogrelha posicionada na interface na condição antes e após o umedecimento do subleito e os modelos correspondentes as equações 4.7 e 4.8

Analisando-se o desenvolvimento do recalque em função do número de ciclos de carga, conforme apresentado na Figura 4.25, observa-se, que após o umedecimento do subleito e para 100.000 ciclos de carga ainda não se alcançou a estabilização das deformações permanentes. Se aos pontos experimentais forem ajustados os modelos de Monismith et al. (1975) e Lentz e Baladi (1981), conforme discutido anteriormente, obtém-se as equações 4.7 e 4.8 , respectivamente. Para esta condição, observa-se que o modelo de Lentz and Baladi (1981), eq. 4.7, apesar de representar bem os pontos experimentais até 50.000 ciclos de carga, não reproduz a tendência do ensaio, que mesmo para 100.000 ciclos não mostra um indicativo da acomodação das deformações permanentes. Neste aspecto, o modelo de Monismith (1975), eq. 4.8, representaria melhor o comportamento observado, apesar de superestimar o valor dos recalques. 


$$
\begin{array}{cc}
\varepsilon_{P}=1 \cdot 10^{-5} \cdot N^{0,473} & \mathrm{R}^{2}=0,95 \\
\varepsilon_{P}=0,0005 . \operatorname{Ln} N-0,0034 & \mathrm{R}^{2}=0,94
\end{array}
$$

Em que: $\quad \varepsilon_{P}=$ deformação permanente (\%);

$\mathrm{N}=$ número de ciclos de carga.

Comparando-se os recalques obtidos sem umedecimento e após umedecimento do subleito para 100.000 ciclos de carga, número de ciclos comum aos dois ensaios, conforme a Figura 4.25, observa-se que o recalque é igual a $0,7 \mathrm{~mm}$ e 2,2mm, respectivamente, para a primeira e segunda condições. Portanto, o umedecimento conduz a um aumento da deformação plástica da ordem de 3 vezes. Aplicando-se o modelo da equação 4.7 que melhor se adéqua ao comportamento após umedecimento, obtém-se por extrapolação, o valor de $3 \mathrm{~mm}$ para o recalque correspondente a 400.000 ciclos de carga. Comparando-se este valor com o obtido sem o umedecimento, $1 \mathrm{~mm}$, a relação entre os mesmo é igual à determinada para 100.000 ciclos.

Conclui-se que a variação da umidade do subleito proporcionou um aumento tanto na deformação permanente quanto na deformação elástica, sendo esse aumento proporcionado pela perda de rigidez do subleito devido elevação do teor de umidade. Quanto à utilização da geogrelha na interface subleito-base pôde-se observar uma redução significativa tanto nas deflexões como nos recalques. Os benefícios decorrentes da utilização do reforço serão detalhados no item 4.4. 


\subsubsection{Ensaio com a utilização de geogrelha no horizonte médio da base}

Neste ensaio procurou-se manter as mesmas configurações dos ensaios apresentados no item 4.3.1 e 4.3.2, diferindo-se do item 4.3.2 apenas na posição da geogrelha, sendo esta posicionada no horizonte médio da camada de base. Nos itens 4.3.3.1 e 4.3.3.2 são analisados as deformações elásticas e permanentes, respectivamente, para a condição em que o subleito encontra-se na umidade ótima de compactação, e no item 4.3.3.3 e 4.3.3.4, são analisadas as deformações elásticas e permanentes, respectivamente, para a condição após a inundação do subleito.

\subsubsection{Análise das deformações elásticas na superfície com a utilização da geogrelha posicionada no horizonte médio da base e subleito na umidade ótima de compactação}

As Figuras 4.26 e 4.27 apresentam, respectivamente, as bacias de deflexões para $50.000,100.000,200.000,300.000$ e 400.000 ciclos de carga e a variação da deflexão máxima com o número de carregamentos. 


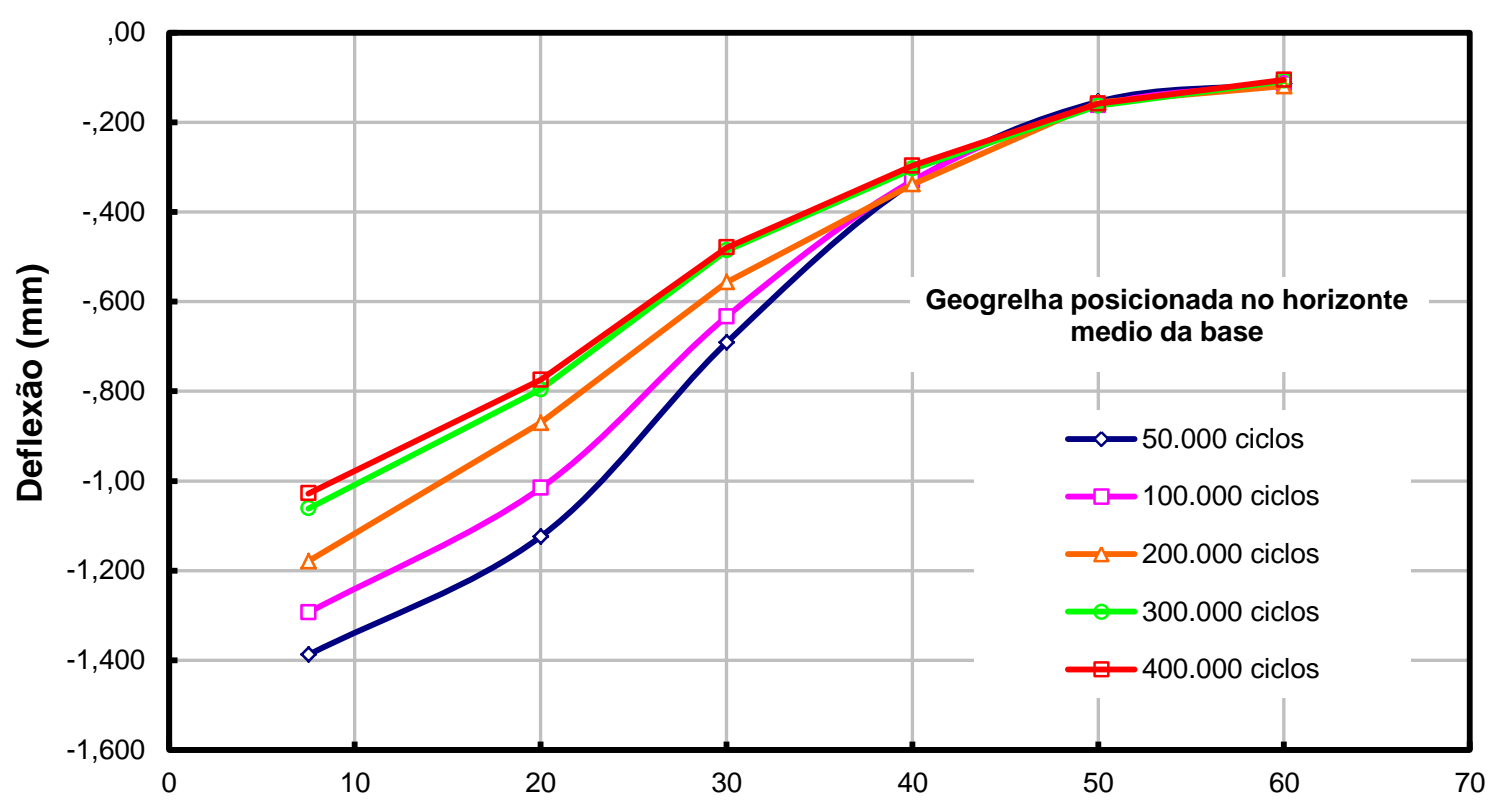

Distância do centro de aplicação de carga (cm)

Figura 4.26 - Bacia de deflexão obtida em diferentes ciclos de carga com a utilização da geogrelha posicionada no horizonte médio da camada de base

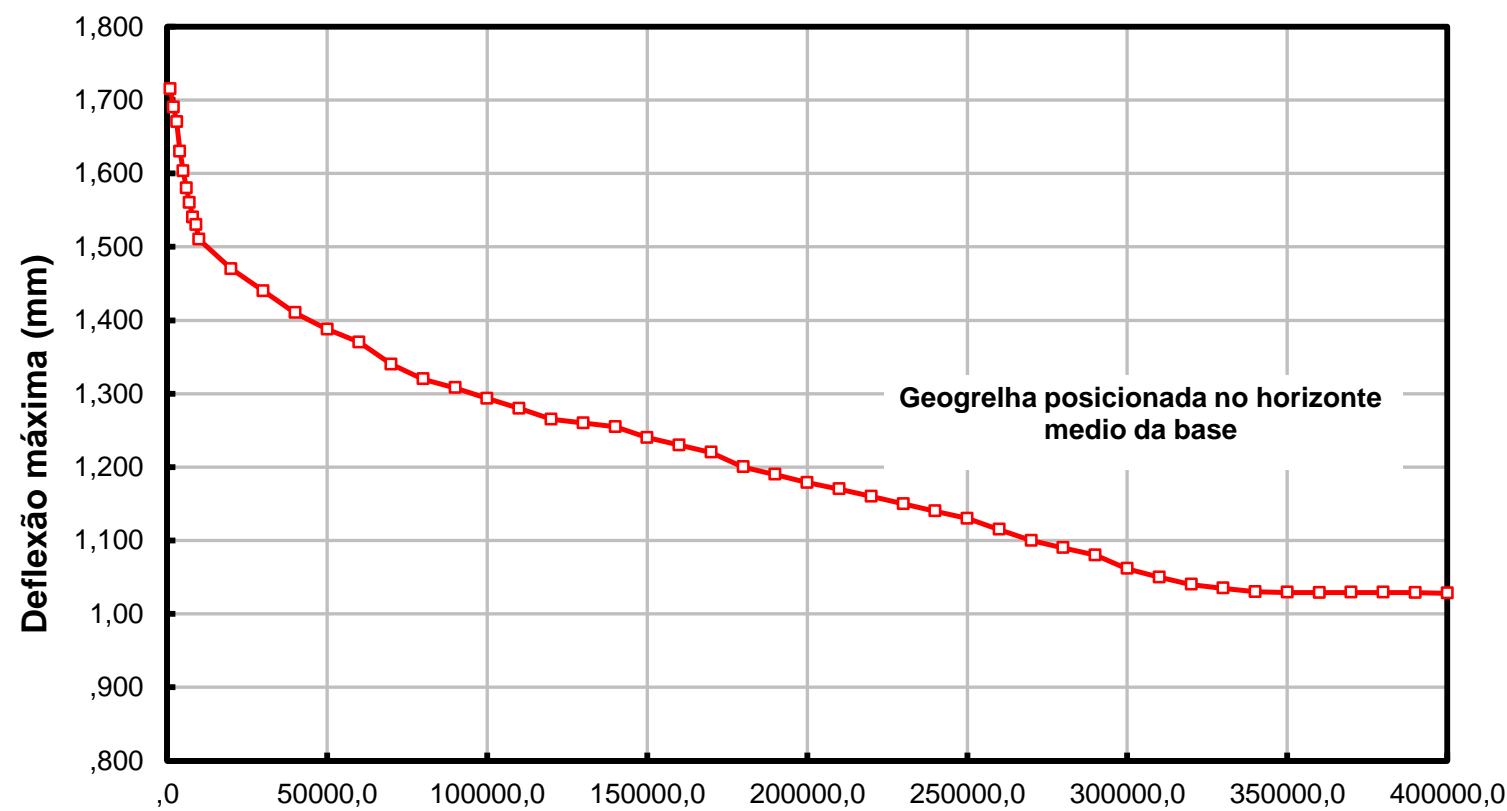

Número de ciclos de carga (N)

Figura 4.27 - Deflexão máxima em função do número de ciclos de carga com a geogrelha posicionada no horizonte médio da camada de base

Analisando-se as bacias de deflexão apresentadas na Figura 4.26, observase que as deflexões diminuem com o aumento do número de ciclos de carga. A 
tendência do desenvolvimento das deflexões segue o mesmo padrão apresentado nos ensaio sem a utilização de reforço e com a geogrelha posicionada na interface subleito-base.

Considerando-se a evolução das bacias com o número de ciclos de carga, observa-se nas Figuras 4.26 e 4.27 que a partir de 350.000 ciclos existe a convergência para um valor único, a partir do qual o processo estabiliza-se. Comparando-se as deflexões máximas para 1.000 e 400.000 ciclos de carga, observa-se uma redução de $40 \%$ no seu valor.

Comparando o número de aplicações para a convergência da deflexão máxima no ensaio com a geogrelha posicionada na interface subleito-base e no horizonte médio da camada de base, verifica-se que a estabilização do valor de deflexão máxima para ambos os ensaios se dá a partir de 350.000 ciclos de carga.

\subsubsection{Análise das deformações permanentes na superfície com a utilização da geogrelha posicionada no horizonte médio da base e subleito na umidade ótima de compactação}

As deformações permanentes desenvolvidas durante a realização do ensaio foram determinadas da mesma forma apresentadas nos ensaios sem reforço e com reforço posicionado na interface subleito-base. A Figura 4.28 apresenta o desenvolvimento do recalque com o número de ciclos de carga e as curvas correspondentes aos modelos das equações 4.9 e 4.10 cujas aplicações serão discutidas posteriormente. 


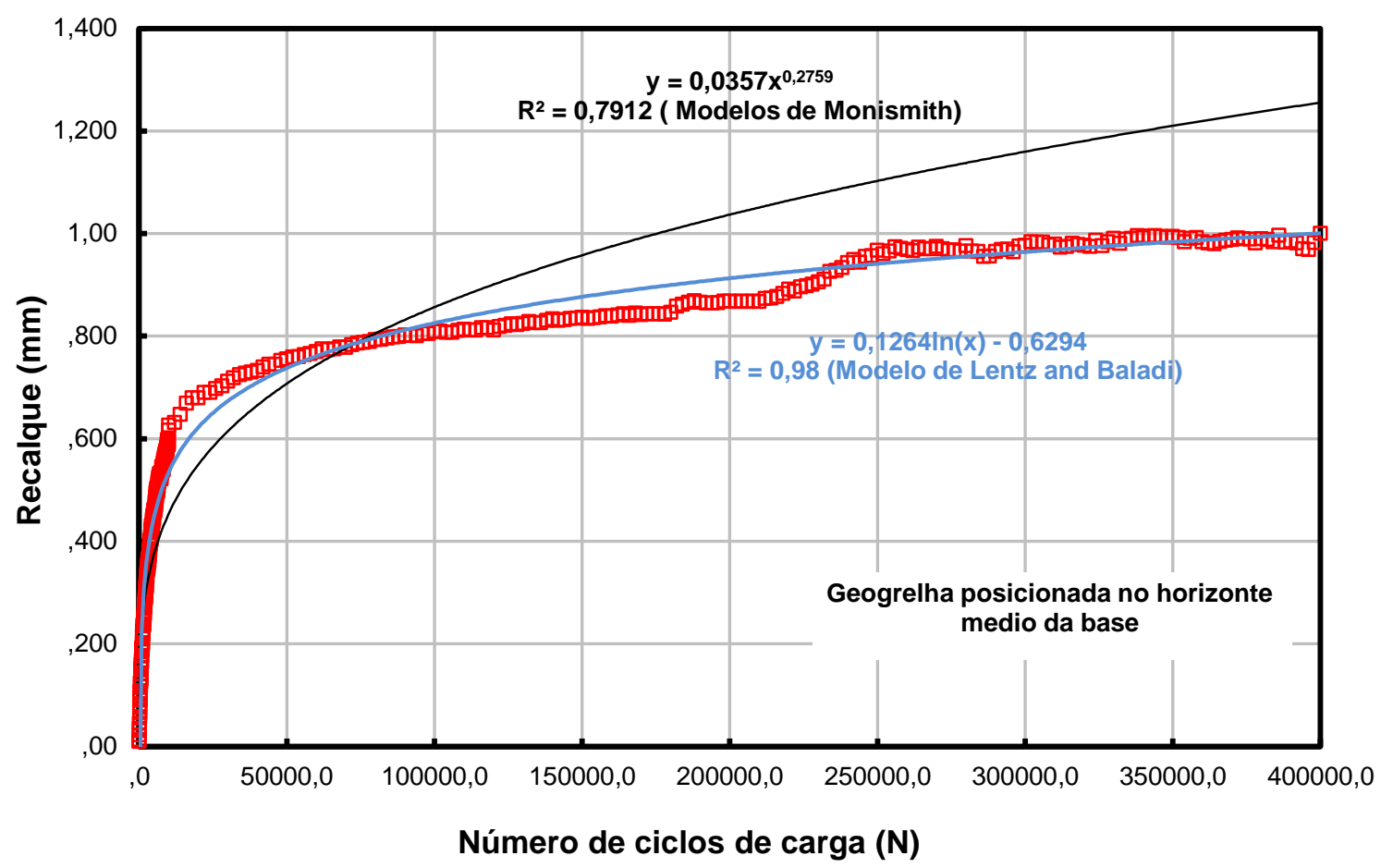

Figura 4.28 - Recalque em função do número de ciclos de carga com a geogrelha posicionada no horizonte médio da camada de base e os modelos correspondentes as equações 4.9 e 4.10

Analisando-se o desenvolvimento do recalque em função do número de ciclos de carga, conforme apresentado na Figura 4.28, observa-se que a taxa de crescimento do recalque é mais acentuado nos primeiros 10.000 ciclos de carga, onde se atinge $60 \%$ do recalque total. Verifica-se ainda, que o recalque estabiliza-se quando o ensaio atinge 300.000 ciclos de carga, quando se alcança um recalque máximo de 1,0mm.

Conforme discutido anteriormente, foram aplicados os modelos de Monismith et al. (1975) e Lentz and Baladi (1981) na representação da variação das deformações permanentes com o número de ciclos de carga, sendo obtidas as equações 4.9 e 4.10, respectivamente. Analisando-se o desempenho destes dois 
modelos observa-se, que neste caso, o modelo de Lentz and Baladi (1981) representou bem a variação das deformações permanentes.

$$
\begin{array}{rr}
\varepsilon_{\mathrm{P}}=5 \cdot 10^{-5} \cdot \mathrm{N}^{0,2759} & \mathrm{R}^{2}=0,80 \\
\varepsilon_{\mathrm{P}}=0,0002 . \text { Ln N }-0,0009 & \mathrm{R}^{2}=0,98
\end{array}
$$

Em que: $\quad \varepsilon_{P}=$ deformação permanente $(\%)$;

$\mathrm{N}=$ número de ciclos de carga .

Analisando-se o desenvolvimento das deformações permanentes segundo a teoria de shakedown, a Figura 4.29 mostra a curva obtida para o modelo de Wekmeister et al. (2001), onde se observa que o pavimento encontra-se em shakedown.

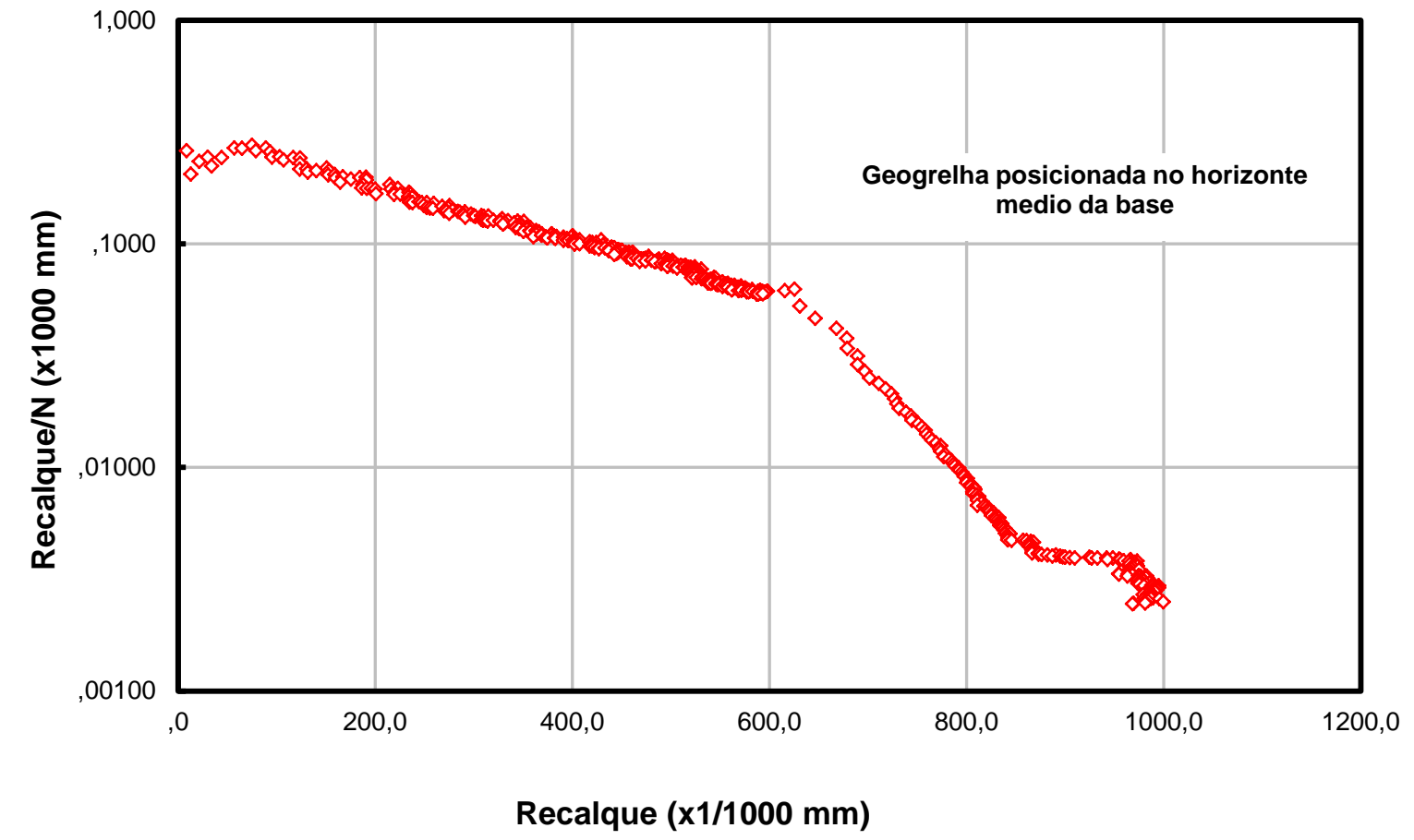

Figura 4.29 - Enquadramento no Modelo de Wekmeister et al. (2001) do ensaio com geogrelha na interface subleito-base 


\subsubsection{Análise das deformações elásticas na superfície com a utilização da geogrelha posicionada no horizonte médio da base na condição após o umedecimento do subleito após o umedecimento do subleito}

Esta etapa do ensaio foi realizada após o término da etapa apresentada no item 4.3.3.2, mantendo-se a estrutura de pavimento inalterada e inundando-se o subleito por ascensão capilar. Nesta etapa, foi observado um intervalo de dez dias após o início do umedecimento para a realização do ensaio com a finalidade de garantir melhor homogeneização da umidade ao longo do perfil do subleito.

Após o umedecimento foram aplicados 100.000 ciclos de carga, nas mesmas condições apresentadas no item anterior. Ao final do ensaio foram coletadas amostras de solo ao longo do perfil do subleito e determinadas as respectivas umidades, conforme apresentado na Figura 4.30. 


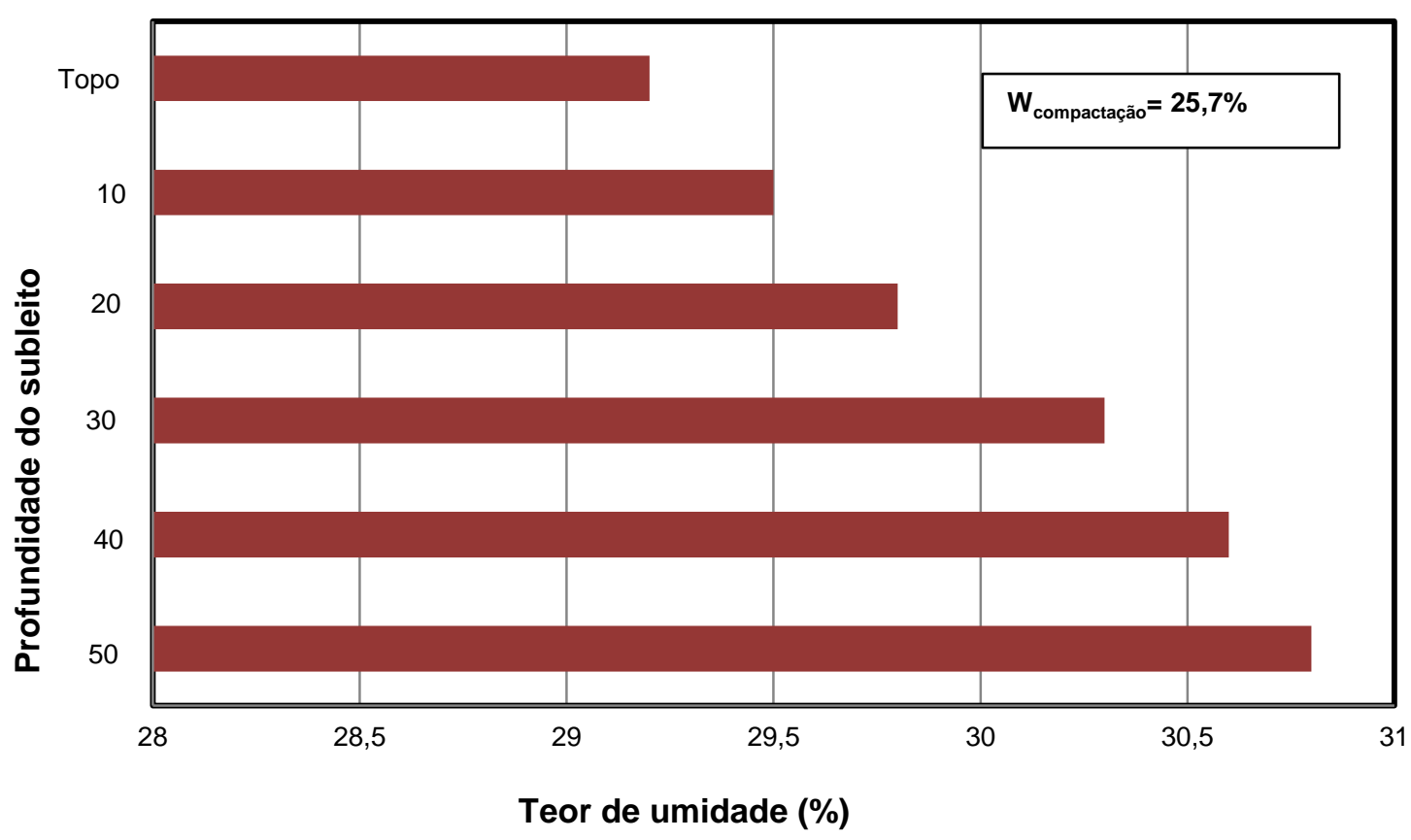

Figura 4.30 - Variação do teor de umidade com a profundidade do subleito após o umedecimento, ensaio com geogrelha na interface

Analisando a umidade ao longo do subleito conforme apresentado na Figura 4.30, observa-se que a mesma é crescente da maior para a menor profundidade, variando de $30,7 \%$ a $29,3 \%$. Tomando-se a média destes teores, igual a $30 \%$, ocorreu uma variação da umidade a partir da umidade de compactação, igual a $25,7 \%$, de 4,3\%. Com relação ao grau de saturação, este variou de $83 \%$ para $97 \%$, considerando-se a umidade ótima e a média das umidades após o umedecimento, respectivamente. Assim, neste caso alcançou-se um umedecimento ligeiramente inferior que dos itens 4.3.1.3 e 4.3.2.3, onde os graus de saturação final foram de 98 e $99 \%$, respectivamente.

As Figuras 4.31 e 4.32 apresentam as bacias de deflexão para 10.000, 50.000 e 100.000 ciclos de carga e a variação da deflexão máxima com o número de carregamentos, sendo que para esta última figura, também foi incluído o resultado da etapa sem umedecimento do subleito. 


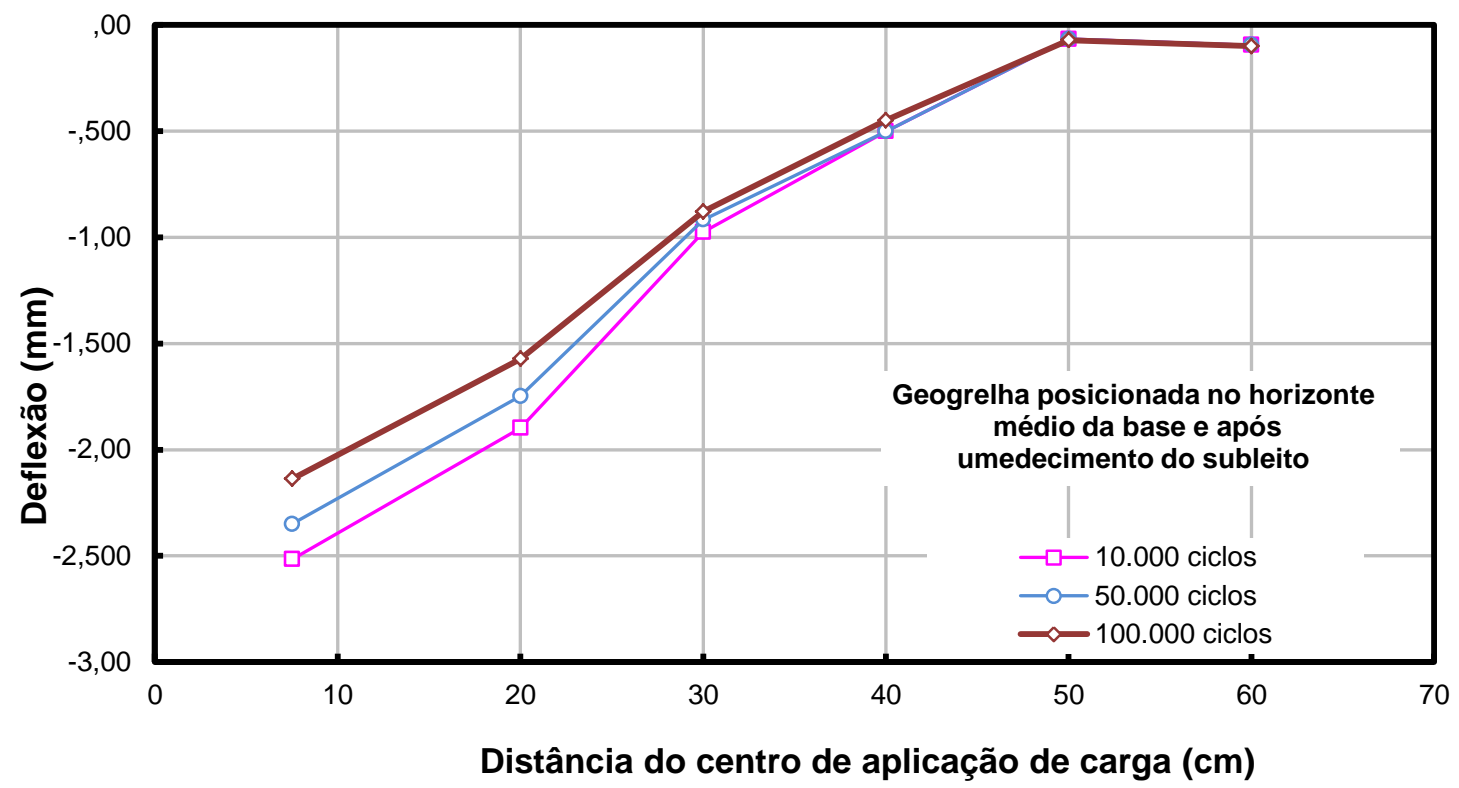

Figura 4.31 - Bacia de deflexão obtida em diferentes ciclos de carga, com a utilização da geogrelha posicionada no horizonte médio da camada de base, situação após o umedecimento do subleito

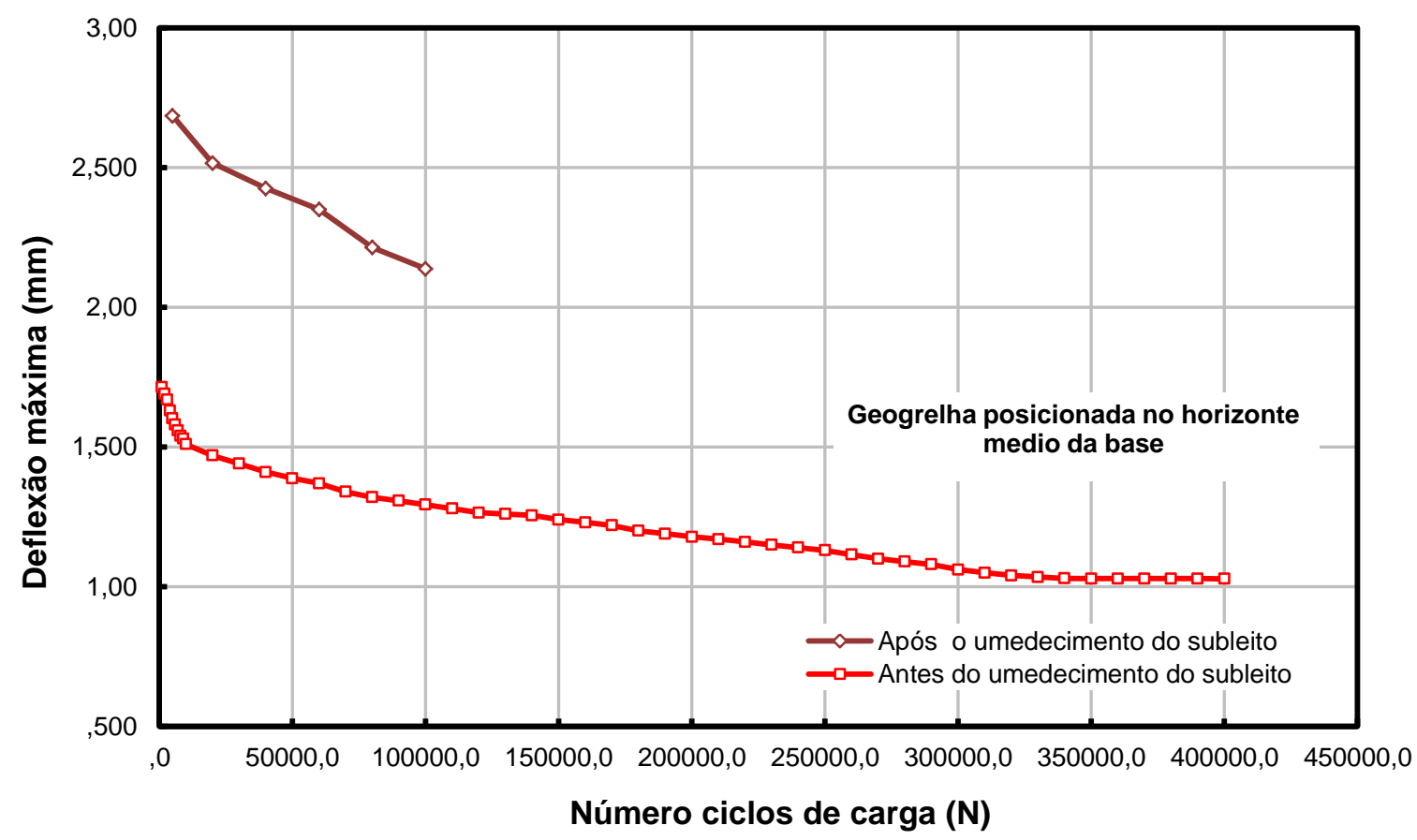

Figura 4.32 - Deflexão máxima em função do número de ciclos de carga, com utilização de geogrelha no horizonte médio da base na situação antes e após o umedecimento do subleito 
Analisando a Figura 4.31 e 4.32, observa-se que as deflexões crescem com o aumento do número de ciclos de carga para as situações sem umedecimento e após umedecimento, observa-se que nesta última condição, ainda não se alcançou a estabilização das deformações elásticas após 100.000 ciclos de carga, número máximo de ciclos aplicados. Possivelmente, se o desenvolvimento das deflexões após o umedecimento apresentasse o mesmo padrão de variação da etapa sem umedecimento, o valor de 2,2mm alcançado para 100.000 aplicações poderia reduzir-se a um valor próximo a 1,8mm, obtido por extrapolação.

A Figura 4.33 apresenta conjuntamente as bacias de deflexão obtidas sem umedecimento e após umedecimento do subleito para 400.000 e 100.000 ciclos de carga. Este valor foi adotado de maneira a permitir a comparação das duas bacias, tendo em vista que após o umedecimento, o ensaio não prosseguiu até a estabilização das deformações elásticas.

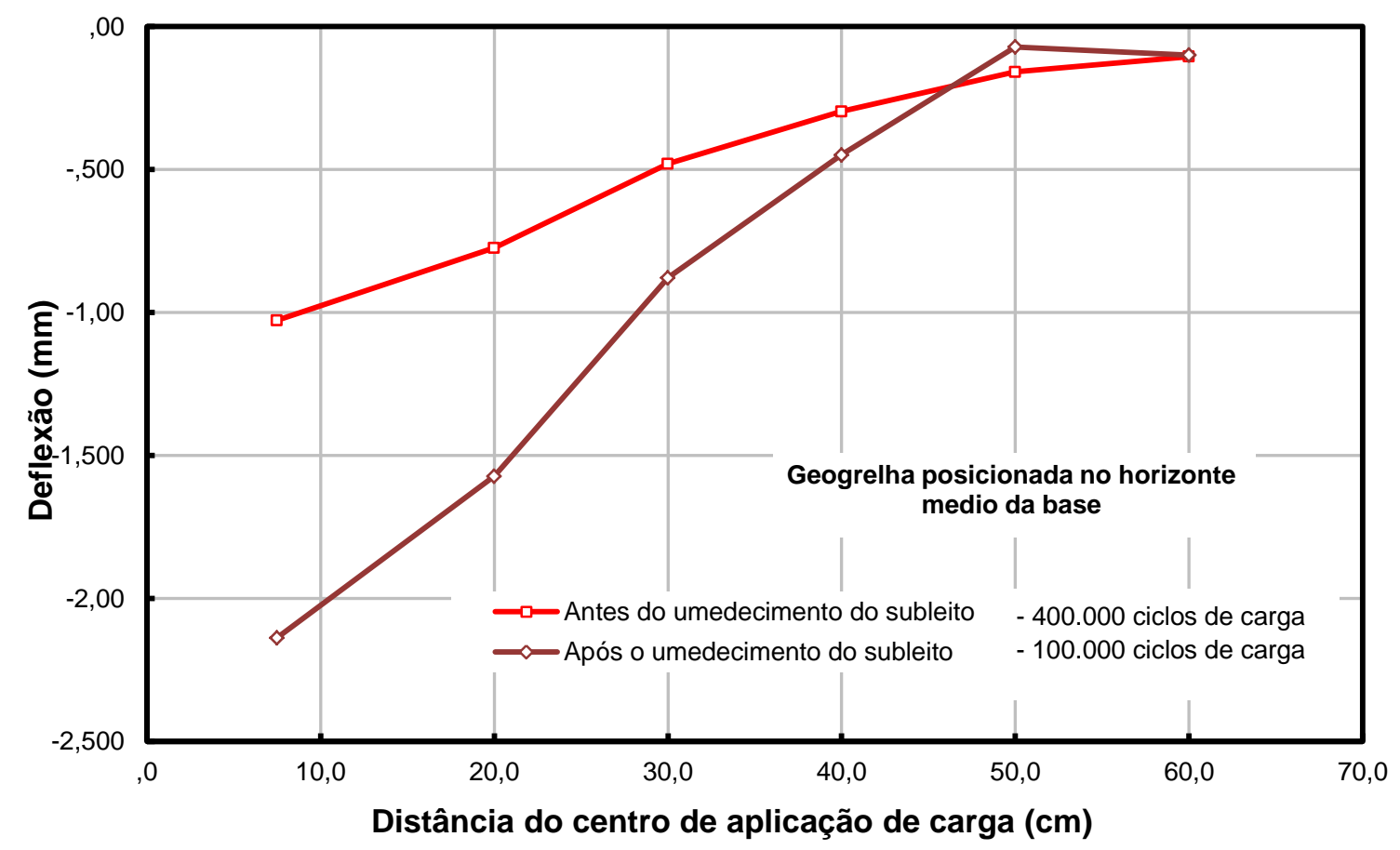

Figura 4.33 - Bacia de deflexão em função do número de ciclos de carga com utilização da geogrelha no horizonte médio da camada de base na situação antes e após o umedecimento do subleito 
Analisando a Figura 4.33 observa-se que a deflexão máxima obtida após o umedecimento, 2,2mm, é 2,2 vezes maior que à obtida sem o umedecimento, igual a 1,0mm. Supõe-se que a diminuição de rigidez seja decorrente do efeito do umedecimento do material do subleito.

4.3.3.4 Análise das deformações permanentes na superfície, com a utilização da geogrelha posicionada no horizonte médio da base após o umedecimento do subleito

As deformações permanentes desenvolvidas durante a realização do ensaio foram determinadas na superfície do pavimento sob a placa de carregamento. A Figura 4.34 apresenta o desenvolvimento do recalque com o número de ciclos de carga antes e após o umedecimento e ainda as curvas correspondentes aos modelos das equações 4.11 e 4.12 cujas aplicações serão discutidas a seguir. 


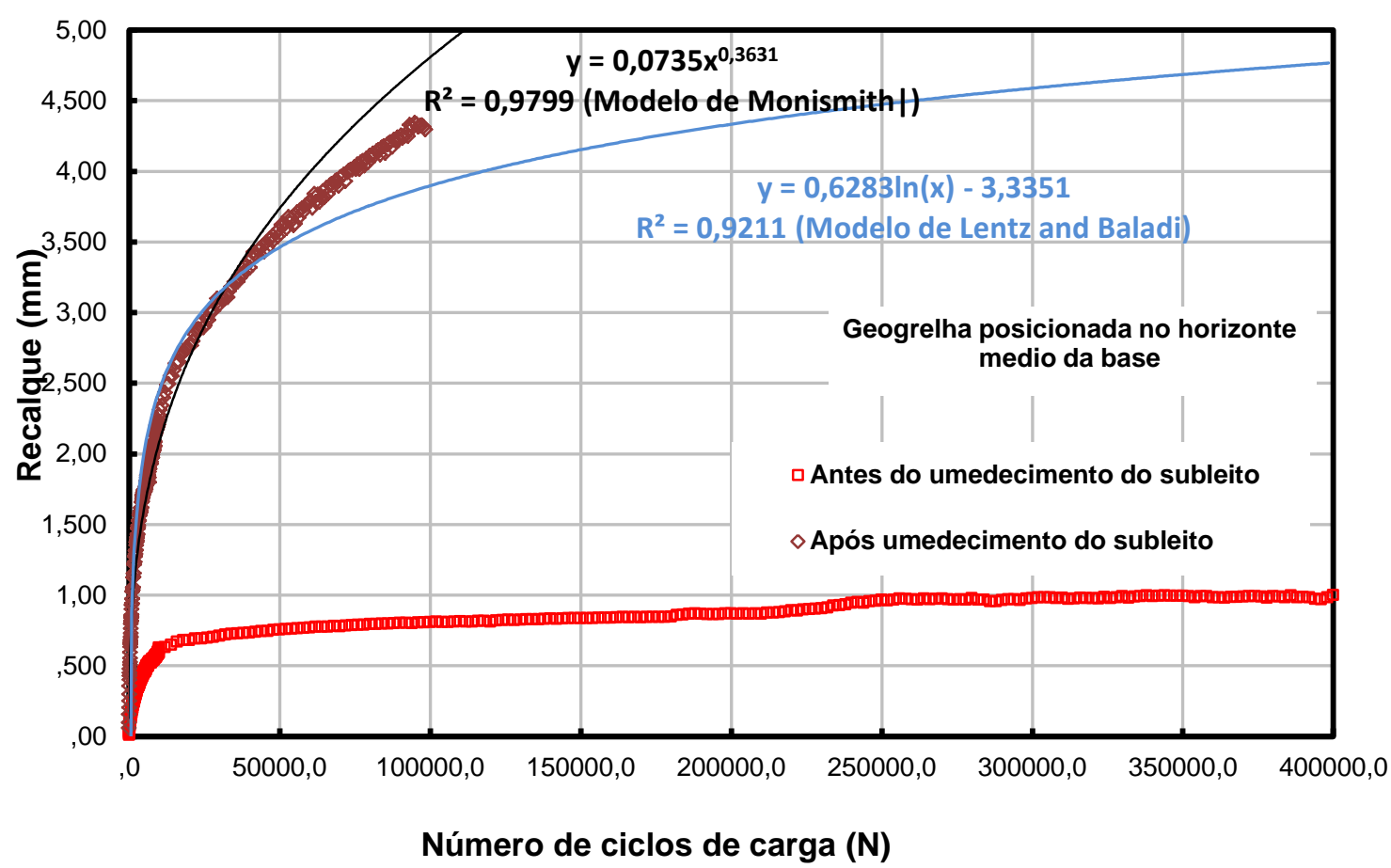

Figura 4.34 - Recalque em função do número de ciclos de carga, com geogrelha posicionada no horizonte médio da camada de base, na situação antes e após o umedecimento do subleito

Analisando-se o desenvolvimento do recalque em função do número de ciclos de carga, conforme apresentado na Figura 4.34, observa-se que após o umedecimento do subleito e para 100.000 ciclos de carga ainda não se alcançou a estabilização das deformações permanentes. Se aos pontos experimentais forem ajustados os modelos de Monismith et al. (1975) e Lentz e Baladi (1981), conforme discutido anteriormente, obtém-se as equações 4.11 e 4.12, respectivamente. Analisando-se estes modelos, observa-se que o modelo de Monismith et al. (1975), a pesar do coeficiente de correlação ser elevado, não representa bem o desenvolvimento dos recalques principalmente para números de ciclos maiores, sendo que o $R^{2}$ reflete a concordância no trecho inicial da curva, onde a concentração de pontos é maior se comparada a do restante da curva. Para o modelo de Lentz and Baladi (1981), a concordância com os pontos experimentais 
parece ser mais representativa para uma extrapolação do recalque para 400.000 ciclos de carga.

$$
\begin{array}{rr}
\varepsilon_{P}=1 \cdot 10^{-4} \cdot N^{0,363} & \mathrm{R}^{2}=0,98 \\
\varepsilon_{P}=0,0009 . \operatorname{Ln} N-0,0048 & \mathrm{R}^{2}=0,92
\end{array}
$$

Em que: $\quad \varepsilon_{P}=$ deformação permanente (\%);

$\mathrm{N}=$ número de ciclos de carga.

Comparando-se os recalques obtidos sem umedecimento e após umedecimento do subleito para 100.000 ciclos de carga, número de ciclos comum aos dois ensaios, conforme a Figura 4.34, observa-se que o recalque é igual a 0,9mm e 4,3mm, respectivamente, para a primeira e segunda condições. Portanto, o umedecimento conduz a um aumento da deformação plástica da ordem de 4 vezes. Aplicando-se o modelo da equação 4.12 que melhor se adéqua ao comportamento após umedecimento, obtém-se por extrapolação, o valor de $4.7 \mathrm{~mm}$ para o recalque correspondente a 400.000 ciclos de carga. Comparando-se este valor com o obtido sem o umedecimento, $1 \mathrm{~mm}$, a relação entre os mesmo é da ordem de 5 vezes.

Conclui-se que a variação da umidade do subleito proporcionou um aumento tanto na deformação permanente quanto na deformação elástica, sendo esse aumento proporcionado pela perda de rigidez do subleito devido à elevação do teor de umidade. Quanto à utilização da geogrelha no horizonte médio da camada de base, pôde-se observar que uma redução significativa tanto nas deflexões como nos recalques. Os benefícios decorrentes da utilização do reforço serão detalhados no item 4.4. 


\subsection{ANÁLISE COMPARATIVA DOS ENSAIOS APRESENTADOS NA ETAPA DEFINITIVA}

Neste item são analisadas e comparadas as deformações elásticas e permanentes dos ensaios apresentados no item 4.3. Nos itens 4.4.1 e 4.4.2 são analisadas, respectivamente, as deformações elásticas e permanentes para a condição em que o subleito encontra-se na umidade ótima de compactação, e nos itens 4.4.3 e 4.4.4 são analisadas as deformações elásticas e permanentes, respectivamente, para a condição após a inundação do subleito.

Ainda no item 4.4 são apresentadas e analisadas as tensões totais fornecidas pelas células de tensão total posicionadas no interior das estruturas e no item 4.5, são apresentados e analisados os módulos de resiliência obtidos por retroanálise das bacias de deflexão.

\subsubsection{Análise comparativa das deformações elásticas para o subleito na umidade ótima}

As Figuras 4.35 e 4.36 apresentam o desenvolvimento da deflexão sob a vertical do carregamento em função do número de ciclos de carga e as bacias de deflexão dos ensaios analisados nos itens 4.3.1.1, 4.3.2.1 e 4.3.3.1, respectivamente. Os ensaios foram realizados com o subleito compactado na umidade ótima e para a determinação das bacias de deflexão foram completados 
400.000 ciclos de carga, para a estrutura sem reforço e com reforço, posicionado no topo do subleito e no horizonte médio da base.

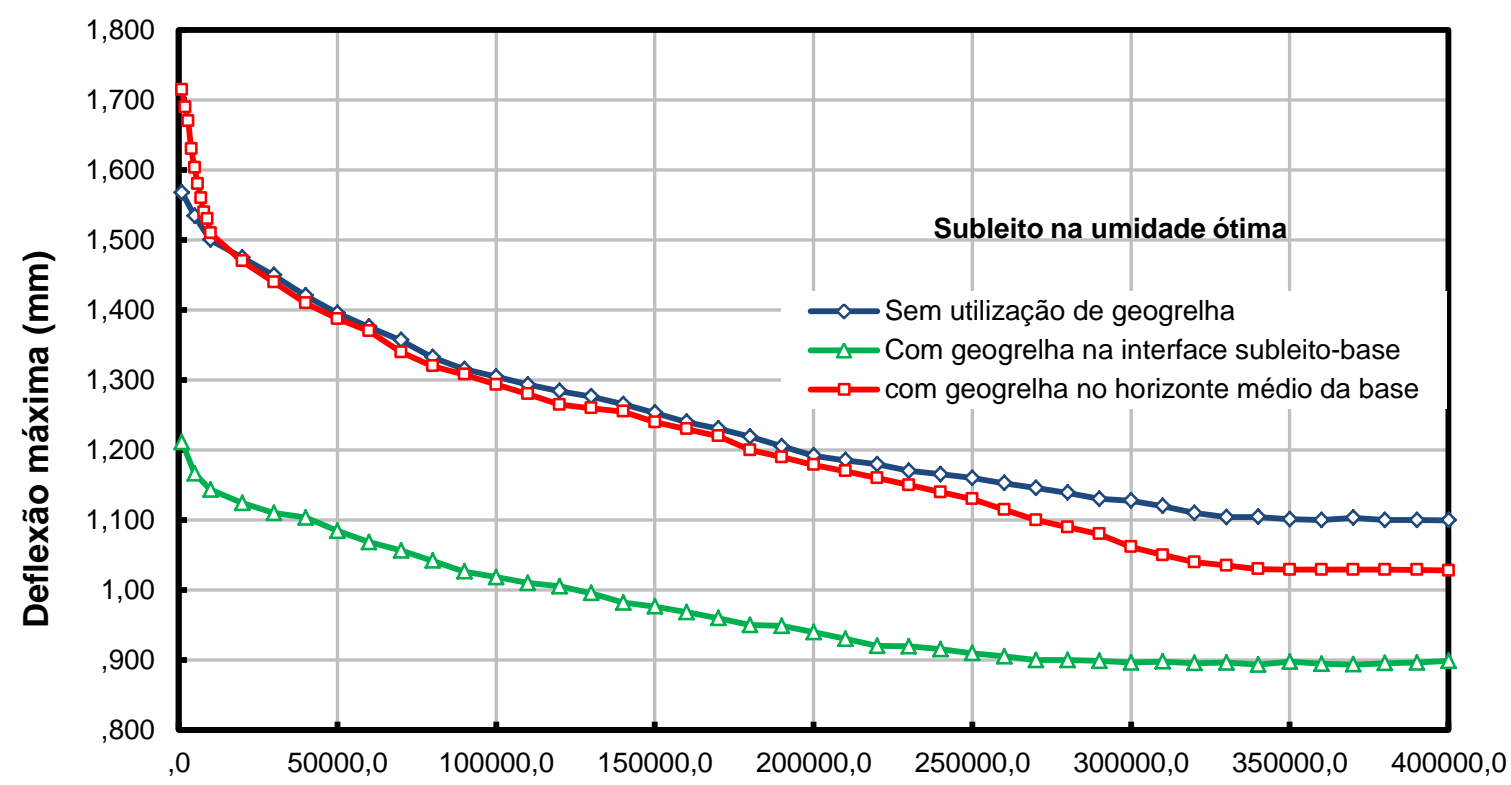

Número de aplicações (N)

Figura 4.35 - Deflexão máxima em função do número de ciclos de carga dos ensaios sem geogrelha e com geogrelha posicionada na interface e no horizonte médio da base, subleito na umidade ótima

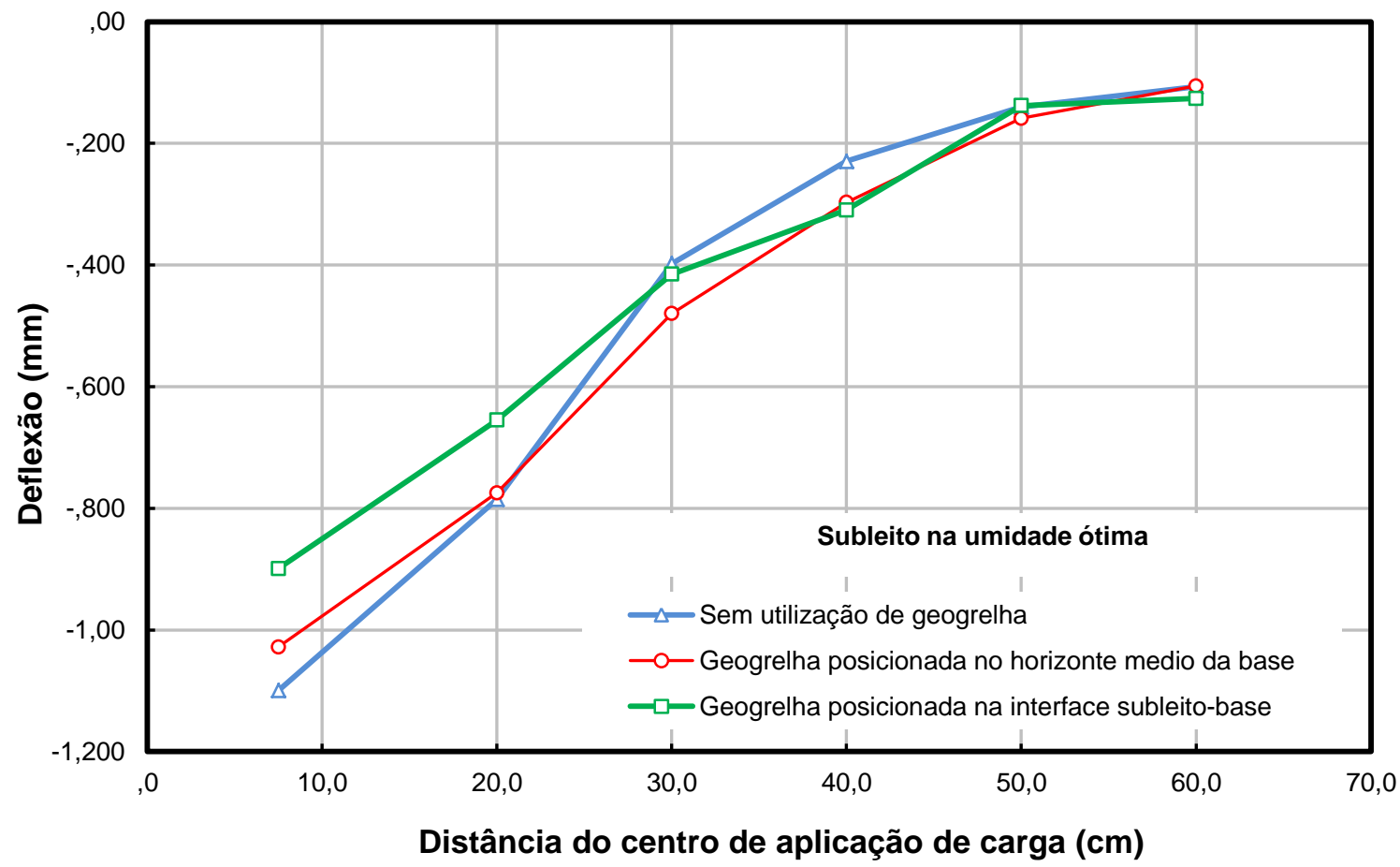

Figura 4.36 - Bacias de deflexão após 400.000 ciclos de carga para estruturas sem e com reforço e subleito na umidade ótima 
Comparando o desenvolvimento das deflexões máximas dos três ensaios analisados na Figura 4.35, verifica-se que a estabilização da deflexão máxima para o ensaio com geogrelha na interface subleito-base é alcançada com 100.000 ciclos de carga a menos que o necessário para convergir a deflexão máxima dos ensaios sem utilização de geogrelha e com a geogrelha posicionada no horizonte médio da base.

Analisando a Figura 4.36 e considerando-se que os valores das deflexões para distâncias da aplicação de carga maiores que $30 \mathrm{~cm}$ são muito reduzidas, podese afirmar que a inserção do reforço não altera de maneira significativa a forma da bacia de deflexão. Para se avaliar o efeito da inserção do reforço, serão comparados apenas os resultados obtidos na vertical da aplicação do carregamento. Neste ponto, as deflexões são 1,1, 1,03 e 0,9mm para as condições sem reforço e com o reforço posicionado no horizonte médio e no topo do subleito, respectivamente.

Tomando-se o ensaio sem utilização de geogrelha como valor de referência, pode-se concluir que quando a geogrelha é posicionada no horizonte médio da camada de base seu benefício nas deflexões elásticas é praticamente nulo. Por outro lado quando a mesma é posicionada na interface subleito-base, gera uma redução de $18 \%$ na deflexão elástica. Esse benefício foi também observado por Dondi (1994), Kinney et al. (1998), Perkins (1999) e outros, que verificaram uma redução no valor da deflexão entre 15 e 30\%, apesar de comparativamente com esta pesquisa, os valores das magnitudes das deflexões obtidas por estes autores serem muito mais elevadas, conforme discutido nos itens 4.3.1.1, 4.3.2.1 e 4.3.3.1.

Para complementar a análise das deflexões, calcularam-se os raios de curvatura para a distância de $25 \mathrm{~cm}$ do ponto de aplicação de carga, segundo a Equação 4.13. 


$$
R=62502 * D_{0}-D_{25}
$$

Em que: $\quad$ Ré o raio de curvatura $(m)$;

$D_{0}$ é a deflexão máxima $(0,01 \mathrm{~mm})$ e

$D_{25}$ é a deflexão a $25 \mathrm{~cm}$ de distância do centro da carga $(0,01 \mathrm{~mm})$.

Os raios de curvatura obtidos foram de 62,76 e $84 \mathrm{~m}$ para o ensaio sem utilização de geogrelha, com a geogrelha posicionada no horizonte médio da camada de base e com a geogrelha posicionada na interface subleito-base, respectivamente. Este resultado evidencia o efeito positivo da inserção do reforço, que contribui para o aumento do raio de curvatura, principalmente para a condição em que o mesmo é posicionado na interface com o subleito, visto que menores raios são indicativos de arqueamento mais severos da camada deformada, denotando uma condição estrutural mais crítica segundo Manual de restauração de Pavimentos - DNIT - IPR720 (2006).

\subsubsection{Análise comparativa das deformações permanentes para o subleito na umidade ótima}

A Figura 4.37 apresenta o desenvolvimento dos recalques dos ensaios analisados nos itens 4.3.1.1, 4.3.2.1 e 4.3.3.1, sem o umedecimento do subleito e após completados 400.000 ciclos de carga, para a estrutura sem reforço e com o reforço, posicionado no topo do subleito e no horizonte médio da base. 


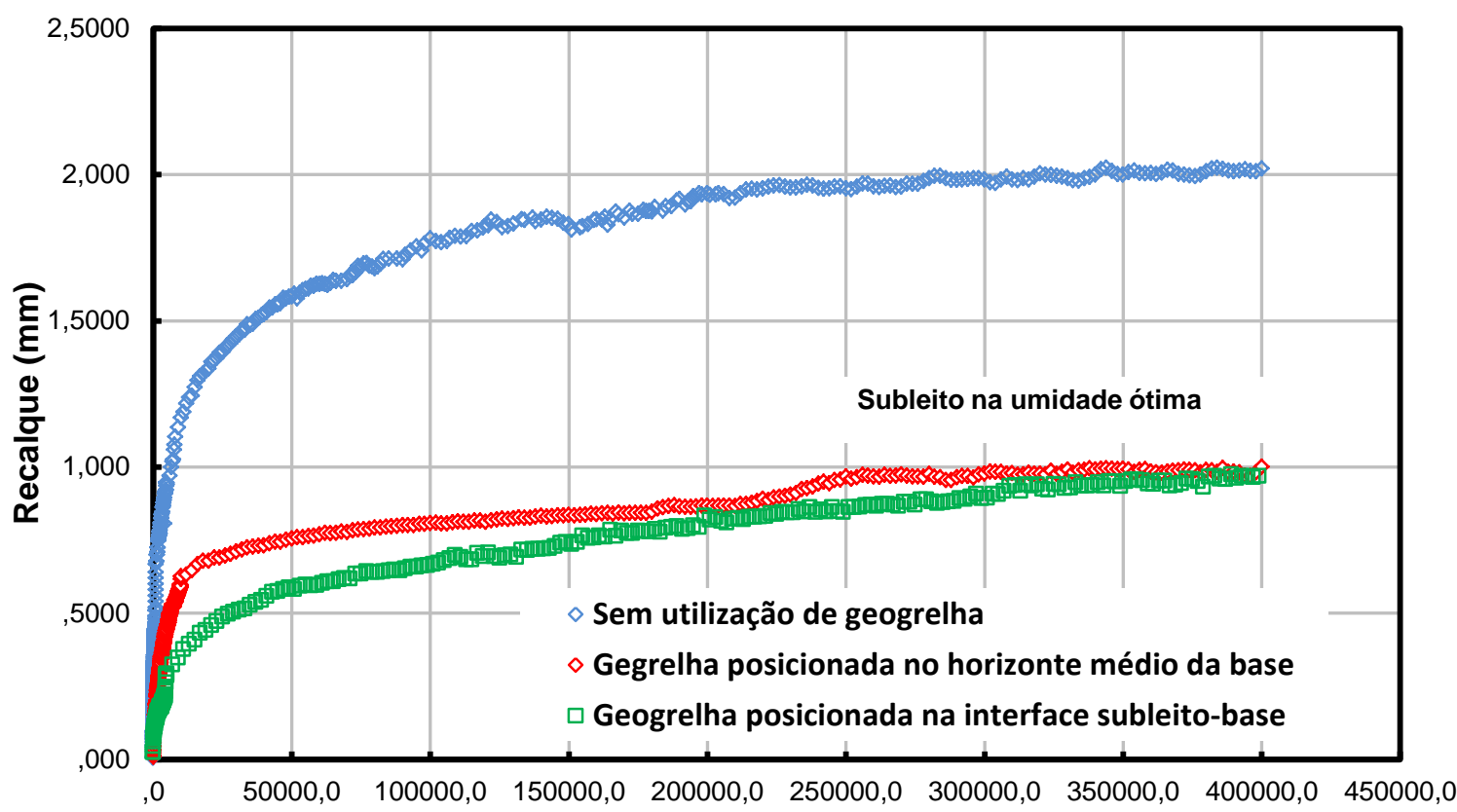

Número de ciclos de carga (N)

Figura 4.37 - Recalque em função do número de ciclos de carga após 400.000 ciclos de carga para estruturas sem e com reforço e subleito na umidade ótima

Analisando a Figura 4.37, observa-se que as curvas apresentam formas semelhantes e que a estabilização dos recalques é alcançada após 300.000 ciclos de carga para as três estruturas analisadas. Comparando-se os recalques obtidos após a aplicação de 400.000 ciclos de carga, 2 e $1 \mathrm{~mm}$, respectivamente para a condição sem e com reforço, conclui-se que a introdução do reforço, independente do seu posicionamento, proporciona uma redução das deformações permanentes da ordem de $50 \%$.

Quando se analisa o benefício gerado pelo uso da geogrelha relatado na literatura, observa-se que o posicionamento do reforço no horizonte médio da camada de base só é considerado para espessuras desta camada superiores a 30cm (COLLIN et al., 1996; HASS et al., 1988; WEBSTER, 1993), assim os valores obtidos nesta pesquisa correspondentes a este posicionamento não puderam ser 
comparados com os da revisão bibliográfica. Para o reforço no topo do subleito e este elemento constituído de diferentes materiais, Miura et al. (1990), Holtz et al.(1995), Perkins (1999) e etc., determinaram taxas de redução no recalque variando de 50 a $250 \%$. Semelhante ao ocorrido com as deflexões, também os recalques relatados por estes autores envolvem magnitudes muito superiores às determinadas nesta pesquisa, conforme discutido nos itens 4.3.1.2, 4.3.2.2 e 4.3.3.2.

Quando são analisadas conjuntamente as deformações elásticas e permanentes obtidas para estruturas reforçadas ou não e o subleito na umidade ótima, conclui-se que o efeito positivo da introdução da geogrelha é maior no sentido da redução dos recalques do que das deflexões, embora segundo este último aspecto, a avaliação de eventuais ganhos deva também incluir a análise da vida de fadiga de capas ou camadas cimentadas sobrepostas à estrutura de pavimento ensaiada, conforme será discutido no item 4.4.6.

Finalmente, quanto ao posicionamento do reforço, a sua instalação no horizonte médio da base ou no topo do subleito contribui igualmente na redução das deformações permanentes. Entretanto, no tocante às deformações elásticas, apenas a instalação do reforço no topo do subleito tem efeito na redução das deflexões. Comportamento semelhante também foi observado após a inundação do subleito, conforme será apresentado no item 4.4.3. Acredita-se que a maior contribuição do reforço no topo do subleito seja decorrente desta região estar sujeita a tensões horizontais superiores às do horizonte médio da camada de base e assim sua maior solicitação contribuiria de maneira mais efetiva na redução das tensões que alcançam o subleito. Holtz et al. (1995), e Hass et al. (1988) concluíram que para bases com dimensões inferiores a $25 \mathrm{~cm}$, o efeito da geogrelha é maximizado 
quando instalada nesta posição. A distribuição de tensões ao longo da estrutura do pavimento será detalhada no exemplo apresentado no item 4.5.1.

\subsubsection{Análise comparativa das deformações elásticas para o subleito umedecido}

As Figuras 4.38 e 4.39 apresentam os desenvolvimentos da deflexão máxima em função do número de ciclos de carga e as bacias de deflexão dos ensaios analisados nos itens 4.3.1.3, 4.3.2.3 e 4.3.3.3, respectivamente. Os ensaios foram realizados após o umedecimento do subleito e para a determinação da bacia de deflexão foram completados 100.000 ciclos de carga, para a estrutura sem reforço e com reforço, posicionado no topo do subleito e no horizonte médio da base.

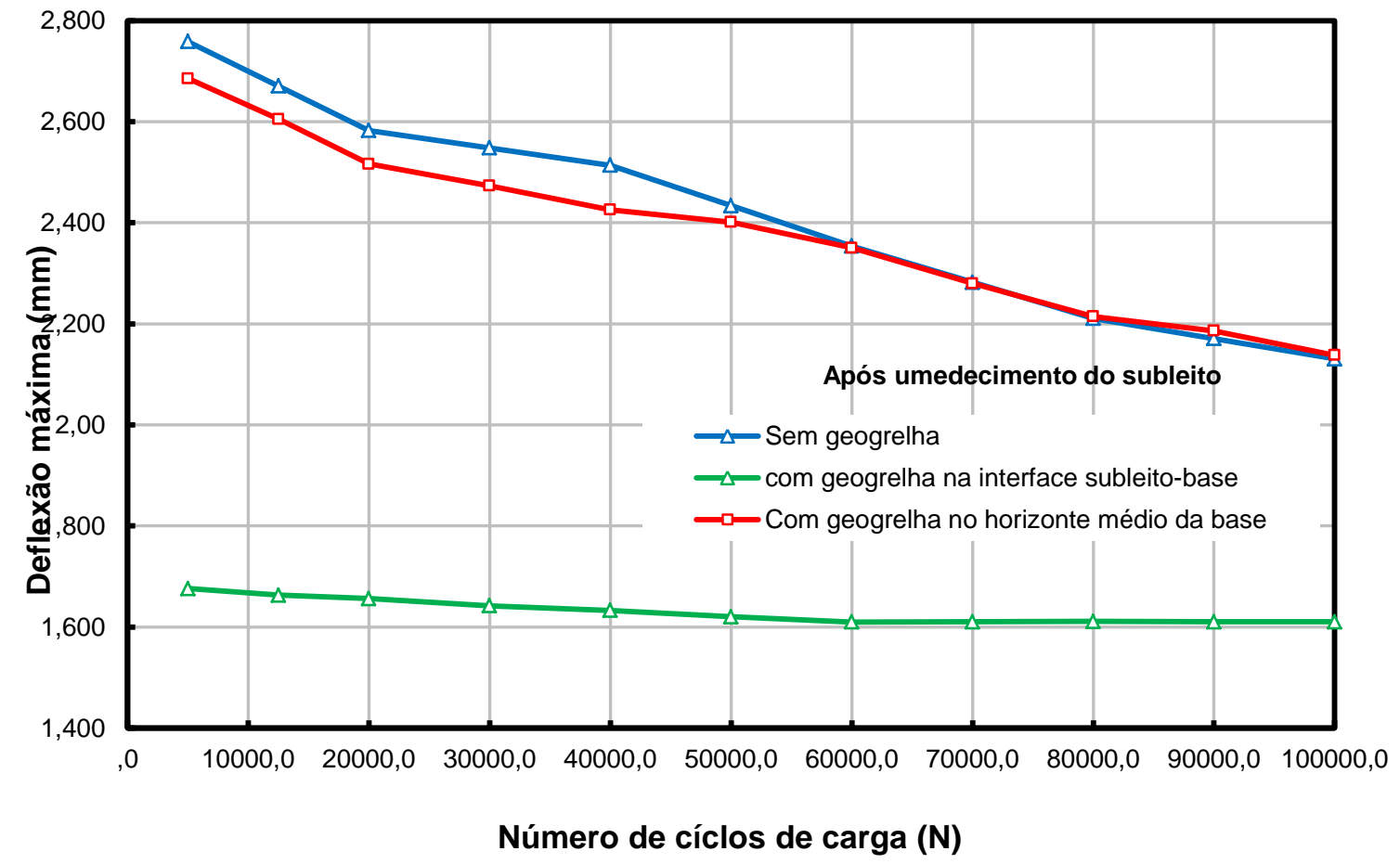

Figura 4.38 - Deflexão máxima em função do número de ciclos de carga dos ensaios sem geogrelha e com geogrelha posicionada na interface e no horizonte médio da base, subleito após inundação 


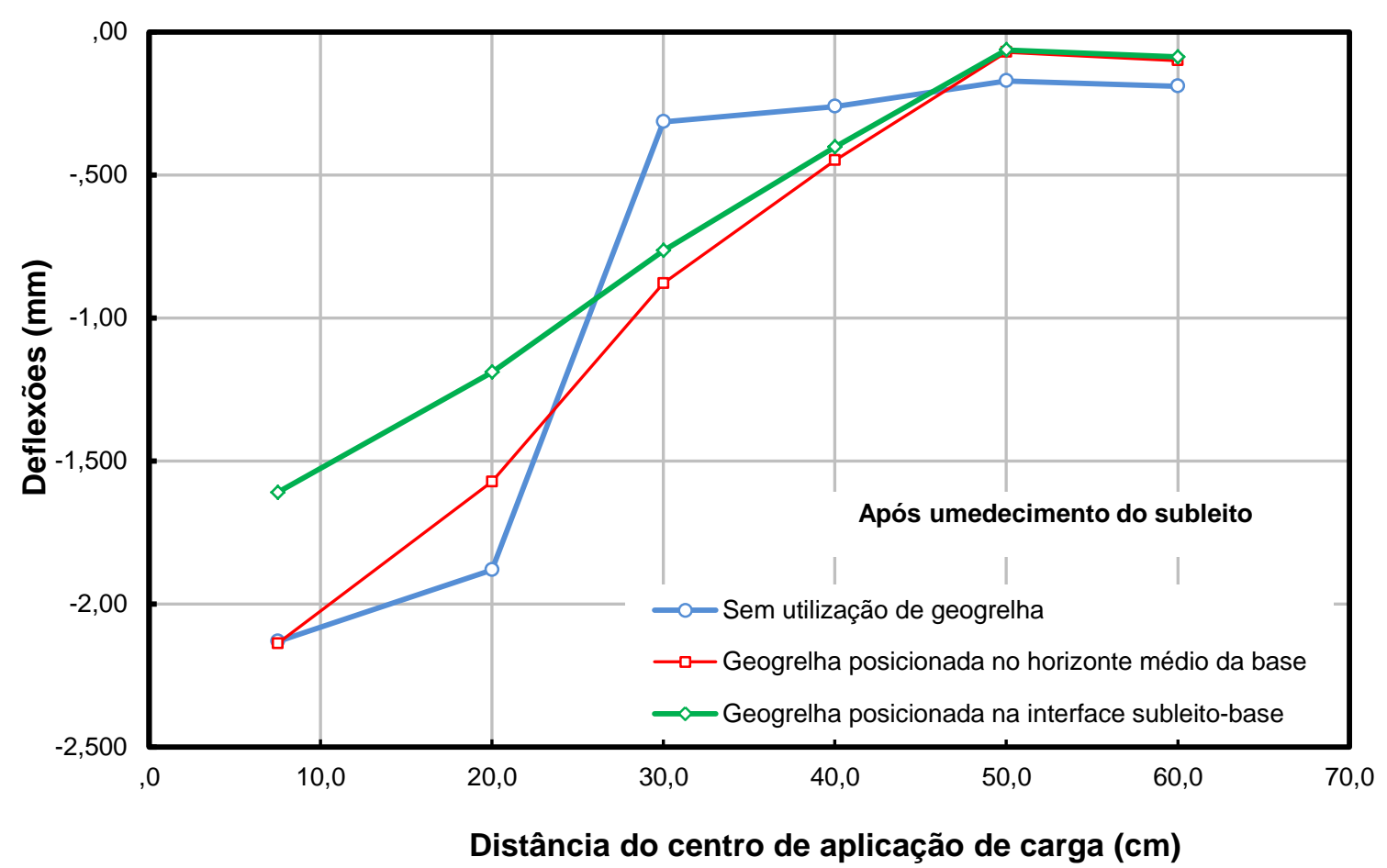

Figura 4.39 - Bacia de deflexão após 100.000 ciclos de carga para estruturas sem e com reforço e subleito após inundação

Comparando o desenvolvimento das deflexões máximas dos três ensaios analisados na Figura 4.38, verifica-se que a estabilização da deflexão máxima só ocorre para o ensaio onde a geogrelha foi posicionada na interface subleito-base enquanto que para os ensaios sem geogrelha e com a geogrelha posicionada no horizonte médio da base não foi atingida a estabilização das deflexões. Deve-se destacar que a redução e a estabilização das deformações elásticas prematuramente, após 60.000 ciclos de carga, implicarão muito positivamente na extensão da vida de fadiga de misturas asfálticas ou cimentadas sobrepostas à estrutura analisada.

Analisando a Figura 4.39 e considerando-se que os valores de deflexões para distâncias da aplicação de carga maiores que $30 \mathrm{~cm}$ são muito reduzidas, pode-se afirmar que a inserção do reforço não altera de maneira significativa a forma da bacia de deflexão, cabe ressaltar que a curva sem utilização de geogrelha 
apresentou provavelmente leituras incorretas, conforme já apresentado no item 4.3.1.3. Ainda, analisando a Figura 4.39 observa-se que as deflexões máximas obtidas para os ensaios sem utilização de geogrelha, com a geogrelha posicionada no horizonte médio da camada de base e com a geogrelha posicionada na interface subleito-base foram de 2,2, 2,2 e 1,6mm, respectivamente. Verifica-se que a deflexão máxima para o ensaio com a utilização de geogrelha na interface é $30 \%$ menor que a obtida do ensaio sem a utilização da mesma. Se comparado esse valor com o obtido antes do umedecimento que foi de $18 \%$, observa-se que com o aumento da umidade do subleito, proporciona um aumento no beneficio gerado pelo uso do geossintético.

Comparando-se os resultados dos ensaios realizados sem e após o umedecimento do subleito, pode-se concluir que a utilização de geogrelha como reforço de base passa a ser mais eficaz à medida que a capacidade de suporte do subleito diminui.

\subsubsection{Análise das deformações permanentes após o umedecimento do subleito}

A Figura 4.40 apresenta o desenvolvimento dos recalques dos ensaios apresentados nos itens 4.3.1.4, 4.3.2.4 e 4.3.3.4, após o umedecimento do subleito e depois de completados 100.000 ciclos de carga, para a estrutura sem reforço e com o reforço, posicionado no topo do subleito e no horizonte médio da base. Conforme discutido nos itens 4.3.1.4, 4.3.2.4 e 4.3.3.4, os ensaios realizados após o 
umedecimento do subleito foram interrompidos antes da estabilização das deformações permanentes.

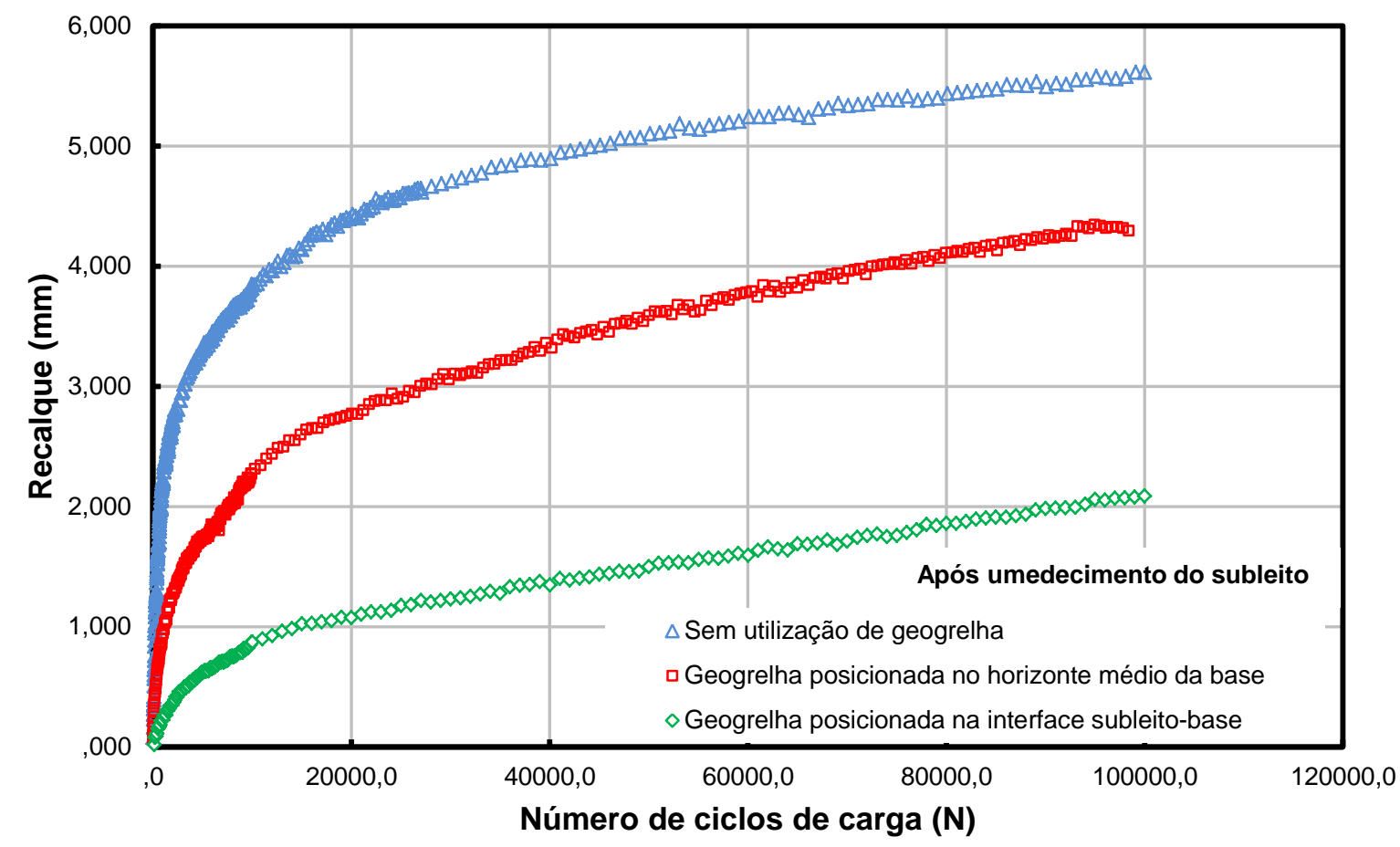

Figura 4.40 - Recalque em função do número de ciclos de carga após 100.000 ciclos de carga para estruturas sem e com reforço e subleito após umedecimento

Analisando a Figura 4.40, observa-se que as curvas apresentam formas semelhantes, repetindo o já observado para o subleito na umidade ótima, apesar de na presente condição, não se ter alcançado a estabilização das deformações permanentes. Após 100.000 ciclos de carga, o recalque obtido foi de 5,5, 4,2 e 2mm para a estrutura sem reforço, e com o reforço posicionado no horizonte médio da base e no topo do subleito, respectivamente. Comparando-se estes valores, concluise que o efeito positivo da utilização da geogrelha na redução das deformações permanentes é de 24 e 64\%, respectivamente para o primeiro e segundo posicionamento do reforço, indicando que a geogrelha no topo do subleito é mais eficaz que quando no horizonte médio da base. Este fato contraria o observado 
anteriormente para o subleito na umidade ótima, quando os dois posicionamentos conduziram a uma mesma taxa de redução de recalque, de 50\%. Quando se analisa o comportamento das deformações permanentes após o umedecimento constata-se que este é compatível com o das deformações elásticas nas duas condições de umidade do subleito, ou seja, o posicionamento do reforço no topo do subleito é mais eficiente que no horizonte médio da base. Assim, a causa da coincidência da redução dos recalques para os dois posicionamentos da geogrelha para o subleito na umidade ótima poderia ser decorrente de um eventual problema durante a execução do ensaio que não foi detectado.

\subsection{ANÁLISES COMPLEMENTARES}

\subsubsection{Análise dos módulos de resiliência obtidos a partir da retroanálise das bacias de deflexão}

As bacias de deflexão utilizadas são as mesmas apresentadas na Figura 4.36. Para retroanálise considerou-se que a estrutura de pavimento é composta de uma camada rígida onde se apóiam as camadas de subleito e de base com espessuras de 50 e $20 \mathrm{~cm}$, respectivamente. A análise restringe-se apenas ao subleito na umidade ótima, visto que foram realizados ensaios triaxiais cíclicos apenas em corpos de prova compactados na umidade ótima de compactação.

Para a comparação dos resultados da retroanálise com os módulos de resiliência de cada uma das camadas calculadas a partir dos ensaios triaxiais 
cíclicos, foi utilizado o modelo composto (Eq. 3.3) ajustado para os mesmos e o programa computacional Fepave, que incorpora um modelo elástico não linear na sua formulação. Complementarmente, para efeito de comparação, repetiu-se o mesmo cálculo utilizando o programa computacional Elsym5. Neste caso, como o programa é unicamente elástico linear, para se alcançar um melhor resultado, dividiu-se a camada de base em quatro seções e por um processo interativo, procurou-se a convergência de valores de módulos de resiliência representativos de cada uma delas.

As Figuras 4.41 e 4.42 apresentam, para a estrutura ensaiada, as variações das tensões horizontais e verticais e os correspondentes valores de módulo de resiliência calculadas a partir do modelo composto usando as tensões determinadas a partir dos programas Fepave e Elsym5.
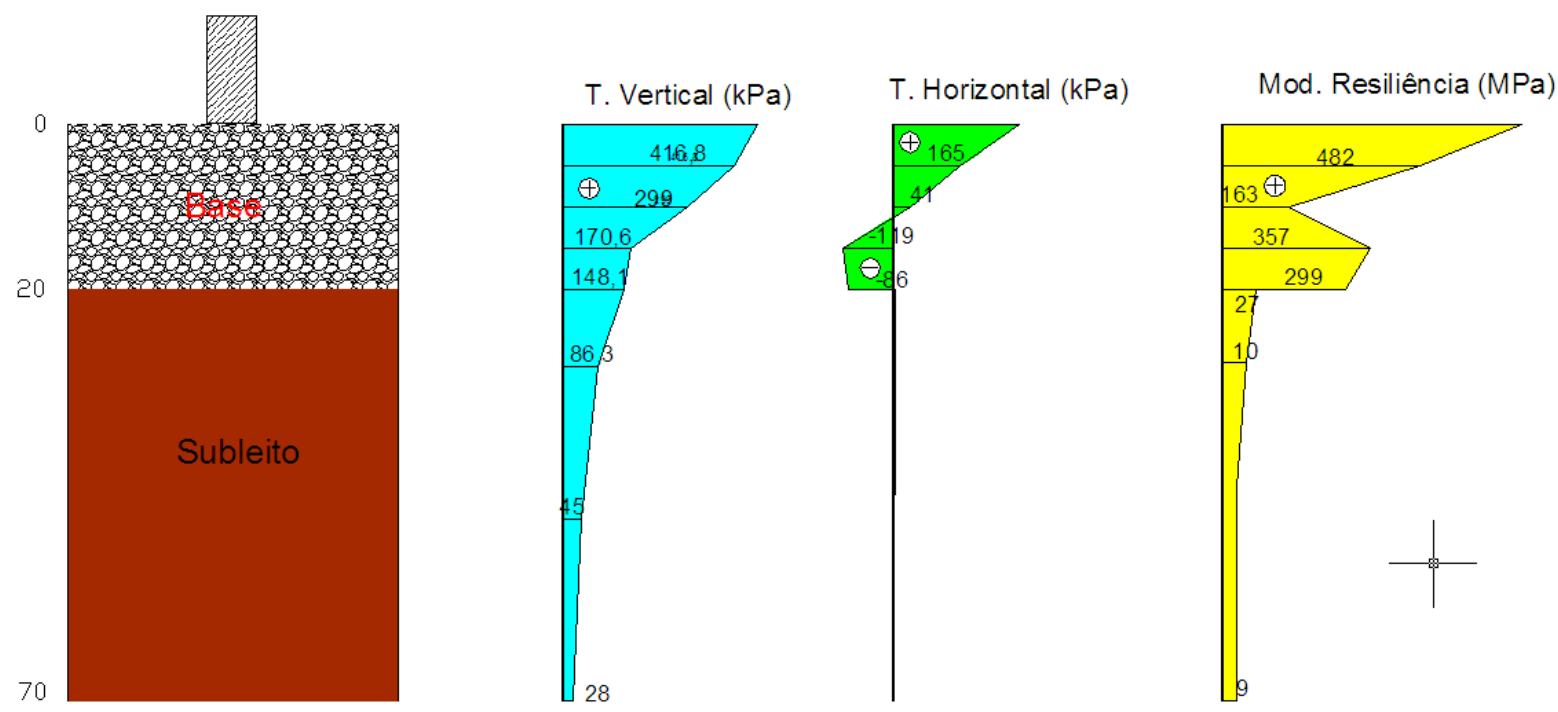

Figura 4.41 - Estrutura do pavimento ensaiado, variação das tensões e módulo de resiliência em função da profundidade, obtidos a partir do ensaio triaxial cíclico, com o auxilio do programa Fepave 

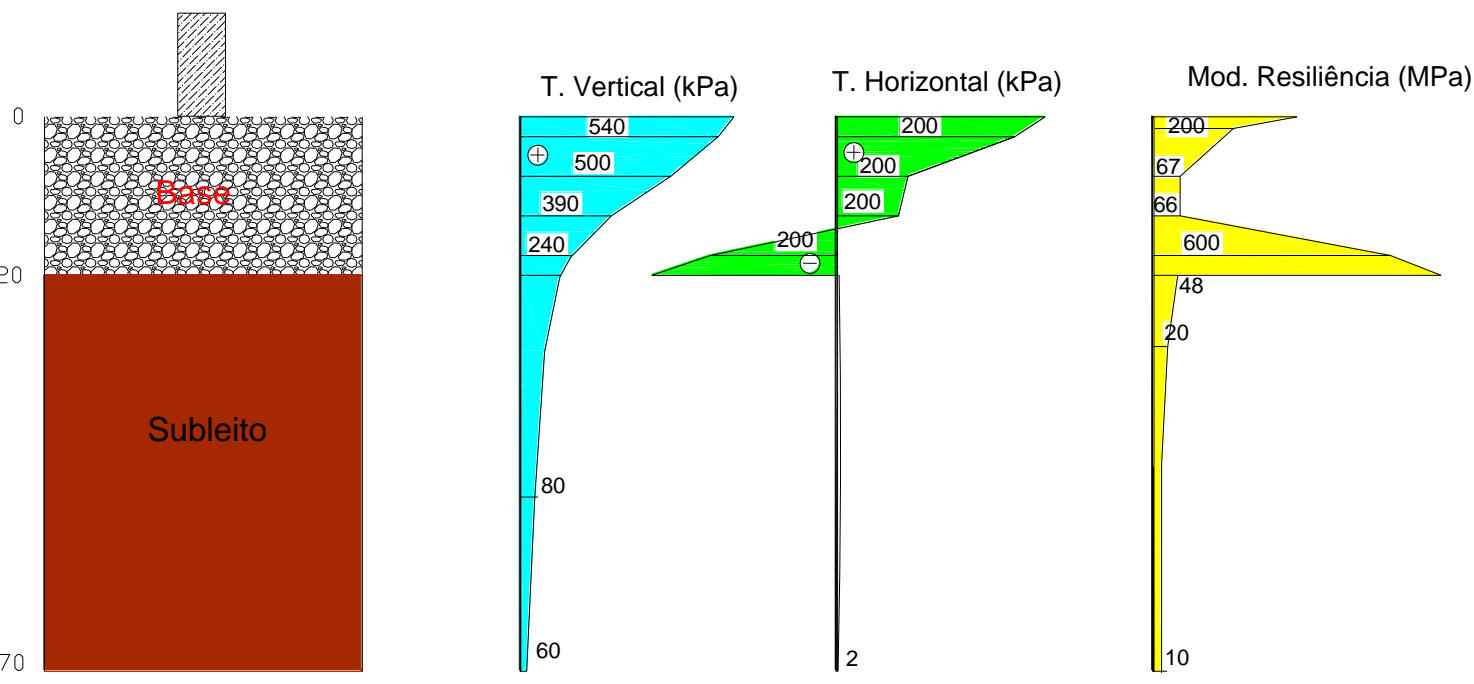

Figura 4.42 - Estrutura do pavimento ensaiado, variação das tensões e módulo de resiliência em função da profundidade, obtidos a partir do ensaio triaxial cíclico, com o auxilio do programa Elsym5

Comparando os resultados fornecidos pelos dois programas, inicialmente é importante destacar que os valores anotados nos dois gráficos não correspondem nas Figuras 4.41 e 4.42 a profundidades coincidentes. Para as tensões verticais e horizontais, apesar dos valores diferirem para os dois programas, os mesmos apresentam a mesma ordem de grandeza, sendo a tensão vertical de compressão ao longo de todo o perfil, e a tensão horizontal, de compressão até a profundidades de 12 e 15cm, respectivamente para o Fepave e o Elsym5, a partir das quais, tornam-se de tração até o topo do subleito, quando ocorre uma nova inversão de sinal. Comparando-se os valores médios dos módulos de resiliência calculadas a partir dos módulos determinados para as diversas profundidades da camada de base, 325 e 233MPa, respectivamente para os programas Fepave e Elsym5, os mesmos diferem da ordem de $40 \%$. Para o subleito, os mesmos valores são de 18 e 20MPa, com uma diferença da ordem de 11\%. A Tabela 4.3 apresenta os valores médios dos módulos de resiliência obtidos com 0 auxilio dos programas 
computacionais Fepave e Elsym5 e os valores dos módulos de resiliência obtidos pela retroanálise da curva de deflexão.

Tabela 4.3 - Módulos de resiliência obtidos a partir do ensaio triaxial cíclico e a partir da retroanálise das bacias de deflexões para condição de subleito compactado na umidade ótima de compactação

\begin{tabular}{cccc}
\hline & \multicolumn{4}{l}{ Módulo de Resiliência - Ensaio sem utilização de geogrelha } \\
\hline & \multicolumn{2}{c}{ Ensaio triaxial cíclico (MPa) } & Retroanálise \\
& Fepave & Elsym5 & (MPa) \\
\hline Base & 325 & 233 & 280 \\
Subleito & 18 & 20 & 37 \\
\hline
\end{tabular}

$\mathrm{Na}$ Tabela 4.3, comparando-se os módulos de resiliência obtidos na retroanálise com os obtidos a partir dos resultados dos ensaios triaxiais cíclicos, observa-se que para a base, o valor de $280 \mathrm{MPa}$ insere-se no intervalo delimitado pelos valores calculados usando os programas Fepave e Elsym5, 325 e 233, respectivamente. Para o subleito, o valor da retroanálise, $37 \mathrm{MPa}$, é superior aos dos determinados a partir do modelo composto, 18 e $20 \mathrm{MPa}$.

Supõe-se que a maior concordância dos resultados referentes à base deva-se à associação de alguns fatores: a menor espessura desta camada faz com que a média das tensões seja mais representativa do que a média das tensões do subleito; o valor do MR do subleito é muito baixo se comparado com a rigidez da maioria dos materiais presentes em obras rodoviárias brasileiros, logo, os erros associados às medidas realizadas nos ensaios são relativamente elevados se comparados ao valor real do módulo; o solo utilizado no subleito mostrou-se de difícil manipulação durante a compactação desta camada na caixa de ensaios, apesar de ter merecido todo cuidado e atenção. Destaca-se que a presente discussão baseia-se nos mesmos 
princípios apresentados anteriormente na discussão de resultados da retroanálise dos ensaios da etapa preliminar, conforme apresentados no item 4.1.1.

Como os resultados de módulos de resiliência obtidos a partir da retroanálise da estrutura sem reforço apresentaram uma boa convergência com os resultados obtidos a partir dos ensaios triaxiais cíclicos, foram também comparados os valores dos módulos de resiliência obtidos, a partir da retroanálise das estruturas onde foi utilizada a geogrelha. A Tabela 4.4 apresenta os módulos de resiliência da camada de base e subleito obtidos por retroanálise das bacias de deflexões fornecidas pelos ensaios sem utilização de geogrelha e com a geogrelha posicionada no horizonte médio da base e no topo do subleito.

Tabela 4.4 - Módulos de resiliência obtidos a partir da retroanálise das bacias de deflexões dos ensaios com e sem reforço, para condição de subleito compactado na umidade ótima

\begin{tabular}{cccc}
\hline & \multicolumn{3}{c}{ Retroanálise do Módulo de resiliência (MPa) } \\
\hline & $\begin{array}{c}\text { Sem utilização de } \\
\text { geogrelha }\end{array}$ & $\begin{array}{c}\text { Com a geogrelha no } \\
\text { horizonte médio da base }\end{array}$ & $\begin{array}{c}\text { Com a geogrelha no } \\
\text { topo do subleito }\end{array}$ \\
\hline Base & 280 & 390 & 490 \\
Subleito & 37 & 30 & 30 \\
\hline
\end{tabular}

Analisando a Tabela 4.4, observa-se que os módulos da camada de base dos ensaios com geogrelha apresentaram valores superiores ao sem a utilização do reforço, esse fato indica que a inserção da geogrelha é equivalente ao enrijecimento da camada de base. Quando se comparam os valores de módulo de resiliência obtidos para os dois posicionamentos da geogrelha, o enrijecimento decorrente do uso do reforço no topo do subleito é maior que quando posicionado no horizonte médio da camada de base, assim faz com que a camada de base absorva parte das tensões que chegariam ao topo do subleito. Ainda, verifica-se que os módulos de 
resiliência das camadas do subleito são menores para os ensaios onde se utilizou a geogrelha. Essa diminuição no módulo do subleito deve-se ao fato do elemento de reforço absorver parte das tensões que chegam ao topo do subleito.

Para averiguar o efeito do umedecimento do subleito foram determinados os módulos a partir da retroanálise das curvas de deflexões obtidas após o processo de inundação do subleito. A Tabela 4.5 apresenta os módulos de resiliência obtidos a partir da retroanálise dos ensaios sem a utilização da geogrelha e com a utilização da geogrelha no horizonte médio da base e no topo do subleito, após umedecimento do subleito. Neste caso, conforme apresentado anteriormente, não foi possível determinar o módulo do ensaio sem a utilização de geogrelha em função da bacia não estar totalmente completa, devido à falha em dois transdutores de deslocamentos impossibilitando a retroanálise da bacia.

Tabela 4.5 - Módulos de resiliência obtidos a partir da retroanálise das bacias de deflexões para condição de subleito após o umedecimento

\begin{tabular}{lccc}
\hline & Sem geogrelha & $\begin{array}{c}\text { Geogrelha no meio da } \\
\text { base }\end{array}$ & $\begin{array}{c}\text { Geogrelha na interface } \\
\text { subleito-base }\end{array}$ \\
\hline & $\mathrm{M}_{\mathrm{R}}(\mathrm{MPa})$ & $\mathrm{M}_{\mathrm{R}}(\mathrm{MPa})$ & $\mathrm{M}_{\mathrm{R}}(\mathrm{MPa})$ \\
Camadas & Retroanálise & Retroanálise & Retroanálise \\
Base & - & 140 & 230 \\
Subleito & - & 19 & 20 \\
\hline
\end{tabular}

Ao retroanalisar a bacia de deflexão dos ensaios em que se utilizaram geogrelha verificou-se que o módulo da camada de base foi maior para o ensaio onde utilizou a geogrelha na interface e os módulos do subleito apresentaram valores muito próximos. Indicando novamente, que este último posicionamento conduz à melhores resultados. 


\subsubsection{Análise do efeito do uso do reforço na fadiga de uma capa asfáltica}

Para ilustrar o efeito positivo da inserção do reforço na base da estrutura de um pavimento, buscou-se avaliar o efeito da utilização de uma geogrelha na fadiga de uma capa asfáltica. Para essa aplicação, adotou-se uma estrutura de pavimento hipotético constituído de uma camada de base de solo-brita de $20 \mathrm{~cm}$ e uma capa asfáltica de $4 \mathrm{~cm}$ de espessura e avaliou-se o número de ciclos de carregamento necessários para a fadiga do revestimento. Adotou-se neste exemplo, para o cálculo da fadiga na capa, a Equação 4.14, apresentado por Furlan et al. (2007) e obtida por Iwanaga, (2009), para uma mistura de agregado de basalto e CAP20 com adição de cal. Para a determinação das tensões geradas na fibra inferior da capa asfáltica foi utilizado o programa Elsym5 considerando-se os módulos de resiliência determinados na retroanálise, conforme valores apresentados na Tabela 4.4.

$$
N=6 \times 10^{7} * 1 \Delta \sigma{ }^{4,78}
$$

Em que: $\quad \mathrm{N}$ é o número de ciclos de carregamento para fadiga do revestimento; $\Delta \sigma$ é a diferença de tensão na fibra inferior (MPa).

A Tabela 4.6 apresenta os valores da diferença de tensão na fibra inferior da capa asfáltica e os valores de $\mathrm{N}$ para a ruptura da capa asfáltica para os ensaios sem geogrelha e com geogrelha posicionada no horizonte médio da base e na interface subleito-base. 
Tabela 4.6 - Tensão desvio na fibra inferior da capa e o número de aplicações de carga para se atingir a fadiga da capa asfáltica, para os ensaios sem e com utilização da geogrelha

\begin{tabular}{ccc}
\hline & $\begin{array}{c}\text { Tensão desvio } \\
(\mathrm{MPa})\end{array}$ & $\mathrm{N}$ \\
\hline Sem geogrelha & 22,3 & $1,3 \times 10^{6}$ \\
Geogrelha no horizonte médio da base & 16,1 & $6,2 \times 10^{6}$ \\
Geogrelha na interface subleito-base & 12,4 & $2,2 \times 10^{7}$ \\
\hline
\end{tabular}

Analisando-se os valores de $\mathrm{N}$ apresentados na Tabela 4.6, verifica-se que a geogrelha posicionada no horizonte médio da camada de base proporcionou uma extensão na vida de fadiga da capa igual a cinco vezes, e na interface, este aumento é de dezessete vezes, repercutindo o maior enrijecimento alcançado para este posicionamento. Este resultado deve ser visto com cautela e só poderá ser extrapolado para condições de campo após um maior aprofundamento dos estudos.

\subsubsection{Análise das células de tensão total}

Nos ensaios realizados nesta pesquisa foram instalados dois pares de células de tensão total sendo o primeiro no horizonte médio da camada de base e 0 segundo no topo do subleito. Cada par foi posicionado de maneira a medir tensões horizontais e verticais em cada um dos horizontes.

Para todas as estruturas ensaiadas não foi possível obter medidas confiáveis das tensões horizontais devido à conjunção de dois fatos: durante a compactação não se podia garantir a verticalidade da célula e também os instrumentos utilizados 
não foram projetados para funcionarem no caso das tensões serem de tração. A obtenção das tensões verticais também foi parcialmente prejudicada pois encontrouse dificuldade na instalação das células na mistura solo-brita e em duas montagens ocorreu o rompimento do cabo elétrico. Assim, apenas as leituras de tensão vertical no topo do subleito, quando as células eram instaladas no material argiloso, puderam ser consideradas confiáveis.

A partir dos resultados da célula posicionada horizontalmente a $3 \mathrm{~cm}$ abaixo da interface subleito-base, obtiveram-se os valores de tensão vertical apresentados na Tabela 4.7.

Tabela 4.7 - Tensões verticais no topo do subleito obtidas com a célula de tensão total no topo do subleito

\begin{tabular}{ccc}
\hline & \multicolumn{2}{c}{ Tensão vertical (kPa) } \\
\cline { 2 - 3 } Condição do subleito & Wo & Após umedecimento \\
\hline Sem geogrelha & 130 & 135 \\
Geogrelha no horizonte médio da base & 113 & 121 \\
Geogrelha na interface subleito-base & 110 & 116 \\
\hline
\end{tabular}

A partir dos resultados de tensão total obtidos da célula posicionada a $3 \mathrm{~cm}$ abaixo da interface subleito-base, observou-se que o ensaio com utilização de geogrelha na interface proporcionou uma redução de tensão no topo do subleito de 15\% para a condição antes do umedecimento e 17\% após umedecimento do subleito se comparado com os resultados do ensaio sem a utilização da geogrelha. Perkins (1999) obteve valores de 20 a $40 \%$ menores quando utilizado um geossintético como reforço de base. 
Conclui-se que as células de tensão total utilizadas nesta pesquisa somente devem ser usadas para obtenção de tensões verticais. Devido à pequena quantidade de informações obtidas das células de tensão total, teve-se a cautela de apenas fazer-se uma análise qualitativa quanto às tensões verticais que chegam ao topo do subleito. Baseando-se nos resultados obtidos nesta pesquisa e amparado nos resultados da bibliografia, pode-se verificar que a utilização da geogrelha como reforço de base reduziu a tensão que chega ao topo do subleito em aproximadamente $15 \%$, nesta configuração de solos e montagens. 


\section{Capítulo 5 Conclusões}

\subsection{CONCLUSÕES}

Esta pesquisa teve como objetivo desenvolver, construir e testar um equipamento que permitisse a avaliação e a análise do comportamento mecânico de seções de pavimentos com dimensões similares às reais submetidas a carregamentos cíclicos. Estudou-se, com a aplicação do modelo físico desenvolvido, o efeito da incorporação de uma geogrelha como elemento de reforço em uma base de solo-brita apoiada a uma camada de subleito a partir da análise das bacias de deflexão e das deformações permanentes observadas.

O equipamento desenvolvido, construído e testado nesta pesquisa atendeu às expectativas, podendo-se afirmar que o mesmo apresentou um bom funcionamento. O sistema pneumático de carregamento atendeu às configurações do projeto e os transdutores de deslocamentos forneceram medidas com a precisão exigida, mostrando ser uma ferramenta eficaz para simular uma estrutura de pavimento sujeita a cargas cíclicas. 
A análise dos resultados obtidos nesta pesquisa e a revisão bibliográfica realizada permitiram as seguintes conclusões:

Quanto às deformações elásticas, pôde-se verificar a sua diminuição com o aumento do número de ciclos de carga, convergindo seu valor para um número de aplicação superior a 300.000. Acredita-se que essa diminuição é devida ao aumento da rigidez das camadas do pavimento decorrente dos sucessivos carregamentos.

Quando se representou o desenvolvimento das deformações permanentes com o número de carregamentos aplicados, dentre os modelos considerados, os coeficientes de regressão alcançaram valores superiores a 0,90 indicando um bom ajuste dos mesmos aos resultados dos ensaios.

A utilização da geogrelha no reforço da camada de base mostrou-se eficaz tanto na redução das deformações permanentes, como nas elásticas. A posição do geogrelha que apresentou melhor desempenho foi na interface subleito-base, acredita-se que a maior contribuição do reforço no topo do subleito seja decorrente desta região estar sujeita a tensões horizontais superiores às do horizonte médio da camada de base e assim a sua maior solicitação contribua de maneira mais efetiva na redução das tensões que alcançam o subleito.

A variação da umidade do subleito repercute na perda de rigidez, gerando maiores deformações, proporcionando um aumento no beneficio da utilização de geogrelha.

A retroanálise das bacias de deflexão permitiu verificar que os módulos da camada de base dos ensaios com geogrelha apresentaram valores superiores ao sem a utilização do reforço, esse fato indica que a inserção da geogrelha é 
equivalente ao enrijecimento da camada de base e observou-se uma diminuição no módulo do subleito, quando utilizado um reforço. Quando se comparam os valores de módulo de resiliência obtidos para os dois posicionamentos da geogrelha, o enrijecimento decorrente do uso do reforço no topo do subleito é maior que quando posicionado no horizonte médio da camada de base.

A simulação do efeito do reforço na fadiga de capa mostrou que a geogrelha posicionada no horizonte médio da camada de base proporcionou uma extensão na vida de fadiga da capa igual a cinco vezes, e na interface, este aumento é de dezessete vezes, repercutindo o maior enrijecimento alcançado para este posicionamento. Este resultado deve ser visto com cautela e só poderá ser extrapolado para condições de campo após maior aprofundamento dos estudos.

As células de tensão total utilizadas nesta pesquisa somente devem ser usadas para obtenção de tensões verticais, pois não foi possível obter valores de tensões horizontais confiáveis com a utilização destas células. Verificou-se que ao comparar os resultados dos ensaios sem utilização de geogrelha com os ensaios com utilização da mesma na interface subleito-base, as tensões verticais que chegam ao topo do subleito sofreram uma redução de $15 \%$.

\subsection{SUGESTÕES PARA TRABALHOS FUTUROS}

Ensaiar no equipamento estruturas de pavimento que também incluam revestimento. 
Ensaiar outros tipos de geossintéticos e também utilizá-los como reforço da capa com a função de inibir a propagação das trincas para a superfície do pavimento.

Instrumentar a seção ensaiada com medidores de umidade e sucção e medidores de deslocamento nos geossintéticos. 


\section{REFERÊNCIAS BIBLIOGRÁFICAS}

Albernaz, C. A. V., Caldas, J. E. F., Oliveira, S. E. (1996). "Avaliação estrutural simplificada de pavimentos através de retroanálise”. - 30ª Reunião Anual de Pavimentação - V. 2, pp. 747-774, Salvador, BA, Brasil.

Albernaz, C. A. V, (1997). "Método simplificado de retroanálise de módulos de resiliência de pavimentos flexíveis a partir da bacia de deflexão". Tese de Mestrado, COPPE / UFRJ, 99p.

Al-Qadi, I.L., Brandon, T. L. Lacina, B. A. and Smith, T. E. (1994). “Laboratory evaluation of geosynthetic reinforced pavement sections". TRR1439, Transportation Research Record.

Al-Qadi, I.L., Corre, B. J., Brandon, T.L., Bhutta, S. A., Appea,A.K., (1998), "Quantifying the separation characteristic of geosynthetic in flexible pavements". IV International conference on geosunthetic, Atlanta, EUA.

Al-Qadi, I.L., (2002). "The proper use of geosynthetic s in flexible pavements". Geosynthetics $-7^{\text {th }}$ ICG $-2002-$ Lisse.

Al-Qadi, I.L. \& Appea, A., (2003). “Eight-year field performance of secondary road incorporating geosynthetics at subgrade-base interface"- TRR1849 Transportation Research Record. 
Al-Qadi, I.L. et al. (2008). “Geogrid in flexible pavements”. TRR 2045, Transportation Research Record.

American Association of Highway and Transportation Officials (2001). "Provisional standards interim edition". Washington DC.

American Association of Highway and Transportation Officials (1996). "Designation TP46-94. Standart Method for Determining the Resiliient Moduluds of Solis and Aggregate Materials". Washington

American Association of Highway and Transportation Officials (1993). "Flexible Pavement Structural Design"

ASTM D6140 (2000) - Standard Test Method to Determine Asphalt Retention of Paving Fabrics Used in Asphalt Paving for Full-Width Applications.

ASTM D5858 - 96(2008) - Standard Guide for Calculating In Situ Equivalent Elastic Moduli of Pavement Materials Using Layered Elastic Theory.

ASTM D1196 - 93(2004) - Standard Test Method for Nonrepetitive Static Plate Load Tests of Soils and Flexible Pavement Components, for Use in Evaluation and Design of Airport and Highway Pavements.

AASHTO (1986), Guide for Design of Pavement Structures, AASHTO, Washington.

Austin, R. A., Gilchrist, A. J. T., (1996). "Aggregate enhanced performance of asphalt pavements using geocomposites". Geotextiles and Geomembranas, 14 - 175186.

Baker, W. R., (1987), “Open-grades bases for airfield pavement”, Technicla Report GL-87-16, U.S.Army Corps of Engeneers, Waterways Experiment station, Vicksburg, Mississippi, USA, 76p.

Barksdale, R. D. Brown, S. F. and Chan, F.(1989). "Potential benefits of geosynthetics in flexible pavement systems". National Cooperative Highway 
Research Program Repot No315, Transportation Reseach Board, Washington, USA.

Barksdale, R. D. (1972). "Laboratory evaluation of rutting in base course materials". Third International Conference on the Structural Design of Asphalt Pavements - Michigan.

Basílio, R. (2002). "Análise do comportamento de pavimento de rodovias estaduais de Goiás". Estudo de caso - Dissertação de Mestrado. Universidade Federal de Santa Catarina - UFSC. Florianópolis.

Bauer, G. E. and Adbelhalim (1987). "The performance of geogrid reinforced road bases". Construction and building materials vol1.

Brown, S. F., Jones, C.P.D. and Brodrick, B. v. (1982). "Use of non-woven fabrics in permanent road pavement". Proceeding of the Institution of Civil Engineers, Part 2, vol 73.

Brown, S. F., Jones, C.P.D. and Brodrick, B. v. (1983). "Discussion of paper: Use of non-woven fabrics in permanent road pavement ". Proceeding of the Institution of Civil Engineers, Part 2, vol 75.

Bühler e Wickert (2004). "A utilização de grelhas de reforço na engenharia rodoviária brasileira". 35a Reunião Anual de Pavimentação - Rio de Janeiro-RJ.

Buhler, A. V. (2002). "Estudo do efeito de grelha metálica de reforço em revestimento asfálticos". $33^{\mathrm{a}}$ Reunião Anual de Pavimentação - Florianópolis-SC.

Buhler, A. V. e Wickert, F. (2004). "Guidelines for using geosynthetics with hot mix asphalt overlays to reduce reflective cracking". TRB- annual meeting cd-rom.

Button, J. W. et al. (2007). “Utilização de grelhas de reforço na engenharia rodoviária brasileira". 35 a Reunião Anual de Pavimentação - Rio de Janeiro - RJ. 
Button, J. W.; Epps J. A.; Lytton R. L.(1982). "Fabric Interlayer for Pavement Overlays". Second International Conference on Geotextiles, Las Vegas, U.S.A., pp. 523-528, 1982.

Buhler, A. V. e Wickert, F. (2004). "Guidelines for using geosynthetics with hot mix asphalt overlays to reduce reflective cracking". TRB- annual meeting cd-rom.

Burd, H.J., (1995) “Analysis of membrane action in reinforced unpaved roads" Canadian geotechnical Journal 32.

Cancelli, A., Montanelli, F., Rimoldi, P. and Zhao, A. (1996). "Full scale laboratory testing on geosynthetics einforced paved roads".

Cardoso, S. H. (1995). "Faixas de Módulos Dinâmicos (Elásticos) Obtidos por Retroanálise Durante Sete Anos". 29a. RAPv, ABPV, Cuiabá-MT.

Cardoso, S.H. (1987). "Procedure for Flexible Arrfield Pavement Design Based on Permanent Deformation". PhD Thesis, University of Maryland, 1987.

Carmo, C. A. et al. (2002). "Utilização de geogrelha de polyester na restauração de

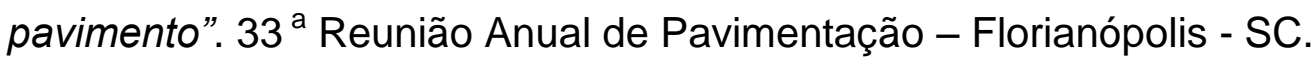

Chan, F.; Barksdale, R. D.; Brow, S. F., (1989). "Aggregate base reinforcement of surfaced pavements”. Geotextiles and Geomembranas, 8, 165-189.

Chang, D. T. et al. (1998). "Laboratory study of the dynamic test system on geogrid reinforced subgrade soil”. VI International Conference on Geosynthetics Atlanta, EUA.

Collin, J.C., Kinney, T. C. and Fu, X. (1996). "Full-scale highwayload test of flexible pavement systems with geogrid reinforced base courses". Geosynthetics International, v. 3. N-4. 
Collin, I. F e Boulbibane, M. (2000). "Shakedown Under Moving Loads With Applications to Pavement Design and Wear". Develops in the Theoretical Geomechanics (The J. Booker Memoril Volume).Ed by D. Smith e J. Carter, Balkema, pag 655-674.

Colombier, G. (1989). "Fissuration des Chausses nature et Origine des Fissures moyens Pour Maitriserleur Remontee" Reflective Cracking in Paviments - I International RILEM Conference (Ed. Rigo and R. Degeimbre, Rilem), Liege, Bélgium, pp. 273-281.

Coutinho, N. B. (2000) "Redes neurais artificiais como procedimento para retroanálise de pavimento flexíveis". Dissertação (mestrado) - Escola de Engenharia de São Carlos - Universidade de São Paulo.

De Groot, M., Janse, E., Maagdenberg, T.A.C., and Van Den Berg, C. (1986),"Design method and guidelines for geotextile application in road construction" $3^{\text {rd }}$ International Conference on Geotextiles, Viena, Vol 3, p.741.

DeMerchant, M. R., Valsangkar, A. J., Schriver, A. B. (2002). "Plate load tests on geogrid-reinforced expanded shale lightweight aggregate". Geotextiles and Geomembranes 20.

Douglas, R. A., Valsangkar, A. J., (1992). "Unpaved Geosynthetic-buit resource asccess roads: stiffness rather than rut depth as the key design criterion". Geotextile and geomembranes, vol 11, pp. 45-59.

Douglas, R. A. (1997). "Repeated-Load Behaviour of geosynthetics-Buit unbound roads". Canadian Geotechnical Journal, vol 4,N2, pp. 197-203.

DNER 35 (1992) - prova de carga estática para determinação do coeficiente de recalque do subleito e sub-base em projeto e avaliação de pavimentos rígido. 
DNER (1996). Determinação de deflexões com o FWD: DNER-PRO 273/96. Rio de Janeiro.

DNER (1996), Manual de Pavimentação, 2ed, Rio de Janeiro, pp. 204-211.

DNER-PRO 10/79. Avaliação Estrutural dos Pavimentos Flexíveis. (Procedimento A) $-1979$.

DNER-PRO 11/79. Avaliação Estrutural dos Pavimentos Flexíveis. (Procedimento B) $-1979$.

DNER-PRO 159/83. Projeto de Restauração de Pavimentos Flexíveis e SemiRígidos - 1983.

DNER-PRO 269/94. Projeto de Restauração de Pavimentos Flexíveis- TECNAPAV1994.

DNER-ME 039/94 - Pavimento - Determinação das deflexões pelo Dynaflect.

DNER-ME 024/94 - Pavimento - Determinação das deflexões pela Viga de Benkelman

DNER-ES 306/97- Pavimentação - Imprimação DNER-PRO 273/96 - Determinação das deflexões utilizando o deflectômetro de impacto tipo "FALLING WEIGHT DEFLECTOMETER - FWD"

DNIT. Manual de Restauração de pavimentos asfálticos.2 ed. Rio de Janeiro. 2005 (IPR publ 720).

Dondi, G. (1994). "Three-dimensional finite element analysis of a reinforced paved road” V International Conference on Geotextiles, Geomembranes and Related Products - Cingapura. 
El-Badawy and Witczad (2007), "Development of a universal permanent strain model for the subgrade pavemente material". Annual meeting cd-rom - TRB.

Engineer technical letter (2003), "Use of geogrid in pavement construction". U.S. Army Corp of Engineers.

Fabrício, J. M., Gonçalves, E. A., Fabrício, O. F. (1988). "Metodologia não destrutiva para avaliação estrutural dos pavimentos flexíveis através da Interpretação das bacias de deformação". $23^{a}$ Reunião Anual de Pavimentação. V. 3, pp. 14151446, Florianópolis, SC, Brasil.

Fabrício, J.M., Silva, G.A., Gonçalves, E.A. (1994). "Método Simplificado de Retroanálise em Pavimentos Flexíveis". In: 28a Reunião Anual de Pavimentação. V. 1, pp. 658-682, Belo Horizonte, MG, Brasil.

Fereidoon Moghaddas-Nejad and John C. Small (1996). "Effect of geogrid reinforcement in model track tests on pavements". Journal of Transportation Engineering - November/December- 468-474.

Fonseca, J. L. G. (2002). "Um método de retroanálise de bacias de deflexão de pavimentos". Dissertação. Tese - Universidade Federal do Rio de Janeiro, COPPE. Rio de Janeiro.

Fritzen, M. A. (2005). "Avaliação de soluções de reforço de pavimento asfáltico com simulador de tráfego na rodovia Rio Teresópolis". Dissertação de Mestrado Universidade Federal do Rio de Janeiro.

Franco, F. A. C. P. (2000). "Um sistema para análise mecanística de pavimentos asfálticos". Tese de Mestrado, COPPE / UFRJ, Rio de Janeiro.

Furlan et al., (2007). "Influência do modo de preparo e do tipo de filer nas propriedades de misturas asfálticas densas". Anpet. 
Giroud, J. P. and Noray, L. (1981). "Geotextile reinforced unpaved Road design" Journal of the Geotechnical Engineering Division, vol 107.

Giroud, J. P. and Han, j. (2003). "Desing method for tensar geogrid reinforced unpaved roads" disponivel em www.tensar .com.uk.

Giroud, J. P. and Han, j. (2004). "Desing method for geogrid-reinforced unpaved roads" ASCE Journal of geotechnical and geoenvironmental engineering, vol 130.

Gonçalves, F. (1997). "Utilização de expert systems na manutenção de pavimentos". Mestrado ITA Campo Montenegro São José dos Campos, SP, Brasil.

Gonçalves, F.J.P., (2002) - "Estudo do Desempenho de Pavimentos Flexíveis a Partir de Instrumentação e Ensaios Acelerados" - Tese de Doutorado, UFRGS, Rio Grande do Sul, 467 pp.

Gontijo, P. R. A. (1980). "Reologia, propriedades viscoelásticas lineares e conceito de módulo de rigidez de betumes puros e de misturas betuminosas - Método de cálculo". 5ํㅡㄹ Encontro de Asfalto, IBP.

Gregory, G. H., Bang,s. (1994) "Design of flexible pávement subgradeswith geosynthetics." 30 Symposium onEnginnering geology and geotechnical engineering, Idaho.

Guimarães, A. C. R. (2001) "Estudo de deformação permanente em solos e a teoria do shakedown aplicada a pavimentos flexíveis." Engenharia Civil, Tese Universidade Federal do Rio de Janeiro, COPPE.

Guimarães, A. C. R. (2009) "Um método mecanístico empírico para a previsão da defomação permanente em solos tropicais constituintes de pavimentos" Rio de Janeiro:UFRJ/COPPE. 
Guo, Z., et al. (2002). "Research on the mechanical performance of the asphalt concrete reinforced with geosynthetics". Geosynthetics $-7^{\text {th }}$ ICG.

Gurung, N. (2003). "A laboratory study on the tensile response of unbound granular base road pavement model using geosynthetics". Geotextiles and Geomembranas, 21, 59-68.

Halliday, A. R. and Potter, J. F., (1984). "The performance of a flexible avement constructed on a strong fabric". TRR-1123, Transportation Reserch Board.

Hass, R., Walls, J., and Carroll, R.G. (1988). "Geogrid reinforcement of granular bases in flexible pavement.". TRR-1188, Transportation Reserch Board, 19-27.

Haas, R., et al. (1994). "Modern Pavement Management". Malabar, Florida, Krieger Publishing Company.

Hoe I. L. and Zeng L. (2001). "Performance of Geosynthetic - Reinforced Asphalt Pavements". Journal of Geoenvironmental Engineering - February - pg 177-184

Hoe I. L. and Huabei, L. (2003). "Finite element studies of asphalt concrete pavement reinforced with geogrid". ASCE, vol 129, Issue7, pp 801-811.

Hoe I. Ling, Yoshiyuki Mohri, and Toshinori Kawabata - "Tensile properties of geogrids under cyclic loadings" - Journal of geotechnical and geoenvironmental engineering - august 1998.

Holtz, D., Christopher, B. R. and Berg, R. R.., (1995). "Geosynthetic design and construction guidelines". Report No FHWA-A-HI-95, U.S. Department of Transportation, Federal Highway Administration, National Highway Institute Course n 13213, waxhington DC, EUA.

Holtz, D., Rut, (1998). "Prediction for roadways with geosynthetic separators". VI International Conference on Geosynthetic - EUA. 
Houlsby, G. T., Jewell, R. A., (1990). "Design of reinforced unpaved roads for small rut depths". Proceedings of the 4 international Conference on Geotextile geomembranes and related rpducts.

Hufenus, R., et al. (2006)."Full-scale field tests on geosynthetic reinforced unpaved roads on soft subgrade". Geotextiles and Geomembranas (24).

Iwanaga, F. I. (2007) "Avaliação da influencia do tipo de agregado, do tipo de ligante, do tipo de moldagem e do tipo de filer na vida de fadiga de mistura asfáltica densa" - dissertação de mestrado - Escola de Engenharia de São Carlos USP.

Jenner, C. G., et. Al (2002). "Trafficking of reinforced, unpaved subbases over a controlled subgrade ". Geosynthetics $-7^{\text {th }}$ ICG.

Jianjun Leng and Mohammed A. Gabr (2002). "Characteristics of Geogrid-Reinforced Aggregate Under Cyclic Load “. TRR 1786, Transportation Research Board..

Kherdr, S. (1985). "Deformation characteristics of granular base course in flexible pavements". TRR 1043, Transportation Research Board.

Kim, S., Hugo, F, and Rosset J. M., (1998). "Small-scale accelerated pavement testing". Journal of Transportation Engineering". March/April.

Kim, J. and Buttlar, W. G. (2002). "Analysis of reflective crack control system involving reinforcing grid over base-isolating interlayer mixture". Journal of Transportation Engineering - July/August.

Kim, W. H. et al. (2005). "Structural contribution of geosynthetic-reinforced working platforms in flexible pavement". TRR 1936, Transportation Research Board. 
Kim, W. H. et al. (2006). "Deflection of prototype geosynthetic-reinforced working platforms over soft subgrade". TRR 1975, Transportation Research Board.

Kinney, T. C. et al. (1998). "Benefits of using geogrids for base reinforcement with regard to rutting". TRR-1611, Transportation Research Board.

Kinney, T. C. et al. (1998). "Using geogrids for base reinforcement as measured by falling weight deflectometer in full-scale laboratory study". TRR-1611, Transportation Research Board.

Klein, R. J., Vidal, D. M. e Rodrigues, R. M. (2003). "Estudo dos efeitos nas propriedades do material compactado em obras de reforço de base de pavimentos com geossintéticos". IV Simpósio Brasileiro de Geossintéticos Porto Alegre -RS.

Klein, R. J., Wickert, F. e Vidal, D. M. (2003). "Estudo de aderência de diferentes ligantes asfálticos utilizados na impregnação de geotêxteis em obras de restauração de pavimentos flexíveis". $34^{\mathrm{a}}$ Reunião Anual de Pavimentação Campinas-SP.

Koerner, R. M. (2000). "Emerging and future developments of selected geosynthetic application". Journal of Geotechnical and Geoenvironmental Engineering vol126.

Koerner, R. M. (1998). "Designing with geosynthetics, 4a ed., Prentice-Hall EUA.

Komatsu, T., et al. (1998). "Durability assessment of geogrid-reinforced asphalt concrete". Geotextiles and Geomembrane - 16 -1998

Krystyna Kazimierowicz-Frankowska (2007) "Influence of geosynthetic reinforcement on the load-settlement characteristics of two-layer subgrade". Geotextiles and Geomembranes (25). 
Lages, R. G. (2004). "Aplicação de métodos convencionais no dimensionamento de pavimentos com base reforçada utilizando geossintéticos". Tese de mestrado Instituto Tecnológico de Aeronáutica, São José dos Campos.

Leng, J. and Gabr, M. A. (2002). "Characteristics of geogrid-reinforced aggregate under cyclic load". TRR 1786, Transportation Research Board.

Leng, J. and Gabr, M. A. (2006). "Deformation-resistance model for geogridreinforced unpaved road". TRR 1975, Transportation Research Board.

Lentz, R. W. \& Baladi, G. Y. (1981). "Constitutive equation for permanent strain of sand subjected to cyclic loading". TRR 1810, Transportation Research Board.

Ling, H. I., Mohri, Y., and Kawabata, T. (1998). "Tensile properties of geogrids under cyclic loadings". Journal of geotechnical and geoenvironmental engineering august.

Ling, H. I. and Liu, H. (2001). "Finite element studies of asphalt concrete pavement reinforced with geogrid". Journal of Engineering Mechanics - ASCE -2003.

Lugmaur, R. G., et al. (2002). "The use of geosynthetics in paving applications factors influencing the reflective cracking". Geosynthetics $-7^{\text {th }}$ ICG.

Luz, M. P. (2003). "Análise dos resultados do ensaio de CBR realizado em condições variadas de umidade pós-compactação". Dissertação (mestrado)- Escola de Engenharia de São Carlos- Universidade de São Paulo.

Macêdo, F. N. (2003). "Retroanálise de bacias de deflexão reais e teóricas obtidas por métodos estáticos e dinâmicos". Dissertação de Mestrado. Universidade de Brasília - Unb. Distrito Federal. 
Macêdo, J. G. (1996). "Interpretação de ensaios de defletométricos para avaliação estrutural de pavimentos flexíveis" (COPPE/UFRJ, D.Sc., Engenharia Civil, 1996) .Tese - Universidade Federal do Rio de Janeiro, COPPE.

Marques, J. R. F. (2002). "Dimensionamento de reforço mediante retroanálise de avaliações estruturais não-destrutivas". Dissertação. Escola de Engenharia de São Carlos.

Matys, M. and Baslik, R., (2002). "Geogrid efficiency in a push test". Geosynthetics $7^{\text {th }}$ ICG -Lisse.

Medina, J., et al. (1994). "Utilização de ensaios defletométricos e de laboratório para a avaliação estrutural de pavimentos". In: 28a Reunião Anual de Pavimentação. V. 1, pp. 595-625, Belo Horizonte, MG, Brasil.

Medina, J. (1997). "Mecânica dos Pavimentos". Editora UFRJ, Rio de Janeiro.

Medina, J., Motta, L. M. G.(2005) “Mecânica dos Pavimentos”. 2 ed. Rio de Janeiro.

Meiarashi, S. et al. (2002). "Performance testing method of geotextile for interlocking block pavement". Geosynthetics $-7^{\text {th }}$ ICG.

Milligan, G. W. E., Jewell, R. A. Houlsby, G. T., Burd, H. J. (1989) "A new approach to the design of unpaved roads". Ground Engineering 22.

Miura, N., Sakai, A., Taesiri, Y., Yamanouchi, T. and Yasuhara, K. (1990). "Polymer grid reinforced pavement on soft clay grounds". Geotextiles and Geomembranas, vol 9.

Moghaddas-Nejad, F. and Small, J.C. (1996). "Effect of geogrid reinforcement in model track test on pavements". Journal of Transportation Engineering Nov/Dec. 
Mondolfo, M., Rabaça, S. R., Monstestruque, G. (2003). “Aplicação de geogrelha como sistema anti-reflexão de trincas na implantação de trecho do anel viário de campinas". 34 ${ }^{\mathrm{a}}$ Reunião Anual de Pavimentação - Campinas - SP.

Monismith, C. L. et al. (1975). "Permanent deformation characteristics of subgrade soils due to repeated loading". 54 th annual meeting of TRB - Washington.

Motta, L. M. G. et al. (1995). "Avaliação Estrutural de Trechos Experimentais na Rodovia Carvalho Pinto - Análise Preliminar”, 29a RAPv - ABPv, Cuiabá.

Motta, L. M. G. (1991). "Método de Dimensionamento de Pavimentos Flexíveis: Critério de Confiabilidade e Ensaios de Cargas Repetidas”. Tese de Doutorado, COPPE / UFRJ, Rio de Janeiro, 366p.

Müller; R. M. (2005). “Avaliação de Transmissão de Esforços em Pavimentos Intertravados de Blocos de Concreto". Rio de Janeiro, 2005. XXI, 234 p. 29,7 cm (COPPE/UFRJ, M.Sc., Engenharia Civil).

Nagao, E. M. (2001). "Considerações de parâmetros de curvatura da bacia de deforma;ao e do numero estrutural no dimensionamento de reforço de pavimento flexível." Dissertação.Universidade de São Paulo. Escola Politecnica. São Paulo, 2001.

Narejo, D. B. (2003). "Opening size recommendations for separation geotextiles used in pavements". Geotextiles and Geomembranes (21).

NBR 7180/84 (ABNT) - Solo - Determinação do limite de plasticidade

NBR 6459/84 (ABNT) - Determinação do limite de liquidez

NBR 6508/84 (ABNT) - Grãos de solo que passam na peneira de 4,8mm Determinação da massa específica

NBR 12824/93 (ABNT) - Geotêxteis - Determinação da resistência à tração nãoconfinada - Ensaio de tração de faixa larga - Método de ensaio. 
NBR 12553 (1991) Geossintético - Terminologia, Associação Brasileira de Normas Técnicas.

Nóbrega, E. S. (2003). “Comparação entre métodos de retroanálise em pavimentos asfálticos". Rio de Janeiro - XIX 365 p., 29,7cm (COPPE/UFRJ, M.Sc., Engenharia Civil,)

Nogami, J.S., Villibor, D. F. (1995). "Pavimentação de baixo custo com solos lateríticos". São Paulo, Editora Vilibor. 213p.

Noureldin, A. S. (1993). "A New Scenario for Backcalculation of Layer Moduli of Flexible Pavement". TRR 1384, Transportation Research Board.

Pereira, A. S. (2002). "Utilização de Geotêxteis em Reforço Pavimento aplicado em um Trecho Experimenta". Rio de Janeiro, XIV, 195 p. 29,7 cm (COPPE / UFRJ, M.Sc., Engenharia de Transportes).

Pereira, A. S., Motta, L.M.G. (2001). "A utilização de geotêxteis como camada de desvio de trincas em pavimentos asfaltico urbano". XV ANPET, Campinas. SP.

Pereira, A. S., Motta, L.M.G. (2002). "Avaliação de dois pavimentos com camada intermediaria de geotêxtil no revestimento". $33^{\text {a }}$ Reunião Anual de Pavimentação - Florianópolis-SC.

Perkins, S. W. and Ismeik, M. (1997). "A synthesis and evaluation of geosyntheticreinforce base layer in flexible pavement: Part I". Geosynthetic International vol 4.

Perkins, S. W. and Ismeik, M. (1997) "A synthesis and evaluation of geosyntheticreinforce base layer in flexible pavement: Part II" Geosynthetic International vol 4. 
Perkins, S. W., Ismeik, M., Folgelsong, M.L., Wang, Y. e Cuello, E., (1998) "Geosynthetic-reinforced pavements: Overview and preliminary results" VI International conference on geosynthetic, Atlanta-EUA

Perkins, S. W., (1999) "Mechanical response of geosynthetic-reinforced flexible pavement". Geosynthetic International - vol 6.

Perkins, S. W., (1999) "Constitutive Modeling of Geosynthetic". Geotextile and Geomembranes

Perkins, S. W. and Cuelho, E. (1999). "Soil-Geosynthetic Interface Strength and Stiffness relationships From Pullout tests" Geosynthetic International - vol 6

Perkins, S. W., et al. (2002). "Mechanistic-empirical models for reinforced pavements". Geosynthetics $-7^{\text {th }}$ ICG - Lisse.

Perkins, S. W. and Cuelho, E. (2007). "Mechanistic-empirical design model predictions for base-reinforced pavements". TRR 1989.

Pinto, S. (1991). "Estudo do comportamento à fadiga de misturas betuminosas e aplicação na avaliação estrutural de pavimentos”. Tese de Doutorado, COPPE/UFRJ, Rio de Janeiro, 478p.

Pinto, S. e Motta, L. M. G. (1995). "Catálogo de curvas de fadiga. Boletim técnico número 16". Associação Brasileira de Pavimentação - ABPv, Rio de Janeiro.

Pinto, S.; Preussler, E. (2002). "Pavimentação Rodoviária. Conceitos Fundamentais Sobre Pavimentos Flexíveis". COPIART, Rio de Janeiro - RJ.

Puppala, A. and Mohammad, L. N. (1999). "Permanent deformation characterization subgrade soil from RLT test”. ASCE, vol 11, Issue4. 
Rezende, L. R. (1999). "Técnicas alternativas para a construção de bases de pavimentos rodoviários". Dissertação de Mestrado, Departamento de Engenharia Civil - Universidade de Brasília - DF.

Rodrigues, R. M. (1991). Estudo dos Trincamentos dos Pavimentos. Tese de Doutorado, COPPE/UFRJ, Rio de Janeiro.

Santos, J. D. G. (1998). "Contribuição ao estudo dos solos lateríticos granulares como camada de pavimento". Tese de D.Sc. COPPE / UFRJ, Rio de Janeiro.

Santos, C. R. G. (2005). "Avaliação das Influências do tipo de ligante e do volume de vazios na vida da fadiga de algumas misturas asfálticas". Dissertação. Universidade de São Paulo. Departamento de Transportes. São Carlos.

Saraiva, S. L., Gomes, R. C. \& Fernandes, G. (2005). "Estudo alternativo de superestrutura rodoviária com resíduos de mineração de ferro associados à geossintéticos em trecho experimental instrumentado na Rodovia ItabiraItambé de Minas". 10 ENACOR - Joinville -SC.

Saraiva, S. L., Gomes, R. C. \& Fernandes, G. (2005). "Construção de trecho experimental instrumentado para análise da superestrutura rodoviária com utilização de solos finos e resíduos de mineração de ferro associado à geossintéticos". $36^{a}$ Reunião Anual de Pavimentação - Curitiba.

Silva, B. A.(2009) "Análise Mecânica de um Pavimento Rodoviário Submetido à Oscilação do Lençol Freático Simulada em Modelo Físico de Verdadeira Grandeza" Tese - Rio de Janeiro: UFRJ/COPPE

Simpson, Daleiden e Hadley (1995). "Rutting analysis from a different perspective", TRR 1473, p9-17.

Som, N. and Sahu, R. B. (1999). "Bearing capacity of a geotextili reinforced unpaved road as a function of deformation". Geosynthetic International - vol 6. 
Steen, E. R., et. al. (2002). "New road constructions, stress relief of cement treated base courses". Geosynthetics $-7^{\text {th }}$ ICG.

Svenson, M. (1980). "Ensaios triaxiais dinâmicos de solos argilosos". Tese de Mestrado, COPPE/UFRJ, Rio de Janeiro.

Tiaesiri, Y., Sinweeruthai, A., Lim, L.K., (2005). "Geotextile paving ffabric for road rehabilitation words:Field experience in Thailand.

Takeda, M. C. (2006). "A influencia da variação da umidade pós-compactação no comportamento mecânico de solos de rodovias do interior paulista". Tese (doutorado) - Escola de Engenharia de São Carlos - Universidade de São Paulo.

Tingle, J. S. and Jersey, S. R. (2005). "Cyclic plate load testing of geosyntheticreinforced unbound aggregate roads". TRR-1936, Transportation Research Board.

Tingle, J. S. and Webster, S. L. (2003). "Corps of engineers designs of geosyntheticreinforced unpaved road". TRR-1849, Transportation Research Board.

Tingle, J. S. and Jersey, S. R. (2007). "Empirical Design Methods for GeosyntheticReinforced Low-Volume Roads". TRR-1989, Transportation Research Board.

Tschegg, E. K., Ehart, R. J. A. \& Ingruber, M. M. (1998). "Fracture behavior of geosynthetic interlayers in road pavements". Journal of Transportation Engineering - Sept/Oct.

Thuler, R. B. (2005). "Estudo de solos do Estado do Rio de Janeiro para aplicação em rodovias de baixo volume de tráfego". Rio de Janeiro- COPPE/UFRJ, M.Sc., Engenharia Civil, 2005- Tese - Universidade Federal do Rio de Janeiro, COPPE. 
Ullidtz, P. (1987). "Pavement Analysis. In: Developments in Civil Engineering”. vol.19. Amsterdam, The Netherlands, Elsevier Science Publishers B.V.

Vertamatti, J. C./Coordenador (2004). "Manual Brasileiro de Geossintéticos" - Ed. Edgard Bhucher - São Paulo.

Vesic, A. S. (1975). "Bearing capacity of shallow foundations." - Ed. Edgard Bhucher - São Paulo.In: Winterkorn, H.F.; Fang, H. (

Vilchez, G. E. M. (1996). "Estudo de sistemas anti-reflexão de trincas na restauração de pavimentos asfálticos". Dissertação de Mestrado, ITA - São José dos Campos.SP.

Viswanadham, B. V. S. and Rao, G. V. (1999). "Effect of geogrid reinforcement in model track tests". Journal of Transportation Engineering - May/June.

Wickert, F.; Buhler, A. V.; Vidal, D. M.; Rodrigues, R. M. (2003). "Análise de insucessos na aplicação de geotêxtil como camada anti-reflexão de trincas na restauração de pavimentos flexíveis" In: IV Simpósio Brasileiro de Geossintéticos, Porto Alegre

Woon-Hyung kim, Tuncer B. E,, Craig, H. B. and Burak F. T. (2005). "Structural contribution of geosynthetic reinforced working platforms in flexible pavement" TRR1936

Webster, S. L. (1993). "Geogrid reinforced base course for flexible pavement for light Aircraft, test section construction behavior under traffic, laboratory tests, and design criteria "Army corps Engineering, Vicksburg Mississippi, USA.

WERKMEISTER, S., DAWSON, A. R., WELLNER, F. (2001). Permanent Deformation Behavior of Granular Materials and the Shakedown Concept. Transportation Research Record ํㅜ 01-0152, Washington, DC. 
WERKMEISTER, S., NUMRICH, R., DAWSON, A., WELLNER,F. (2003). "Design of Granular Pavement Layers Considering Climatic Conditions”. Transportation Research Board, 82ํㅡㄹ Annual Meeting. January 12-16, 2003, Washington D.C.

WERKMEISTER, S. (2003). “Permanent Deformation Behavior of Unbound Granular Materials in Pavement Constructions" Tese de Doutorado, Universidade Técnica de Dresden, 189 pg.

WERKMEISTER, S., DAWSON, A. R., WELLNER, F. (2004). "Pavement Design for Unbound Granular Materials." Journal of Transportation Engineering ASCE/September/October.

Yegian, M. K. and Kadakal, U. (1998). "Geosynthetic Interface Behavior Under Dynamic Loading". Geosynthetic International - vol 5.

Zhou, Z-G and Zheng, J-L. (2002). "The effect of geosynthetic materials in preventing asphalt pavements from reflective cracking". Geosynthetics $-7^{\text {th }}$ ICG. 